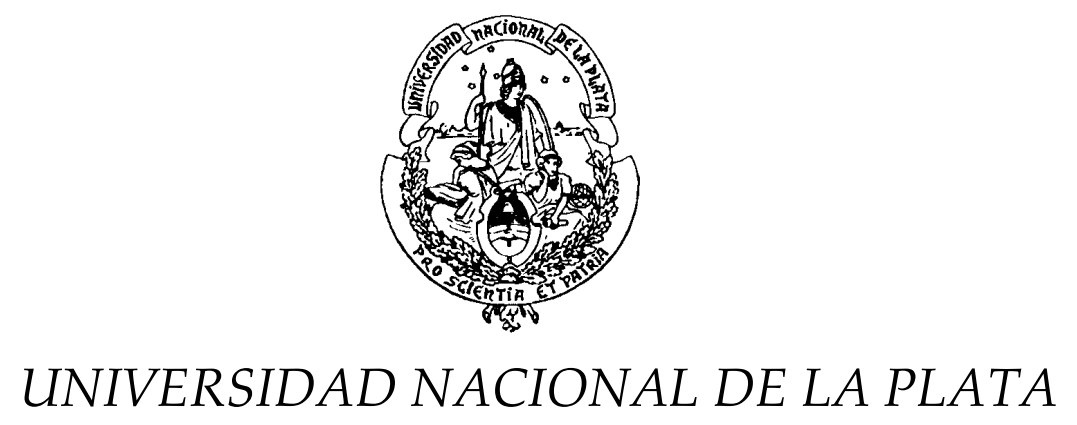

Facultad de Ciencias Exactas

Departamento de Ciencias Biológicas

Trabajo de Tesis Doctoral

\title{
PROPIEDADES ESTRUCTURALES Y FUNCIONALES DE PREPARADOS PROTEICOS DE AMARANTO MODIFICADOS Y SOJA-AMARANTO
}
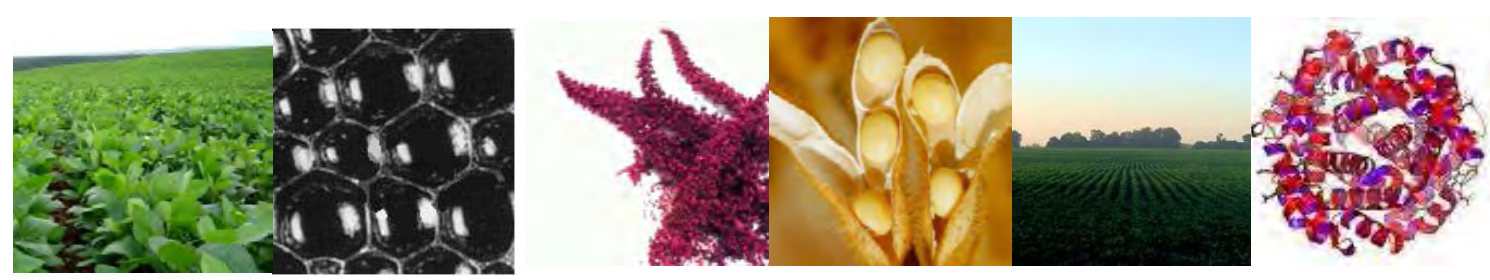

Tesista: Lic. Jorge Luis Ventureira

Directora.: Dra. M. C. Añón

Codirectora: Dra. E.N. Martínez

Año 2010 
Ventureira, Jorge Luis

Propiedades estructurales y funcionales de preparados proteicos de amaranto modificados y soja-amaranto. - 1a ed. - La Plata : Universidad Nacional de La Plata, 2012. E-Book.

ISBN 978-950-34-0815-5

1. Soja. 2. Tesis de Doctorado. I. Título CDD 641.35655

Fecha de catalogación: 25/11/2011 

Este trabajo está dedicado a mi familia. 

"La curiosidad es una de las más permanentes y seguras características de una vigorosa inteligencia."

Samuel Johnson 

El presente trabajo, para optar por el grado académico de Doctor de la Facultad de Ciencias Exactas, fue realizado en el Centro de Investigación y Desarrollo en Criotecnología de Alimentos (CIDCA-CONICET-UNLP, La Plata, Argentina) bajo la dirección de la Dra. María Cristina Añón y la codirección de la Dra. Nora Martínez.

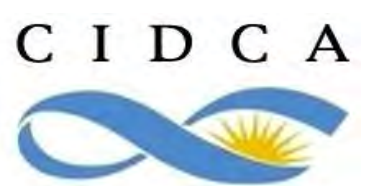

A GE N C I A

CONICET IA PIATA

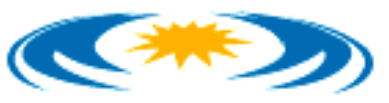





\section{Agradecimientos}

A CONICET y ANPCyT por financiar los trabajos de investigación.

A la universidad pública y gratuita que permitió formarme como le permite a muchísimas personas todos los años, con un alto nivel académico y de exigencia.

A mis directoras Cristina y Nora, por ayudarme a encontrar en mi una persona mejor.

A mis padres y hermanos por alentarme y brindarme todo su amor.

Al personal directivo, técnico y administrativo del CIDCA por la asistencia brindada en los momentos que la necesité.

A todos mis compañeros de laboratorio y de escritorio, por compartir conmigo conocimientos, reflexiones, ideas y ratos divertidos.

A mis compañeros de cátedra, por los momentos de trabajo cargados de buena onda.

Al personal del INRA-Nantes, especialmente a Marc, Cachito y Anne-Laure por enseñarme, ayudarme y compartir momentos inolvidables.

A todo el personal del CIDCA que me brindó colaboración, apoyo o conversaciones agradables.

Al personal de otros institutos y cátedras de la Facultad de Ciencias Exactas que me ayudaron en distintas ocasiones.

A mis amigos, por ser amigos. 



\section{Índice}

Introducción 1

I. Generalidades de la soja y el amaranto 1

$\begin{array}{ll}\text { I.I. Los cultivos } & 1\end{array}$

I.II. Composición de los granos 3

I.II.I Proteínas de soja y amaranto 4

II. Fenómenos de superficie 8

II.I. Tensión interfacial $\quad 8$

II.II. Tensioactivos. Comportamiento superficial de pequeños 9 surfactantes y proteínas

$\begin{array}{ll}\text { II.III. Interfases curvas } & 11\end{array}$

$\begin{array}{ll}\text { II.IV. Tensión superficial dinámica } & 12\end{array}$

$\begin{array}{ll}\text { II.V. Reología interfacial } & 14\end{array}$

II.V.I. Reometría interfacial con parámetros de 15 compresión o dilatacionales

$\begin{array}{ll}\text { II.V.II. Reometría interfacial rotacional } & 17\end{array}$

II.V.III. Relación de la reología interfacial con la 17 estabilidad de emulsiones y espumas

$\begin{array}{ll}\text { III. Emulsiones } & 19\end{array}$

$\begin{array}{ll}\text { III.I. Introducción } & 19\end{array}$

$\begin{array}{ll}\text { III.II. Formación de la emulsión } & 21\end{array}$

III.III. Maduración de la interfase $\quad 22$

$\begin{array}{ll}\text { III.IV. Desestabilización de emulsiones } & 23\end{array}$ 
III.IV.I. Cremado / sedimentación 24

III.IV.II. Floculación 24

$\begin{array}{ll}\text { III.IV.III. Coalescencia } & 27\end{array}$

III.IV.IV. Maduración de Ostwald 28

$\begin{array}{ll}\text { IV. Espumas } & 29\end{array}$

$\begin{array}{ll}\text { IV.I. Introducción } & 29\end{array}$

$\begin{array}{ll}\text { IV.II. Espumado } & 31\end{array}$

$\begin{array}{lll}\text { IV.II.I. Dispositivos de espumado } & 31\end{array}$

IV.II.II. Relación con la tensión interfacial dinámica 32

IV.III. Estabilidad de espumas $\quad 32$

IV.III.I. Evaporación y maduración de Ostwald 32

IV.III.II. Drenado de la espuma 33

IV.III.IV. Drenado del film 34

IV.III.IV. Fuerzas superficiales 34

IV.III.V. Coalescencia o colapso de los films $\quad 35$

$\begin{array}{ll}\text { Objetivos } & 37\end{array}$

Capítulo 1. Tratamiento ácido de aislados proteicos de soja y 39 amaranto

1.1. Materiales y métodos 39

1.1.1. Preparación de harinas de distintos aislados $\quad 39$

1.1.2. Caracterización química de los aislados $\quad 40$

$\begin{array}{ll}\text { 1.1.3. Reactivos } & 41\end{array}$

1.1.4. Tratamiento ácido de los aislados $\quad 41$

1.1.5. Solubilidad 41

1.1.6. Electroforesis $\quad 42$

1.1.6.1. Aspectos teóricos y técnicas 42

1.1.6.2. Reactivos 43

1.1.6.3. SDS-PAGE $\quad 45$

1.1.6.4. SDS-PAGE en condiciones reductoras 45

1.1.6.5. N-PAGE 45

1.1.6.6. Electroforesis bidimensionales (N-PAGE $\rightarrow$ SDS- $\quad 45$

PAGE)

1.1.6.7. Coloración 46

1.1.6.8. Obtención de las imágenes y análisis de los geles 46

1.1.7. Determinación de la hidrofobicidad superficial 46

1.1.7.1. Determinación por la sonda ANS 46 
1.1.7.2. Determinación por medida de la fluorescencia intrínseca

1.1.8. Cromatografía rápida de proteínas en medio líquido (FPLC)

1.1.8.1. Filtración en gel o cromatografía de exclusión molecular

1.1.8.2. Preparación de muestras $\quad 48$

1.1.8.3. Desarrollo 49

1.1.8.4. Calibración $\quad 49$

1.1.9. Calorimetría diferencial de barrido (DSC) 50

1.1.9.1. Principio 50

1.1.9.2. Operación 50

1.1.10. Tensiómetro de volumen de gota pendiente 51

1.1.10.1. Principio 51

1.1.10.2. Operación $\quad 52$

1.1.11. Propiedades espumantes $\quad 52$

1.1.12. Preparación de emulsiones 55

1.1.13. Estabilidad de emulsiones $\quad 55$

1.1.13.1. QuickScan 55

1.1.13.2. Operación 57

1.1.14. Distribución de tamaño de gota de las emulsiones 57 aceite/agua

1.1.14.1. Principio 57

1.1.14.2. Operación $\quad 58$

1.1.14.3. Tratamiento de resultados 59

$\begin{array}{ll}\text { 1.1.15. Microscopía óptica } & 60\end{array}$

$\begin{array}{ll}\text { 1.2. Resultados y discusión } & 60\end{array}$

$\begin{array}{ll}\text { 1.2.1 Caracterización } & 60\end{array}$

1.2.1.1. Calorimetría diferencia de barrido (DSC) 60

1.2.1.2. Electroforésis y cromatografías de exclusión 63 molecular FPLC

1.2.1.2.1. Determinación de tamaños moleculares 63

de especies nativas

1.2.1.2.2. Determinación de tamaños moleculares 68

de especies tratadas

1.2.1.2.3. Determinación de la naturaleza del factor $\quad 75$

hidrolítico presente en API que se activa a $\mathrm{pH}$ ácido

1.2.3. Hidrofobicidad superficial 
1.2.3.1. Medida utilizando sonda fluorescente ANS 78

1.2.3.1. Fluorescencia intrínseca 80

$\begin{array}{ll}\text { 1.2.4. Solubilidad } & 81\end{array}$

1.2.5. Tensión superficial $\quad 82$

1.2.6. Propiedades espumantes 86

1.2.6.1. Velocidad inicial de formación de espuma 86

1.2.6.2. Estabilidad de espumas 88

1.2.6.3. Volumen máximo de líquido incorporado a la 90 espuma

1.2.7. Emulsiones 91

1.2.7.1. Distribución de tamaño de gota y $\mathrm{D}_{3,2} \quad 91$

1.2.7.2. Estabilidad de emulsiones 93

1.2.7.3. Microscopía de las emulsiones 102

$\begin{array}{ll}\text { 1.3. Conclusiones } & 102\end{array}$

Capítulo 2. Hidrólisis enzimática de aislados proteicos de amaranto 107

2.1. Materiales y métodos 107

2.1.1. Preparación de harina y aislado de amaranto 107

2.1.2. Caracterización química de los aislados 107

2.1.3. Hidrólisis del API y medida del grado de hidrólisis 108

2.1.4. Soluciones buffer utilizadas 108

$\begin{array}{ll}\text { 2.1.5. Solubilidad } & 109\end{array}$

2.1.6. Cromatografía rápida de proteínas en medio líquido 109 (FPLC)

2.1.7. Electroforesis 109

2.1.8. Isotermas de Langmuir 109

2.1.8.1. Placa de Wilhelmy $\quad 109$

2.1.8.2. Balanza de Langmuir 110

2.1.8.3. Isotermas 111

2.1.9. Tensiometría de gota dinámica y reología interfacial 112

2.1.9.1. Tensiometría de gota 112

2.1.9.2. Reología interfacial $\quad 113$

2.1.9.3. Operación 114

2.1.10. Preparación de emulsiones 115

2.1.10.1. Emulsiones con menor relación proteína/aceite 115

2.1.10.2. Emulsiones con mayor relación proteína/aceite 115

2.1.11. Estabilidad de emulsiones 116 
2.1.12. Distribución de tamaño de gota de las emulsiones aceite/agua

2.1.13. Microscopía óptica

2.1.14. Determinación de proteína adsorbida 117

$\begin{array}{ll}\text { 2.2. Resultados y discusión } & 119\end{array}$

2.2.1. Determinación de tamaños moleculares 119

$\begin{array}{ll}\text { 2.2.1.1. SDS-PAGE } & 119\end{array}$

2.2.1.2. Cromatografías FPLC 120

$\begin{array}{ll}\text { 2.2.2. Solubilidad } & 121\end{array}$

2.2.3. Curvas de tensión superficial en la balanza de Langmuir 123

2.2.3.1. En $\mathrm{pH} 2,0 \quad 123$

2.2.3.2. En $\mathrm{pH} 8,0 \quad 125$

2.2.3.3. Comparación a $\mathrm{pH} 2,0$ y pH 8,0 127

2.2.4. Cinéticas de tensión interfacial en la interfase aceite:agua 128

$\begin{array}{lll}\text { 2.2.4.1. } & \text { En } \mathrm{pH} 2,0 & 128\end{array}$

2.2.4.2. En $\mathrm{pH} 8,0 \quad 132$

2.2.4.3. Comparación a pH 2,0 y pH 8,0 134

2.2.5. Reología interfacial en la interfase aceite:agua 136

2.2.6. Emulsiones con baja relación proteína/aceite 138

2.2.6.1. Actividad emulsificante 138

2.2.6.2. Estabilidad de emulsiones 142

2.2.6.3. Relación entre solubilidad, propiedades 150

superficiales y comportamiento de las emulsiones

2.2.7. Emulsiones con alta relación proteína/aceite 152

$\begin{array}{ll}\text { 2.3. Conclusiones } & 158\end{array}$

$\begin{array}{ll}\text { Conclusiones Generales } & 161\end{array}$

$\begin{array}{lr}\text { Bibliografía } & 163\end{array}$ 



\section{Introducción}

\section{Generalidades de la soja y el amaranto}

\section{I.I. Los cultivos}

La soja es un miembro importante de la familia de las leguminosas y desempeña un papel primordial en la nutrición saludable. En Oriente, desde hace más de 5000 años, se emplea con éxito en la alimentación humana como poroto entero, harina tostada, poroto germinado y fermentado, leche, queso y salsa de soja, etc. Fue identificada como uno de los cinco granos sagrados conjuntamente con el arroz, el trigo, la cebada y el mijo, considerados esenciales para la supervivencia de su civilización. En el mundo occidental fue incorporada a través de los Estados Unidos recién a partir del siglo $\mathrm{XX}$ al conocerse su alto tenor en proteínas de alta calidad nutricional y las posibilidades tecnológicas de su utilización. Actualmente su uso se extendió como fuente de aceite y de proteínas en distintos alimentos proteicos a América del Sur (principalmente Brasil) y Europa (Erickson 1995). En Argentina, el cultivo de soja se realiza en forma consistente desde hace unos 30 años y se convirtió desde hace una década en el cultivo más importante del país haciéndolo el mayor productor per cápita del mundo, y el mayor exportador absoluto de aceite y de harina desgrasada. El complejo de la soja (poroto, aceite y pellets/harinas) se destina a exportación $(>85 \%)$. Los pellets y las harinas se destinan fundamentalmente a la alimentación del ganado (Franco 2004). La proteína de soja se genera como un subproducto de la industria aceitera. 
El amaranto es un vegetal autóctono de América Central que fue un cultivo muy importante de los pueblos originarios como los Incas, Mayas y Aztecas que lo utilizaban tanto para la alimentación como para rituales religiosos (Saunders y Becker, 1984). Después de la conquista española se prohibió el cultivo por ser utilizado en rituales que iban contra las creencias de la iglesia católica. Técnicamente el grano de amaranto es considerado como un pseudocereal ya que comparte algunas características con los cereales. Posee cantidades importantes de almidón, aunque éste se encuentra almacenado en el perisperma. Sin embargo como pertenece a las dicotiledóneas no es considerado un cereal verdadero. El cultivo tiene las ventajas de ser resistente a las sequías y suelos salinos aumentando su potencial de cultivo en suelos no aptos para otras especies, tiene un metabolismo $\mathrm{C} 4$ lo que le permite fijar más eficientemente el dióxido de carbono, se aprovechan tanto sus semillas como sus hojas para la alimentación y el grano posee un alto contenido proteico (Bressani, 1994).

En la Figura I se muestran fotografías de los granos de soja y amaranto (Amaranthus hypochondriacus).

(a)

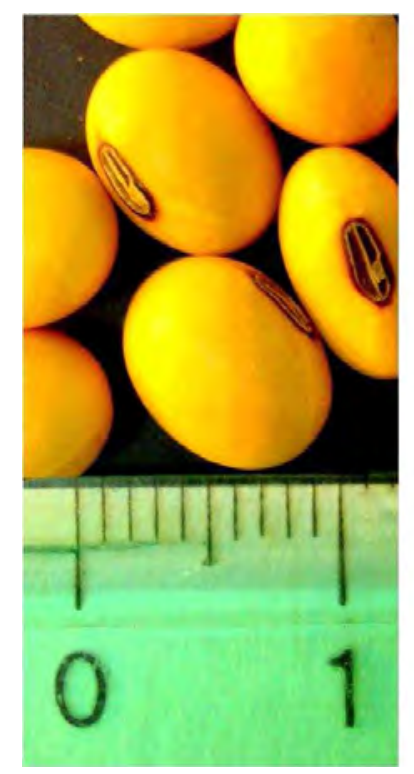

(b)

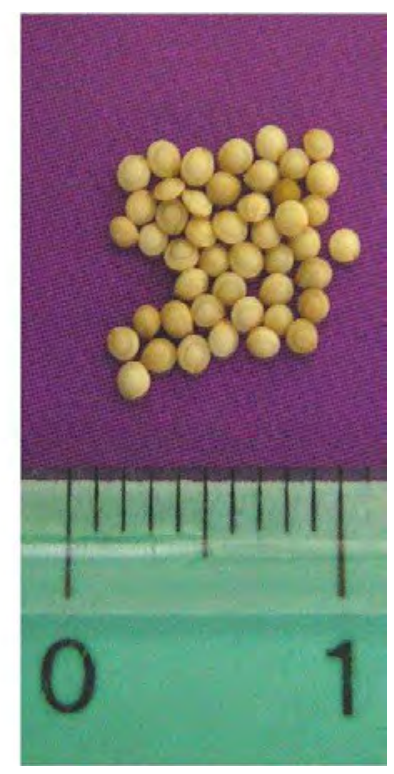

Figura I: Granos de soja (a) y amaranto (amaranthus hypochondriacus) (b), escala de $1 \mathrm{~cm}$. 


\section{I.II. Composición de los granos}

La Tabla I muestra la composición porcentual de los granos de soja y amaranto.

Tabla I.: Composición de granos de soja y amaranto maduros, crudos. Fuente: USDA SR-21 (USDA National Nutrient Database for Standard Reference, Release 21).

\begin{tabular}{lcc}
\hline \multicolumn{1}{c}{ Componente } & Soja & Amaranto \\
\hline Agua (\%) & 8,5 & 11,3 \\
Proteínas (\%) & 36,5 & 13,6 \\
Lípidos (\%) & 19,9 & 7 \\
Fibra dietaria (\%) & 9,3 & 6,7 \\
Cenizas (\%) & 4,9 & 2,9 \\
Carbohidratos (\%) & 20,9 & 59 \\
Calorías (kCal \%) & 446 & 371 \\
\hline
\end{tabular}

Los lípidos del grano de soja están compuestos principalmente por triglicéridos que constituyen un 95 a 97 \% del total. Los triglicéridos están constituidos por un $15 \%$ aproximadamente de ácidos grasos saturados y el resto insaturados. Entre los lípidos también se destacan los fitoesteroles y los tocoferoles que constituyen un 0,33\% y 0,2 \% del total de lípidos respectivamente (Pryde 1980). Los lípidos de amaranto están compuestos por un $90 \%$ de triglicéridos de los cuales el $20 \%$ contienen ácidos grasos saturados (Paredes-López 1994). Además contienen un 0,05\% de tocoferoles (Qureshi, Lehmann y col. 1996) y un alto contenido de escualeno (4,2 \%) (He y Corke 2003) que tiene la capacidad de disminuir el colesterol y que ha sido estudiado también por su capacidad antioxidante y el efecto anticarcinogénico (Smith 2000).

El contenido de carbohidratos del grano de amaranto es mayor que el del grano de soja. En soja los principales carbohidratos estan representados por oligosacáridos como la rafinosa y la estaquiosa (Smith y Cirek 1972). Los carbohidratos de amaranto se distribuyen en 57,5\% de almidón y 1,5\% de azúcares (USDA SR-21) 


\section{I.II.I Proteínas de soja y amaranto}

Según la clasificación de Osborne (1924) las proteínas vegetales se agrupan de acuerdo a su solubilidad en diferentes solventes, de la siguiente manera: albúminas, solubles en agua; globulinas, solubles en soluciones salinas diluidas; prolaminas, solubles en alcohol y glutelinas, solubles en soluciones alcalinas o ácidas.

El grano de soja tiene un contenido de proteína del 38-44 \%, que es mayor que en otras leguminosas y mucho mayor que en los cereales. Esto unido al buen perfil de aminoácidos aumenta su valor como alimento y es una de las razones de su importancia económica (Kashaninejad, Ahmadi y col. 2008). Las proteínas de soja como la de la mayoría de las leguminosas están compuestas por globulinas, aproximadamente $70 \%$ del total de proteínas y un 30\% de albúminas que corresponden entre otros a factores antitrípticos (Bowman Birk y Kunitz) y a la lectina (Palazolo 2006). Las proteínas de amaranto estan constituidas principalmente por albúminas que conforman alrededor del 49 al 65\% del total, seguidas en abundancia por las glutelinas, 22,4 al 42,3\%, las globulinas, 13,7 al $18,1 \%$ y finalmente las prolaminas que conforman del 1 al 3,2\% del total de proteínas (Segura-Nieto, Barba De La Rosa y col. 1994). Según la Organización Mundial de la Salud, las proteínas del grano de amaranto presentan un buen balance de aminoácidos, con un contenido importante de lisina, triptófano y de aminoácidos azufrados (principalmente metionina), esenciales en la alimentación humana y que comúnmente son limitantes en otros cereales (Gorinstein, Delgado-Licon, y col., 2001).

La composición porcentual de aminoácidos de los aislados proteicos de soja y amaranto se muestra en la Tabla II. En ella se puede ver que el contenido de los aminoácidos esenciales es muy similar para las dos especies menos en el caso de metionina, siendo su presencia en el aislado de amaranto entre 3 y 4 veces más abundante que en el de soja.

En los aislados proteicos de soja y amaranto obtenidos por precipitación isoeléctrica predominan las globulinas por sobre las otras especies proteicas. Las globulinas pertenecen a la superfamilia de las cupinas. Estas proteínas comparten dos motivos de secuencias cortas de consenso conservadas y un dominio estructural de donde proviene el término cupinas ("cupa" que en latín significa pequeño barril) (Dunwell, 1998). Dentro de la fracción globulinas, se caracterizaron dos clases con coeficientes de sedimentación comprendidos entre 7 y $8 S$ y entre 11 y $12 S$ denominadas vicilina y legumina respectivamente. Ambos tipos de globulinas comparten algunas de las características estructurales: tienen 
subunidades formadas por dos dominios (N-terminal y C-terminal) de estructura equivalente lo que hace suponer que han derivado de un ancestro común.

Tabla II.: Composición porcentual de aminoácidos en proteínas de aislados proteicos de soja y amaranto y cociente entre los porcentajes de soja y amaranto.

\begin{tabular}{|c|c|c|c|}
\hline Aminoácido & Soja $(\%)^{a}$ & Amaranto $(\%)^{b}$ & Soja/Amaranto \\
\hline Ala & 4,5 & 5,6 & 0,80 \\
\hline Arg & 7,7 & 6,9 & 1,12 \\
\hline AsX & 12,1 & 8,4 & 1,44 \\
\hline Cys & 1,5 & 2,0 & 0,75 \\
\hline GIX & 18,9 & 15,8 & 1,20 \\
\hline Gly & 4,4 & 8,2 & 0,54 \\
\hline $\mathrm{His}^{*}$ & 2,7 & 2,2 & 1,23 \\
\hline $\mathrm{Ile}^{*}$ & 5,0 & 4,6 & 1,09 \\
\hline Leu $^{*}$ & 8,2 & 7,5 & 1,09 \\
\hline Lys ${ }^{*}$ & 6,5 & 5,2 & 1,25 \\
\hline Met $^{*}$ & 1,4 & 5,2 & 0,27 \\
\hline Phe* & 5,2 & 4,4 & 1,18 \\
\hline Pro & 5,6 & 5,8 & 0,97 \\
\hline Ser & 5,3 & 6,7 & 0,79 \\
\hline Thr* & 4,3 & 3,8 & 1,13 \\
\hline $\operatorname{Tr} p^{*}$ & 1,4 & $\mathrm{n} / \mathrm{d}$ & ----- \\
\hline Tyr & 3,9 & 2,0 & 1,95 \\
\hline Val $^{*}$ & 5,3 & 5,5 & 0,96 \\
\hline
\end{tabular}

a Datos de Central Soya Company, Inc., Fort Wayne, Indiana, USA

${ }^{\mathrm{b}}$ Resultados obtenidos en nuestro laboratorio

* Aminoácidos esenciales

Las globulinas 11S, presentes tanto en los aisaldos de soja y amaranto, (Figura II) están organizadas en hexámeros y se caracterizan por ser solubles en soluciones 
salinas de alta fuerza iónica y $\mathrm{pH}$ neutro, teniendo masas moleculares aparentes entre 300 y 360 kDa (Marcone, Kakuda y col., 1998, Marcone, 1999). Los hexámeros están formados por subunidades de masa molecular aproximada entre 50 y $70 \mathrm{kDa}$ que se mantienen unidas por interacciones no covalentes. Cada una de las subunidades, a su vez, está conformada por un polipéptido ácido de masa molecular aproximada $30 \mathrm{kDa}$ y un polipéptido básico de alrededor de 20 $\mathrm{kDa}$. Esos polipéptidos se encuentran unidos por un enlace disulfuro, cuya posición ha sido conservada entre las distintas globulinas 11S (Adachi, Takenaka y col., 2001; Adachi, Kanamura y col. 2003).

(a)

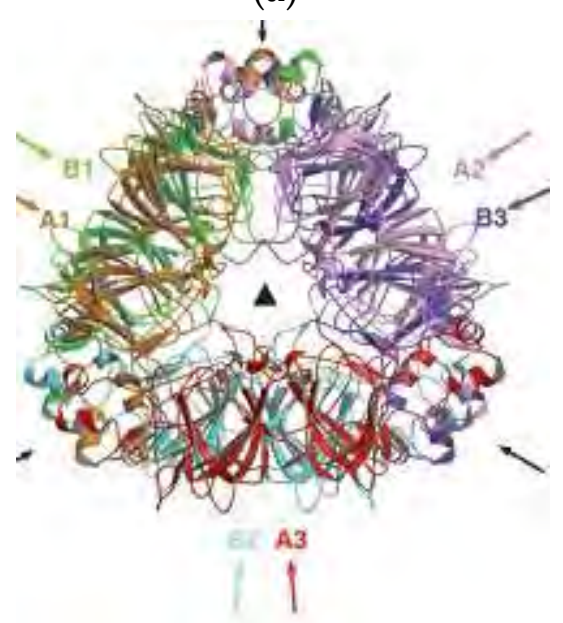

(b)

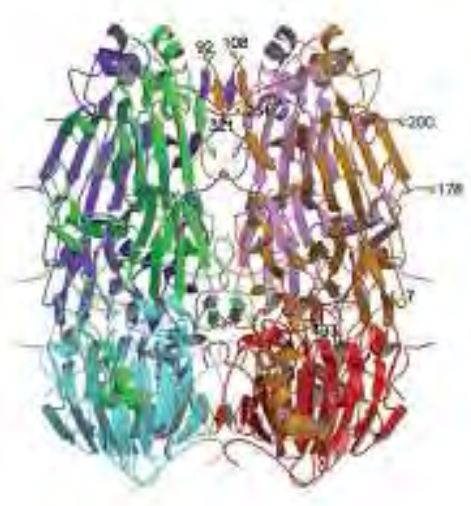

Figura II. Estructura del homohexámero de la globulina 11S (Adachi, Kanamori y col., 2003). Los seis protómeros de la glicinina hexamérica se muestran en: naranja (A1), rosa (A2), rojo (A3), verde (B1), celeste (B2), azul (B3). (a) y (b) son vistas de la molécula rotadas entre si $90^{\circ}$.

Las globulinas 7S (Figura III) se encuentran en mayor proporción en los aislados proteicos de soja aunque también se encuentran presentes en los aislados de amaranto. Se organizan formando trímeros, cuya masa molecular varía entre 150 y 200 kDa (Casey, Domoney y col., 1986). A diferencia de lo que se describió para las leguminas, las subunidades que forman los trímeros en vicilinas no poseen uniones disulfuro. Se distinguen dos tipos de subunidades dentro de los trímeros en la mayoría de las proteínas que pertenecen a esta clase, unas de masa molecular entre 70 y $80 \mathrm{kDa}$ y otras de masa molecular $50 \mathrm{kDa}$. Ambos tipos de subunidades comparten una gran homología en la secuencia. En la soja a la globulina 7S se la denomina $\beta$-conglicinina que es una glicoproteína formada por tres subunidades posibles $\alpha(\approx 72 \mathrm{kDa}), \alpha^{\prime}(\approx 68 \mathrm{kDa})$ y $\beta(\approx 52 \mathrm{kDa})$ pudiéndose combinar de 7 formas distintas: $\left(\alpha^{\prime} \beta 2, \alpha \beta 2, \alpha \alpha^{\prime} \beta, \alpha 2 \beta, \alpha 2 \alpha^{\prime}, \alpha 3\right.$ y $\left.\beta 3\right)$ (Maruyama, Adachi y col. 2001) 
En los aislados de amaranto se encuentra presente la fracción globulina-P. Ésta globulina tiene la particularidad de formar agregados de alto peso molecular (600-1500 kDa) (Castellani, 2000) estabilizados por puentes disulfuro. Una proporción baja de las moléculas de globulina-P se encuentra libre, las cuales poseen una masa molecular de alrededor de $300 \mathrm{kDa}$. La globulina-P posee una alta estabilidad térmica.

(a)

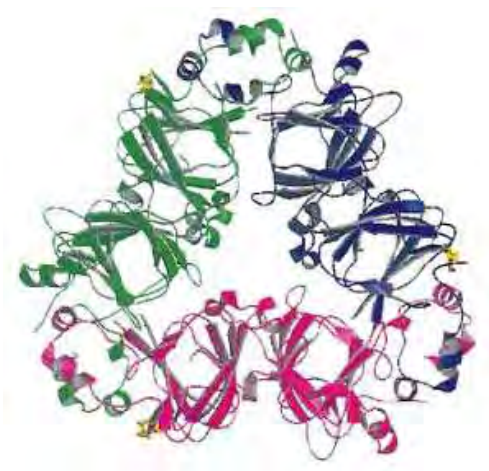

(b)

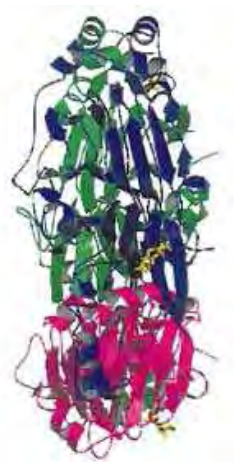

Figura III. Estructura del trímero de la globulina 7S de soja ( $\beta$-conglicinina). Los monómeros se muestran en rosa, verde y azul. Las posiciones glicosiladas se señalan en color amarillo. (a) y (b) son vistas de la molécula rotadas entre si $90^{\circ}$.

En los aislados de amaranto hay una cantidad importante de albúminas que se caracterizan por la alta solubilidad. Varios autores coinciden que esta fracción está compuesta por polipéptidos de masas moleculares de 10 a 40 kDa (Gorinstein, Moshe, y col., 1991, Segura-Nieto, Vázquez-Sánchez y col., 1992). Sus polipéptidos no se encuentran unidos por enlaces disulfuro y tienen baja estabilidad térmica con una temperatura de desnaturalización de alrededor de $60{ }^{\circ} \mathrm{C}$ (Martínez y Añón, 1996, Gorinstein, Delgado-Licon y col., 2001). En su estructura se determinó un elevado contenido de estructura $\beta$-plegada y una baja proporción de estructura terciaria (Marcone, Niekamp y col., 1994), lo que haría que sean moléculas de gran flexibilidad.

En la semilla de amaranto se encuentran presentes, además de albúminas y globulinas, las prolaminas y glutelinas características de cereales tales como trigo cebada y maíz. Las prolaminas son solubles en alcohol y las glutelinas en soluciones de pHs extremos, por lo tanto se las encuentra en baja cantidad en los aislados proteicos de amaranto obtenidos por precipitación isoelectrica.

Las prolaminas están compuestas por polipéptidos de baja masa molecular comprendidos entre 10-22 kDa (Abugoch 2006). 
Para la extracción de glutelinas de amaranto se suelen utilizar, aparte de las condiciones de $\mathrm{pH}$ extremas $(\mathrm{pH} 10)$, detergentes como el SDS y agentes reductores que aumentan el rendimiento de extracción. En medio desnaturalizante no reductor, se han descrito en esta fracción polipéptidos de masas moleculares entre 50-67 kDa, 30-38 kDa y 20-28 kDa, además de subunidades agregadas que no penetran en el gel. En presencia de 2-ME se detectan subunidades de masa molecular semejante a las de las globulinas y la globulina-P. Se han identificado especies de 54-60 kDa, 35-38 kDa y 24-26 kDa, disminuyendo la cantidad de polipéptidos agregados (Gorinstein y col., 1998 y 1991; Barba de la Rosa y col., 1992).

\section{Fenómenos de superficie}

\section{II.I. Tensión interfacial}

En el límite entre las fases de dos fluidos inmiscibles, hay un exceso de energía libre $\left(\mathrm{J} / \mathrm{m}^{2}\right)$. Una interfase fluida es deformable y la energía libre interfacial se manifiesta como una tensión interfacial bidimensional $(\mathrm{N} / \mathrm{m})$. Si una de las fases es gaseosa, se la denomina tensión superficial. La tensión interfacial $(\gamma)$ actúa en la dirección de la interfase y se opone al crecimiento de ésta, propiedad en la que se basan los métodos que pueden medirla (Walstra 2000). Hay sustancias que disminuyen el valor de $\gamma$ adsorbiéndose y acomodándose en la interfase. Esas sustancias se llaman tensioactivos, de sus propiedades dependen cuanto y como se adsorben en la interfase. El descenso de $\gamma$ se suele expresar en términos de la llamada presión interfacial $(\pi)$.

$$
\text { (I) } \pi=\gamma_{0}-\gamma
$$

Siendo $\gamma_{0}$ la tensión interfacial del solvente puro y $\gamma$ el valor de la tensión interfacial en presencia del tensioactivo.

La Tabla III muestra valores aproximados típicos de tensiones interfaciales y superficiales a la temperatura ambiente: 
Tabla III.: Tensiones superficiales e interfaciales aproximadas a temperatura ambiente en $\mathrm{mN} / \mathrm{m}$ (Walstra, 2000)

\begin{tabular}{lcc}
\hline Material & Frente al aire & Frente al agua \\
\hline Agua & 72 & 0 \\
Disolución saturada de $\mathrm{NaCl}$ & 82 & 0 \\
Etanol & 22 & 0 \\
Triglicéridos & 34 & 27 \\
Mercurio & 484 & 415 \\
\hline
\end{tabular}

\section{II.II. Tensioactivos. Comportamiento superficial de pequeños surfactantes y proteínas.}

Cuando se añade una sustancia con actividad superficial al agua, espontáneamente ésta se adsorbe en la superficie y disminuye la energía superficial (si no fuera así, no sería espontánea la adsorción) (Adamson 1976). Los tensioactivos pertenecen a dos tipos de moléculas, polímeros o sustancias similares al jabón, pequeñas. Los tensioactivos constan de una o más zonas que tienen afinidad por la fase polar (hidrofílicas) que normalmente es agua y una o más zonas que tienen afinidad por la zona no polar que es un gas en el caso de una espuma o un aceite en el caso de una emulsión. Las macromoléculas como las proteínas pueden tener gran actividad superficial. Tienden a adsorberse formando trenes, bucles y colas. Las proteínas suelen ser los agentes tensioactivos de elección en la industria alimentaria, especialmente para la formación de espumas y emulsiones o/w (ver sección III.I.) (Dickinson 1992; Walstra y De Roos 1993). Las proteínas en la interfase normalmente sufren un cambio en su conformación, en algunas ocasiones muy acusado. La mayoría de las proteínas globulares parecen retener en la interfase una conformación aproximadamente globular aunque no la nativa. Las proteínas con escaso contenido de estructura secundaria como la caseína o la gelatina tienden más a adsorberse como un polímero lineal. Si se compara la actividad superficial de una proteína con la de un surfactante de menor peso molecular, como un fosfolípido o un monoglicérido, la proteína producirá descensos de la tensión interfacial a menores concentraciones, pero la molécula pequeña podrá lograr 
valores de tensión interfacial menores siempre que se encuentre en la concentración suficiente. Los surfactantes pequeños responden a la ecuación de Gibbs que relaciona la concentración de moléculas tensioactivas en la interfase con la actividad de las moléculas en el seno de la solución, sin embargo con las proteínas no sucede lo mismo. La desorción de una proteína no se produce por una simple dilución o por lavado. Entre las proteínas de la interfase hay reacciones de entrecruzamiento entre las moléculas adsorbidas mediante interacciones electrostáticas, hidrofóbicas o covalentes (puentes disulfuro) (Dickinson y Matsumura 1991). El hecho de que los surfactantes pequeños produzcan mayores presiones superficiales que las proteínas, hace que puedan desplazar a éstas de la interfase con el tiempo (Pugnaloni, Dickinson y col. 2004). Usualmente es difícil conocer la cantidad de tensioactivo adsorbido en la interfase, porque la mayoría de las moléculas con actividad superficial se encuentran disueltas en el seno del agua. La termodinámica predice que la concentración superficial, $\Gamma$, se relaciona con la concentración c de las moléculas dentro del líquido a través de:

$$
\text { (II) } \quad \Gamma=-(1 / \mathrm{kT}) \times \delta \gamma / \delta \ln \mathrm{c}
$$

donde $\mathrm{k}$ es la constante de Boltzmann y $\mathrm{T}$ la temperatura absoluta. Esta es la ecuación de Gibbs y como se mencionó antes se ajusta bastante bien para moléculas pequeñas, las cuales tienen una adsorción reversible ( $\mathrm{Lu}$, Lee y col. 1993).

En el caso de proteínas, la ecuación de Gibbs es menos útil, dado que la adsorción es frecuentemente irreversible. Por otra parte las proteínas cambian parcialmente la conformación durante la adsorción para exponer los grupos hidrofóbicos hacia el aire, entonces las moléculas que se encuentran en la superficie difieren de las moléculas que se encuentran en el seno de la solución por lo tanto no se respetan las condiciones que debe tener el sistema para poder aplicar la ecuación. La concentración superficial puede medirse mediante elipsometría y por reflectividad de rayos X o de neutrones (McClements 2005). Alternativamente, las capas de proteínas pueden extenderse sobre la superficie como monocapas insolubles, que son aparentemente idénticas a las adsorbidas desde la solución (Mellema, Clark y col. 1998) y de esta manera se logra una determinación fácil de la concentración superficial, $\Gamma$.

Las proteínas flexibles, como la $\beta$-caseína, cambian la conformación más fácilmente que las proteínas globulares, como la $\beta$-lactoglobulina, o como las 
proteínas mayoritarias de los aislados proteicos de proteínas vegetales como soja y amaranto. Las moléculas flexibles se adsorben en cantidades ligeramente mayores en la superficie (típicamente $2-3 \mathrm{mg} / \mathrm{m}^{2}$ en lugar de $1-2 \mathrm{mg} / \mathrm{m}^{2}$ de las proteínas globulares). Las proteínas flexibles también producen presiones superficiales algo mayores y potencialmente podrían desplazar proteínas globulares de la superficie. Sin embargo, debido a la adsorción cuasi irreversible, la capa adsorbida es dominada, en la práctica, por la proteína que se adsorbió primero en la superficie (Mackie, Gunning y col. 2001). Las proteínas también pueden desplazarse de la superficie por surfactantes ya que estos tienen mayor capacidad tensioactiva y producen mayores presiones superficiales.

\section{II.III. Interfases curvas}

La presión de un límite entre fases curvas es siempre mayor del lado cóncavo que del convexo. La diferencia entre ambos lados es la llamada presión de Laplace $\left(\mathrm{p}_{\mathrm{L}}\right)$ que para una superficie esférica de radio $\mathrm{r}$ equivale a:

$$
\text { (III) } \quad \mathrm{pL}=2 \gamma / \mathrm{r}
$$

Como consecuencia de esto, las gotas y burbujas tienden a ser esféricas y son difíciles de deformar a medida que se van haciendo más pequeñas (la pL aumenta). Si la forma no fuese esférica su radio de curvatura sería desigual en distintos puntos y por ende diferencias de presión en el interior de la gota o burbuja e implicaría movimiento de material que la forma de zonas de alta a zonas de baja presión para retomar la forma esférica. Las gotas o las burbujas solo se deforman cuando se aplica un esfuerzo externo. Por ejemplo, en una gota de aceite de una emulsión, que tenga un diámetro de $0,5 \mu \mathrm{m}$ y que posea una tensión interfacial de $10 \mathrm{mN} / \mathrm{m}$, la pu es de 40000 Pa y será necesaria una presión externa considerable para deformarla sustancialmente. En cambio en una burbuja de aire de $1 \mathrm{~mm}$ de diámetro y $\gamma$ de $50 \mathrm{mN} / \mathrm{m}$, pL valdrá 100 Pa lo que la hace mucho más deformable a presiones externas. La presión de Laplace es la responsable del ascenso de agua en un capilar ya que el sistema reacciona tratando de igualar la presión de la columna de agua con la presión existente en la interfase agua/aire. Otra consecuencia de la presión de Laplace es el aumento de la solubilidad del gas de una burbuja en el líquido en su entorno. Esto se debe a que la solubilidad de un gas es proporcional al aumento de la presión como lo establece la ley de Henry. Lo mismo sucede con cualquier otro material como lo 
establece la ecuación de Kelvin que compara solubilidades de superficies planas con superficies curvas. El incremento de la solubilidad de los materiales en las superficies curvas es el responsable de la maduración de Ostwald que se explicará más adelante (secciones III.IV.IV. y IV.VI.I.) como también la madurez hacia la redondez de los cristales en solución (Walstra 2000).

\section{II.IV. Tensión superficial dinámica}

Cuando se crea una interfase, las moléculas se adsorben desde el seno de la solución y forman un film superficial. Las cinéticas de adsorción han sido muy estudiadas con diferentes equipos en los cuales se crean superficies libres, como por ejemplo gotas, y con los cuales se mide $\gamma$ en función del tiempo (van Hunsel y Joos 1989). Esos aparatos son usualmente llamados tensiómetros dinámicos. Cuando la adsorción está controlada por la difusión, a tiempos cortos la concentración superficial del tensioactivo puede aproximarse a la ecuación:

$$
\Gamma=2 \times((\mathrm{Dt} / \pi) \times \mathrm{c})^{1 / 2}
$$

Siendo D el coeficiente de difusión de la molécula y c la concentración en el seno de la solución. Para los surfactantes pequeños, las concentraciones superficiales típicas son del orden de una molécula por nanómetro cuadrado. Para órdenes de concentraciones de $1 \mathrm{mM}$, los tiempos de adsorción son próximos a 1 centésima de segundo, pero para concentraciones del orden de $0,1 \mathrm{mM}$, aumenta a $1 \mathrm{~s}$. Al principio la adsorción es muy rápida porque la superficie es fluida, luego va disminuyendo progresivamente a medida que se van adsorbiendo más y más moléculas y se comienza a comportar como un sólido (Ybert y di Meglio 1998).

En el caso de proteínas, y en ausencia de movimientos convectivos, las cinéticas de adsorción son mucho más lentas que las predichas por los mecanismos de difusión. Luego de un paso inicial de difusión, tiene lugar un segundo proceso de reorganización en la monocapa proteica. Este proceso es en general más largo para proteínas globulares, dado que el desplegamiento parcial en la superficie requiere de mayor energía de activación. Para concentraciones del orden de 0,1 $\mathrm{mg} / \mathrm{ml}$, el proceso toma de 1 a $2 \mathrm{~h}$ dependiendo de la libertad de la molécula para cambiar la conformación rápidamente. Para proteínas flexibles, como la $\beta$ caseína, el proceso es más veloz ya que la molécula no posee gran cantidad de estructura secundaria (Figura IV). 


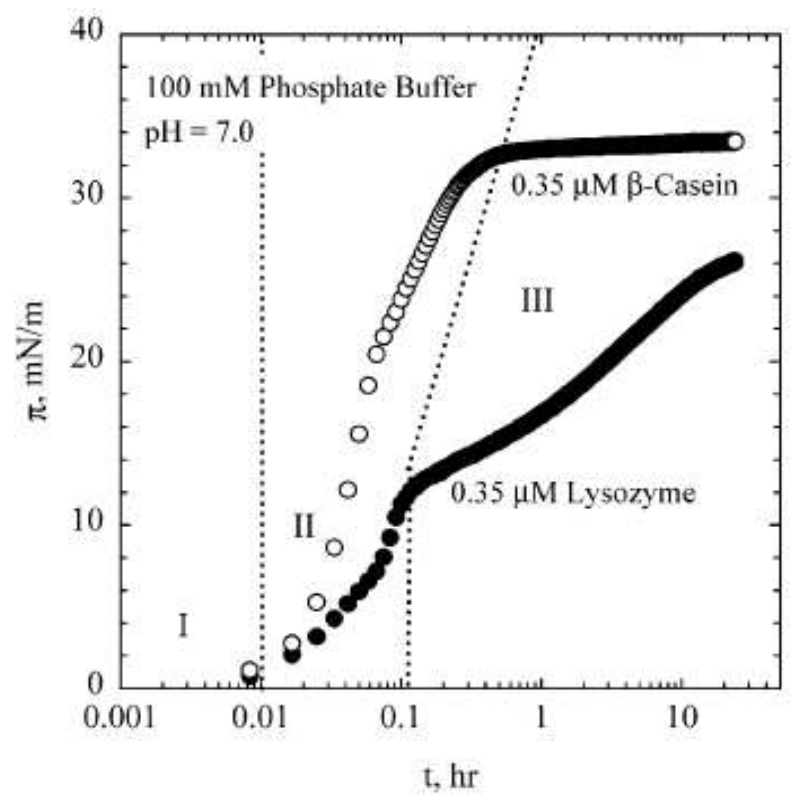

Figura IV.: Comparación de las cinéticas de presión superficial dinámica para dos moléculas de diferente estructura: $\beta$-caseína (flexible), lisozima (rígida y globular) (Freer, Yim y col. (2004)).

El grado del empaquetamiento de las moléculas en la superficie tiene una considerable influencia en el grado de cambio de la conformación (Dickinson 1999). A menor cantidad de moléculas adsorbidas, existe mayor espacio en la superficie para que la proteína pueda extenderse y aumentar las posibilidades y estados de desnaturalización. Las proteínas que se suelen adsorber primero en la superficie suelen mostrar mayor pérdida de actividad y se intercambian muy poco con el seno de la solución luego de la adsorción. A tiempos más largos, ocurre un tercer proceso: la gelificación de la superficie, que se observa especialmente con proteínas globulares. Se piensa que el desplegamiento parcial producido luego de la adsorción, facilita las interacciones atractivas y enlaces cruzados entre las moléculas proteicas, lo que se refleja en un aumento gradual de la irreversibilidad de la adsorción (Van Aken, Blijdenstein y col. 2003). Las moléculas de proteína que se adsorben más tarde, tienden a retener mayor su actividad y pueden participar también en multicapas menos retenidas. La formación de multicapas da lugar a un comportamiento mecánico inusual en las burbujas, una capa rígida que se forma alrededor de la burbuja de gas ( $\mathrm{Li}$, Zhang y col. 2001). La adsorción en la interfase aire/agua, es mucho más lenta que la adsorción en la interfase aceite/agua (Beverung, Radke y col. 1999). 
El descenso de la $\gamma$ es importante para la formación de la espuma, pero deja de lado parte de su importancia cuando se lo relaciona con la estabilidad de la espuma. Entonces aparece otro parámetro de suma importancia y más relevancia en la estabilidad: la viscoelasticidad superficial.

\section{II.V. Reología interfacial}

La reología interfacial estudia la deformación de las interfases por esfuerzos aplicados sobre ellas. Se pueden distinguir entre las deformaciones dilatacionales de corte y de flexión. En las deformaciones dilatacionales el área de la superficie del líquido se aumenta y decrece, mientras que la forma de la interfase del líquido se mantiene aproximadamente igual; en las deformaciones por esfuerzos de corte se cambia la forma de la interfase y se mantiene el área constante (Figura V.); en las deformaciones de flexión se punzan superficies planas para que adquieran superficies esféricas (Bos y Van Vliet 2001).
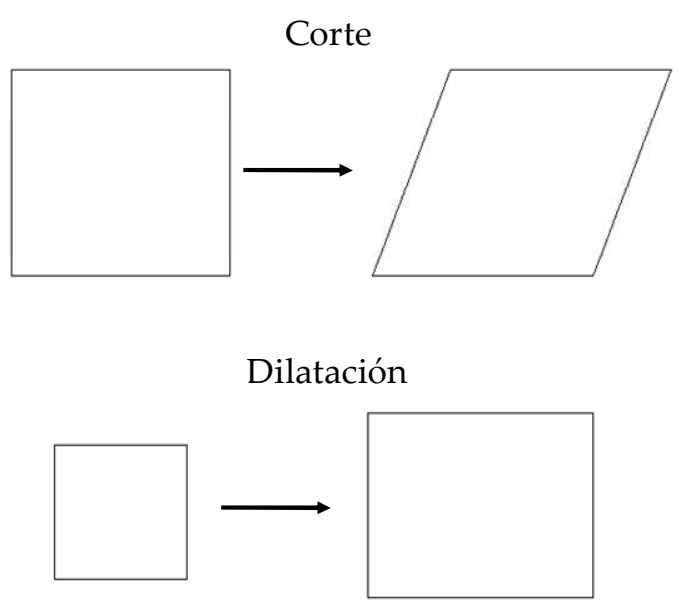

Figura V.: Ejemplos de deformaciones en la interfase en dos dimensiones.

En el caso de pequeños surfactantes se observó que el comportamiento de las interfases era de un carácter más líquido cuando las moléculas con actividad interfacial eran más solubles en una de las fases (De La Fuente Feria y Rodríguez Patino 1995). Este comportamiento se atribuye al intercambio de moléculas adsorbidas de la monocapa con las de la subfase que les otorga más movilidad y un comportamiento más viscoso. En cambio la elasticidad de la interfase aumenta cuando las moléculas son más insolubles. También se observó un comportamiento más elástico cuando las temperaturas descienden (en un rango 
de 10 a $40^{\circ} \mathrm{C}$ ) y cuando la presión interfacial se incrementa. También se observó que mezclas de dos moléculas tensioactivas diferentes pueden dar monocapas más densamente pobladas que cualquiera de las dos especies por separado o producir un efecto contrario, dependiendo de la naturaleza de cada una de las especies (Rodríguez Niño, Wilde y col. 1996).

Para definir la concentración de superficie, Gibbs, introdujo el concepto de propiedades de exceso superficial. Las elasticidades y viscosidades pueden ser definidas como propiedades de excesos. En este sentido pueden introducirse parámetros elásticos y viscosos que se verán a continuación.

\section{II.V.I. Reometría interfacial con parámetros de compresión o dilatacionales}

La reología dilatacional está basada en la aplicación de un cambio del área interfacial durante el cual se mide la tensión interfacial todo el tiempo. Existen varios métodos para medirla como las balanzas de Langmuir o los tensiómetros de gota pendiente o montante (Benjamins, Cagna y col. 1996; Loglio, Pandolfini y col. 2001; McClements 2005). Usando este tipo de reometría se han realizado estudios con surfactantes de bajo peso molecular (monoglicéridos, fosfolípidos) y con polímeros de mayor tamaño (proteínas).

Por analogía con sistemas tridimensionales el módulo elástico (E) puede definirse como:

$$
\text { (V) } \quad \mathrm{E}=-\mathrm{A} \times(\delta \pi / \delta \mathrm{A})
$$

donde $\mathrm{A}$ es el área superficial. Para una monocapa insoluble $\Gamma \approx 1 / \mathrm{A} \quad \mathrm{y} E=\mathrm{E}_{0}$ dando:

$$
\mathrm{E}_{0}=-\Gamma \times(\delta \gamma / \delta \Gamma)
$$

Eo usualmente es llamada Elasticidad de Gibbs. Si ocurre un relajamiento durante la compresión, puede introducirse la viscosidad de compresión, $\kappa$. En el caso de una deformación sinusoidal de frecuencia $\omega$ a pequeña amplitud, $\kappa$ se relaciona con la parte imaginaria del módulo complejo describiendo una respuesta linear:

(VII) $\quad \mathrm{E}^{*}=\mathrm{E}^{\prime}+\mathrm{iE}^{\prime \prime}=\mathrm{E}^{\prime}+\mathrm{i} \omega \kappa$ 
Estos parámetros, son llamados parámetros dilatacionales.

En las proteínas la interpretación de los datos de reología interfacial dilatacional depende de las escalas de tiempos en las velocidades de dilatación y las frecuencias en las que se realizan esas mediciones (Bos y Van Vliet 2001).

Para proteínas con poca estructura interna se pudo observar un gran cambio de la reología interfacial en función del tiempo o de la presión interfacial (Graham y Phillips 1979; Gau, Yu y col. 1994). Con el tiempo se observa la variación de un comportamiento totalmente elástico a uno viscoelástico de la interfase con el incremento de la presión interfacial. En el caso de proteínas poco estructuradas, a partir de cierta concentración en la interfase pueden darse procesos de intercambio difusional y de relajación que pueden modificar el comportamiento reológico interfacial a uno menos elástico (Bos y Van Vliet 2001).

Se han informado grandes variaciones en los coeficientes viscoelásticos al variar la frecuencia de las oscilaciones en las interfases solubles, particularmente en el caso de coeficientes de compresión. Estas variaciones con la frecuencia son debidas a un intenso acoplamiento de las moléculas de la monocapa con el seno del agua. En el caso de que la frecuencia sinusoidal de compresión sea baja, la monocapa tiene siempre tiempo de llegar a un equilibrio y no hay resistencia a la compresión: $E^{\prime}=\omega \kappa=0$. Sin embargo cuando la frecuencia es alta, la monocapa no tiene tiempo de responder y se comporta como si fuera insoluble: $\kappa=0$ y $E^{*}$ es real e igual a E. En el rango intermedio de frecuencias se sigue:

$$
\text { (VIII) } \quad \mathrm{E}^{*}=\mathrm{E}_{0} /(1+(1+\mathrm{i}) \times \Omega)
$$

con $\Omega=(\mathrm{D} / 2 \omega \mathrm{dc} / \mathrm{d} \Gamma)^{1 / 2}$ siendo $\mathrm{D}$ el coeficiente de difusión de las moléculas tensioactivas en el seno de la fase acuosa. La frecuencia característica límite se incrementa con el incremento de la concentración, entonces el régimen de monocapa insoluble sólo se ve a bajas concentraciones, a altas concentraciones la monocapa se comprime instantáneamente. La ecuación sirve cuando no hay barreras para la adsorción o desorción (Langevin 2008).

Las proteínas globulares, más estructuradas, y formadoras de interfases más cerradas, normalmente no crean interfases que produzcan cambios homogéneos con las variaciones del área. En este tipo de proteínas también se han visto efectos de disminución de la elasticidad con el aumento de la temperatura, al igual que lo que sucede cuando el $\mathrm{pH}$ se acerca al punto isoeléctrico de las especies proteicas. Por el contrario, se observaron aumentos de la elasticidad con 
el aumento de la fuerza iónica o con el aumento de la concentración de moléculas en la interfase (Burgess y Sahin 1997).

La viscoelasticidad de compresión de capas de proteínas es similar a la de los pequeños surfactantes (Bos y Van Vliet 2001). El módulo elástico suele ser mayor para las proteínas globulares. Por ejemplo, con concentraciones de 0,1 g/l, luego de $100 \mathrm{~s} E^{\prime}=11 \mathrm{mN} / \mathrm{m}$ para las soluciones de $\beta$-caseína y $28 \mathrm{mN} / \mathrm{m}$ para la $\beta$-lactoglobulina. Luego de $2 \mathrm{~h}$ (cuando la reorganización de la superficie se completó), $E^{\prime}=38$ y $63 \mathrm{mN} / \mathrm{m}$, respectivamente. En el caso de las proteínas flexibles como la $\beta$-caseína, parte de la monocapa, puede comportarse como soluble con la correspondiente respuesta reológica que describe la ecuación (VIII) (Freer, Yim y col. 2004).

\section{II.V.II. Reometría interfacial rotacional}

Los aparatos más comunes que miden los parámetros de cizalla o de esfuerzo de corte son los viscosímetros de canal (para monocapas insolubles) y los discos oscilantes (Miller, Wüstneck y col. 1996).

La diferencia en los parámetros de cizalla entre distintos tipos de moléculas proteicas es mucho mayor que la diferencia en los parámetros dilatacionales. La viscosidad superficial de cizalla es del orden de $1 \mathrm{mNs} / \mathrm{m}$ para proteínas flexibles y de $1000 \mathrm{mNs} / \mathrm{m}$ para proteínas globulares. Para pequeños surfactantes los valores son del orden de $1 \mu \mathrm{Ns} / \mathrm{m}$. Los parámetros de cizalla son muy pequeños durante la primera etapa de adsorción de las proteínas, y pueden llegar a valores altos sólo después de muchas horas, probablemente porque están asociados con la tercera etapa de adsorción cuando se produce la gelificación de la superficie. Cuándo se añaden tensioactivos a las interfases estabilizadas por proteínas los valores de viscoelasticidad caen pero mantienen valores mayores que los de las interfases estabilizadas por pequeños surfactantes. Éste efecto también puede observarse en los parámetros de compresión, aunque menos pronunciado (Langevin 2008).

\section{II.V.III. Relación de la reología interfacial con la estabilidad de emulsiones y espumas}

Las medidas descriptas anteriormente se hacen sobre superficies macroscópicas y los rangos de esfuerzos y deformaciones aplicados en las superficies no reflejan las condiciones prácticas de la formación y evolución de las espumas o 
emulsiones, por ejemplo la formación de burbujas involucra grandes deformaciones y altas velocidades de deformación (Bos y Van Vliet 2001). Esto significa que la reología de respuesta linear discutida antes podría no tener tanta relevancia en las propiedades de una espuma o una emulsión.

Se ha demostrado recientemente que la viscoelasticidad de las monocapas de proteína se aparta significativamente de la linealidad y muestra una clara dependencia de las magnitudes de la tensión y de las velocidades de deformación. Algunos nuevos métodos están disponibles para estudiar la reología de la monocapa bajo condiciones de no equilibrio y amplias deformaciones. Es el caso del cilindro rebalsado o derramado (overflowing cylinder) que puede usarse para medir la reología interfacial dinámica (van Kalsbeek y Prins 1999). Este método se basa en la medida de la tensión superficial o interfacial de un líquido que derrama en el extremo de un cilindro. Se regula la maduración de la interfase con el caudal que se hace circular dentro del cilindro.

Muchas teorías describen la coalescencia como la formación de un hueco en la interfase. Aparentemente la formación de ese hueco depende del espesor del film. Se cree que son importantes la elasticidad y viscosidad interfacial para explicar la ruptura del film que va a formar ese hueco que contribuye con la coalescencia. Hay evidencia experimental que demuestra relaciones entre la reología interfacial de films de $\beta$-lactoglobulina en la interfase o/w y la estabilidad de las emulsiones estabilizadas por la misma proteína (Dickinson, Owusu y col. 1993). También se ha observado que el entrecruzamiento producido por enzimas como la transglutaminasa, aumenta la estabilidad en emulsiones estabilizadas por proteínas (Faergemand, Murray y col. 1997) debido al aumento de la viscoelasticidad de la interfase que se produce por la interacción entre cadenas. Aparentemente la presencia de una cierta cantidad de tensioactivos de bajo peso molecular podría producir un ablandamiento y mayor movilidad de las interfases de proteínas lo que podría permitir una recuperación más rápida de la película y así contrarrestar los esfuerzos producidos durante las colisiones de gotas o burbujas resultando en emulsiones y espumas más estables. Esa dureza dependería tanto de la proteína como del surfactante de bajo peso molecular. Entonces posiblemente la interfase no debería ser totalmente rígida, sino que debería poseer cierto grado de relajación para una óptima protección contra la coalescencia. Sin embargo no existe aún una teoría confiable para una relación directa entre las propiedades reológicas e interfaciales (Bos y Van Vliet 2001). 


\section{Emulsiones}

\section{III.I. Introducción}

Las emulsiones líquidas consisten en gotas de un líquido dispersas en otro líquido que constituye la fase continua (Robins, Watson y col. 2002). Si el líquido dispersado es, por ejemplo aceite, y la fase continua agua se dice que es una emulsión de aceite en agua o una emulsión o/w (oil/water en inglés). Las emulsiones son sistemas termodinámicamente inestables debido a que poseen una gran cantidad de área interfacial, acompañada por una alta tensión interfacial, lo que genera un aumento de la energía libre del sistema (Wagner 2000).

La variación de energía libre para crear una emulsión está dada por la expresión:

$$
\text { (IX) } \Delta \mathrm{Gem}_{\mathrm{em}}=\gamma_{\mathrm{i}} \Delta \mathrm{A}-\mathrm{T} \Delta \mathrm{S}_{\mathrm{em}}
$$

siendo $\gamma_{i}$ la tensión interfacial y haciéndose el último término (T $\left.\Delta \mathrm{S}_{\mathrm{em}}\right)$ despreciable en el caso de las emulsiones alimentarias que tienen tamaños entre 0,2 y $100 \mu \mathrm{m}$, por lo tanto van a ser termodinámicamente inestables. El emulsificante va a disminuir el valor de $\gamma_{i}$ al tener afinidad por ambas fases por tratarse de una molécula anfifílica.

$\mathrm{Si}$ suponemos que se mezclan dos líquidos A y $\mathrm{B}$, el cambio energético que sucede en el sistema se puede representar con:

$$
\text { (X) } \quad \Delta \mathrm{G}_{\mathrm{mez}}=\Delta \mathrm{E}_{\mathrm{mez}}-\mathrm{T} \Delta \mathrm{S}_{\mathrm{mez}}
$$

siendo $\Delta \mathrm{G}_{\text {mez, }} \Delta \mathrm{Emez}$ y $\Delta \mathrm{S}_{\text {mez }}$ la variación de energía libre, la variación de la energía de interacción y la variación de entropía debida al mezclado respectivamente.

E se puede representar como:

$$
\text { (XI) } \quad \mathrm{E}=\mathrm{n}_{\mathrm{AA}} \mathrm{W}_{\mathrm{AA}}+\mathrm{nBB}_{\mathrm{B}} \mathrm{WBB}_{\mathrm{B}}+\mathrm{n}_{\mathrm{AB}} \mathrm{W}_{\mathrm{AB}}
$$

donde $\mathrm{n}$ es el número de interacciones $\mathrm{y} \mathrm{w}$ el par potencial a separación de equilibrio. Con el mezclado el número de enlaces varía entonces. 
siendo $\mathrm{n}$ el número de moles, $\mathrm{w}$ el parámetro de interacción efectiva $\mathrm{y} \mathrm{X}_{\mathrm{A}} \mathrm{y} \mathrm{X}_{\mathrm{B}}$, las fracciones molares de A y B. El parámetro de interacción efectiva $\mathrm{w}$ es una medida de la compatibilidad de las moléculas en una mezcla, negativo si favorece el mezclado y positivo si lo dificulta.

S está dada por la expresión:

$$
(\mathrm{XIII}) \quad \mathrm{S}_{\mathrm{mez}}=-\mathrm{nR}\left(\mathrm{X}_{\mathrm{A}} \ln \mathrm{X}_{\mathrm{A}}+\mathrm{X}_{\mathrm{B}} \ln \mathrm{X}_{\mathrm{B}}\right)
$$

$A S_{m e z}$ va a ser siempre positiva y por lo tanto va a contribuir a disminuir la energía libre de mezclado.

Entonces la expresión de la energía libre queda como:

$$
(\mathrm{XIV}) \quad \Delta \mathrm{Gmez}_{\mathrm{mez}}=\mathrm{n}\left(\mathrm{X}_{\mathrm{A}} \mathrm{X}_{\mathrm{B}} \mathrm{w}+\mathrm{R} \mathrm{T}\left(\mathrm{X}_{\mathrm{A}} \ln \mathrm{X}_{\mathrm{A}}+\mathrm{X}_{\mathrm{B}} \ln \mathrm{X}_{\mathrm{B}}\right)\right)
$$

De esta ecuación se deduce que los líquidos A y B son miscibles cuando $\mathrm{w}<2 \mathrm{RT}$ porque domina la contribución de la entropía, parcialmente inmiscibles cuando $2 \mathrm{RT}<\mathrm{w}<4 \mathrm{RT}$ y totalmente inmiscibles cuando $\mathrm{w}>4 \mathrm{RT}$.

El sistema tiende disminuir la superficie disminuyendo el número de gotas lo que desestabiliza las emulsiones.

Muchas proteínas son moléculas con actividad superficial que pueden ser usadas como emulsificantes por su capacidad de facilitar la formación, mejorar la estabilidad y producir propiedades físico-químicas deseables en las emulsiones $\mathrm{o} / \mathrm{w}$. Las proteínas se adsorben en las superficies de las gotas de aceite recién formadas mediante la homogenización de mezclas de aceite-agua-proteína, en donde las proteínas facilitan la ruptura de gotas por producir un descenso en la tensión interfacial y un retardo de la coalescencia de las gotas al formar membranas interfaciales que las rodean (Walstra 2003). La capacidad de las proteínas de generar interacciones repulsivas (estéricas, electrostáticas) entre las gotitas de aceite y de formar una membrana interfacial que sea resistente a la ruptura juega un papel importante en la estabilización de las gotas contra la floculación y la coalescencia durante los almacenamientos a largo plazo (Wilde, Mackie y col. 2004).

El desarrollo de las emulsiones estabilizadas por proteínas con propiedades mejoradas o novedosas se basa en comprender el comportamiento interfacial de las proteínas adsorbidas y en elucidar la relación existente entre las 
características de la interfase y las propiedades físico-químicas del seno de las emulsiones. Se ha avanzado mucho en la investigación relacionada con el desempeño de las proteínas en las interfases, pero normalmente los ensayos se hacen en condiciones modelo bien definidas como $\mathrm{pH}$, fuerza iónica $\mathrm{y}$ temperatura fijas que quizás no representen lo que suele suceder en los productos alimenticios basados en emulsiones donde las situaciones son más variables durante la producción, almacenamiento y utilización.

\section{III.II. Formación de la emulsión}

Para producir una emulsión o/w se necesita aceite, agua, un agente emulsificante y energía. Fabricar las gotas es fácil, romperlas en otras más pequeñas es difícil. Las gotas a medida que se hacen más pequeñas van volviéndose más resistentes a las deformaciones debido a que se opone la presión de Laplace que se incrementa al disminuir el tamaño de la gota. La energía necesaria se reduce si se reduce la tensión superficial y esta es una de las funciones del emulsificante.

La energía necesaria para formar y romper las gotas se suministra generalmente por agitación intensa con la cual se producen fluctuaciones de presión debido al flujo turbulento. Los equipos que pueden utilizarse son:

- Agitadores rotatorios de alta velocidad

- Molinos coloidales

- Homogenizadores de válvulas

- Homogenizadores por ultra sonido

- Microfluidizadores

Todos ellos se encuentran esquematizados en la Figura VI.

Durante la formación de la emulsión, al aparecer una nueva área interfacial, el agente emulsificante debe adsorberse en la interfase a alta velocidad para estabilizarla, si así no lo hiciera, las gotas formadas podrían coalescer nuevamente (Figura VII.). 

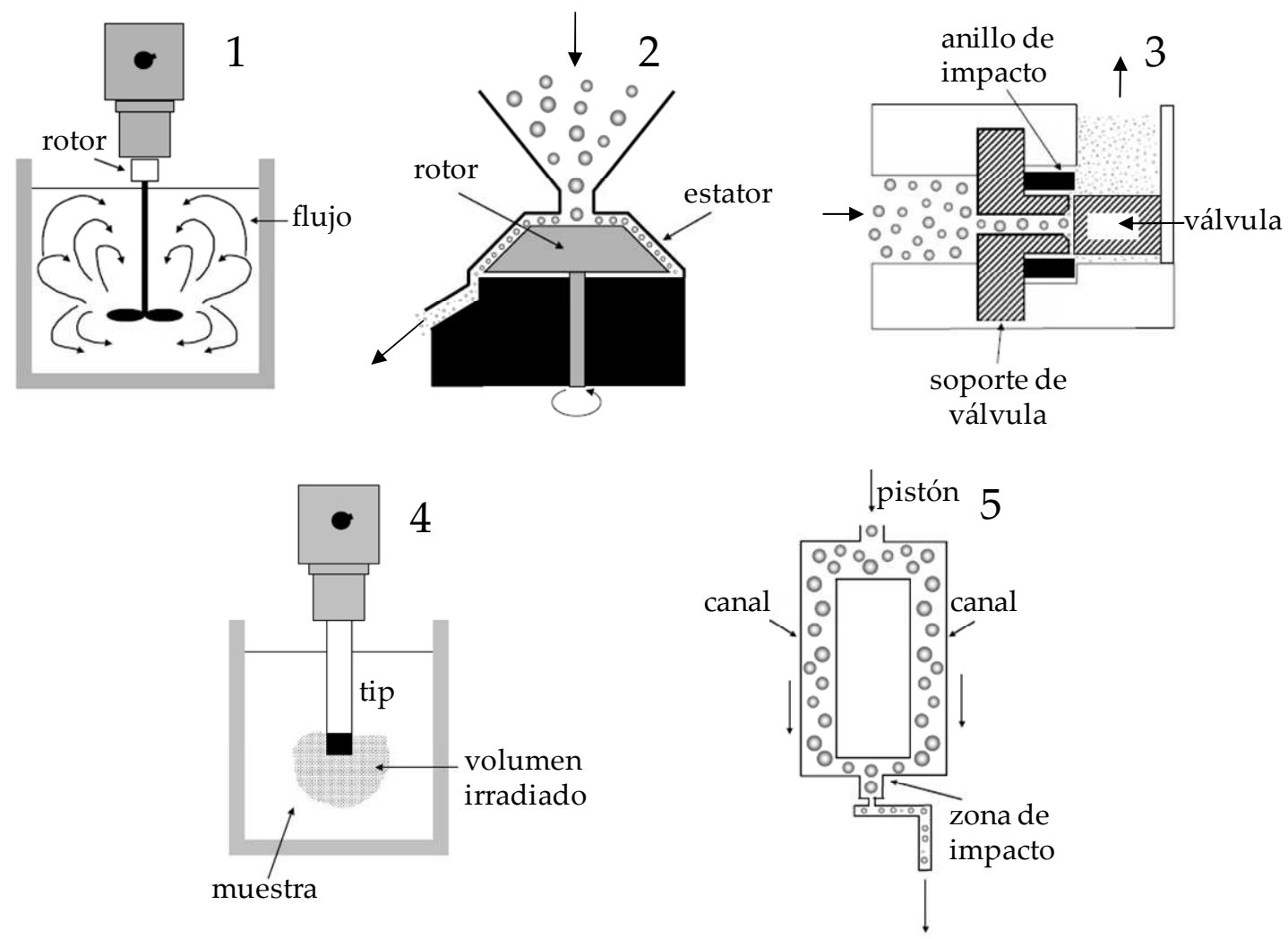

Figura VI.: Esquema de distintos homogenizadores para producir emulsiones: (1) agitador de alta velocidad, (2) molino coloidal, (3) homogenizador de válvulas, (4) homogenizador por ultra sonido, (5) microfluidificador.

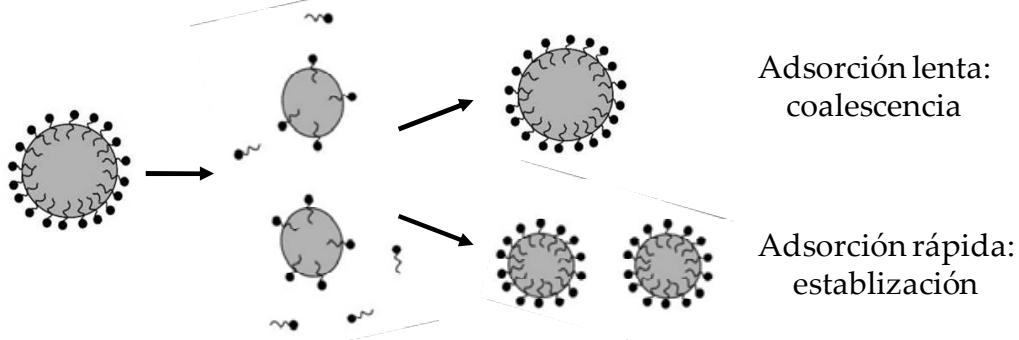

Figura VII.: Tamaño de las gotas resultantes dependiendo de la velocidad de adsorción del emulsificante durante la homogenización.

\section{III.III. Maduración de la interfase}

Luego de la adsorción en la interfase, la proteína puede sufrir cambios sustanciales en su conformación y en las interacciones que establece con otras proteínas debido al cambio del entorno de la molécula. En la fase acuosa, la 
proteína está rodeada por moléculas de agua pero en la interfase $\mathrm{o} / \mathrm{w}$ se encuentra rodeada por agua de un lado y por aceite del otro, además de entrar en contacto íntimo con otras moléculas proteicas que se adsorben al mismo tiempo. Las proteínas producen cambios conformacionales en su nuevo entorno para maximizar la cantidad de interacciones favorables y minimizar las desfavorables. El tiempo que tardan en producir esos cambios va a estar dado por la flexibilidad y estructuración de la propia molécula (Freer, Yim y col. 2004). Las proteínas relativamente flexibles, como la caseína, producen los cambios conformacionales de manera rápida mientras que las globulares, como la lisozima, pueden tardar mucho más tiempo. Esos cambios conformacionales que resultan de la adsorción pueden considerarse como una desnaturalización parcial.

Para muchas proteínas globulares la desnaturalización en la interfase puede llevar a la exposición de zonas no polares y de grupos sulfhidrilo. Cuando las gotas de aceite estabilizadas por proteínas se acercan demasiado, por ejemplo a pHs cercanos al PI o a altas fuerzas iónicas, la desnaturalización de las proteínas en la interfase puede producir floculación a través de un aumento de la atracción hidrofóbica o por la formación de puentes disulfuro entre proteínas adsorbidas en diferentes gotas. Sin embargo, cuando las gotas se mantienen lejos unas de otras, a pHs lejanos de PI de las proteínas o a bajas fuerzas iónicas, la interacción de las proteínas en la interfase es más difícil de romper por la interacción con otras gotas, lo que puede producir una mejor estabilidad contra la coalescencia de las gotas (Bos y Van Vliet 2001).

\section{III.IV. Desestabilización de las emulsiones}

Las emulsiones pueden desestabilizarse de diferentes maneras ya sea por cambio de tamaño de las gotas (maduración de Ostwald, coalescencia) de las emulsiones o por variación de su posición o distribución en el espacio (cremadosedimentación, floculación) (Figura VIII.). Estos procesos pueden verse mutuamente afectados. Por ejemplo, la floculación facilita considerablemente el cremado, y si este ocurre, facilita la floculación, además si la emulsión concentrada de la crema es muy compacta, más rápida será la coalescencia. 


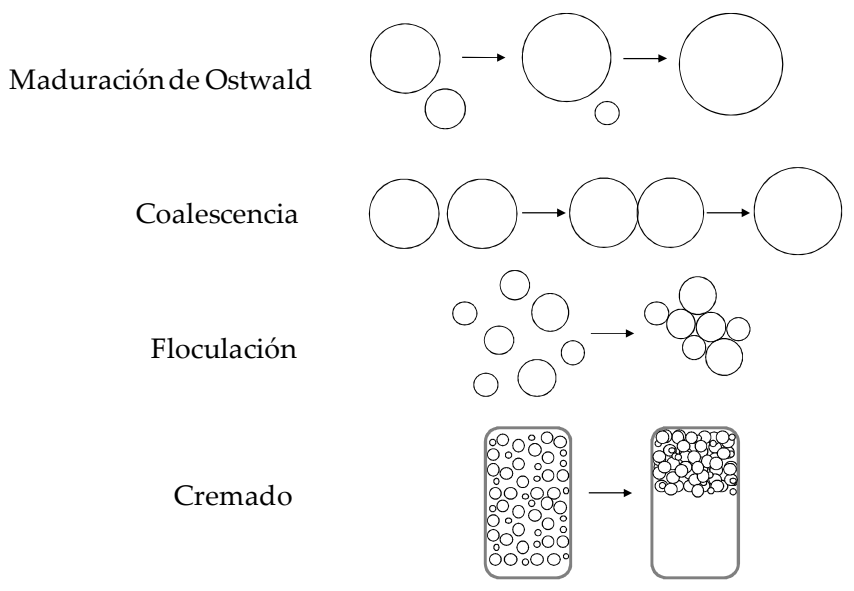

Figura VIII.: Distintas desestabilizaciones que pueden ocurrir en las emulsiones o/w.

\section{III.IV.I. Cremado / sedimentación}

El cremado (en emulsiones o/w) o la sedimentación (en emulsiones w/o) se produce por la diferencia de densidad $(\rho)$ entre los dos fluidos lo que producirá en los objetos una fuerza de empuje. Las gotas cremarán o sedimentarán a cierta velocidad ( $\mathrm{V}_{\mathrm{s}}$ ) que se puede aproximar con algunas limitaciones por la ley de Stokes:

$$
(X V) \quad V_{s}=g(\rho D-\rho c) d^{2} / 18 \eta_{c}
$$

donde los subíndices D y C corresponden a la fase dispersa y continua respectivamente, $\mathrm{d}$ es el diámetro de la partícula, $\mathrm{g}$ es la aceleración de la gravedad y $\eta$ la viscosidad. Como se puede ver, el cremado depende notablemente del tamaño de la partícula, las más pequeñas lo harán más lentamente que las más grandes. Igualmente en el comportamiento real de las emulsiones en los alimentos existen muchas desviaciones de la ley, debido a la concentración y distribución de tamaños de gotas presentes y a la viscosidad de la fase continua. Para evitar o tratar de impedir el cremado se puede disminuir el tamaño de gota, aumentar la viscosidad o minimizar la diferencia de densidad de las fases por agregado de sustancias que la modifiquen.

\section{III.IV.II. Floculación}

La floculación es el proceso por el cual dos o más gotas se asocian unas con otras, pero mantienen su integridad individual. La floculación de gotas puede ser 
favorable o perjudicial para la calidad de la emulsión en función de la naturaleza del tipo de sistema que se desee. La floculación acelera la velocidad de cremado en las emulsiones diluidas, situación que no suele ser deseable ya que reduce su vida útil (Luyten, Jonkman y col. 1993; Tan 2004). También puede causar un aumento pronunciado de la viscosidad de la emulsión e incluso puede dar lugar a la formación de un gel (Demetriades, Coupland y col. 1997). En ciertos productos se espera tener una baja viscosidad y por lo tanto la floculación juega en contra de lo deseado. En otros productos, una floculación controlada puede ser ventajosa, ya que conduce a la creación de una textura más deseable.

Para que ocurra floculación lo primero que tiene que suceder es que las gotas se aproximen. Esto puede producirse por diversos mecanismos como el movimiento browniano, la acción de la gravedad o la aplicación de esfuerzos mecánicos al sistema como ocurre durante la homogenización. Luego tiene que disminuir el espacio entre las gotas que se va transformando en un film de fase continua el que se adelgaza cada vez más. El proceso usualmente genera una resistencia hidrodinámica en el sistema debido a la resistencia que genera el flujo de fase continua afuera del film (Ivanov, Danov y col. 1999). Luego que el film entre las dos gotas alcanza cierto valor crítico pueden suceder tres cosas: que las gotas se separen y no haya agregación; que se mantengan unidas pero de manera débil en un mínimo secundario produciendo una floculación débil o que se unan fuertemente ya que el choque superó la energía de activación necesaria para que suceda la floculación.

La frecuencia de las colisiones va a determinar la velocidad de floculación y se puede estimar mediante ecuaciones complejas para los distintos tipos de formas que tienen las gotas para encontrarse. La eficiencia de las colisiones va a estar dada por la energía de los choques y si esta supera la barrera energética necesaria para que se produzca la floculación.

Los métodos para controlar la floculación se basan en controlar la frecuencia de las colisiones (por ejemplo aumentando la viscosidad de la fase continua o evitando las agitaciones durante el almacenamiento) o disminuyendo la eficiencia de las colisiones (disminuyendo las interacciones coloidales atractivas). La floculación puede darse por diversos tipos de interacciones:

-Interacciones electrostáticas: en el caso de las proteínas la carga de las mismas varía con el $\mathrm{pH}$ de la fase acuosa. En valores cercanos al punto isoeléctrico (PI \pm 2) (McClements 2005) de las especies proteicas la floculación va a tener mayores posibilidades de producirse por la disminución de la repulsión entre las proteínas que estabilizan la superficie de las gotas. Además el aumento de la 
fuerza iónica apantalla las repulsiones electrostáticas que pueden darse por la carga de la proteína pudiendo producir floculación, siendo mucho más efectivos los iones divalentes que los monovalentes.

-Interacciones estéricas: generalmente son repulsivas y protegen de la floculación y la coalescencia, pero si por ejemplo las condiciones del solvente cambiaran y pasaran a favorecer la interacción entre polímeros y no la de los polímeros con el medio, se favorecería la floculación.

-Interacción por puenteo: se puede producir cuando una molécula del biopolímero se une a dos gotas diferentes al mismo tiempo formando puentes entre ellas (Dickinson 2003). Por ejemplo, si alguna zona hidrofóbica de una proteína está expuesta al ambiente acuoso puede interaccionar con alguna zona de la superficie de otra gota que se encontrase sin cubrir. Generalmente se da cuando hay deficiencia de agente emulsificante (Dickinson y Euston 1991).

-Interacciones hidrofóbicas: estás pueden darse entre zonas hidrofóbicas que puedan existir en la superficie de las gotas. Las interacciones hidrofóbicas son importantes en las emulsiones en las que no hay suficiente emulsionante para saturar totalmente la superficie de las gotas de (Dickinson, 2003).

-Interacción por depleción: se produce cuando hay partículas coloidales no adsorbidas en la fase acuosa. Al aproximarse dos gotas y cuando la concentración de coloide en el espacio entre gotas es baja se produce un efecto osmótico que resulta en la interacción. Generalmente aumenta con el aumento de la concentración del coloide no adsorbido, con el aumento del tamaño del coloide y con el aumento del tamaño de gota (McClements 2000). Son interacciones normalmente débiles y reversibles.

-Interacciones covalentes: cuando se intercambian puentes disulfuro entre proteínas de distintas gotas. Por calentamiento a altos $\mathrm{pHs}$ se ven favorecidas.

Los flóculos pueden adoptar dos tipos de geometrías, abiertos y cerrados (Figura IX.). Se produce uno $\mathrm{u}$ otro dependiendo de las interacciones coloidales que se producen entre las superficies de las gotas siendo más específicas en el caso de los abiertos. Cuando los flóculos son abiertos se puede producir un red tridimensional a lo largo de toda la emulsión que puede hacer que esta tome un comportamiento de gel (Bijsterbosch, Bos y col. 1995). La presencia de flóculos aumenta la viscosidad de la emulsión por aumento del radio hidrodinámico de las partículas. 

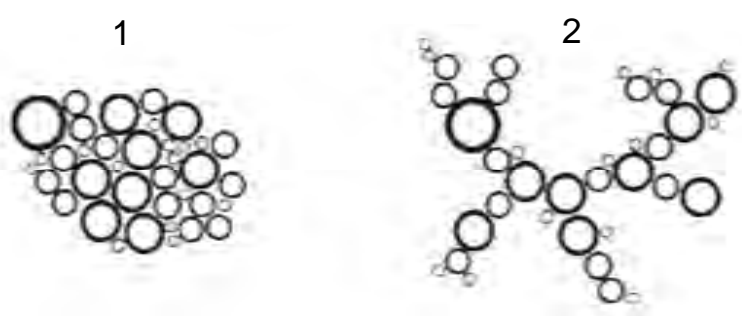

Figura IX.: Diferentes geometrías que pueden adoptar los flóculos: (1) flóculos cerrados, (2) flóculos abiertos.

\section{III.IV.III. Coalescencia}

Es el proceso por el cual dos gotas diferentes de una emulsión se unen para formar una única gota de mayor tamaño.

La coalescencia se ve favorecida por diferentes situaciones:

-Pérdida de la forma esférica: esta sucede cuando las gotas se empacan demasiado y adoptan formas poliédricas. En las zonas que se achatan baja la presión de Laplace, lo que conduce a una menor estabilidad de las gotas. Las gotas más grandes son las más susceptibles a la deformación mientras que las más pequeñas requieren mayores esfuerzos para ser deformadas (Walstra 2003).

-Ruptura del film: La ruptura del film puede deberse a diferentes causas. Se puede producir un hueco espontáneamente en el film por movimientos vibracionales térmicos de las moléculas del emulsificante; dicho hueco puede interaccionar con la superficie sin cubrir de otra gota y causar coalescencia. La cantidad insuficiente de emulsificante puede hacer que queden huecos en la membrana interfacial sin cubrir y si estos entran en contacto se puede producir la coalescencia de las gotas (principalmente durante la homogenización). Si se estira el film por acción de fuerzas paralelas puede disminuir la concentración del tensioactivo en esa zona del film y abrir huecos en la superficie susceptibles de producir coalescencia. Cuando las membranas son más cohesivas o viscoelásticas (como las formadas por proteínas globulares) se pueden producir desgarramientos de la membrana por la acción de las fuerzas paralelas que pueden exponer la superficie de la gota (Van Aken 2004).

Los factores que afectan la coalescencia pueden ser:

-Tipo de emulsificante: Las proteínas suelen ser buenos emulsificantes porque producen tamaños de gotas pequeños, pueden provocar interacciones repulsivas importantes por una combinación de repulsiones electrostáticas (según el pH y la fuerza iónica del medio) y estéricas, forman films viscoelásticos resistentes a la 
ruptura y no disminuyen mucho la tensión interfacial lo que le aporta rigidez al film y a la estructura de la gota. Los emulsionantes pequeños estabilizan las gotas con interacciones de largo alcance y no por la estructura de la membrana ya que ésta tiene un carácter muy fluido. En el caso del SDS, por ejemplo, se estabiliza por repulsión electrostática que se anula al aumentar la fuerza iónica del medio.

-Influencia de las condiciones y almacenamiento del medio: Las emulsiones pueden sufrir coalescencia cuando se las expone a vibraciones o a esfuerzos mecánicos prolongados (Van Aken 2004); también si son congeladas dado que aumenta la concentración de las gotas en las partes que permanecen líquidas lo mismo que la de las sales. Estas son situaciones que pueden desestabilizar el sistema (Van Aken 2004). Si se quiere obtener polvos a partir de emulsiones mediante el secado de las mismas (spray, liofilización), se puede producir la ruptura de la membrana interfacial lo que llevaría a la coalescencia al tratar de reconstituir la emulsión (Young, Sarda y col. 1993). También se puede favorecer la coalescencia si se producen reacciones químicas (como la oxidación de lípidos) y éstas forman productos con actividad superficial que desplacen los emulsionantes de la interfase o que produzcan la hidrólisis de proteínas o hidratos de carbono que estabilizan la interfase (Euston, Finnigan y col. 2001).

-Influencia de impurezas: si en el medio se encuentran impurezas como pequeños sólidos, estos pueden romper la membrana, especialmente si se somete la emulsión a esfuerzos mecánicos (Van Aken 2004).

\section{III.IV.IV. Maduración de Ostwald}

La maduración de Ostwald es el proceso por el cual las gotas más grandes crecen a expensas de las gotas más pequeñas debido al transporte de fase dispersa a través de la fase continua. Este proceso es prácticamente despreciable en el caso de las emulsiones de aceite en agua que conforman la mayoría de los productos alimenticios, pero tiene más importancia en las emulsiones con aceites más solubles como pueden ser aceites esenciales, en emulsiones que contengan una parte de alcohol en la fase continua y en las emulsiones agua/aceite. La maduración de Ostwald se produce porque la solubilidad de un material se incrementa con el descenso del tamaño de gota, fenómeno que es descripto por la ecuación de Kelvin (ecuación XVI). Esto hace que se solubilice más fase dispersa de las gotas pequeñas y que termine en las gotas más grandes.

$$
(\mathrm{XVI}) \quad S(\mathrm{r})=S(\infty) \exp (2 \gamma \mathrm{Vm} / \mathrm{R} \mathrm{T} \mathrm{r})
$$


$\mathrm{S}(\mathrm{r})$ es la solubilidad de la fase dispersa contenida en una gota de radio $\mathrm{r}$ y $(2 \gamma$ Vm / R T r) es una escala de longitud característica, Vm es el volumen molar de agente disperso, $\gamma$ la tensión interfacial y $S(\infty)$ es la solubilidad de la fase dispersa en una gota de curvatura infinita o una superficie plana. Se puede dar con mayor facilidad en el caso de las emulsiones concentradas que en las emulsiones diluidas. Factores para controlarla o que la afectan pueden ser:

-Distribución de tamaño de gota: Con distribuciones más estrechas, con menor polidispersidad el fenómeno es menos manifiesto.

Solubilidad: Hay sustancias que pueden aumentar la solubilidad de los triglicéridos en agua y favorecer la maduración de Ostwald como el alcohol o micelas de surfactante dispersas (Weiss y McClements 2000).

-Composición de la membrana interfacial: Esta puede facilitar o no la salida de las moléculas de la fase dispersa. Por ejemplo si es más gruesa es más eficiente para impedir la maduración de Ostwald, lo mismo si disminuyen los valores de la tensión interfacial.

-Composición de las gotas: si éstas se componen de más de una sustancia es menos favorable la maduración de Ostwald debido a que cambiarían los potenciales químicos entre gotas y jugaría en contra de la entropía de mezclado del sistema.

\section{Espumas}

\section{IV.I. Introducción}

Las espumas son dispersiones de gas en matrices sólidas o líquidas. Las propiedades de la espuma dependen mucho de la fracción volumétrica del gas en la misma $\left(\varphi_{\mathrm{G}}\right)$. Las espumas hechas con líquidos si tienen un $\varphi_{\mathrm{G}}$ mayor a 0,6 se comportan como sólidos. Eso se debe a que en esas condiciones las burbujas de aire no son más de forma esférica, y se requiere energía elástica para producir un esfuerzo de corte de la red de burbujas. Cuando la fracción de gas es menor las burbujas son esféricas y pueden comportarse con mayor independencia entre sí. $\mathrm{Al}$ igual que para las emulsiones, para hacer una espuma se necesita energía para crear la superficie de las burbujas; esta energía es igual a $\gamma \mathrm{A}$, siendo $\gamma$ igual a la tensión superficial del líquido y A al área creada. En consecuencia las espumas 
son termodinámicamente inestables porque no se minimiza el área, sino que se la crea. Sin embargo las configuraciones metaestables pueden ser producidas de tal manera de que cada burbuja tome la forma adecuada para minimizar el área: esférica para burbujas individuales o poliédricas (Figura X.) para espumas con alto $\varphi \mathrm{G}$.

Las espumas líquidas son mayormente acuosas. Los líquidos orgánicos suelen dar espumas más inestables. Las espumas acuosas son muy utilizadas en detergentes, cosméticos, combate de incendios y en lo que nos atañe, en los alimentos. Las mayoría de las espumas acuosas están estabilizadas por surfactantes, excepto en los alimentos que las mayoría están estabilizadas por proteínas (Murray y Ettelaie 2004; Rullier, Novales y col. 2008). Esas proteínas son solubles en agua y pueden exponer grupos hidrofóbicos a la superficie aire/agua y comportarse como surfactantes. Luego de la formación de la espuma el líquido drena (o las burbujas ascienden) debido a la acción de la gravedad. Para evitar desestabilización se pueden agregar polímeros (como la gelatina o diferentes gomas) para gelificar o aumentar la viscosidad del sistema antes de la formación de la espuma como sucede en numerosos alimentos industrializados como mousse de chocolate o yogur. En otros casos la espuma se solidifica por un proceso de calentamiento y evaporación de agua, como sucede en el pan, tortas, merengue, o por un proceso de congelamiento, como en el helado. Luego de la adsorción las superficies se tornan viscoelásticas, eso permite a los films superficiales darle estabilidad a la espuma. Los films de líquido entre las dos burbujas, conocidos como lamelas, juegan también un rol importante en la estabilización de la espuma.

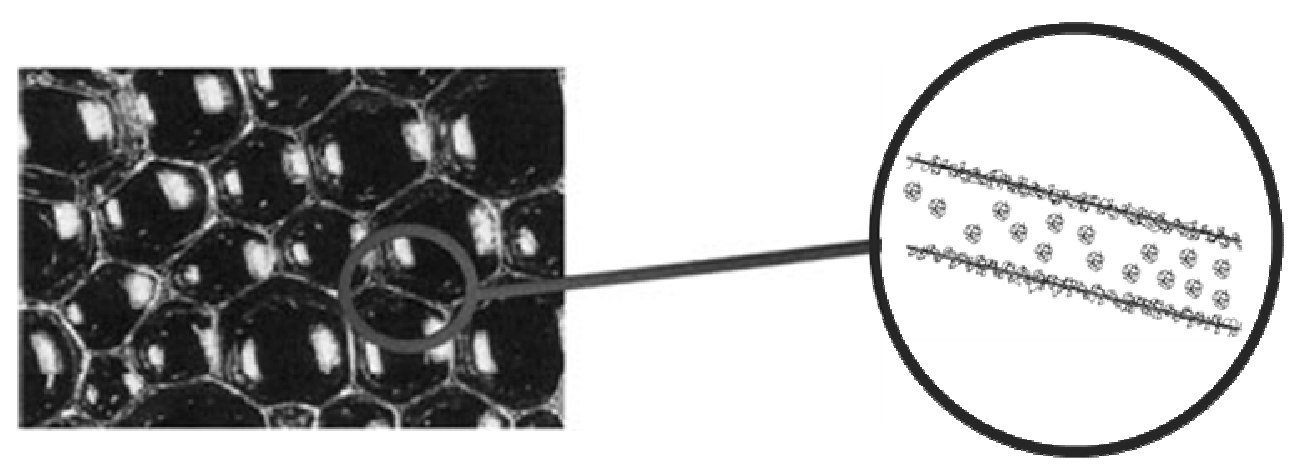

Figura X.: Fotografía de una espuma con burbujas de geometría poliédrica, con alto $\varphi$ G. Representación esquemática de la lamela estabilizada por proteínas globulares. 


\section{IV.II. Espumado}

\section{IV.II.I. Dispositivos de espumado}

Existe una gran variedad de métodos de espumado: agitación, batido, burbujeo de gas, descompresión de gas, mezclado con pistones porosos, mezclado turbulento de líquido y gas, etc. Cuando la espuma se forma, las interfases son estiradas rápidamente y se rompen en diferentes condiciones de flujo de acuerdo con el dispositivo utilizado: laminar para mezcladores de baja cizalladura, turbulento para máquinas de alta cizalladura, y extensional en el caso de jets y burbujeo a través de membranas porosas.

Existe una concentración mínima de moléculas con actividad superficial requerida para la producción de espumas. En el caso de pequeños surfactantes esta concentración se asocia con la cobertura de la superficie de las gotas en el orden de $1 \mathrm{mg} / \mathrm{m}^{2}$ y ocurre cuando se arriba, aproximadamente, a un décimo de la concentración micelar crítica en la concentración del surfactante en la solución. La concentración mínima requerida depende de la concentración de moléculas en la superficie de las burbujas que a su vez depende del método de espumado empleado.

Las soluciones para espumar que contienen agentes gelificantes pueden ser muy viscosas y en ese caso la espuma es muy difícil de producir, aunque la estabilidad va a aumentar como consecuencia del retardo del drenado

Hay nuevos métodos de espumado que se basan en los estudios de los microflujos. El más conocido se llama principio del enfoque de flujo (flow focusing) que produce burbujas sorprendentemente monodispersas (Van Der Net, Drenckhan y col. 2006). Se basa en la creación de un "lente" de gas en forma de embudo que se crea por el pasaje del gas a gran velocidad a través de un orificio inmerso en un líquido (Figura XI).

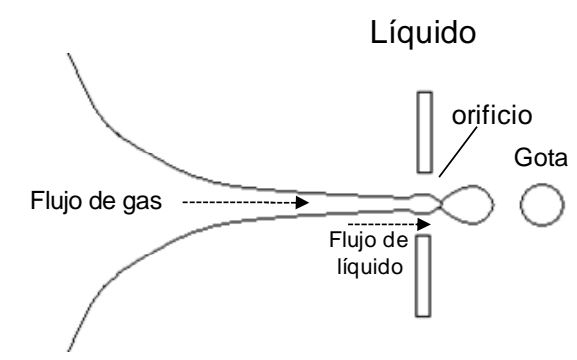

Figura XI.: Esquema del principio de flow focusing. 


\section{IV.II.II. Relación con la tensión interfacial dinámica}

La eficiencia del espumado se encuentra estrechamente relacionada con las cinéticas de adsorción de las moléculas tensioactivas. Cuando se agitan los fluidos, se crea una gran área, y luego de un tiempo, las moléculas se adsorben desde el seno de la solución y forman capas en las interfases aire agua que son capaces de proteger las burbujas contra el colapso o coalescencia.

Para concentraciones de surfactantes pequeños en el orden del porcentaje en peso, los tiempos de adsorción calculados para un proceso controlado por la difusión (ecuación (IV)) son mucho menores que los tiempos de espumado. Además existe un transporte convectivo de gran importancia en las condiciones prácticas de espumado que tiene como consecuencia la disminución de los tiempos de adsorción.

En el caso de proteínas, la cinética de adsorción es más lenta que la predicha por los mecanismos de difusión. Se ha demostrado que en condiciones donde la tensión superficial de la solución de espumado se mantiene similar a la del agua sola, se forman films de espumas gelificados cuando la concentración de proteínas supera cierto valor que coincide con la concentración sobre la que el espumado comienza a hacerse apreciable (Saint-Jalmes, Peugeot y col. 2005). La concentración mínima de proteínas requerida para producir buenos espumados depende del tipo de proteína. La cantidad de espuma es mayor con las proteínas flexibles que se adsorben más rápido que las globulares (Martin, Grolle y col. 2002). A las proteínas globulares, que se adsorben lentamente, le cuesta mucho más producir espumas por lo que las características de estas espumas dependen de las escalas de tiempo a las que se van formando las burbujas.

\section{IV.III. Estabilidad de espumas}

\section{IV.III.I. Evaporación y maduración de Ostwald}

Cuando las espumas se dejan al aire libre, se van destruyendo por la evaporación del líquido Las capas superficiales pueden afectar las velocidades de evaporación. Se sabe que las monocapas muy compactas pueden reducir la evaporación acuosa. Aunque el factor más importante es el grado de compactación de las proteínas de la monocapa, existe alguna correlación con la reología interfacial. 
La maduración de Ostwald involucra el transporte de gas entre burbujas de diferentes tamaños. Es consecuencia de la distinta presión a la que se encuentran los gases que contienen las burbujas debido a los diferentes radios de curvatura como predice la ley de Laplace, las burbujas más pequeñas tienen una mayor presión que las más grandes. Esta situación va a influir en la solubilidad de los gases que contienen las burbujas ya que la solubilidad de los gases aumenta con la presión, o sea con la disminución del radio de las burbujas. Como con la evaporación, la presencia de monocapas en las superficies afecta el desarrollo de la maduración de Ostwald. Es de gran importancia la naturaleza del gas utilizado para el espumado; por ejemplo los gases solubles en agua, como el $\mathrm{CO}_{2}$, dan espumas menos estables que los menos solubles como el $\mathrm{N}_{2}$, porque el $\mathrm{CO}_{2}$ se transporta a través de los films a mayor velocidad. La estabilidad de las espumas de $\mathrm{CO}_{2}$ puede aumentarse agregando pequeñas cantidades de $\mathrm{N}_{2}$ para que no varíen los potenciales químicos dentro de la burbuja en equilibrio con el líquido (Weaire y Pageron 1990).

Durante el proceso de achicamiento de las burbujas pequeñas, el área se reduce por lo que aumenta la elasticidad interfacial. Cuando $E>\gamma / 2$, el encogimiento de la burbuja se detiene (Kloek, van Vliet y col. 2001). Para surfactates pequeños, el achicamiento puede llevar a que las moléculas se redisuelvan en el líquido y que la elasticidad no varíe. En el caso de proteínas, que se adsorben irreversiblemente, la elasticidad superficial puede fácilmente alcanzar valores muy altos. El proceso es más lento que para surfactantes pequeños por la existencia de films gruesos entre las burbujas.

\section{IV.III.II. Drenado de la espuma}

Las burbujas con tamaños mayores que unos pocos micrones ascienden debido a la acción de la gravedad. Para dispersiones diluidas y superficies rígidas, la velocidad de ascenso de la burbuja de radio $R$ en un fluido de densidad $\rho$ y de viscosidad $\eta$ está dado por la ley de Stokes (ecuación $(X V)$ ). Cuando la espuma se comporta como un sólido $(\varphi \cong 0,6)$, las burbujas no son más esféricas y se distorsionan en poliedros, con los films líquidos en las zonas planas llamados lamelas. En estas condiciones la gravedad igualmente produce drenado. El líquido fluye a través de los espacios intersticiales entre las burbujas que son las lamelas y los bordes de Plateau que son los espacios o nodos en donde tres lamelas distintas se interceptan Figura XII. Cuando continúa el drenado, los films separados por burbujas se adelgazan y eventualmente se rompen. 


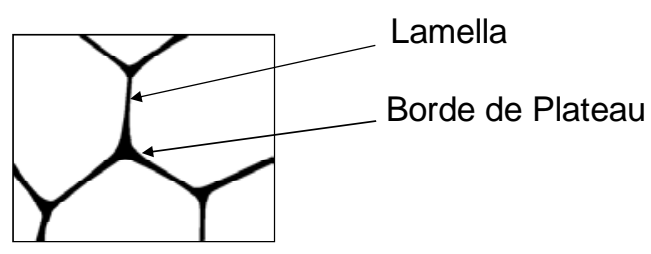

Figura XII.: Esquema de una espuma con burbujas poliédricas.

El tiempo de drenado $t$, o la velocidad de drenado $V(V \approx 1 / t)$ del proceso es variable: depende del tamaño de las burbujas, de la reología de la interfase y de la solución y de la naturaleza del gas (Saint-Jalmes, Zhang y col. 2004).

Las velocidades de drenado no suelen diferir para pequeñas moléculas comparadas con las proteínas si se está en iguales condiciones del tamaño de burbujas y de viscosidad del líquido. Los factores principales que influyen en el drenado son los mismos en los dos casos: tamaño de burbujas, fracción volumétrica del líquido.

\section{IV.III.III. Drenado del film}

El drenado de los films de la espuma aporta una contribución despreciable al total del drenado debido a que está involucrada una baja cantidad de líquido. Sin embargo, el drenado del film juega un papel importante en la estabilidad ya que cuando se reduce el espesor del film se facilitan la maduración de Ostwald y el colapso o coalescencia.

Los films drenan no sólo debido a la gravedad, sino también por la presión capilar que se produce por la diferencia de las presiones de Laplace de los films con los bordes de Plateau y que hace que el líquido drene desde los films hacia los bordes.

\section{IV.III.IV. Fuerzas superficiales}

Si el drenado ha sido muy suave y el espesor del film disminuye a valores de 10 a $100 \mathrm{~nm}$, pasan a tener importancia las interacciones entre ambos lados del film. Se producen las interacciones típicas como fuerzas de van der Waals, fuerzas electrostáticas. El hecho de que se encuentren tan cerca permite la actuación de las fuerzas de corto alcance y que éstas tengan un efecto sobre la estabilidad del film. 


\section{IV.III.V. Coalescencia o colapso de los films}

Con el drenado, las lamelas se afinan cada vez más hasta casi desaparecer. A cierto espesor crítico los films no son los suficientemente resistentes y se puede formar un orificio. Debido a la curvatura del film y la presión de Laplace, el orificio formado se agranda y termina en la fusión de las dos burbujas adyacentes para forma una sola. El proceso de ruptura comienza cuando la fracción volumétrica de gas se hace superior a un valor mínimo que depende del tensioactivo y de su concentración (Carrier y Colin 2003); aparentemente el valor mínimo corresponde a la dilatación máxima que pueden soportar los films debida a los reordenamientos inducidos por el drenado. El colapso no depende directamente del tamaño de las burbujas, pero la estabilidad de las espumas es mayor cuando son de burbujas pequeñas dado que el drenado es más lento por la tortuosidad del camino del líquido hacia abajo.

El espesor crítico del film depende mucho de la naturaleza de la molécula tensioactiva y la viscoelasticidad del film que producen (Klitzing y Müller 2002). Debido al drenado y a la evaporación los films más estrechos son los que se encuentran en la parte superior de la espuma y por lo tanto son los que más rápido se rompen. 



\section{Objetivos}

La aparición de nuevas proteínas con cierta funcionalidad que tengan un alto valor biológico y que además sean económicamente atractivas en su producción es buena y necesaria para el consumidor y la industria alimentaria. Ciertos cultivos, como la soja, contienen proteínas que son utilizadas actualmente alrededor del mundo debido a su efectividad y a su bajo costo; sin embargo su cultivo no se adapta a todo tipo de suelo y clima. El cultivo del amaranto, por otra parte, posee mayor adaptación a condiciones ambientales más drásticas y sus granos contienen proteínas de alto valor nutricional. Estos hechos hacen interesante el estudio de sus proteínas y su funcionalidad en los alimentos a efectos de obtener nuevos ingredientes alimentarios.

\section{Objetivo general}

El objetivo general de este trabajo es generar conocimientos que sirvan de base para la preparación de mezclas proteicas soja-amaranto y aislados de amaranto modificados con características estructurales y funcionales determinadas.

\section{Objetivos específicos}

- Obtener aislados mixtos soja-amaranto nativos y modificados por acción de $\mathrm{pH}$ extremo y de aislados proteicos de amaranto modificados por hidrólisis enzimática.

- Caracterizar desde el punto de vista estructural las proteínas presentes en las mezclas obtenidas.

- Estudiar las propiedades funcionales de superficie de las mezclas proteicas soja-amaranto, nativas y modificadas y amaranto modificado. 



\section{Capítulo 1:}

\section{Tratamiento ácido de aislados proteicos de soja y amaranto}

\subsection{Materiales y Métodos}

\subsubsection{Preparación de harinas y de distintos aislados}

El aislado proteico de soja fue obtenido a partir de harina desgrasada comercial proveniente de la empresa Sanbra S. A. de Brasil. El aislado proteico de amaranto se preparó en el laboratorio a partir de la molienda de semillas de Amaranthus Hypochondriacus, cultivar comercial Mercado, provisto amablemente por la Estación Experimental del Instituto Nacional de Investigaciones Forestales y Agropecuarias (INIFAP), Chapingo, México. Las semillas fueron molidas en un molino ciclónico UDY (UDY Corporation, EE.UU) de $1 \mathrm{~mm}$ de malla y tamizadas y seleccionadas por un tamiz de 10 xx (92 $\mu \mathrm{m})$ en la cátedra de Cerealicultura de la Facultad de Ciencias Agrarias y Forestales de la Universidad Nacional de La Plata. Posteriormente la harina se desgrasó mediante un proceso de extracción con n-hexano en una relación de $10 \mathrm{~g}$ de harina por cada $100 \mathrm{ml}$ de n-hexano. Este proceso se realizó a temperatura ambiente con agitación continua durante $5 \mathrm{~h}$ y en reposo durante $19 \mathrm{~h}$ completándose todo el proceso en $24 \mathrm{~h}$ de contacto de la harina con el solvente. Luego se separó la harina del hexano por filtración y se la dejó a temperatura ambiente bajo campana durante $12 \mathrm{~h}$ esparcida sobre 
una superficie plana para eliminar los restos de hexano. La harina se almacenó a $4{ }^{\circ} \mathrm{C}$ hasta su utilización.

El aislado proteico de soja (SN) fue obtenido según el método descripto por Petrucelli y Añón (Petruccelli y Añón 1995). La harina de soja desgrasada fue suspendida en agua en una concentración de $10 \mathrm{~g}$ de harina por cada $100 \mathrm{ml}$ de agua, se llevó el pH de la suspensión a 8,0 con $\mathrm{NaOH} 2 \mathrm{~N}$ bajo una agitación intensa y se lo mantuvo durante $1 \mathrm{~h}$ controlando el $\mathrm{pH}$ regularmente. Transcurrido ese tiempo se centrifugó $30 \mathrm{~min}$ a $10000 \mathrm{~g}$ a una temperatura de $4{ }^{\circ} \mathrm{C}$. Se separó el sobrenadante, se lo llevó a pH 4,5 con una solución de $\mathrm{HCl} 2 \mathrm{~N}$ para precipitar proteínas manteniéndolo durante $10 \mathrm{~min}$ bajo agitación y luego se centrifugó $20 \mathrm{~min}$ a $10000 \mathrm{~g} \mathrm{y} 4^{\circ} \mathrm{C}$. Se separó el precipitado de proteínas y se lo suspendió en agua llevando el $\mathrm{pH}$ a 7,0 con $\mathrm{NaOH} 2 \mathrm{~N}$. Luego se congeló la suspensión y se liofilizó. El liofilizado se molió con mortero y se guardó herméticamente a $4{ }^{\circ} \mathrm{C}$ hasta su utilización.

El aislado proteico de amaranto (AN) se preparó de acuerdo el método descripto por Martínez y Añón (Martínez y Añón 1996). Se suspendió la harina desgrasada en agua (10 g / $100 \mathrm{ml})$, se llevó a pH 9,0 con $\mathrm{NaOH} 2 \mathrm{~N}$, se agitó la suspensión 1 h, se centrifugó a $4{ }^{\circ} \mathrm{C}$ por $20 \mathrm{~min}$ a $9000 \mathrm{~g}$ y el sobrenadante fue ajustado a $\mathrm{pH}$ 5,0 con $\mathrm{HCl} 2 \mathrm{~N}$. Luego se lo centrifugó 20 min a 9000 g a $4{ }^{\circ} \mathrm{C}$, se lo suspendió en agua y se lo neutralizó con $\mathrm{NaOH} 0,1 \mathrm{~N}$. Para su conservación se utilizaron las condiciones descriptas para el aislado de soja.

\subsubsection{Caracterización química de los aislados}

Una vez obtenidos los aislados, se determinó su composición química.

El contenido proteico se determinó mediante el método de Kjeldahl (Kjeldahl 1883) utilizando un factor de $\mathrm{N} \times 5,85$ (Becker, Wheeler y col. 1981; Scilingo, Molina Ortiz y col. 2002). Para SN se obtuvo un 85,2 \% $\pm 0,3$ y para AN 83,1 \% \pm 0,5 de proteínas, ambos valores expresados en porcentaje $\mathrm{p} / \mathrm{p}$ en base seca.

El contenido de humedad se determinó en forma indirecta por secado en estufa a $105{ }^{\circ} \mathrm{C}$ hasta peso constante. La humedad de SN fue de $10,5 \% \pm 0,2$ mientras que AN presentó un valor de 10,7 \% $\pm 0,3$.

El contenido de cenizas se determinó por pesada calcinando en mufla a $550{ }^{\circ} \mathrm{C}$ hasta la obtención de cenizas blancas. El contenido de cenizas fue de 3,6 \% $\pm 0,1$ y $2,7 \% \pm 0,1$ para SN y AN, respectivamente. 


\subsubsection{Reactivos}

Buffer A: $\mathrm{NaH}_{2} \mathrm{PO}_{4}$ 0,0056 M; $\mathrm{Na}_{2} \mathrm{HPO}_{4}$ 0,0343 M; $\mathrm{NaCl}$ 0,4 M. A la temperatura a la que se realizaron los ensayos el $\mathrm{pH}$ del buffer A fue 7,5 y la fuerza iónica $(\mu)$ 0,5. Para impedir la acción de bacterias en la solución se utilizó azida de sodio en una concentración de $0,01 \%$ p/v.

\subsubsection{Tratamiento ácido de los aislados}

Los aislados ( $\mathrm{SN}$ y $\mathrm{AN}$ ) fueron suspendidos individualmente y también mezclándolos en proporciones iguales $(\mathrm{MN})$, en una solución de $\mathrm{HCl} \mathrm{0,01} \mathrm{N}$, en una concentración de $10 \mathrm{mg} / \mathrm{ml}$. El pH se ajustó a 2,0 con $\mathrm{HCl} 2 \mathrm{~N}$. las dispersiones se mantuvieron con agitación constante a temperatura ambiente durante $3 \mathrm{~h}$. Posteriormente fueron diluidas 9 veces con buffer $\mathrm{A}$, el $\mathrm{pH}$ se ajustó a 7,5 y se completó con el mismo buffer hasta una concentración de $1 \mathrm{mg} / \mathrm{ml}$. Se siguieron agitando durante $3 \mathrm{~h}$ más a temperatura ambiente y se llevaron a cámara de $4{ }^{\circ} \mathrm{C}$ durante $18 \mathrm{~h}$ antes de usar. Las muestras resultantes luego del tratamiento ácido se denominaron ST, AT y MT dependiendo si provenían de $\mathrm{SN}, \mathrm{AN}$ y $\mathrm{MN}$ respectivamente.

\subsubsection{Solubilidad}

La cantidad de proteína soluble fue determinada por el método de Lowry (Lowry, Rosebrough y col. 1951). Este método se basa en el dosaje colorimétrico de productos de la reducción a $\mathrm{pH}$ alcalino del reactivo fosfotungtomolibdénico por los aminoácidos aromáticos de la proteína. Los productos de reacción toman un color azulado y la absorbancia se mide a una longitud de onda de $750 \mathrm{~nm}$ Para realizar las medidas de solubilidad las muestras nativas fueron dispersadas en buffer A en una concentración de $1 \mathrm{mg} / \mathrm{ml}$ y se agitaron durante $1 \mathrm{~h}$ a $20^{\circ} \mathrm{C}$. A las muestras tratadas por ácido se les realizó el ensayo al finalizar el tratamiento ácido anteriormente descripto. Todas las muestras se centrifugaron a $15000 \mathrm{~g}$ durante $15 \mathrm{~min}$ a $20^{\circ} \mathrm{C}$. Inmediatamente de finalizada la centrifugación se tomó una alícuota del sobrenadante para conocer su contenido de proteína. Para la realización de la curva de calibración se utilizó como proteína patrón albúmina de suero bovino (Sigma Chemical Co., nro. de cat. A-3350, EE.UU) disuelta en el mismo buffer que la muestra. Las lecturas de absorbancia de las distintas 
fracciones proteicas se realizaron en un espectrofotómetro Beckman DU 650 (Beckman Co, EE.UU), a una longitud de onda de $750 \mathrm{~nm}$. La solubilidad es expresada como:

$$
\text { (1) } S \%=P_{s} \times 100 / P_{\text {in }}
$$

Siendo Ps la concentración de proteína en el sobrenadante y Pin la concentración de proteínas inicial.

\subsubsection{Electroforesis}

\subsubsection{Aspectos teóricos y técnicas}

La electroforesis es una de las técnicas más ampliamente utilizadas para la separación y caracterización de proteínas. La movilidad electroforética de una proteína depende de su carga neta (las proteínas presentan carga cuando se encuentran a un $\mathrm{pH}$ diferente de su punto isoeléctrico) así como también de su tamaño y conformación. Los soportes utilizados para la electroforesis se dividen en soportes inertes (acetato de celulosa, sílica gel, papel) e interactivos (azarosa, almidón y poliacrilamida). Los interactivos ayudan en la separación debido a su porosidad, actuando como tamices. Los geles de poliacrilamida son los más utilizados debido a las ventajas que presentan como son alta reproducibilidad, estabilidad (a pH, temperatura, fuerza iónica), transparencia, elasticidad, porosidad controlable, compatibilidad con una gran variedad de compuestos químicos e inercia química. La matriz de poliacrilamida se forma por copolimerización de dos compuestos, la acrilamida y la bis-acrilamida (N,N'-metilen-bis-acrilamida), en una reacción iniciada por la tetrametiletiléndiamina (TEMED) y el persulfato de amonio. El radical persulfato activa al TEMED, el cual a su vez activa al monómero de acrilamida para que polimerice. Las cadenas de poliacrilamida son entrecruzadas al azar por la bisacrilamida, formándose así una red de porosidad bastante uniforme, que puede ser regulada, variando las condiciones de la reacción y las concentraciones de los monómeros.

Entre las diversas técnicas de electroforesis en gel de poliacrilamida (PAGE, por sus siglas en inglés polyacrylamide gel electrophoresis), probablemente la más utilizada es la modalidad que se lleva a cabo en presencia del tensioactivo dodecilsulfato de sodio (SDS-PAGE), tanto para analizar proteínas, como para 
ser combinada con técnicas de inmunoelectrotransferencia. En la técnica de SDS-PAGE, se mezclan las proteínas con el tensioactivo aniónico SDS para formar complejos desnaturalizados, cargados negativamente. La cantidad de SDS unido a las proteínas es proporcional a su tamaño: el SDS se une a la proteína en una proporción aproximada de 1,4:1. Los complejos proteína/SDS poseen una estructura elipsoide o de bastón, donde la cadena proteica es distendida y solubilizada por el tensioactivo. Dado que la relación final carga/masa queda constante para las distintas proteínas (se anula su carga intrínseca), estas van a ser separadas en el gel poroso fundamentalmente en base a sus diferencias de peso molecular (PM): a menor tamaño, mayor movilidad de la proteína, y viceversa. También se pueden realizar electroforesis de proteínas en estado nativo N-PAGE, sin la presencia de SDS, separándose las proteínas por la relación carga masa, ya que las mismas conservan la carga original.

La electroforesis puede ser realizada en sistema continuo, donde la muestra es aplicada directamente en el gel de separación, o en un sistema discontinuo, donde la muestra es aplicada en un gel de apilamiento o stacking gel. El gel de concentración difiere del de separación en el tamaño de poro y en el $\mathrm{pH}$, y tiene la función de concentrar a las proteínas de forma que la resolución no dependa del volumen inicial de la muestra. El gel de apilamiento posee poros de gran tamaño y por lo tanto no retiene a las proteínas. El gel de separación presenta poros más pequeños y ayuda en la separación por tamaño molecular de las proteínas (Hjemel y Chrambach 1981). En el gel separador, la movilidad es restringida por el tamaño del poro, el cual depende de la concentración de monómeros del gel. Así, si se requiere resolver componentes de muy alto PM, se utilizan geles al $5 \%$ o al 7,5\%, mientras que los geles de poro menor, ej. 15-20\% son útiles en la separación de péptidos y proteínas pequeñas. Los geles de poro intermedio (10-12 \%) proveen una separación adecuada para proteínas de $\sim 10-90$ kDa.

\subsubsection{Reactivos}

Se utilizó el sistema de buffers descripto por Laemmli (1970)

Los reactivos utilizados fueron los siguientes.

1. Buffer de electrodo: hidroximetil aminometano- $\mathrm{HCl}$ (Tris- $\mathrm{HCl}) 0,025 \mathrm{M}$, glicina 0,192 M ( $\mathrm{pH} 8,3$ ), con o sin el agregado de SDS 0,1\% p/v, para 
electroforesis desnaturalizante (SDS-PAGE) o no desnaturalizante (NPAGE) respectivamente.

2. Buffer de gel apilador: Tris- $\mathrm{HCl} 0,125 \mathrm{M}(\mathrm{pH} 6,8)$ con y sin SDS $0,1 \%(\mathrm{p} / \mathrm{v})$

3. Buffer de gel separador: Tris- $\mathrm{HCl} 0,375 \mathrm{M}(\mathrm{pH} 8,8)$ con o sin el agregado de SDS $0,1 \% \mathrm{p} / \mathrm{v}$. $\mathrm{N}^{\prime}, \mathrm{N}^{\prime}, \mathrm{N}^{\prime}, \mathrm{N}^{\prime}$, TEMED $0,1 \% \mathrm{v} / \mathrm{v}$.

4. Buffer de muestra SDS-PAGE: Tris- $\mathrm{HCl} 0,185 \mathrm{M}(\mathrm{pH} 8,8)$, glicerol 12,5\% v/v, SDS 2,0\% p/v, y azul de bromofenol 0,05\% p/v con o sin el agregado de 2mercaptoetanol (2ME) 5\% v/v, para obtener condiciones reductoras o no reductoras, respectivamente.

5. Buffer de muestra N-PAGE: Tris- $\mathrm{HCl}$ 0,185 M (pH 8,8), glicerol 12,5\% v/v y azul de bromofenol 0,05\% p/v.

6. Buffer de tratamiento para electroforesis bidimensional: Tris- $\mathrm{HCl} 0,0625 \mathrm{M}(\mathrm{pH}$ $6,8)$, SDS $0,1 \% \mathrm{p} / \mathrm{v}$, sacarosa $20 \% \mathrm{p} / \mathrm{v}$, con o sin el agregado de $2 \mathrm{ME} 0,2 \mathrm{M}$ (Utsumi, Damodaran y col. 1984).

Las muestras se prepararon dispersando la proteína en el buffer de muestra en concentraciones de 5 a $10 \mathrm{mg} / \mathrm{ml}$. En el caso de que las proteínas se encontrasen dispersas en un medio líquido, se mezclaron 3 partes de suspensión proteica con 1 parte de buffer de muestra. Para las electroforesis desnaturalizantes, inmediatamente después de la disolución de la muestra en el buffer, se las calentó a $100{ }^{\circ} \mathrm{C}$ durante 1 min para evitar la acción de proteasas resistentes al SDS (Gallagher 2000). De todas las muestras se sembraron aproximadamente entre 20 y $30 \mu \mathrm{g}$ de proteína por calle contenidos en volúmenes entre 10 y $25 \mu \mathrm{l}$. Todas las electroforesis se realizaron en miniplacas con un equipo BIO-RAD, modelo Mini Protean II (BIO-RAD life science, USA) con separadores de $1 \mathrm{~mm}$ de espesor. Las corridas electroforéticas se llevaron a cabo a una corriente de 20 $\mathrm{mA}$ durante la primera parte de la corrida (alrededor de $20 \mathrm{~min}$ ) y luego de 30 $\mathrm{mA}$ hasta finalizar. 


\subsubsection{SDS-PAGE}

Se utilizaron geles de poliacrilamida de concentración constante de acrilamida $12 \%$ p/v con gel apilador o de stacking de concentración de acrilamida de $4 \%$ p/v (Petruccelli y Añón 1994).

Los patrones de masa molecular utilizados contenían: fosforilasa b (94 kDa); seroalbúmina bovina (67 kDa); ovoalbúmina $(43 \mathrm{kDa})$; anhidrasa carbónica (30 kDa); inhibidor de tripsina $(20,1 \mathrm{kDa})$ y $\alpha$-lactoalbúmina $(14,4 \mathrm{kDa})$ (GEHealthcare EE.UU). Las proteínas patrón fueron solubilizadas en $200 \mu \mathrm{l}$ de buffer de muestra desnaturalizante con 2-ME y sometidas al mismo tratamiento que se aplicó a las muestras. Se construyeron curvas de calibración relacionando el factor de distancia de las distintas proteínas $\left(\mathrm{R}_{\mathrm{f}}\right)$ con el logaritmo de su peso molecular. Los pesos moleculares de los polipéptidos son el resultado de tres determinaciones como mínimo. $R_{f}=D x / D_{F}(D x$ : distancia recorrida por el polipéptido x y DF: distancia recorrida por el frente de corrida).

\subsubsection{SDS-PAGE en condiciones reductoras}

Se realizó del mismo modo que la electroforesis desnaturalizante, con el agregado de 2-mercaptoetanol al buffer de muestra. Las proteínas patrones de masa molecular empleadas fueron las mismas que para el SDS-PAGE sin 2-mercaptoetanol.

\subsubsection{N-PAGE}

Para estas electroforesis se empleó el mismo sistema buffer que para las corridas desnaturalizantes pero sin el agregado de SDS. Para todas las electroforesis en estas condiciones se utilizaron geles en un gradiente de concentración de acrilamida de $4-15 \%$.

\subsubsection{Electroforesis bidimensionales (N-PAGE $\rightarrow$ SDS-PAGE)}

Luego de correr la primera dimensión (geles de $1 \mathrm{~mm}$ de espesor) se cortó la porción del gel correspondiente a una calle con la proteína a analizar y se la sumergió en $30 \mathrm{ml}$ de buffer de tratamiento (descripto previamente), manteniéndola a $55{ }^{\circ} \mathrm{C}$ durante $30 \mathrm{~min}$ con dos cambios de la solución. La porción de gel tratada se colocó sobre el gel de la segunda dimensión de 1,5 mm 
de espesor (SDS-PAGE o SDS-PAGE + 2-ME según correspondiera). En este mismo gel, en una calle aparte y como referencia, se sembró la mezcla de proteínas patrón de masa molecular.

\subsubsection{Coloración}

Los geles fueron fijados y teñidos al mismo tiempo con Coomasie Brilliant Blue R-250 (Anedra, Argentina) al 0,192\% p/v en agua/metanol/ácido acético (10:10:4) durante $12 \mathrm{~h}$ y desteñidos con una mezcla agua/etanol/ácido acético (65:25:10) a temperatura ambiente. Cuando la cantidad de proteína no fue la suficiente para ser detectada con Coomassie Brilliant Blue R-250, se realizó una tinción con plata (Blum, Beier y col. 1987).

\subsubsection{Obtención de las imágenes y análisis de los geles}

Las imágenes de los geles de electroforesis fueron digitalizadas con un equipo BIO-RAD (Gel Doc 1000).

\subsubsection{Determinación de la hidrofobicidad superficial}

La hidrofobicidad es la tendencia de los solutos no polares de adherirse entre sí en entornos acuosos (Murphy, Privalov y col. 1990). Las interacciones hidrofóbicas en las proteínas tienen un rol muy importante en definir la formación y mediación de interacciones proteína-proteína (Kauzmann 1959). El número y el tamaño relativo de los sitios hidrofóbicos en la superficie de una proteína suelen ser determinantes de la solubilidad y tendencia a agregarse de las moléculas proteicas.

\subsubsection{Determinación por la sonda ANS}

La hidrofobicidad superficial $\left(\mathrm{H}_{0}\right)$ de las muestras se determinó siguiendo el método propuesto por Cardamone y Puri (1992). Se utilizó la sonda fluorescente 8-anilino-1-naftalensulfonato de amonio (ANS) (Aldrich Chemical Co., EE.UU). La fluorescencia de esta sustancia aumenta al encontrarse adherida a un sitio hidrofóbico, cualidad que se utiliza para la cuantificación de los sitios hidrofóbicos expuestos, superficiales, de las proteínas midiendo las 
modificaciones en la fluorescencia que producen agregados de sonda a una solución proteica.

Las muestras fueron disueltas en buffer A, centrifugadas a $15000 \mathrm{~g}$ por $20 \mathrm{~min}$ a $20{ }^{\circ} \mathrm{C}$ y diluidas para obtener una concentración final proteica entre 0,10 y 0,15 $\mathrm{mg} / \mathrm{ml}$. También se preparó una solución de ANS $10 \mathrm{mM}$ en buffer A. Se agregaron cantidades crecientes de la solución de ANS a una cubeta conteniendo el blanco de buffer A y a una cubeta conteniendo la muestra de proteína. Las concentraciones de ANS barridas durante el ensayo estuvieron comprendidas entre: 0 y $100 \mu \mathrm{M}$. Para cada una de las concentraciones de ANS utilizadas, se midió la intensidad de fluorescencia de la muestra en contacto con la sonda. Para realizarlo la cubeta conteniendo la mezcla muestra-blanco/ANS fue excitada con UV a una longitud de onda de $350 \mathrm{~nm}$ y el espectro de emisión de la muestra se leyó entre 450 y $540 \mathrm{~nm}$. Para estos experimentos se contó con un espectrofotómetro de fluorescencia Perkin-Elmer LS 50B (Perkin-Elmer Corp., Inglaterra). Primero se procedió a restar al espectro de emisión de cada muestra a cada una de las concentraciones de ANS con el de su blanco correspondiente a la misma concentración de ANS, y se graficó la intensidad de fluorescencia detectada a $470 \mathrm{~nm}$, ya que en esa longitud de onda se presentó el máximo de emisión del complejo proteína-ANS, en función de la concentración de ANS en $\mu \mathrm{M}$. Se ajustaron los datos obtenidos con la ecuación:

$$
\mathrm{IF}=\mathrm{A} \times \mathrm{ANS} /(\mathrm{B}+\mathrm{ANS})
$$

Los valores de A y B se obtuvieron utilizando el software ORIGIN Pro 8 (OriginLab Co; EE.UU) que utiliza métodos numéricos por iteraciones. " $\mathrm{A}$ " es la intensidad de fluorescencia máxima para la concentración de proteína empleada cuando la superficie de la proteína está completamente saturada con la sonda (IFmax). La hidrofobicidad superficial $\mathrm{H}_{0}$ es proporcional a la máxima intensidad de fluorescencia obtenida por mg de proteína y fue estimada a partir de la ecuación anterior realizando el cociente entre " $\mathrm{A}$ " y la concentración de proteína calculada para cada muestra expresada en $\mathrm{mg} / \mathrm{ml}$.

$$
\text { (3) } \quad \mathrm{H}_{0}=\mathrm{A} / \text { conc. prot. }
$$

La concentración proteica se determinó por el método de Lowry (ver sección 1.1.5.). 


\subsubsection{Determinación por medida de la fluorescencia intrínseca}

El espectro de fluorescencia intrínseca se atribuye a los residuos aromáticos de la proteína: triptófano, tirosina $\mathrm{y}$ fenilalanina. El que presenta menos inconvenientes para su medida es el triptófano. El espectro de emisión del triptófano es característico si se excita a $295 \mathrm{~nm}$ y depende del ambiente que rodea a la molécula dentro de la posición en la proteína.

En una cubeta de $3 \mathrm{ml}$ se agregó el volumen necesario de cada una de las muestras disueltas en buffer A para obtener una concentración proteica dentro de la cubeta de $0,05 \mathrm{mg} / \mathrm{ml}$ y se completó el volumen a $3 \mathrm{ml}$ con el mismo buffer. Se midió el espectro de emisión de la muestra de 310 a $550 \mathrm{~nm}$ excitándola a $295 \mathrm{~nm}$.

Cuando los triptófanos se encuentran más expuestos al ambiente hidrofílico la longitud de onda del máximo del espectro de emisión se corre a valores mayores

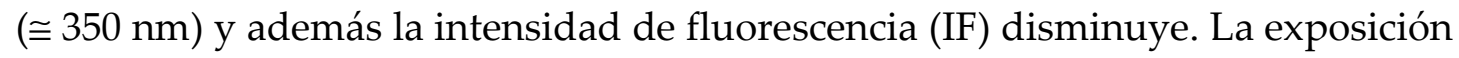
de triptófano (residuos hidrofóbicos) sugiere la presencia de una mayor cantidad de residuos hidrofóbicos en la superficie proteica y por lo tanto mayor hidrofobicidad superficial.

\subsubsection{Cromatografía rápida de proteínas en medio líquido (FPLC)}

\subsubsection{Filtración en gel o cromatografía de exclusión molecular.}

En este tipo de cromatografía la fase estacionaria está constituida por partículas de polímeros de diferente porosidad. La separación se basa en el tamaño de las partículas. Las proteínas más grandes que no pueden penetrar en los poros de las partículas de la matriz de filtración son eluidas con más rapidez que las proteínas más pequeñas que penetran por los poros de las partículas y siguen un camino más tortuoso y más largo. El tamaño de los poros internos depende de la naturaleza del polímero en cuestión, y permite la entrada a proteínas por debajo de un determinado peso molecular.

\subsubsection{Preparación de las muestras}

En el caso de los aislados nativos las muestras liofilizadas se suspendieron en buffer A en una concentración de $1 \mathrm{mg} / \mathrm{ml}$ y se agitaron en agitador magnético 
durante $1 \mathrm{~h}$ a temperatura ambiente. Luego fueron centrifugadas a $15000 \mathrm{~g}$ durante $20 \mathrm{~min}$ a $25{ }^{\circ} \mathrm{C}$. El sobrenadante fue filtrado a través de filtros de nylon de 0,22 $\mu$ m de poro y el filtrado se inyectó en el equipo de FPLC (Pharmacia LKB, Suecia).

\subsubsection{Desarrollo}

Las cromatografías se realizaron a temperatura ambiente utilizando una columna Pharmacia LKB (Suecia), Superose 6B HR 10/30. El buffer A, previamente filtrado a través de filtros de celulosa con diámetros de poro de $0,22 \mu \mathrm{m}$, fue utilizado para suspender la muestra y para el desarrollo de la corrida cromatográfica. Para equilibrar la columna, se pasó un volumen del buffer equivalente al de dos columnas $(50 \mathrm{ml}$ ). La velocidad de flujo seleccionada fue de $0,2 \mathrm{ml} / \mathrm{min}$ y la misma se suministró mediante una bomba Pharmacia LKB P-500, la presión promedio de las cromatografías fue de $0,3 \mathrm{MPa}$. Se inyectaron entre 200 y $500 \mu \mathrm{l}$ de muestras en cada corrida. Se realizó o no una colección automática de las fracciones a medida de que salían de la columna $(0,3 \mathrm{ml})$ empleando el colector FRAC-100 (Pharmacia LKB).

\subsubsection{Calibración}

La calibración de la columna fue realizada utilizando un kit de calibración para cromatografía de filtración en gel de alto peso molecular GE-Healthcare (EE.UU). El volumen muerto $\left(\mathrm{V}_{0}\right)$ se midió con azul dextrano, y las proteínas de peso molecular conocido utilizadas fueron las siguientes:

- ribonucleasa $(13,7 \mathrm{kDa})$,

- ovoalbúmina (43 kDa),

- albúmina $(67 \mathrm{kDa})$,

- alcohol deshidrogenasa (150 kDa),

- tiroglobulina $(669 \mathrm{kDa})$.

Los patrones se disolvieron en buffer A en una concentración de $4 \mathrm{mg} / \mathrm{ml}$ y fueron eluídos de la columna con el mismo caudal que las muestras.

Luego se obtuvo una curva de calibración relacionando el logaritmo de la masa molecular (en kDa) con el $\mathrm{KAV}_{\mathrm{A}}$, siendo $\mathrm{K}_{\mathrm{Av}}$ : 


$$
\mathrm{K}_{\mathrm{AV}}=\left(\mathrm{V}_{\mathrm{e}}-\mathrm{V}_{0}\right) /\left(\mathrm{V}_{\mathrm{T}}-\mathrm{V}_{0}\right)
$$

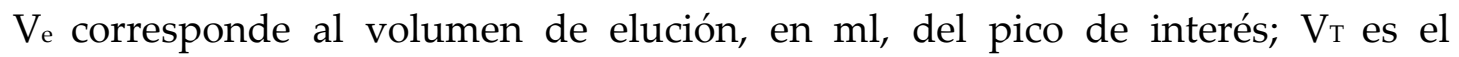
volumen total del lecho de la columna que en este caso por las dimensiones de la misma fue de $25 \mathrm{ml}$ y $\mathrm{V}_{0}$ es el volumen muerto.

Los valores de absorbancia a $280 \mathrm{~nm}$ fueron determinados a lo largo de la corrida en la salida de la columna mediante un monitor UV-1 (Pharmacia LKB) utilizando una sensibilidad entre 0,02 y 0,1. El procesamiento de los perfiles obtenidos se realizó con el programa FPLC Director ${ }^{\mathrm{TM}}$ (Pharmacia LKB).

\subsubsection{Calorimetría diferencial de barrido (DSC)}

\subsubsection{Principio}

La calorimetría diferencial de barrido o DSC (differential scanning calorimetry), se basa en el registro de la diferencia de energía que se debe entregar o quitar a una muestra para calentarla o enfriarla en forma simultánea, a la misma velocidad, que a una referencia inerte en función del tiempo. Si no hubiese eventos térmicos en la muestra las temperaturas de la referencia y la de la muestra aumentarían linealmente en función del tiempo, pero si apareciese un evento térmico en la muestra, como por ejemplo una desnaturalización en el caso de las proteínas, el equipo debería entregar más calor para mantener su temperatura igual a la de la referencia. Estas diferencias se registran como picos positivos o negativos ya sean fenómenos endotérmicos o exotérmicos y el área de los picos se cuantifica como entalpías de transición.

\subsubsection{Operación}

Las medidas de DSC se realizaron en un calorímetro TA Q100 (TA Instruments, EE.UU). El equipo fue calibrado previamente a una velocidad de $10{ }^{\circ} \mathrm{C} / \mathrm{min}$ con indio, ácido láurico y ácido esteárico pro análisis, como patrones. Antes de las medidas las muestras tratadas por ácido fueron dializadas contra agua destilada usando membranas de diálisis (Sigma-Aldrich, EE.UU) y liofilizadas. Todas las muestras en polvo de aislados nativos y tratados fueron suspendidas en buffer A en una concentración de $20 \% \mathrm{p} / \mathrm{v}$. Se prepararon cápsulas de aluminio herméticamente selladas con conteniendo entre 15 y 22 mg de la suspensión de 
aislado. Como referencia se usaron dos cápsulas de aluminio vacías. Las cápsulas fueron calentadas desde 40 a $120^{\circ} \mathrm{C}$ a una velocidad de $10{ }^{\circ} \mathrm{C} / \mathrm{min}$. Luego de cada ensayo las cápsulas fueron pinchadas para permitir la salida de vapor y colocadas en una estufa a $105{ }^{\circ} \mathrm{C}$ hasta el día siguiente determinándose el peso seco de las muestras analizadas. La temperatura de desnaturalización ( $\left.\mathrm{T}_{\mathrm{d}}\right)$ y la entalpía de desnaturalización $\left(\Delta \mathrm{H}_{\mathrm{d}}\right)$ se obtuvieron analizando los termogramas con el software Universal Analysis 2000 relacionándolas con el contenido de proteínas de las muestras obtenido a partir del peso seco.

También se hicieron calorimetrías a muestras de AN suspendidas en sendos buffers fosfato a $\mathrm{pH}$ 2,0 y a pH 8,0 con una fuerza iónica de 0,1 M.

\subsubsection{Tensiómetro de volumen de gota pendiente.}

\subsubsection{Principio}

Esta técnica se basa en la determinación exacta de volumen de una gota de un líquido en el momento que se separa de un capilar.

Incrementando el volumen de una gota pendiente de manera controlada el peso de la gota aumentará hasta llegar a un valor crítico que no puede ser contrarrestado por la tensión superficial del líquido $(\gamma)$. El balance de fuerzas resulta de la siguiente ecuación:

(5) $\quad \gamma=\mathrm{V} \times \mathrm{g} \times \Delta \mathrm{Q} \times \mathrm{F} / 2 \times \pi \times \mathrm{r}_{\text {cap }}$

donde,

$\mathrm{V}$ : volumen de la gota

g: aceleración de la gravedad

$\Delta \mathrm{Q}$ : diferencia de densidades entre el fluido de la gota y el que la rodea

F: factor de corrección

rap: radio del capilar

El factor de corrección F es una función de $\gamma, \mathrm{g}, \Delta \mathrm{Q}$ y rap determinado de manera experimental y teórica. 


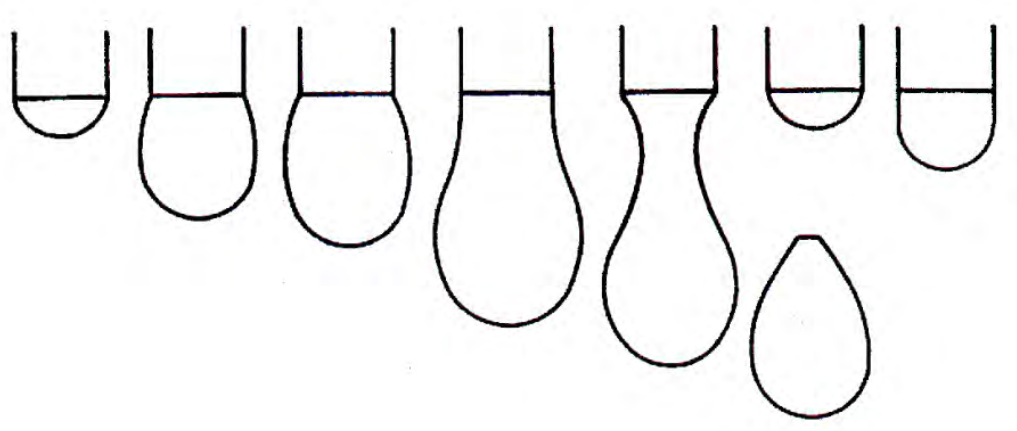

Figura 1.1.: Esquema de las etapas en la formación de a gota y desprendimiento.

\subsubsection{Operación}

El tensiómetro usado fue un LAUDA TVT2 (Lauda DR. R. WOBSER GMBH y Co., Alemania) en modo dinámico. En este modo la gota pendiente es formada a velocidades diferentes y la tensión superficial se calcula a cada velocidad por el volumen de la gota cuando se desprende del capilar, situación que es advertida por un detector que se encuentra analizando un punto de la trayectoria de las gotas cuando se desprenden. La variación de la velocidad de creación de la gota tiene como objetivo controlar la maduración de la interfase, situación útil en el caso de que el medio contuviese surfactantes que produjesen una variación en la tensión superficial. Se realizaron dos experimentos diferentes para cada una de las muestras variando la velocidad de formación de gota y realizando 3 medidas para cada una de las velocidades. Las velocidades de formación de gota variaron entre $1,25 \mu \mathrm{l} / \mathrm{min}$ hasta $12,5 \mu \mathrm{l} / \mathrm{min}$, la temperatura de los ensayos fue de $20 \pm$ $0,5^{\circ} \mathrm{C}$.

Las medidas de tensión superficial se hicieron en la muestras suspendidas en buffer $\mathrm{A}$ y agitadas durante $1 \mathrm{~h}$ a temperatura ambiente. Posteriormente se centrifugó la suspensión por $5 \mathrm{~min}$ a $1000 \mathrm{~g}$ y $20^{\circ} \mathrm{C}$, se tomó el sobrenadante y se estandarizó su contenido proteico a $0,5 \mathrm{mg} / \mathrm{ml}$. El valor de tensión del buffer utilizado fue de $71,3 \pm 0,3 \mathrm{mN} / \mathrm{m}$.

\subsubsection{Propiedades espumantes}

Estas propiedades se midieron en espumas formadas a partir de suspensiones a una concentración de $1 \mathrm{mg} / \mathrm{ml}$ en buffer A, agitadas durante $1 \mathrm{~h}$ a temperatura ambiente en el caso de los aislados nativos y de las suspensiones en el estado en 
el que se encontraban al terminar el tratamiento para el caso de los aislados tratados en medio ácido. Las determinaciones se realizaron por conductimetría utilizando el método desarrollado por Loisel (Loisel 1993). El aparato consta de una columna de acrílico de $3 \mathrm{~cm}$ de diámetro y $30 \mathrm{~cm}$ de alto con un disco de vidrio fritado tipo G4 $(5-15 \mu \mathrm{m})$ en la parte inferior sobre el cual se colocan $6 \mathrm{ml}$ de la suspensión acuosa de la muestra a ensayar. El valor de la conductividad del líquido se registró cada 0,1 s durante todo el ensayo con un par de electrodos ubicados en la parte inferior de la columna, los cuales quedaban sumergidos en la suspensión proteica por sobre el vidrio fritado. Estos detectores están conectados a un conductímetro y éste a un adquisidor de datos conectado a una PC. A través del vidrio fritado se hizo burbujear nitrógeno con un caudal de $40 \mathrm{ml} / \mathrm{min}$ durante $1 \mathrm{~min}$. Si la suspensión bajo ensayo posee propiedades espumantes, el nitrógeno forma espuma al atravesar el vidrio fritado y entra en el seno de la suspensión, lo que hace descender el nivel del líquido en contacto con los electrodos y disminuye el área de los electrodos en contacto con la suspensión lo que conlleva a un descenso de los valores de conductividad (Figura 1.2.). Las cinéticas de conductividad registradas, fueron transformadas en cinéticas de líquido incorporado o no a la espuma durante su formación así como durante la posterior desestabilización mediante la siguiente fórmula:

$$
\text { (6) } \mathrm{V}=(6-\mathrm{C} \times 6) / \mathrm{C}_{0}
$$

Siendo $\mathrm{V}$ el líquido que paso a la espuma en $\mathrm{ml}, \mathrm{C}$ la conductividad de la espuma y $\mathrm{C}_{0}$ la conductividad inicial del líquido antes del burbujeo. 


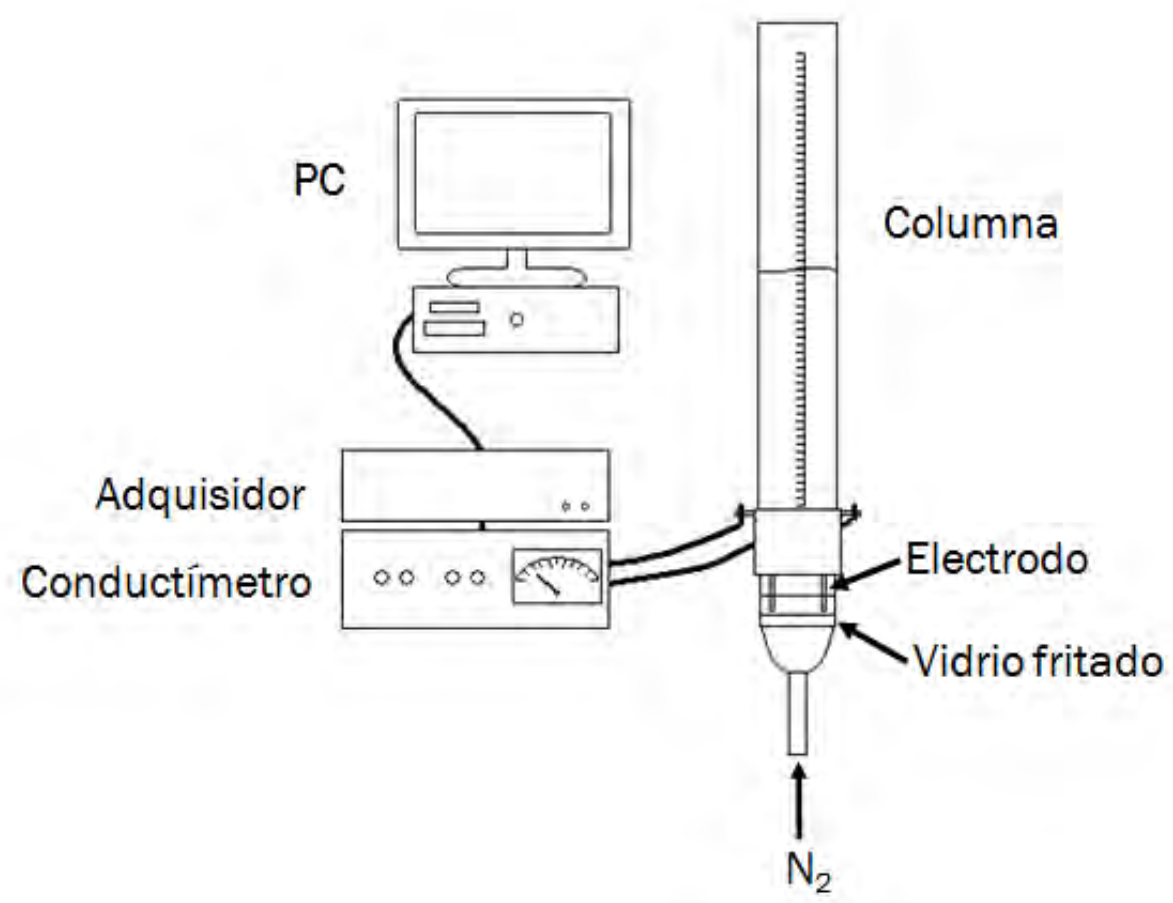

Figura 1.2.: Esquema del aparato utilizado para la medición de las propiedades espumantes.

Para caracterizar la espuma se utilizaron los siguientes parámetros:

- vo: es la velocidad inicial de formación de espuma. Este valor puede relacionarse con la velocidad de la proteína para migrar y reacomodarse en la interfase y poder producir una disminución de la tensión interfacial que permita la formación de la espuma. La vo se midió como la pendiente de la recta obtenida por regresión lineal de todos los puntos medidos entre los 5 y $15 \mathrm{~s}$ del tiempo de burbujeo.

- $V_{\text {max: }}$ es el volumen máximo de líquido incorporado a la espuma

- $t_{1 / 2}$ : es el tiempo en el que se drenó la mitad del $V_{\max }$ de espuma, medido a partir de la finalización del burbujeo. 


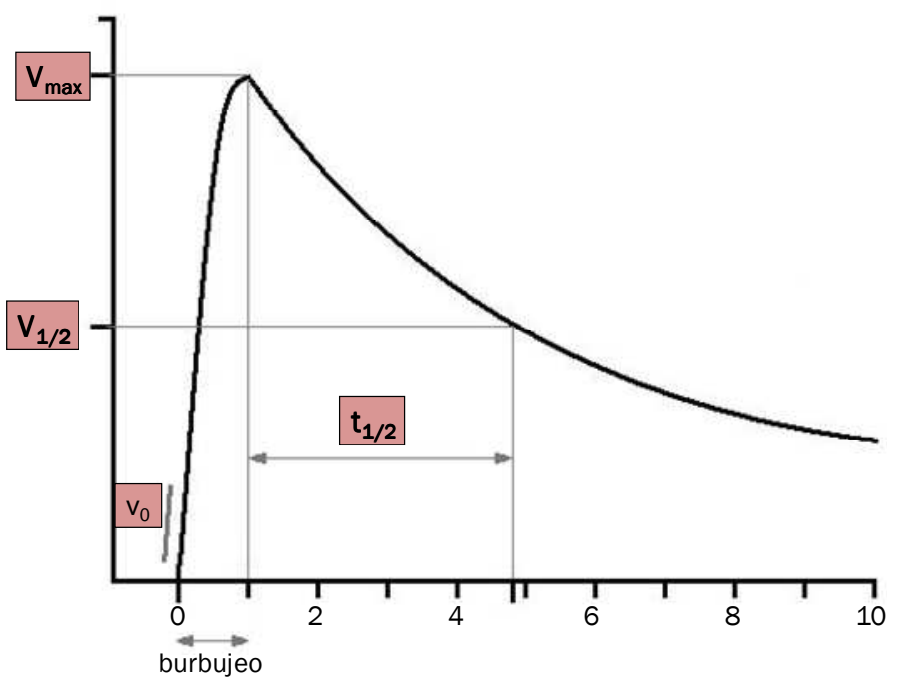

Figura 1.3.: Gráfico de comportamiento del líquido en la espuma con el tiempo.

\subsubsection{Preparación de emulsiones}

Las muestras nativas, $\mathrm{SN}, \mathrm{MN}$ y $\mathrm{AN}$ se dispersaron en una concentración de $1 \mathrm{mg} / \mathrm{ml}$ en buffer A y se agitaron durante $1 \mathrm{~h}$ antes de usarlas. Las muestras tratadas fueron usadas inmediatamente luego del tratamiento. Las emulsiones se prepararon homogeneizando 7,5 $\mathrm{ml}$ de aceite de girasol refinado con $14 \mathrm{ml}$ de suspensión (relación de aceite/agua o $\phi=0,35$ ) con un homeginzador rotatorio Ultra Turrax T-25 (IKA-Labortechnik, Alemania) usando el rotor dispersorhomogenizador S25 N-10 G de un diámetro de 7,5 mm a 20000 RPM durante 1,5 min en un vaso de vidrio de $28 \mathrm{~mm}$ de diámetro.

\subsubsection{Estabilidad de emulsiones}

\subsubsection{QuickScan}

Al finalizar la homogenización, las emulsiones fueron analizadas utilizando un analizador óptico vertical de barrido modelo QuickScan (Beckman-Coulter inc., USA). Este equipo se basa en la aplicación de una fuente lumínica láser (800 nm) a un tubo que contiene la emulsión. El aparato cuenta con dos detectores, uno detrás de la muestra que recibe la luz transmitida a través del tubo (un ángulo de $0^{\circ}$ ), y uno colocado a un ángulo de $135^{\circ}$ que mide luz dispersada (backscattered light) por la muestra. Tanto la fuente de luz como los dos detectores se mueven a lo largo del tubo periódicamente para medir la emulsión en todas las alturas de 
la célula de medida, y poder representar el estado de la emulsión en todo el tubo. Las medidas que se obtienen son cinéticas de \% de luz dispersada (\%BS) y de luz transmitida de la muestra en función de la altura de la muestra.

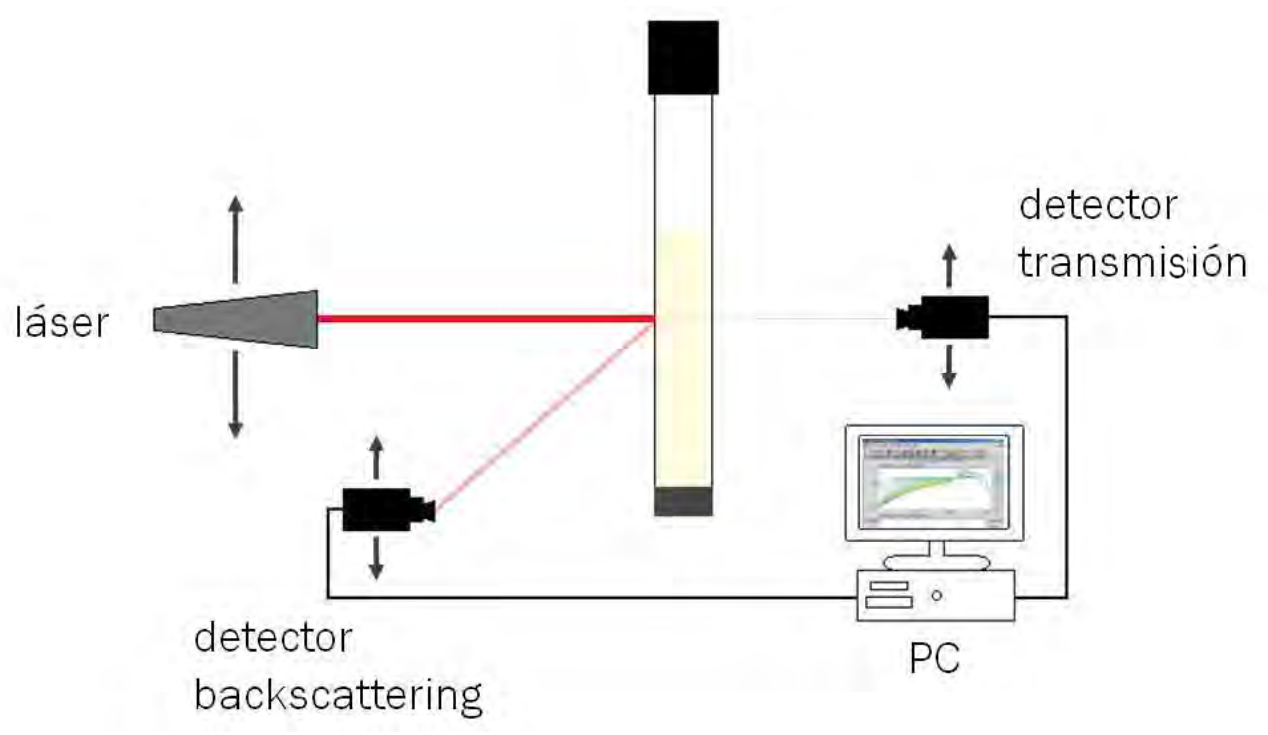

Figura 1.4.: Esquema sencillo del fundamento de funcionamiento del analizador QuickScan.

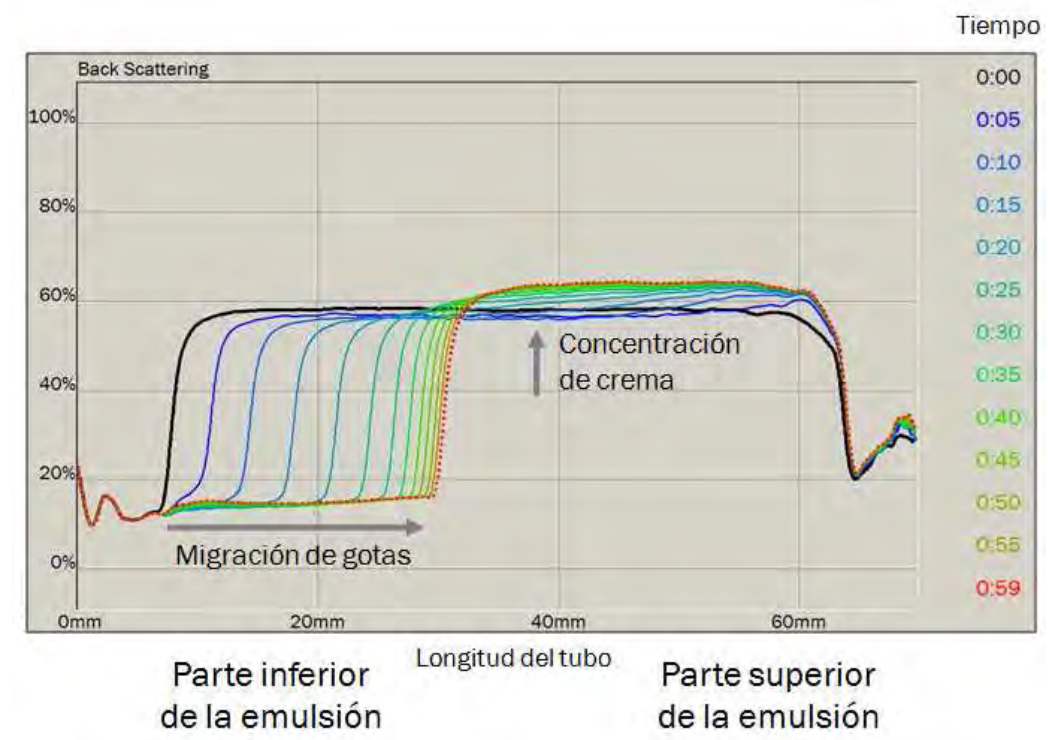

Figura 1.6.: Gráfico de la cinética de variación de BS en función de la longitud del tubo para una emulsión típica. 


\subsubsection{Operación}

Finalizada la homogenización se colocaron inmediatamente en la celda de medida del QuickScan aproximadamente $6 \mathrm{ml}$ de la emulsión y se procedió a ubicar la celda en el equipo. Se hizo una medida por min durante $1 \mathrm{~h}$ a temperatura ambiente. Luego de transcurrido ese lapso se mantuvieron las emulsiones en reposo a temperatura ambiente y se realizó una medida puntual a las $24 \mathrm{~h}$ de reposo. A partir de las medidas obtenidas se graficaron las cinéticas de \%BS medio en la parte inferior del tubo (10-15 mm desde la base) y en la parte superior (40-50 mm desde la base). También se calculó la constante $\mathrm{K}_{0,1}$ de cremado y el porcentaje de desestabilización de la fase crema (\% CD).

El $\mathrm{K}_{0,1}$ se calculó a partir de los valores promedio de \%BS en la parte baja del tubo (10-15 mm):

$$
\text { (7) } \quad \mathrm{K}_{0,1}=\left(\% \mathrm{BS} \text { in } \times \mathrm{t}_{0,1}\right)^{-1}
$$

donde $t_{0,1}$ es igual al tiempo en que se produjo una disminución del $10 \%$ del $\% B S$ in (\%BS inicial).

El valor \% CD se calculó de los valores promedio de \%BS en la parte superior del tubo (40-50 mm) de acuerdo a la siguiente ecuación:

$$
\% \mathrm{CD}=100 \times\left(\% \mathrm{BS}_{\max }-\% \mathrm{BS}_{24 \mathrm{~h}}\right) / \% \mathrm{BS}_{\max }
$$

siendo \%BSmax el valor máximo de \%BS alcanzado durante el ensayo en esa parte del tubo y \%BS $24 \mathrm{~h}$ es el valor del \%BS a las $24 \mathrm{~h}$ después de la primera medida.

\subsubsection{Distribución de tamaño de gota de las emulsiones aceitelagua}

\subsubsection{Principio}

Este método se basa en el análisis de los espectros de difracción y de difusión de luz láser producidos por partículas que en este caso son las gotas de aceite de una emulsión o/w. La técnica se basa en las teorías de Fraunhofer y de Mie. Según Fraunhofer el ángulo de difracción es mayor cuando el radio de las partículas es menor. Cuando el tamaño de las partículas se acerca al de la 
longitud de onda de la luz incidente (menos de $50 \mu \mathrm{m}$ ) se debe aplicar la teoría de Mie, similar a la de Fraunhofer, pero que tiene en cuenta los índices de refracción complejos de la partícula y del dispersante. Estos índices poseen una parte real que tiene que ver con la velocidad de la luz en los distintos medios y una imaginaria que tiene en cuenta la absorción del material. En la práctica el análisis se hace sobre todas las partículas que circulan en el camino de un rayo laser. Se analizan las intensidades a los diferentes ángulos y los espectros de difusión (McClements, 2005).

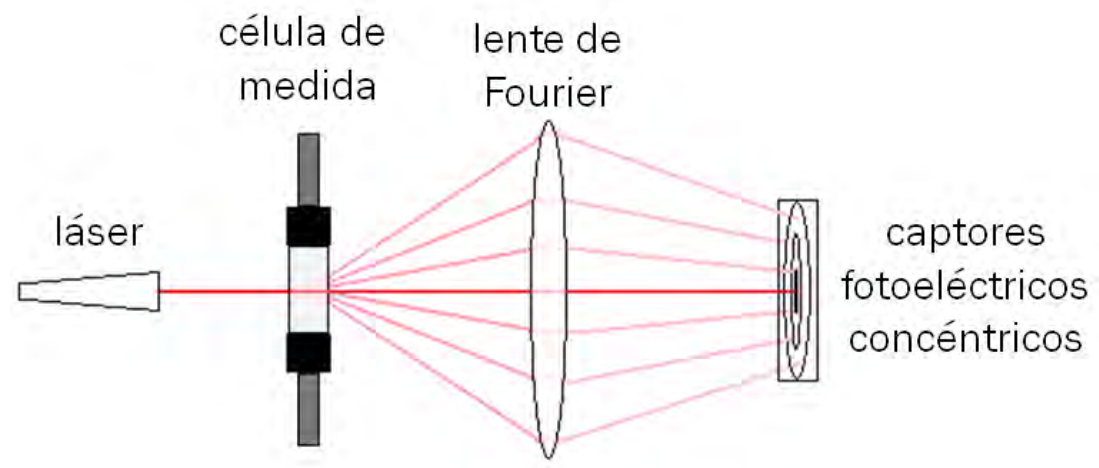

Figura 1.7.: Esquema de los componentes del analizador de tamaño de gota por dispersión de luz.

La luz dispersada es captada por un detector constituido por fotodiodos que reconstruyen un patrón de difracción de las distintas intensidades luminosas obtenidas en los distintos ángulos. Estos patrones son transformados en distribuciones de tamaño de gota de acuerdo a la teoría de Mie.

\subsubsection{Operación}

Las distribuciones de tamaño de gota que se realizaron fueron determinadas en un analizador láser Coulter LS-230 (Coulter Electronics, EE.UU) que permite medir en un rango de 0,1 a $1000 \mu \mathrm{m}$.

Las medidas se hicieron en presencia y en ausencia de SDS. El SDS es utilizado para evitar la floculación ya que carga negativamente a las moléculas de proteína o con el tiempo, reemplaza a las mismas de la interfase y produce repulsión electrostática entre las gotas. Para permitir la acción del SDS $125 \mu \mathrm{l}$ de las emulsiones a ensayar se colocaron en un tubo que contenía $2875 \mu$ l de solución 
de SDS $1 \%$, y se las mezcló suavemente. Primero se hizo la medida de la emulsión y luego de $1 \mathrm{~h}$ de estabilización, se midió la que contenía SDS. La diferencia en el tamaño de gota entre las emulsiones con y sin SDS permitió conocer el grado de floculación.

Luego se agregó la emulsión en la cuba de agua con circulación del equipo hasta llegar a un nivel de obscuración entre 5 y 10 \%. Los parametros utilizados que se establecieron para los cálculos fueron de 1,458 para el índice de refracción y de de $0,942 \mathrm{~g} / \mathrm{cm}^{3}$ para la densidad.

\subsubsection{Tratamiento de los resultados}

A partir de la distribución de tamaño de gota se calcularon diferentes parámetros estadísticos.

El equipo originalmente obtiene la distribución de tamaño de gota:

$$
d=\sum_{i}^{N} \frac{d_{i} \times n_{i}}{N}
$$

luego se calcularon los $\mathrm{d}_{3,2}$ y $\mathrm{d}_{4,3}$ :

$$
\mathrm{d}_{3,2}=\sum_{\mathrm{i}}^{\mathrm{N}} \frac{\mathrm{d}_{\mathrm{i} \times \mathrm{ni}}^{3}}{\mathrm{~d}^{2} \times \mathrm{ni}_{\mathrm{i}}}
$$

$$
\mathrm{d}_{4,3}=\sum_{\mathrm{i}}^{\mathrm{N}} \frac{\mathrm{di}_{\mathrm{i}}^{4} \times \mathrm{ni}}{\mathrm{di}_{\mathrm{3} \times \mathrm{n} i}^{3}}
$$

El d $\mathrm{d}_{3,2}$ da una idea de la superficie creada durante la emulsificación y la distribución de los $\mathrm{d}_{3,2}$ muestra el porcentaje de la superficie total creada está compuesta por gotas de los distintos rangos de tamaño. Las distribuciones de $\mathrm{d}_{4,3}$ representan el porcentaje del volumen total de aceite utilizado que representan cada uno de los rangos de tamaño de gota de la distribución.

A partir del d3,2 se calculó el área interfacial específica creada como:

$$
\mathrm{SIA}=6 \times \phi / \mathrm{d}_{3,2}
$$

donde $\phi$ es la relación volumétrica de aceite en la emulsión. 


\subsubsection{Microscopía óptica}

Las micro fotografías de las emulsiones fueron obtenidas en un microscopio LEICA DMLB (Leica Microsystems, Alemania) asociado a una cámara fotográfica digital DC100 (Leica Microscopy Systems Ltd., Suiza). El aumento total de las imágenes fue de 100X. En el momento de finalizar la homogenización se colocaron $200 \mu \mathrm{l}$ de cada una de las emulsiones en $2 \mathrm{ml}$ de buffer A conteniendo $1 \%$ de SDS y se agitó suavemente para diluir la emulsión sin afectar las gotas. Luego se tomaron $20 \mu \mathrm{l}$ de cada una de las emulsiones, se las colocó en un portaobjeto y cada muestra se cubrió cuidadosamente con un cubreobjeto para ser observadas en el microscopio y poder tomar las microfotografías. Para evaluar la estabilidad de las emulsiones en el tiempo se repitió el mismo procedimiento luego de $1 \mathrm{~h}$ y $24 \mathrm{~h}$ desde la finalización del proceso de emulsificación tomando muestras de la emulsión original almacenada en reposo a temperatura ambiente.

\subsection{Resultados y Discusión}

\subsubsection{Caracterización estructural de los aislados}

\subsubsection{Calorimetría diferencial de barrido (DSC)}

La Figura 1.8. muestra los termogramas obtenidos para los diferentes aislados ensayados, en ella se puede observar que los aislados que no recibieron tratamiento ácido muestran dos transiciones endotérmicas correspondientes a la desnaturalización de diferentes especies proteicas. Las temperaturas de desnaturalización son algo mayores para SN que para AN. En el caso de SN, el primer pico endotérmico se detectó a $88,4 \pm 0,3{ }^{\circ} \mathrm{C}$ y corresponde a la desnaturalización de la fracción $\beta$-conglicinina (Wagner, Sorgentini y col. 1996) y el segundo a $104,2 \pm 0,2{ }^{\circ} \mathrm{C}$ el cual es atribuido al desplegamiento de la fracción glicinina (11S). Para el AN también se detectaron dos endotermas a 75,5 $\pm 0,2{ }^{\circ} \mathrm{C}$ y 101,8 \pm 0,3 ${ }^{\circ} \mathrm{C}$. La primera corresponde a la desnaturalización de la fracción albúminas y la segunda a la de las globulinas (Martínez y Añón 1996). En el caso 
de $\mathrm{MN}$ se observaron termogramas con dos endotermas cuyas temperaturas de máxima deflexión son intermedias entre las indicadas anteriormente (86,6 \pm $0,4{ }^{\circ} \mathrm{C}$ y $\left.103,6 \pm 0,3^{\circ} \mathrm{C}\right)$.

En el termograma perteneciente a ST las temperaturas de los picos de desnaturalización detectados fueron $89 \pm 1,5{ }^{\circ} \mathrm{C}$ y $104,4 \pm 0,4{ }^{\circ} \mathrm{C}$ respectivamente. En el caso de AT no se detectaron endotermas mientras que en el termograma correspondiente a MT se pudo detectar una sola endoterma pequeña de desnaturalización a $86,1 \pm 1,1{ }^{\circ} \mathrm{C}$. Probablemete existe un segundo pico a una temperatura de alrededor de $105^{\circ} \mathrm{C}$, pero el software de cálculo no lo identifica como tal por el bajo valor de entalpía de desnaturalización del mismo.

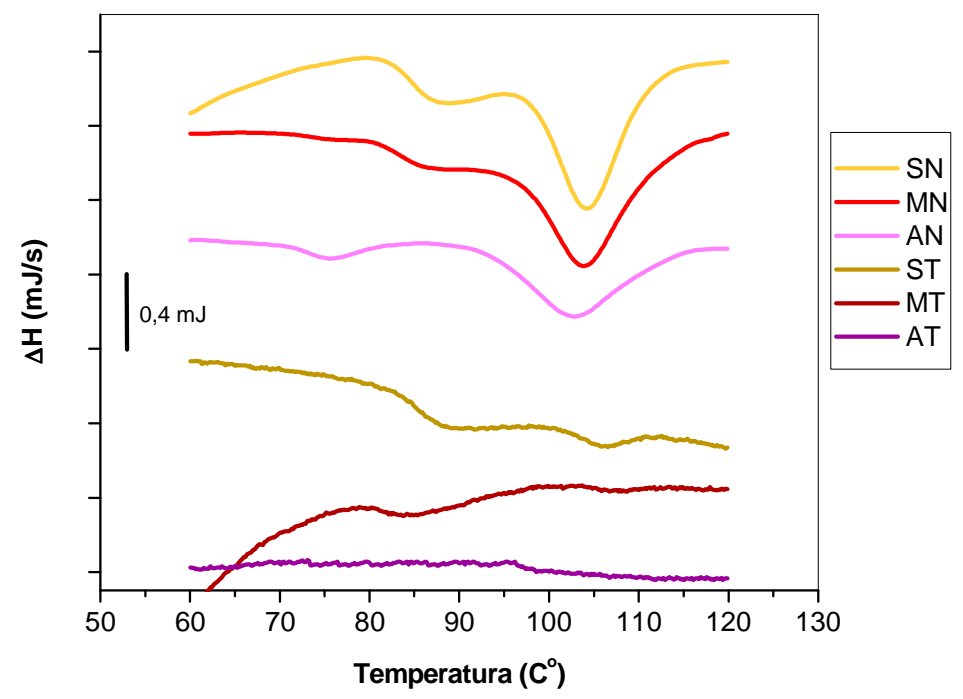

Figura 1.8.: Termogramas de DSC correspondientes a las distintas muestras analizadas. Velocidad de calentamiento: $10^{\circ} \mathrm{C} / \mathrm{min}$

Las muestras nativas ( $\mathrm{SN}, \mathrm{AN}$ y $\mathrm{MN}$ ) mostraron en todos los casos endotermas con valores de área mayores que los correspondientes a las muestras que sufrieron tratamiento ácido (ST, AT y MT). Esto se debería al hecho que el tratamiento ácido provoca la desnaturalización total o parcial de las especies proteicas presentes. Las entalpías de cada una de las muestras ensayadas se presentan en la Tabla 1.1. En ella se observa que las proteínas de soja tienen entalpías de desnaturalización mayores que las de amaranto (aproximadamente un $50 \%$ ) y que los valores decrecen luego del tratamiento ácido lo que 
evidenciaría una mayor resistencia al $\mathrm{pH}$ ácido. Evidentemente las proteínas de SN poseen una mayor cantidad de interacciones inter e intramoleculares, como puentes de hidrógeno, uniones electrostáticas o interacciones hidrofóbicas, que estabilizan las estructuras terciarias y cuaternarias. ST muestra la conservación de aproximadamente un $30 \%$ de la estructura molecular luego del tratamiento ácido. Se puede destacar el corrimiento del pico endotérmico perteneciente a $11 \mathrm{~S}$ hacia mayores valores de temperatura, podría pensarse que las moléculas proteicas más resistentes a la desnaturalización por el tratamiento ácido lo sean también a la desnaturalización por calor. AT no muestra entalpía de desnaturalización alguna. La mayor sensibilidad de las proteínas de amaranto al tratamiento ácido podría deberse a la presencia de un número mayor de grupos que se ionizan con carga positiva en el interior de su estructura (aminos y guanidinio). Cuando las condiciones de $\mathrm{pH}$ permiten el ingreso de los protones hacia el interior, los residuos aminoacídicos se ionizan y producen una desestabilización estructural en la parte interna de la molécula que tiene como consecuencia un mayor grado de desnaturalización. En el caso de MT la entalpía puesta en juego en la desnaturalización es intermedia entre las correspondientes a ST y AT.

Tabla 1.1. Entalpías de desnaturalización de las distintas muestras.

\begin{tabular}{ccc}
\hline Muestra & $\Delta \mathbf{H}(\mathbf{J} / \mathbf{g})$ & Desnaturalización (\%) \\
\hline $\mathrm{SN}_{\mathrm{a}}$ & $14,7 \pm 0,8$ & 0 \\
$\mathrm{MN}_{\mathrm{b}}$ & $11,6 \pm 0,6$ & 0 \\
$\mathrm{AN}_{\mathrm{c}}$ & $7,4 \pm 0,6$ & 0 \\
$\mathrm{ST}_{\mathrm{d}}$ & $4,6 \pm 0,4$ & $68,8 \pm 2,7$ \\
$\mathrm{MT}_{\mathrm{e}}$ & $2,0 \pm 0,3$ & $82,8 \pm 2,5$ \\
$\mathrm{AT}_{\mathrm{f}}$ & 0 & 100 \\
$\mathrm{AN} \mathrm{pH} 2 \mu .0,1^{*}$ & 0,2 & - \\
$\mathrm{AN} \mathrm{pH} 8 \mu .0,1^{*}$ & 10,2 & - \\
\hline
\end{tabular}

Las muestras con subíndices iguales no son significadamente diferentes ( $\alpha=0,05$, Tukey test). *No se realizaron réplicas.

En el caso de las muestras de AN suspendido a $\mathrm{pH} 2,0$ y 8,0 y $\mu$ 0,1 (termogramas no mostrados), se observó al $\mathrm{pH}$ más ácido un termograma con un pico endotérmico muy pequeño a $98,1^{\circ} \mathrm{C}$ mientras que a $\mathrm{pH} 8,0$ se detectaron 2 picos 
bien definidos a 70,1 y $98,6^{\circ} \mathrm{C}$. El desplazamiento de las temperaturas de los picos de desnaturalización a mayores valores con el aumento de la fuerza iónica podría atribuirse a la presencia de sales en el medio que compiten por el agua con las proteínas. Esta competencia resulta en una menor cantidad de agua disponible para atacar los sitios susceptibles a la ruptura de enlaces, en consecuencia para igual gradiente de aumento de temperatura se requiere mayor temperatura para producir desnaturalización.

\subsubsection{Electroforesis y cromatografías de exclusión molecular FPLC}

\subsection{Determinación de tamaños moleculares de especies nativas}

Las corridas SDS-PAGE en condiciones reductoras y no reductoras correspondientes a las proteínas de SN y AN mostraron los siguientes perfiles (Figura 1.9.).

En ausencia de 2-ME (Figura 1.9.(a)) el perfil SN muestra la presencia de agregados proteicos que no entran al gel, agregados solubles de más de $100 \mathrm{kDa}$, los polipéptidos $\alpha^{\prime}(76 \pm 4 \mathrm{kDa}), \alpha(67 \pm 3 \mathrm{kDa})$ y $\beta(48 \pm 4 \mathrm{kDa})$ pertenecientes a la globulina $7 \mathrm{~S}$ o $\beta$-conglicinina, la subunidad $\mathrm{AB}(51 \pm 4 \mathrm{kDa})$ de la globulina $11 \mathrm{~S}$ o glicinina y polipéptidos de menor masa molecular en particular los polipéptidos A (30-34 $\pm 3 \mathrm{kDa})$ y B $(21 \pm 2 \mathrm{kDa})$ de $11 \mathrm{~S}$ que se encuentran libres.

En el perfil correspondiente a AN se observan tres bandas con pesos moleculares de $56 \pm 4,51 \pm 3$ y $47 \pm 3 \mathrm{kDa}$ correspondientes a las globulinas 11S, P y 7S, más abajo dos bandas de $30 \pm 1$ y $28 \pm 1 \mathrm{kDa}$ correspondientes a polipéptidos de la fracción albúminas y/o a los polipéptidos A de las globulinas 11S y P; y en la parte inferior del perfil bandas de $16 \pm 1,13 \pm 1,10$ y $8 \mathrm{kDa}$, todas ellas pertenecientes a polipéptidos de la fracción albúminas. Se puede observar además una banda muy tenue alrededor de $20 \pm 1 \mathrm{kDa}$ y que correspondería a los polipéptidos B de las globulinas $11 \mathrm{~S}$ y $\mathrm{P}$. 
(a)

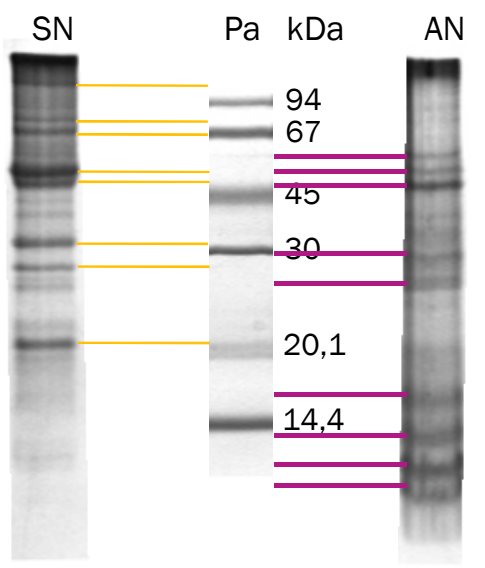

(b)

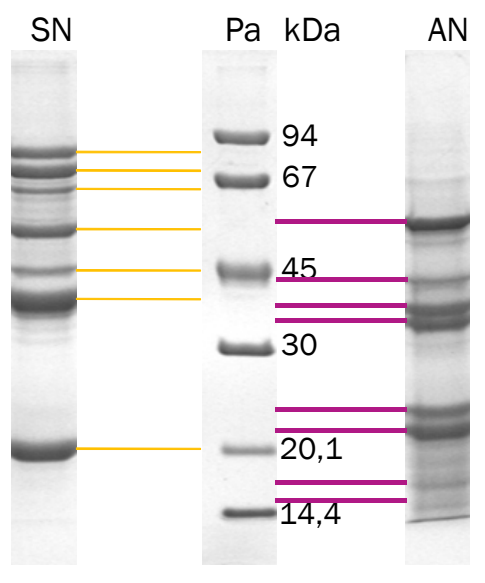

Figura 1.9. (a) SDS-PAGE; (b) SDS-PAGE + 2-ME de SN y AN, Pa: proteínas patrón de masa molecular $(\mathrm{kDa})$ conocida detalladas en la figura. Concentración de acrilamida: $12 \%$.

En condiciones reductoras (Figura 1.9.(b)), en el caso del SN desaparecen del perfil los agregados que no ingresaban al gel, al igual que los agregados solubles de alta masa molecular. Siguen detectándose los polipéptidos $\alpha^{\prime}$ (alrededor de 80 $\pm 5 \mathrm{kDa}), \alpha(70 \pm 3 \mathrm{kDa})$ de $7 \mathrm{~S}$, una especie polipeptídica de $63 \pm 4 \mathrm{kDa}$, el polipéptido $\beta$ (51 $\pm 4 \mathrm{kDa}$ ) de $7 \mathrm{~S}$, un polipéptido de aproximadamente $43 \mathrm{kDa}$ y los polipéptidos $\mathrm{A}(\cong 31 \pm 3 \mathrm{kDa})$ y B $(\cong 21 \pm 3 \mathrm{kDa})$ pertenecientes a $11 \mathrm{~S}$.

$\mathrm{El}$ análisis del perfil de AN en condiciones reductoras permite identificar bandas bien definidas del polipéptido $\mathrm{M}(56 \pm 4 \mathrm{kDa})$ perteneciente a la globulina-P, el polipéptido $\mathrm{L}$ de $7 \mathrm{~S}(43 \pm 3 \mathrm{kDa})$, dos bandas de $36 \pm 2$ y $34 \pm 2 \mathrm{kDa}$ correspondientes a las fracciones $\mathrm{A}_{1} \mathrm{y} \mathrm{A}_{2}$ de $11 \mathrm{~S}$ y dos bandas que pertenecen a los polipéptidos $\mathrm{B}_{1}$ y $\mathrm{B}_{2}$ de $11 \mathrm{~S}$ de 25 y $23 \mathrm{kDa}$ respectivamente. A continuación se detectan algunas bandas más pequeñas de $14 \pm 1$ y $16 \pm 1 \mathrm{kDa}$ pertenecientes a la fracción albúminas. Estos resultados son coincidentes con otros obtenidos anteriormente en nuestro laboratorio (Martínez y Añón 1996; Quiroga 2008).

La Figura 1.10. muestra las electroforesis nativa y bidimensional de SN y AN. Para SN (Figura 1.10.(a)) en condiciones nativas se puede observar una mayor concentración de proteínas en la parte superior de la calle. Esta zona de alta concentración proteica puede dividirse en dos subzonas. En la electroforesis bidimensional puede observarse que la subzona superior corresponde a los polipéptidos $\alpha^{\prime}, \alpha$ y $\beta$ pertenecientes a la $\beta$-conglicinina y a polipéptidos A y B de la glicinina 11S; la zona inferior corresponde exclusivamente a polipéptidos A y $\mathrm{B}$ de la fracción 11S. En el perfil-nativo, también se detectó una banda en la parte 
inferior de la calle que de acuerdo a la electroforesis bidimensional correspondería al polipéptido B de la 115 el cual se encontraría libre en el aislado nativo.

(a)
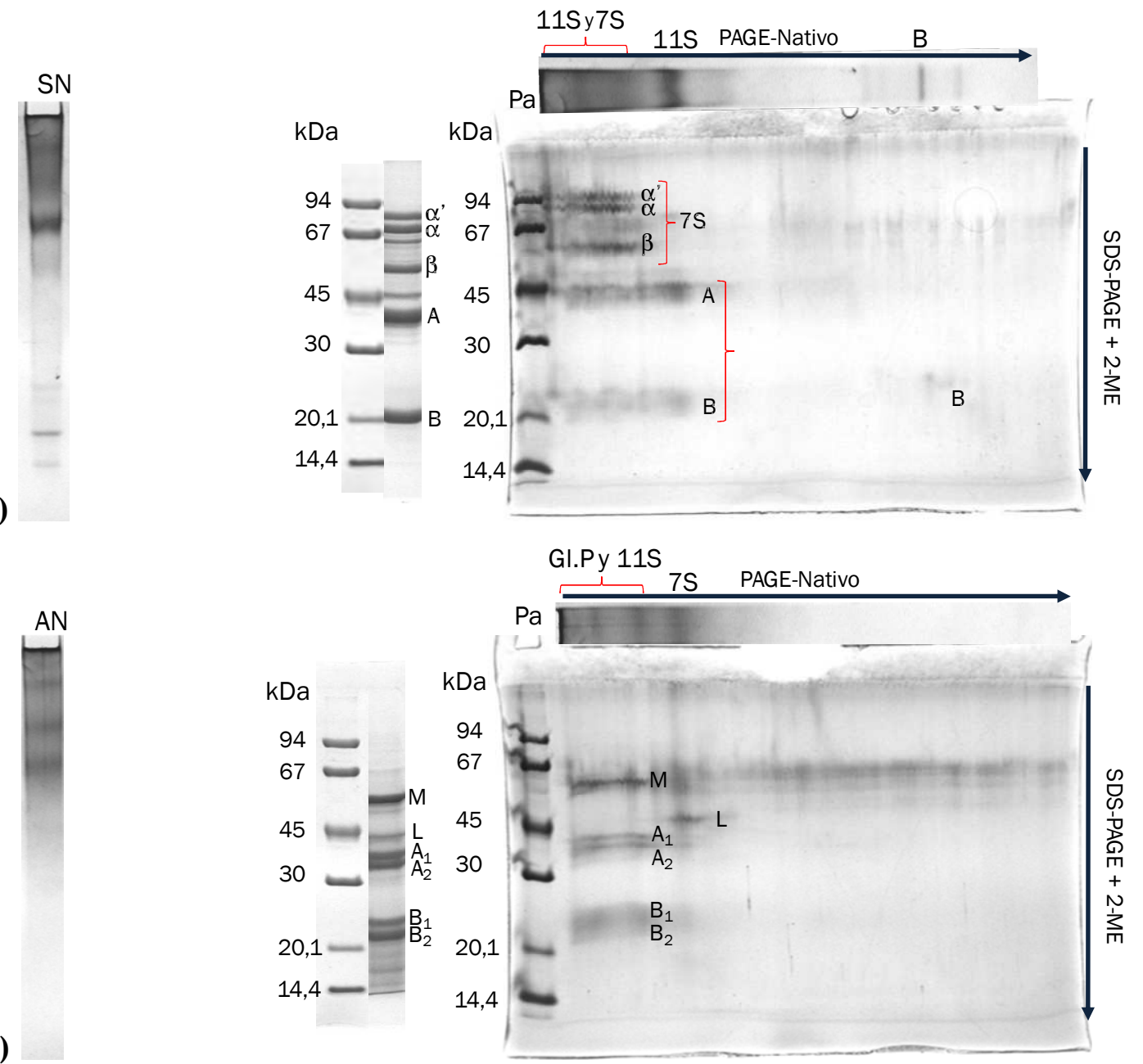

(b)

Figura 1.10.: PAGE-nativo en gradiente de concentraciones de acrilamida creciente (4-15\%) y electroforesis bidimensionales PAGE-nativo $\rightarrow$ SDS + 2-ME de los aislados nativos. (a) SN, (b) AN. Primera dimensión con un gradiente de concentración de acrilamida de 4 a $15 \%$. Segunda dimensión con una concentración de acrilamida de 12\%. Pa: proteínas patrón de masa molecular $(\mathrm{kDa})$ conocida detalladas en las figura.

En el caso del AN figura 1.10. (b), el perfil nativo muestra una acumulación de proteínas en la parte superior del gel pudiéndose distinguir tres bandas. De acuerdo a la información obtenida en la segunda dimensión las primeras dos bandas corresponderían a los polipéptidos de las globulinas-P y $11 \mathrm{~S}$ (M, A1, $\mathrm{A}_{2}$, $\mathrm{B}_{1}$ y $\left.\mathrm{B}_{2}\right)$, mientras que a la última contribuiría el polipéptido L de la $7 \mathrm{~S}$. En el gel de la segunda dimensión no se pueden observar las bandas correspondientes a 
las albúminas. Esto probablemente podría deberse a una difusión de dichos polipéptidos al medio cuando el gel fue sumergido en el buffer de tratamiento (sección 1.1.6.6.).

$\mathrm{SN}$, AN y una mezcla que contiene cantidades iguales de ambos aislados (MN) suspendidas en buffer A, fueron separados mediante cromatografías de exclusión molecular. Las fracciones colectadas de los diferentes picos de los cromatogramas fueron analizadas mediante SDS-PAGE en condiciones reductoras para identificar las especies proteicas que contribuían a cada uno de ellos. Los resultados obtenidos se muestran en la Figura 1.11. (a), (b) y (c). En el caso de SN (Figura 1.11.(a)) los picos indicados como 1, 2, 3 y 4 están compuestos principalmente por polipéptidos pertenecientes a las globulinas 7 y 11S. En el pico número 5 , que muestra valores de absorbancia mayores, se puede observar la presencia muy tenue del polipéptido $\beta$ de $\beta$-conglicinina (7S) y de los polipéptidos A y B de la glicinina (11S). En las calles correspondientes a los picos 7 y 8 se detectó principalmente el polipéptido B de 11S. Las calles 9, 10 y 11 no presentaron bandas, ello puede ser debido al hecho que el tamaño molecular de las especies presentes sea demasiado pequeño para ser retenidas en el gel y/o que la concentración proteica fue muy baja como para ser detectada. En el caso de AN (Figura 1.11.(b)) al primer pico del cromatograma contribuyen polipéptidos pertenecientes a las globulinas $\mathrm{P}$ y 11S. A partir del pico número 2 se comienza a observar la banda L de $43 \mathrm{kDa}$ perteneciente a la proteína minoritaria $7 \mathrm{~S}$ de amaranto, que se ve más definida en la calle del gel correspondiente al pico 3. También a este pico contribuyen polipéptidos de peso molecular menor a $20 \mathrm{kDa}$ pertenecientes a la fracción albúminas. En el pico 4 aparecen sólo albúminas de bajo peso molecular y el polipéptido $\mathrm{B}_{2}$ perteneciente a la globulina $11 \mathrm{~S}$ mientras que en los picos 5 y 6 , que constituyen los picos mayoritarios del cromatograma en términos de absorbancia a $280 \mathrm{~nm}$, se detectan albúminas de masa molecular cada vez más pequeña. Las especies proteicas que se separan en los picos 7 y 8 no pudieron identificarse en las electroforesis probablemente por las razones indicadas previamente. El perfil electroforético de MN (Figura 1.11.(c)) es intermedio entre los cromatogramas de SN y AN. Se puede ver en las electroforesis que los primeros picos corresponden a las globulinas de soja y en menor medida a las de amaranto. En los picos 4 y 5 se detectan principalmente $11 S$ de soja y globulinas de amaranto. En el pico 6 se observan tenuemente polipéptidos de tipo B correspondientes a la 11S de soja y de amaranto mientras que al pico 7 contribuyen albúminas de amaranto. Los picos 8 y 9 no quedan 
retenidos en el gel debido al bajo peso molecular de sus componentes, estos pertenecerían probablemente a especies presentes en el amaranto.

(a)

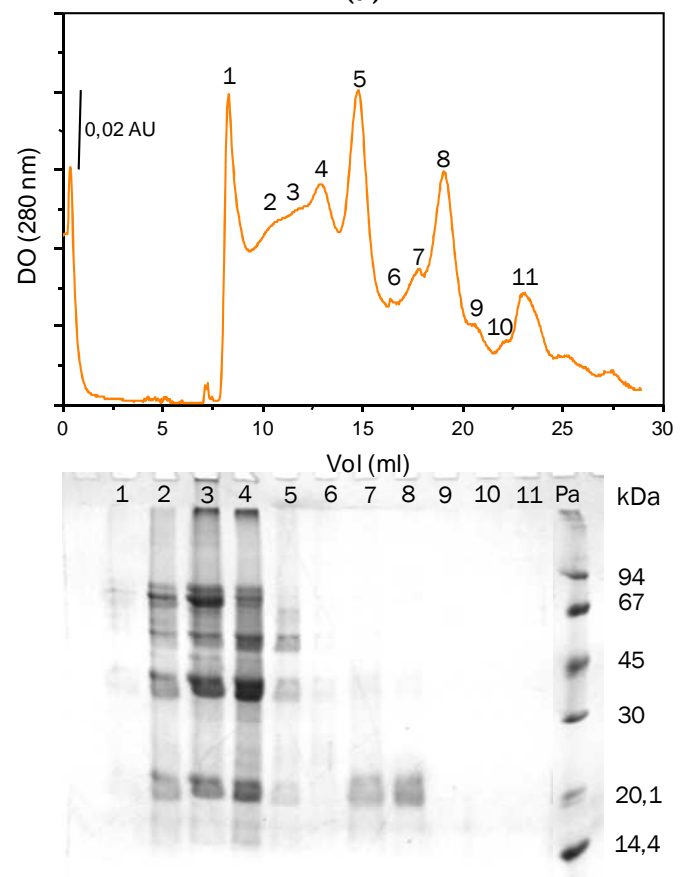

(b)
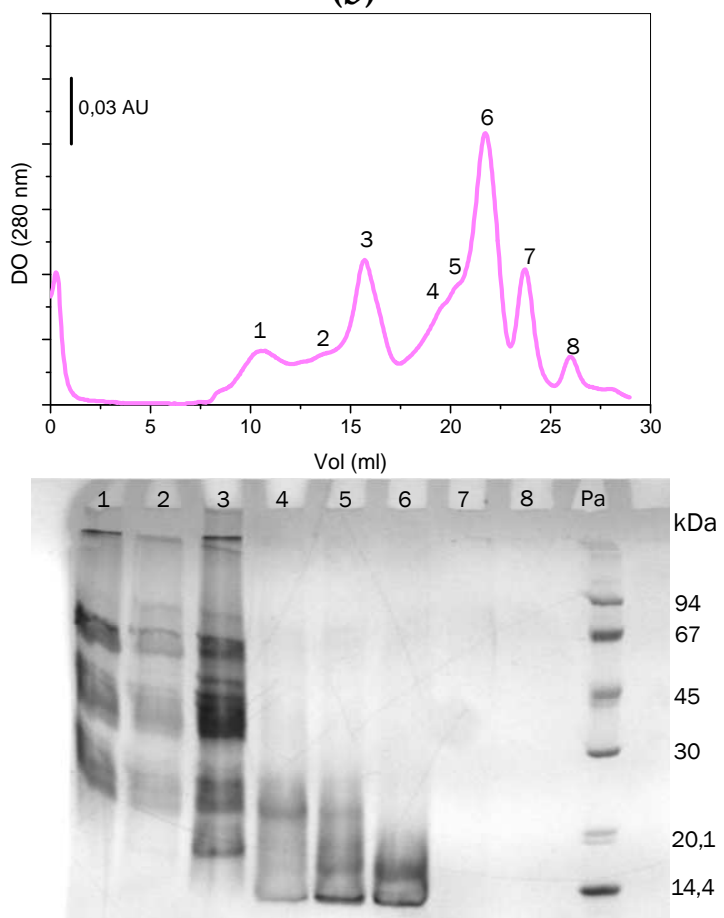

(c)

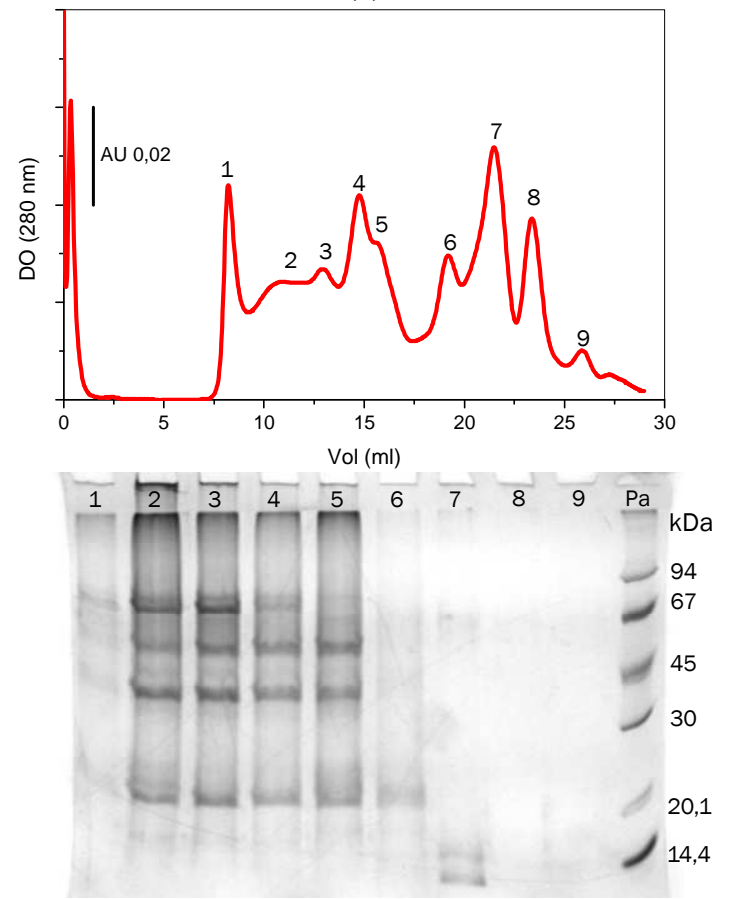

Figura 1.11.: Cromatografías FPLC y SDS-PAGE en condiciones reductoras de cada uno de los picos indicados en el cromatograma. (a) SN, (b) AN y (c) MN. Concentración de acrilamida: $12 \%$. 


\subsection{Determinación de tamaños moleculares de especies tratadas}

La Figura 1.12. muestra los perfiles PAGE-nativos de las distintas muestras analizadas antes y después del tratamiento ácido. Se puede observar en el caso de las muestras que recibieron tratamiento ácido un aumento de la relación carga masa respecto a las no tratadas, comportamiento indicado con flechas en la figura. En el caso de soja (SN y ST) se observó que las proteínas que mostraban baja movilidad electroforética se transformaron en especies de mayor movilidad. Este comportamiento se puede atribuir a la disociación producida a $\mathrm{pH}$ ácido de las estructuras cuaternarias de las globulinas (Puppo y Añón 1999). Algunos autores han utilizado tratamientos ácidos para producir disociación de aislados proteicos de soja, avena y girasol (Matsudomi, Sasaki y col. 1985; Ma, Khanzada y col. 1988; Claughton y Pearce 1989). En el caso de amaranto (AN y AT), se observó un desplazamiento aún mayor de la movilidad electroforética de las especies presentes que en el aislado proteico de soja, detectándose la aparición de bandas nítidas en la parte inferior de la calle que no se encontraban antes del tratamiento ácido. La razón de este desplazamiento sería también debida a la disociación proteica. La mezcla de aislados proteicos (MN y MT) muestra un comportamiento intermedio.

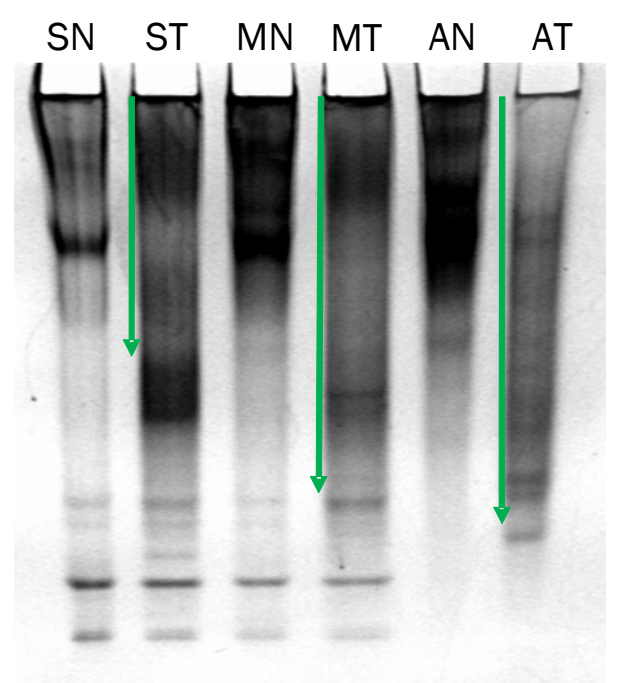

Figura 1.12.: PAGE-nativo en gradiente de concentraciones de acrilamida 4-15\%.

En las corridas SDS-PAGE sin y con 2-ME (Figura 1.13. (a) y (b)) se pueden diferenciar los comportamientos de las proteínas de las distintas muestras. En el caso de soja, el tratamiento ácido no parece afectar la composición polipeptídica 
de la muestras observándose el mismo patrón de bandas en SN y ST. En cambio en el caso de amaranto se detectan cambios en los perfiles de AN y AT.

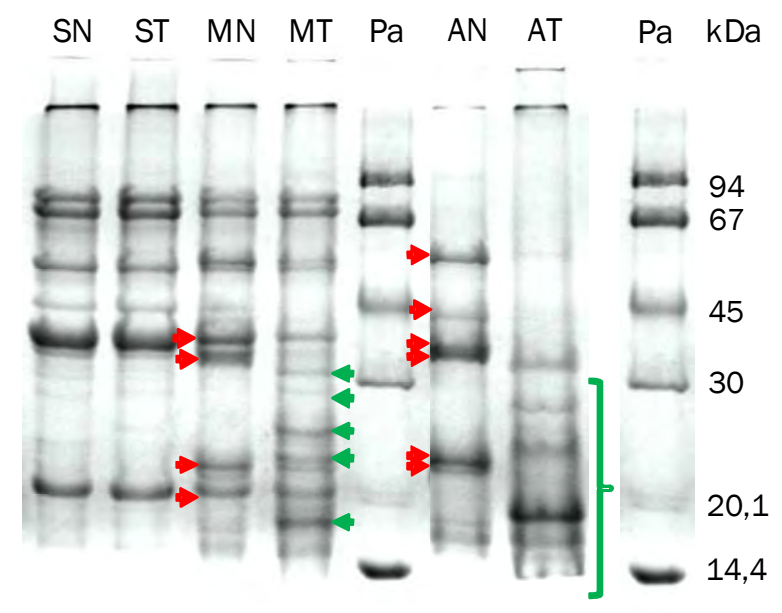

(a)

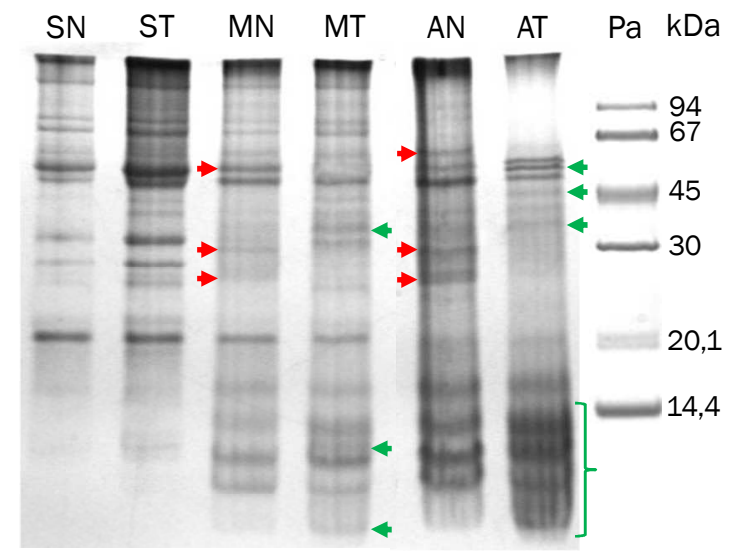

(b)

Figura 1.13.: (a) SDS-PAGE + 2-ME; (b) SDS-PAGE de las distintas muestras. Pa: proteínas patrón de masa molecular $(\mathrm{kDa})$ conocida detalladas en las figura. Las flechas rojas indican bandas que desaparecen mientras que las flechas verdes indican la aparición de nuevas bandas luego del tratamiento. Las llaves verdes indican zonas de cambios en la composición polipéptidica. Concentración de acrilamida: $12 \%$.

Evidentemente el tratamiento ácido produjo la ruptura de algunos polipéptidos, dando lugar a la aparición de polipéptidos de menor tamaño. Este comportamiento se observa tanto en condiciones reductoras como no reductoras, aunque en presencia de 2-ME los cambios se notan más nítidamente. 
Luego del tratamiento ácido en condiciones reductoras desaparecen total o parcialmente las especies M (56 kDa), L (45 kDa), la banda correspondiente a $\mathrm{A}_{1}$ (36 kDa), A2 $(34 \mathrm{kDa}), y$ las correspondientes a $\mathrm{B}_{1}(25 \mathrm{kDa})$ y $\mathrm{B}_{2}(23 \mathrm{kDa})$, polipéptidos pertenecientes a las globulinas $\mathrm{P}, 11 \mathrm{~S}$ y $7 \mathrm{~S}$. Paralelamente se detecta la aparición de bandas correspondientes a polipéptidos con pesos moleculares de 31, 29, 27 y $16 \mathrm{kDa}$ aproximadamente. En las corridas SDS-PAGE realizadas en ausencia de 2-ME, en la calle correspondiente a AT, desaparecen las bandas de 56 $\mathrm{kDa}$ (polipéptido $\mathrm{M}$ ) y las de pesos moleculares de alrededor de $30 \mathrm{kDa}$ ( $\mathrm{A}_{1} \mathrm{y}$ $\mathrm{A}_{2}$ ), pero se detecta la aparición de una banda de $55 \mathrm{kDa}$, otra de 47 y otra de 36 $\mathrm{kDa}$. El cambio más importante se observa en la parte inferior del gel, por debajo de $14 \mathrm{kDa}$, en donde aumenta la intensidad de concentración proteica y se pueden observar la aparición de nuevas bandas a bajos pesos moleculares (alrededor de $8 \mathrm{kDa}$ ).

La SDS-PAGE en condiciones reductoras correspondiente a MN (mezcla de SN y AN 1:1) presenta un perfil intermedio entre SN y AN. Pero en la calle correspondiente a MT se produjo la desaparición de especies de mayor peso molecular y aparición de especies de menor tamaño, al igual que en el caso de AT. También hay ciertos polipéptidos que aporta la soja que disminuyeron su intensidad en forma parcial luego del tratamiento ácido, como el polipéptido A de la proteína $11 \mathrm{~S}$ de un peso molecular de alrededor de $30 \mathrm{kDa}$. Esta desaparición parcial no se produjo cuando se analizó ST. En los geles en condiciones no reductoras, sobre la calle correspondiente a MT también se puede observar que con el tratamiento ácido se produjo la desaparición de la banda correspondiente $\mathrm{AB}$ de la fracción $11 \mathrm{~S}$ perteneciente a la soja que tiene un peso molecular aproximado de $54 \mathrm{kDa}$. Estos resultados sugieren la existencia de un factor hidrolizante que está presente en el aislado de amaranto y que se activa en algún momento del tratamiento ácido realizado. Este factor hidrolizante también actúa sobre algunos polipéptidos de las proteínas de soja cuando se tratan los aislados proteicos de ambas especies juntos. Al suceder esta hidrólisis sobre los polipéptidos de soja se puede descartar que el $\mathrm{pH}$ ácido del medio utilizado durante el tratamiento fuese la razón de la hidrólisis de las proteínas de amaranto. Los resultados hicieron que se profundice en este fenómeno para poder dilucidar la naturaleza del factor hidrolítico (sección 1.2.1.2.3.).

Se realizaron SDS-PAGE en condiciones reductoras de todas las muestras para diferenciar la solubilidad relativa en buffer A de los distintos polipéptidos que integran la mezcla proteica. Se suspendieron los aislados en el buffer en una concentración de $3 \mathrm{mg} / \mathrm{ml}$ y se agitaron durante $1 \mathrm{~h}$ a temperatura ambiente para 
permitir la solubilización. Se tomó una alícuota para preparar las muestras correspondientes a las proteínas totales presentes en los aislados. Luego se centrifugó la suspensión durante $15 \mathrm{~min}$ a $15000 \mathrm{~g}$ manteniendo la temperatura a $20{ }^{\circ} \mathrm{C}$. Finalizada la centrifugación se separó el sobrenadante (fracción soluble) y el precipitado fue resuspendido en buffer de muestra (fracción precipitado).

La composición polipeptídica de las fracciones solubles e insolubles en buffer A se muestra en la Figura 1.14. (a) y (b). Las proteínas de SN y ST que quedaron en el sobrenadante y las del precipitado no varían mucho en su naturaleza. En cambio para AN y AT se pueden observar diferencias entre las proteínas solubles y las que precipitaron. En AN (Figura 1.14.(a)), las proteínas solubles corresponden a las de menor peso molecular, pertenecientes a la fracción de albúminas y una pequeña cantidad de globulinas. Esto se hace visible en el cambio de las intensidades relativas entre las proteínas de bajo peso molecular y las globulinas de mayor peso molecular cuando se compara la calle sembrada con proteína soluble con la calle sembrada con el total de las proteínas de AN. En esa comparación se observa que las especies de bajo peso molecular casi no disminuyen su intensidad pero las globulinas la disminuyen muy notoriamente. En la fracción precipitada, como era de esperar, se observa una concentración mucho mayor de polipéptidos pertenecientes a las globulinas $(\mathrm{P}, 11 \mathrm{~S}$ y $7 \mathrm{~S})$ y una menor concentración de albúminas. Si observamos la calle correspondiente a AT, los resultados fueron similares (Figura 1.14.(b)). Los polipéptidos de menor tamaño que aparecieron por la hidrólisis de los polipéptidos originales de las globulinas se mantuvieron principalmente en la fracción precipitada, mientras que los de menor peso molecular, pertenecientes a las albúminas, permanecieron en el sobrenadante. En el caso de MN y MT se observa que los polipéptidos de soja como las albúminas de amaranto predominan en el soluble, mientras que los polipéptidos de las globulinas de amaranto predominan en el precipitado.

Los cromatogramas de la fracción soluble de las especies tratadas se muestran en la Figura 1.15. Comparando los perfiles cromatográficos de SN y ST ácido (Figuras 1.11.(a) y 1.15.(a)) se observa una importante disminución relativa de las intensidades de los picos 4 y 5 del cromatograma de SN que corresponde a los picos 3 y 4 en el cromatograma de ST. Esos picos pertenecen a globulinas 7 y $11 S$. El pico 5 corresponde al polipéptido $\beta$ de $7 \mathrm{~S}$ y a los polipéptidos A y B de 11S. Al comparar los picos 6 y 7 del cromatograma de ST con los picos correspondientes al mismo volumen de elución en el cromatograma de SN, picos 9 y 10, se detecta un cambio en la relación de sus intensidades. 
(a)

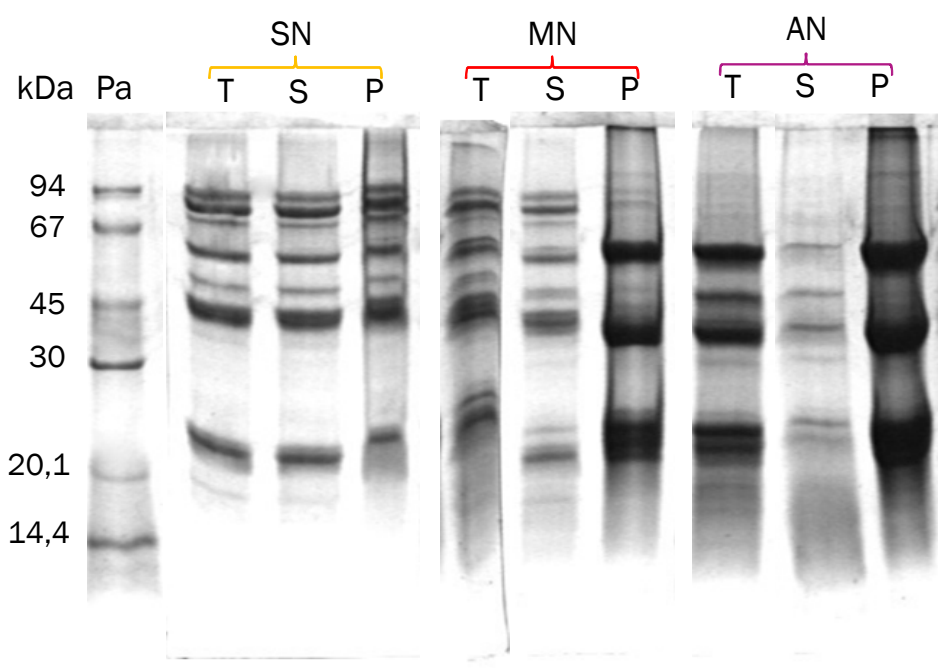

(b)

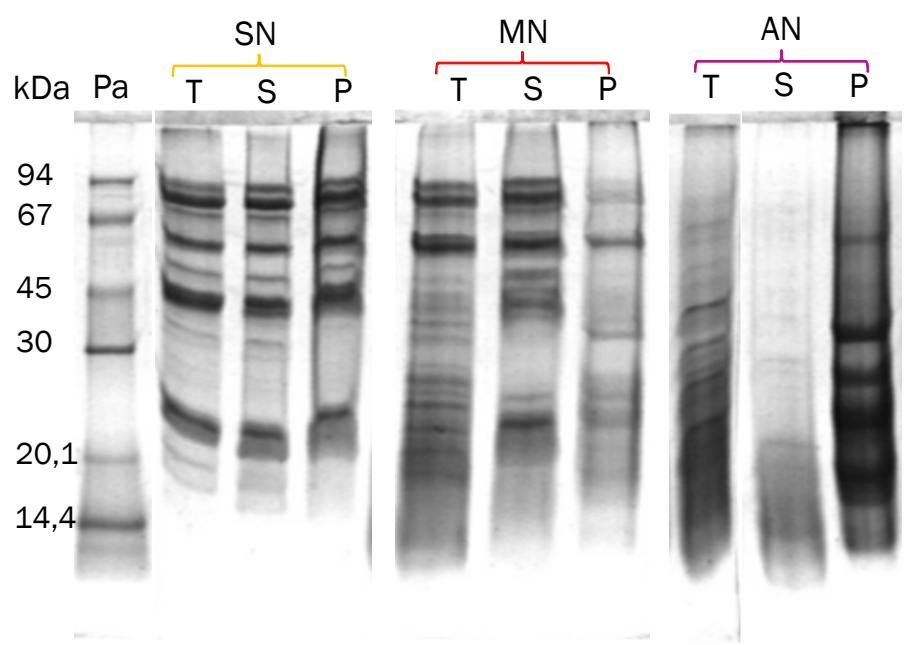

Figura 1.14.: SDS-PAGE de las muestras, (a): sin tratamiento ácido, (b): con tratamiento ácido. T: total de proteínas, S: polipéptidos del sobrenadante, P: polipéptidos del precipitado, Pa: patrones de proteína de peso molecular conocido expresados en kilodaltons $(\mathrm{kDa})$. Concentración de acrilamida: $12 \%$. 
(a)

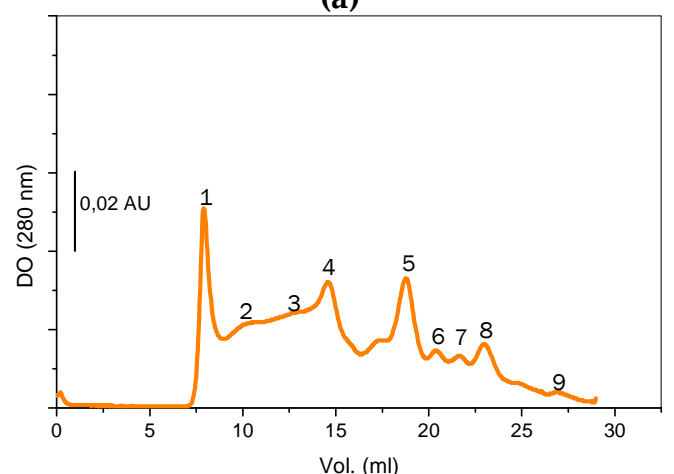

(b)
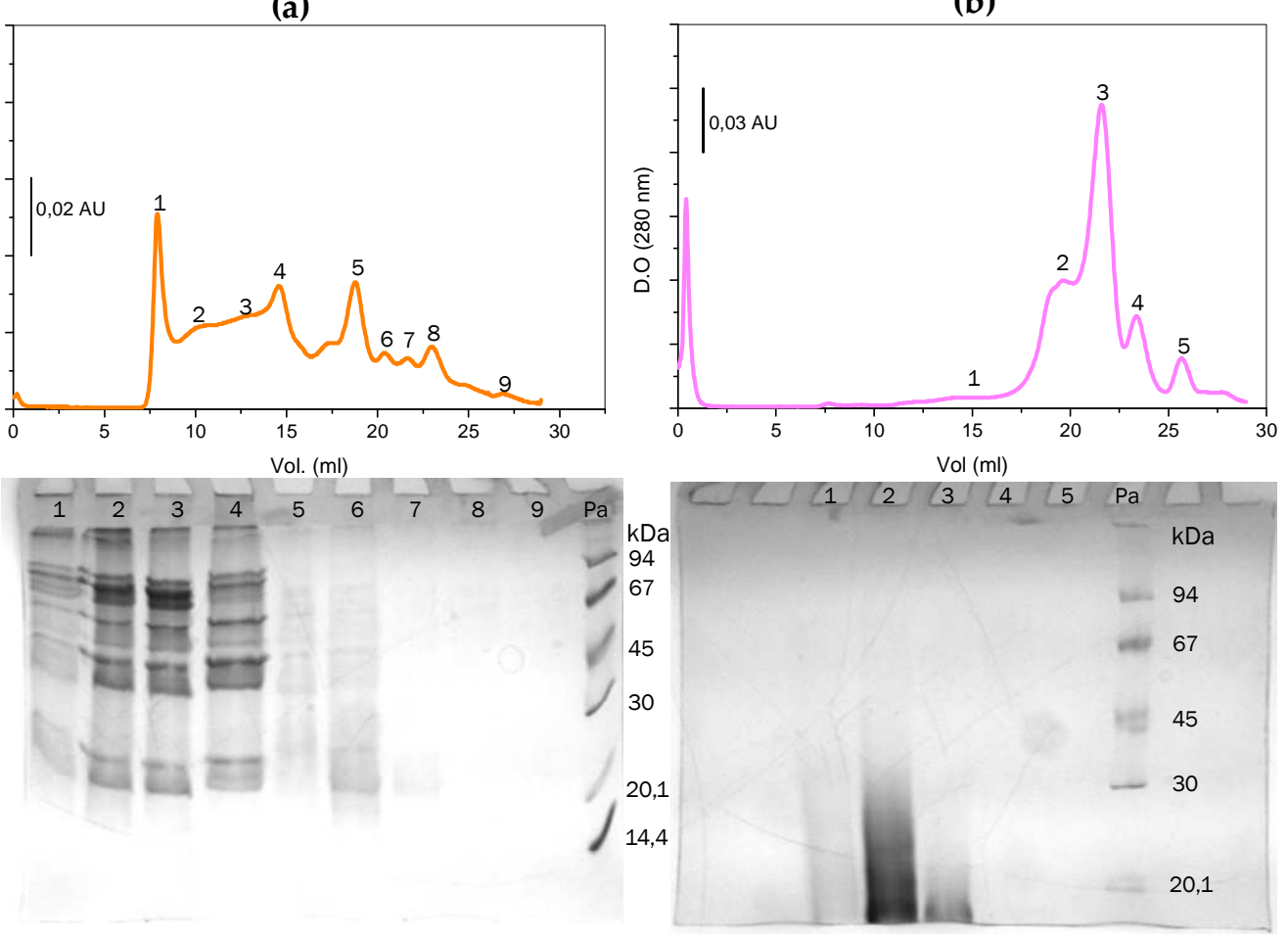

(c)
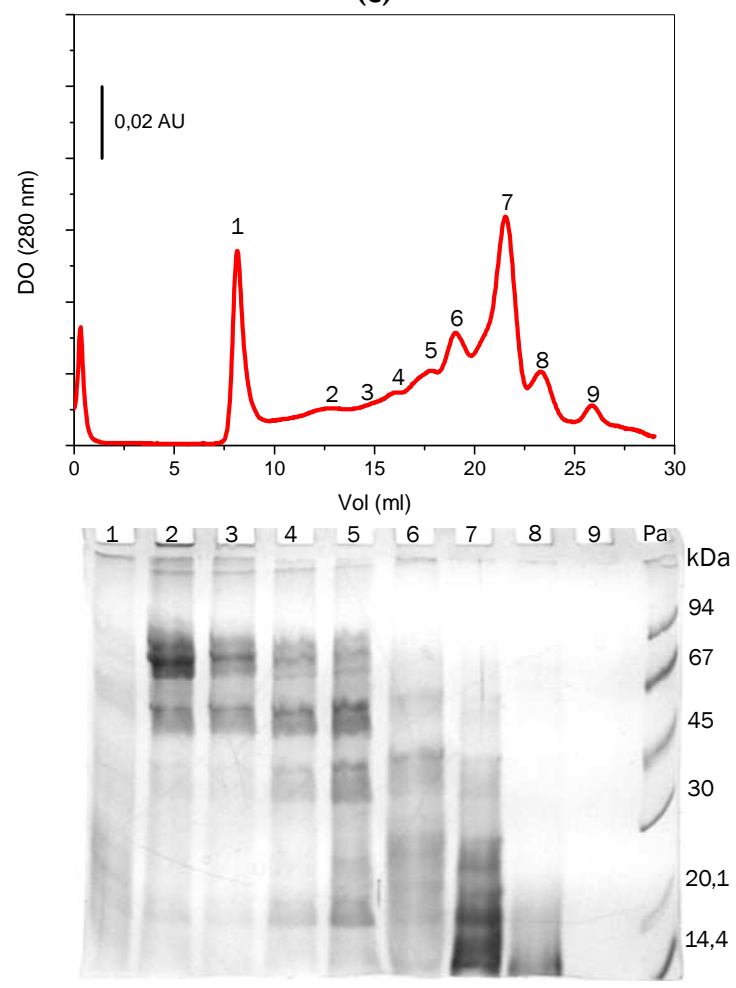

Figura 1.15.: Cromatografías FPLC de exclusión molecular de las muestras sometidas al tratamiento ácido y geles de poliacrilamida en condiciones desnaturalizantes y reductoras de los polipéptidos correspondientes a los distintos picos indicados en el cromatograma. (a) aislado proteico de soja, (b) aislado proteico de amaranto, (c) mezcla de aislados proteicos. Concentración de acrilamida de los geles: $12 \%$. 
Si en el cromatograma de ST (Figura 1.15.(a)) se integran las áreas bajo la curva para volúmenes menores y mayores de $16,5 \mathrm{ml}$, se dividen entre sí (vol. menores/vol. mayores), y se compara con el mismo cálculo realizado sobre el cromatograma de $\mathrm{SN}$, se observa que al tratar las muestras con ácido la relación de áreas disminuye desde 1,65 hasta 1,53. Este resultado indica que tienen mayor importancia las especies de menor tamaño molecular en ST que en SN y se debería a la disociación que se produce de la estructura cuaternaria de las proteínas al someterlas a $\mathrm{pH}$ ácido $(2,0)$ y que no se recupera con el posterior aumento de pH (Puppo y Añón 1999).

Para AT se puede ver en la Figura 1.15.(b) que desaparecen los picos correspondientes a las especies de mayor peso molecular que sí eran apreciados en el cromatograma de la especies no sometidas al tratamiento (picos 1, 2 y 3 de la Figura 1.11.(b)). Esos picos corresponden principalmente a las globulinas. En el mismo cromatograma se pueden apreciar picos de especies de menor tamaño molecular correspondientes a la fracción albúminas o probablemente a los polipéptidos A y B de la 11S (en el gel se puede corroborar que no poseen tamaños moleculares mayores a $30 \mathrm{kDa}$ ). Los polipéptidos correspondientes a los últimos picos del cromatograma no se pueden observar en la corrida electroforética porque, tal como se indicó previamente, el bajo peso molecular de los polipéptidos que contienen impidió que fueran retenidos en el gel y/o se encuentran en una baja concentración y/o corresponden a compuestos de naturaleza no peptídica. Si se hace la misma relación que se hizo anteriormente del área del cromatograma a la izquierda y derecha de $16,5 \mathrm{ml}$ para AN y AT los valores pasan de 0,58 a 0,08. Evidentemente sucede lo mismo que en el caso de SN y ST, las especies solubles disminuyen su tamaño molecular pero en mayor magnitud.

En los perfiles cromatográficos de MT (Figura 1.15.(c)) se observa que los valores de los pesos moleculares de las especies solubles disminuyen ya que eluye una mayor cantidad de especies a volúmenes altos al igual de lo que sucedía para ST y AT. En el mismo cromatograma puede verse que el aporte de algunos de los picos correspondientes a polipéptidos con mayores masas moleculares, que pertenecen a polipéptidos característicos de soja (2, 3, 4 y 5) aparecen con menos intensidad de la que se esperaría si se la compara con el cromatograma de ST (Figura 1.15.(a).). Por ejemplo, el pico 4 o el pico 5 del cromatograma de ST, que eluyen a $14,6 \mathrm{ml}$ y 18,7 $\mathrm{ml}$ respectivamente y que poseen una gran magnitud, no se aprecian con claridad en el cromatograma de MT. En esa zona sólo se puede apreciar nítidamente un pico con un máximo a los 19,1 ml (pico 6). Los picos 7 y 
8 corresponden a especies moleculares menores a $30 \mathrm{kDa}$ que aporta principalmente el amaranto. Si tomamos como parámetro, al igual que con las otras muestras, el valor límite de volumen de $16,5 \mathrm{ml}$ y se cuantifica y relaciona el área a volúmenes menores y mayores, para ST la relación entre volúmenes fue de 1,53, para AT: 0,08 y finalmente para la mezcla de aislados: 0,49. Si suponemos que la muestra de MT está compuesta por una cantidad equivalente de proteínas de ST y de AT, el promedio entre las relaciones de área de ST y de AT sería de 0,8, sin embargo MT da como resultado 0,49 marcadamente por debajo de lo esperado. Este resultado indica que las proteínas de soja no solo sufrieron la disminución de peso molecular debida al tratamiento como cuando se las trata aisladamente, sino que también experimentaron un efecto adicional que hizo que los tamaños moleculares disminuyeran más aún de lo esperado. En base a esto se puede formular una hipótesis similar a la que se surgió con las corridas electroforéticas SDS-PAGE de la existencia de un factor hidrolítico que actúa sobre el aislado proteico de amaranto cuando es sometido al tratamiento ácido, y que actúa también, al menos parcialmente, sobre las proteínas del aislado proteico de soja cuando éstas se encuentran en presencia del aislado proteico de amaranto durante el tratamiento. Esto indica que el factor hidrolítico se encontraría presente precisamente en el aisaldo de amaranto.

1.2.1.2.3. Determinación de la naturaleza del factor hidrolítico presente en el aislado de amaranto que se activa a $\mathrm{pH}$ ácido

Para determinar la causa de la hidrólisis de las proteínas de amaranto a pH ácido se hicieron diferentes ensayos.

Primero se incubó el aislado a pH 2,0 durante un lapso de $3 \mathrm{~h}$ durante el cual se sacaron muestras a diferentes tiempos de incubación Figura 1.16.

Se puede observar que se produce una hidrólisis importante ya a los $20 \mathrm{~min}$ de incubación y que esta aumenta progresivamente hasta las $3 \mathrm{~h}$, con la desaparición y aparición de bandas, explicadas en la sección 1.2.1.2.2., correspondientes a distintos polipéptidos. 


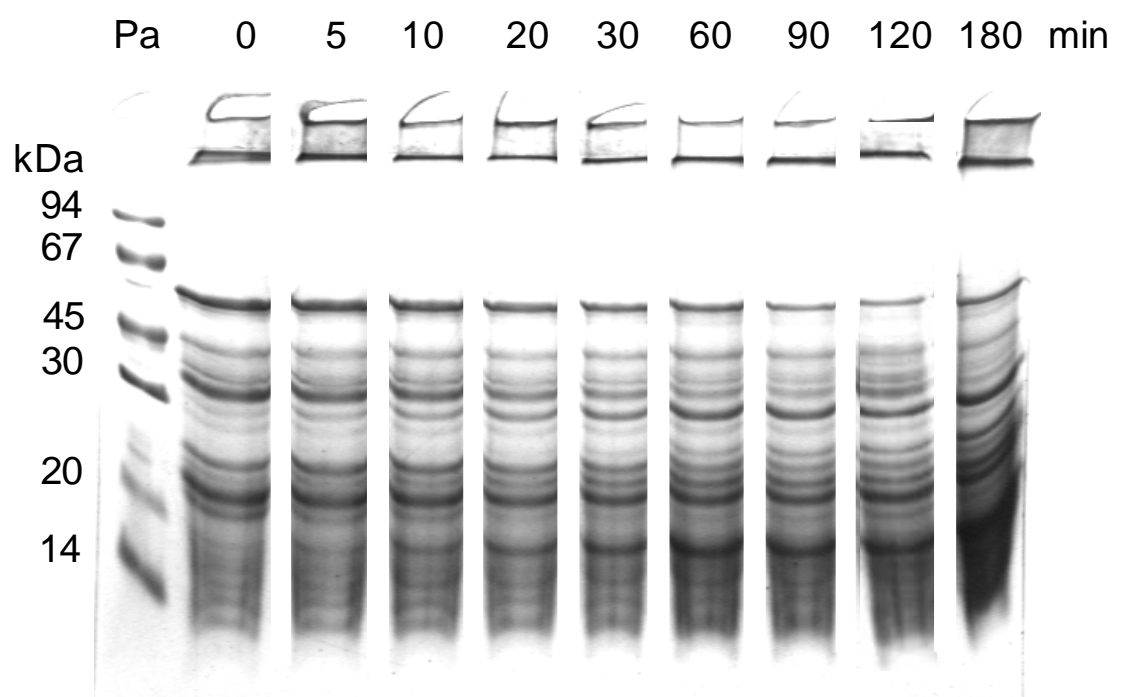

Figura 1.16.: SDS-PAGE en condiciones reductoras de AN incubado a $\mathrm{pH} 2,0$ a distintos tiempos expresados en minutos en la parte superior de las calles. Pa: patrones de proteína de peso molecular conocido expresados en kilodaltons $(\mathrm{kDa})$. Concentración de acrilamida: $12 \%$.

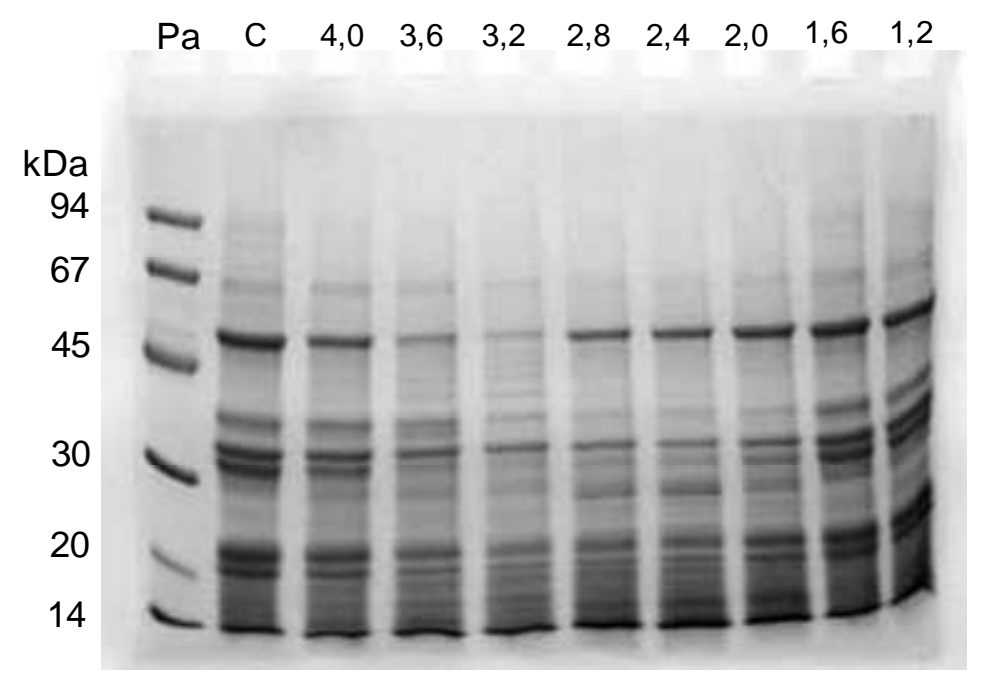

Figura 1.17.: SDS-PAGE en condiciones reductoras de AN incubado durante $3 \mathrm{~h}$ a distintos $\mathrm{pH}$ en la parte superior de las calles. Pa: patrones de proteína de peso molecular conocido expresados en kilodaltons $(\mathrm{kDa})$. C, control de proteína sin incubar. Concentración de acrilamida: $12 \%$.

Luego se determinó el rango de $\mathrm{pH}$ a los cuales se pudo observar hidrólisis. La determinación se realizó incubando la muestra durante $3 \mathrm{~h}$ en diferentes condiciones de $\mathrm{pH}(3,4$ a 1,2), con variaciones de 0,2 puntos de $\mathrm{pH}$ intermedios. 
Luego se prepararon muestras para SDS-PAGE en condiciones reductoras de los aislados incubados a cada uno de los $\mathrm{pH}$. Los resultados obtenidos mustran que a medida que se acidifica el medio la hidrólisis se hace más evidente. Es leve a $\mathrm{pH} \mathrm{3,6} \mathrm{y} \mathrm{aumenta} \mathrm{hasta} \mathrm{pH}$ 2,4. Para un valor de $\mathrm{pH} 2,0$ se detectó algo de inhibición de la hidrólisis mientras que a los pHs más ácidos ensayados, 1,6 y 1,2 no se observó hidrólisis (Figura 1.17).

En base a estos resultados se consideró que la hidrólisis podría deberse a la acción de una proteasa que se activaría a pH ácido.

A efectos de comprobar esta hipótesis se sometió al AN a un tratamiento térmico previo de $100{ }^{\circ} \mathrm{C}$ durante $10 \mathrm{~min}$ para poder inactivar la posible proteasa. Luego se incubó la muestra a pH 2,0 durante $24 \mathrm{~h}$ y se tomaron muestras a distintos tiempos durante la incubación para analizarlas por SDS-PAGE en condiciones reductoras. Los resultados obtenidos no mostraron la existencia de un proceso hidrolítico (Figura 1.18). Esto sugiere la presencia de un comportamiento sensible a las altas temperaturas.

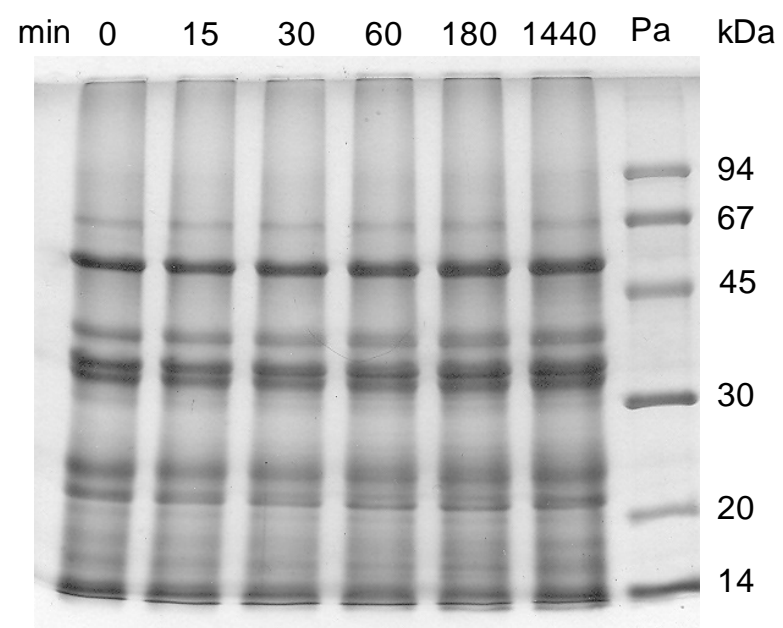

Figura 1.18.: SDS-PAGE en condiciones reductoras de AN tratado térmicamente $\left(100{ }^{\circ} \mathrm{C}, 10\right.$ min) incubado a $\mathrm{pH}$ 2,0 a distintos tiempos expresados en minutos en la parte superior de las calles. Pa: patrones de proteína de peso molecular conocido expresados en kilodaltons ( $\mathrm{kDa})$. Concentración de acrilamida: $12 \%$.

Luego se incubó la muestra con un inhibidor de proteasas, el PMSF (fenilmetilsulfonil fluoruro) que es un inhibidor de serin proteasas. La incubación se realizó a tiempos crecientes a los que se tomaron muestras para analizar mediante SDS-PAGE. Los resultados obtenidos de las electroforesis (resultados no mostrados) no mostraron inhibición de la posible hidrólisis por parte de PMSF. 
Finalmente se incubó AN a pH 2,0 durante $3 \mathrm{~h}$ en presencia y ausencia del inhibidor pepstatina $\mathrm{A}$ que es un hexapéptido que contiene el aminoácido estatina que se comporta como un inhibidor potente de las proteasas aspárticas. La pepstatina mostró inhibición de la hidrólisis en ese lapso de tiempo. En la Figura 1.19. se puede observar la similitud de los perfiles electroforéticos de las calles de AtI (AN incubado en presencia de inhibidor) con la de AN como también la disminución de polipéptidos de mayor masa molecular y aparición de polipéptidos de masas moleculares menores en el caso de $\mathrm{AN}$ incubado a $\mathrm{pH}$ 2,0 (At).

De estos resultados deduce que la causa de la hidrólisis se debe a una proteasa aspártica presente en el aislado de amaranto que se activa a pHs bajos y en un rango acotado. Hay que tener en cuenta que las proteasas aspárticas son activas a pH ácido, como ocurre en este caso (Rao, Tanksale y col. 1998).

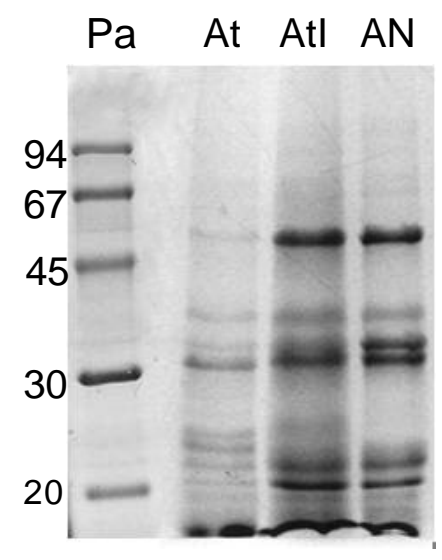

Figura 1.19.: SDS-PAGE en condiciones reductoras de AN incubado durante 3 h a pH 2,0 (At), incubado $3 \mathrm{~h}$ a pH 2,0 con inhibidor de proteasa (AtI) y sin incubar (AN). Pa: patrones de proteína de peso molecular conocido expresados en kilodaltons $(\mathrm{kDa})$.

\subsubsection{Hidrofobicidad Superficial}

\subsubsection{Medida utilizando la sonda fluorescente ANS}

Generalmente en las proteínas globulares los aminoácidos hidrofóbicos tienden a ubicarse en la parte interior de la estructura para no quedar expuestos al ambiente hidrofílico, situación que sería termodinámicamente desfavorable. Pero por ciertos impedimentos estéricos no todos los aminoácidos pueden ubicarse en el interior de la molécula. La hidrofobicidad superficial de una proteína es una 
medida de la cantidad de zonas o ambientes de alta hidrofobicidad que tiene expuestos la proteína al medio que la rodea. Ella va a depender de la estructura, por lo tanto va a depender también de las variables fisicoquímicas del medio en el que se encuentra la proteína $\left(\mathrm{pH}, \mu, \mathrm{T}^{\circ}\right)$. La cantidad de zonas hidrofóbicas y su ubicación espacial ha sido relacionada con las propiedades funcionales. En numerosos estudios se encontraron relaciones de la hidrofobicidad superficial con la solubilidad, las propiedades de superficie, la tensión interfacial, propiedades espumantes y emulsificantes, etc. (Keshavarz y Nakai 1979; Kato y Nakai 1980; Nakai 1983; Townsend y Nakai 1983; Hayakawa y Nakai 1985; Aluko y Yada 1993).

La Figura 1.18. muestra los resultados obtenidos en los ensayos de hidrofobicidad superficial realizados con las distintas muestras sometidas o no al tratamiento ácido, ensayos en los que se ha utilizado la sonda fluorescente ANS.

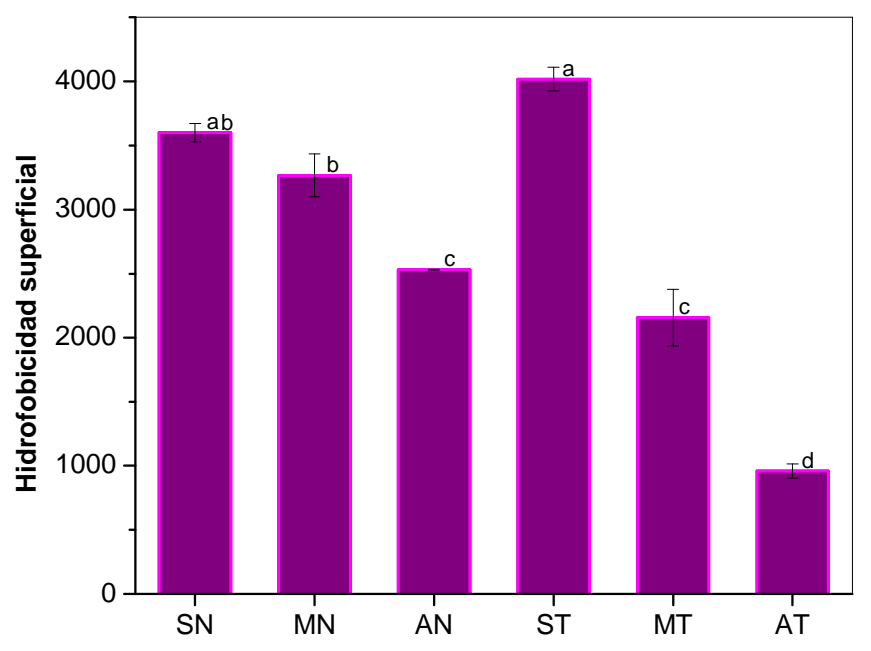

Figura 1.18.: Valores de hidrofobicidad superficial medida por fluorescencia de la sonda ANS de las muestras. Las barras con letras iguales no son significativamente diferentes $(\alpha=0,05$, Tukey test).

Se observa una disminución de los valores de hidrofobicidad superficial de las proteínas luego del tratamiento en medio ácido, con excepción de la muestra de soja que no muestra diferencias significativas. MN y MT se comportan de manera intermedia a las demás muestras sin tratar y tratadas por ácido respectivamente.

Al tratar las muestras en medio ácido se puede suponer que la hidrofobicidad debería aumentar ya que la estructura sufrió un desplegamiento demostrado por 
calorimetría DSC, lo que resultaría en una mayor exposición de aminoácidos hidrofóbicos. Probablemente esa exposición suceda, pero no se la puede determinar por esta técnica ya que la misma requiere que se trabaje sólo con proteína soluble, y las especies solubles antes y luego del tratamiento cambian (sección 1.2.1.2.2.). Otra razón para que no la detecte puede deberse a que cambia el tamaño de los polipéptidos debido a la hidrólisis ya que pueden disminuir los valores de hidrofobicidad calculados debido a que las sondas fluorescentes que se utilizan tienen valores bajos de rendimiento cuántico de fluorescencia (fluorescence quantum yields) cuando se unen a polipéptidos hidrofóbicos de menores tamaños moleculares (Nakai, Li-Chan y col. 1996) ya que no producen entornos hidrofóbicos adecuados para la unión de la sonda. Finalmente, también se puede sugerir la aparición de agregados solubles que no precipitaron en la centrifugación y que oculten sitios hidrofóbicos.

\subsubsection{Fluorescencia intrínseca}

Otro método para estimar la hidrofobicidad superficial de las proteínas es la medida de la fluorescencia intrínseca de soluciones de proteína. Las medidas realizadas haciendo uso de esta técnica se muestran en la Figura 1.19.

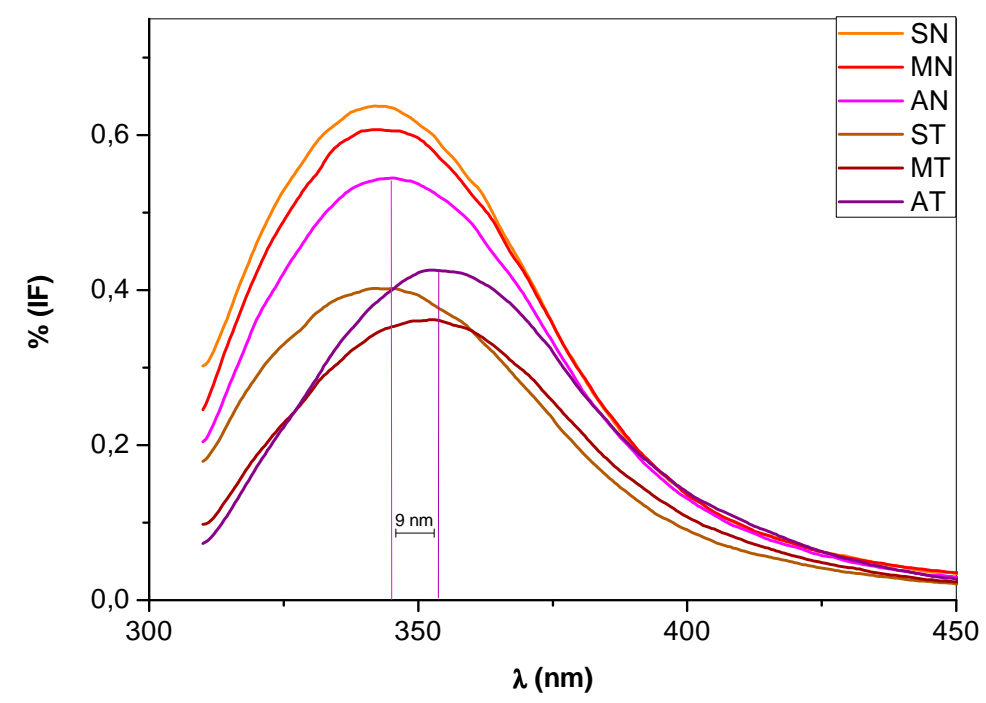

Figura 1.19.: Espectro de fluorescencia de las distintas muestras de soluciones de proteína. SN, MN y AN: aislados proteicos de soja, mezcla y de amaranto respectivamente sin tratamiento ácido; ST, MT y AT: aislados proteicos de soja, mezcla y de amaranto respectivamente tratados. 
Como se explicó en la sección 1.1.7.2. la exposición de los residuos triptófano al medio acuoso produce un corrimiento del máximo del espectro de fluorescencia hacia la derecha además de una disminución de la intensidad del pico. El tratamiento ácido efectuado no parece afectar en gran medida los valores de longitud de onda del máximo de fluorescencia de las proteínas de soja que fueron para SN: $343 \mathrm{~nm}$ y para ST: $344 \mathrm{~nm}$, sin embargo las muestras de amaranto (AN y AT) mostraron un corrimiento de la longitud de onda del máximo de fluorescencia hacia mayores longitudes de onda (345 a $353 \mathrm{~nm}$ ), además de producirse un descenso en la intensidad del pico. Estos dos cambios sugieren que la exposición de los residuos triptófano de AT hacia el medio polar es mayor luego del tratamiento ácido. Algo similar puede observarse en el caso de las proteínas de la mezcla de aislados (MN y MT) que también muestran un corrimiento importante a valores mayores de longitud de onda luego del tratamiento ácido (344 a $351 \mathrm{~nm}$ ) como también la disminución de la altura del pico. Mientras que MN muestra un valor intermedio al de SN y AN, MT se parece más a AT que a ST.

Los residuos triptófano que se encuentran completamente rodeados de regiones no polares en la molécula cuando son excitados a $295 \mathrm{~nm}$ producen un máximo de fluorescencia entre 330 y $332 \mathrm{~nm}$, los que están completamente expuestos al ambiente hidrofílico, lo producen entre 350 y 353 nm (Nakai, Li-Chan y col. 1996). Evidentemente las estimaciones de hidrofobicidad superficial obtenidas por este método contradicen los resultados obtenidos por la medida de la misma con la sonda ANS y respaldaría la hipótesis que sugiere la exposición de residuos hidrofóbicos luego del tratamiento a pH 2,0 por el desplegamiento de estructuras.

\subsubsection{Solubilidad}

Entre las propiedades funcionales de las proteínas, la solubilidad es de importancia primaria debido a su influencia en las otras propiedades funcionales (Halling 1981). En general las proteínas utilizadas como componentes funcionales en los alimentos deben poseer una buena solubilidad lo que suele reflejarse en buenas propiedades espumantes, emulsionantes y/o gelificantes (Vojdani 1996). La solubilidad provee un buen índice de las aplicaciones potenciales, o bien de las limitaciones de una dada proteína (Pilosof 2000). Los resultados de solubilidad de las diferentes muestras obtenidas se presentan en la Figura 1.20. Las proteínas de soja mostraron mayor solubilidad que las de 
amaranto en las condiciones de $\mathrm{pH}$ y de fuerza iónica utilizadas en el ensayo $(\mathrm{pH}$ 7,5 y $\mu$ 0,5). No se observan diferencias significativas entre cada uno de los aislados sin tratar con su correspondiente tratado. A pesar de producirse cambios conformacionales en las moléculas proteicas debidos al tratamiento la relación de proteína en el sobrenadante, respecto a la proteína que se mantuvo en el precipitado no cambió significativamente. Los valores de solubilidad obtenidos para los aislados nativos en condiciones similares de $\mathrm{pH}$ y fuerza iónica son semejantes a los obtenidos por otros investigadores (Marcone y Kakuda 1999; Lakemond, De Jongh y col. 2000; Abugoch 2006). Probablemente en las condiciones del ensayo y con las proteínas en estudio la solubilidad esté más ligada a la composición de aminoácidos de las proteínas que a la estructura, o que los cambios producidos en las estructuras produzcan la insolubilización de algunos polipéptidos pero la solubilización de otros que compensen los valores de solubilidad.

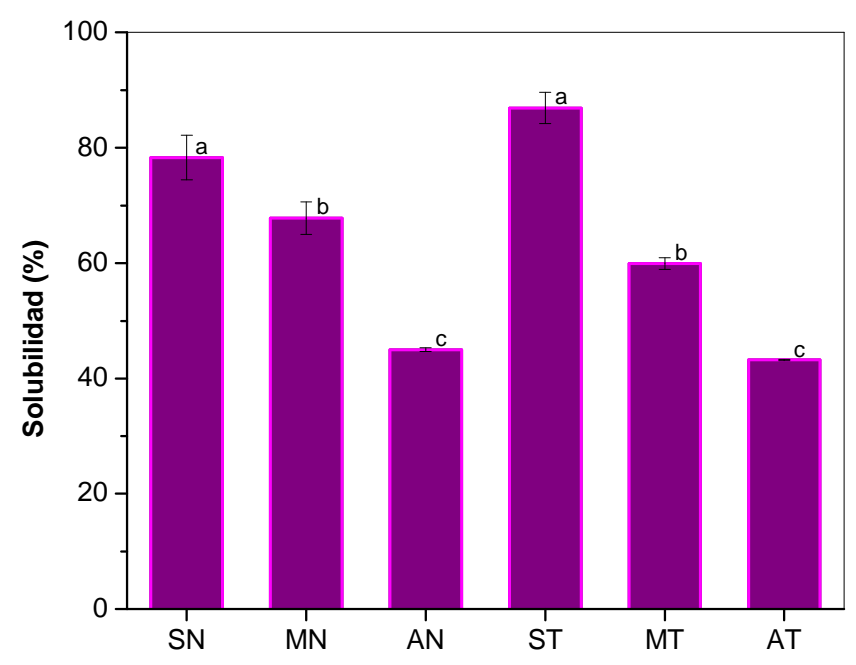

Figura 1.20:: Porcentajes de solubilidad de las muestras. Las barras con letras iguales no son significativamente diferentes $(\alpha=0,05$, Tukey test).

\subsubsection{Tensión superficial}

El conocimiento de las propiedades interfaciales que posee una molécula es de gran utilidad en el estudio de las propiedades funcionales de superficie (Walstra 2003). Estas propiedades van a determinar la capacidad y velocidad de la 
molécula, en este caso una proteína, para disminuir la tensión interfacial entre dos fluidos inmiscibles, condición necesaria para la formación de espumas y emulsiones. Una menor tensión interfacial reduce el trabajo mecánico necesario para hacer una espuma o una emulsión (Bos y Van Vliet 2001).

Las medidas de la tensión superficial se muestran en la Figura 1.21. En ella se pueden identificar comportamientos distintos entre las muestras. El tratamiento ácido no parece afectar la actividad tensioactiva de las proteínas de soja en la misma medida que la correspondiente a las otras muestras, dado que las curvas pre y pos-tratamiento ácido no presentan grandes diferencias solapándose en algunos puntos. Estas proteínas fueron además las que redujeron en menor medida los valores de tensión superficial en los tiempos del ensayo. Las curvas de AN y MN sin tratar están casi solapadas, probablemente porque las proteínas de amaranto dominan en el comportamiento de la mezcla de aislados (MN) sobre las proteínas de soja. Por el contrario, en las muestras tratadas, la curva de disminución de la tensión superficial de AT se diferencia de la de MT. En ambos casos el tratamiento ácido mejoró la capacidad tensioactiva de los aislados proteicos ya que se observó un incremento de las velocidades de disminución de la tensión superficial.

Se debe tener en cuenta que se utilizó el modo dinámico para hacer las mediciones (explicado en la sección 1.1.10.2.). En este modo, para la máxima velocidad de formación de la gota $(12,5 \mu \mathrm{l} / \mathrm{min})$, que el tiempo medido de una determinada muestra resulte menor, indica que la gota se desprendió con un menor volumen. Se puede deducir que la velocidad de disminución de la tensión superficial es mayor cuanto menor sea el tiempo de desprendimiento de la gota. Los valores de tensión superficial medidos por el tensiómetro en el momento de desprenderse la primera gota se encuentran representados en la Figura 1.22. Si se comparan las muestras que recibieron tratamiento ácido con las muestras que no lo recibieron se observa una disminución de la tensión superficial en todos los casos. 


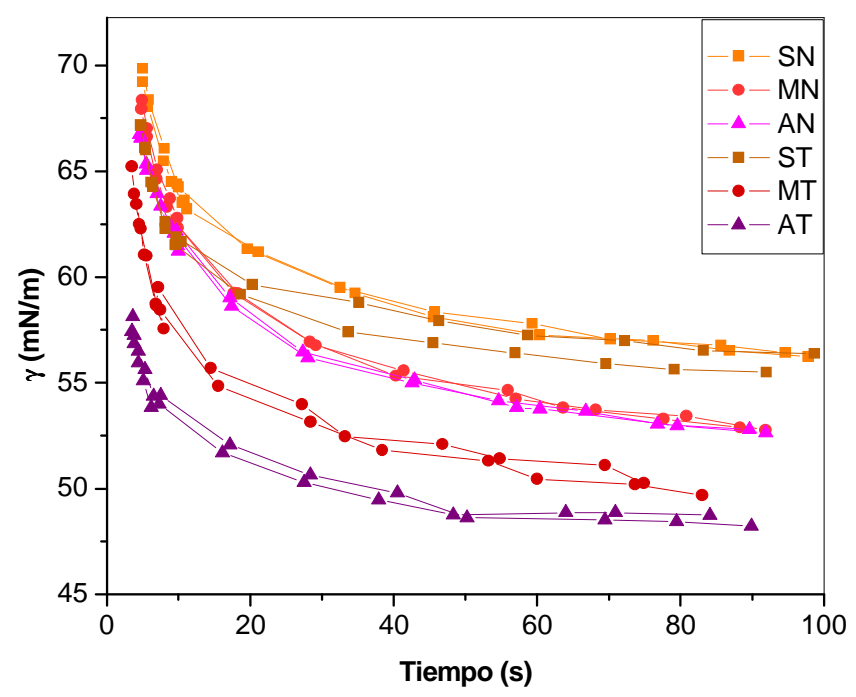

Figura 1.21.: Cinéticas de descenso de la tensión superficial para las distintas muestras. Se graficaron dos curvas independientes de cada muestra y cada punto es un promedio de 3 gotas formadas, no se graficó el desvío de cada punto para facilitar la lectura pero la variación máxima de las medidas no fue mayor a $\pm 0,47 \mathrm{mN} / \mathrm{m}$.

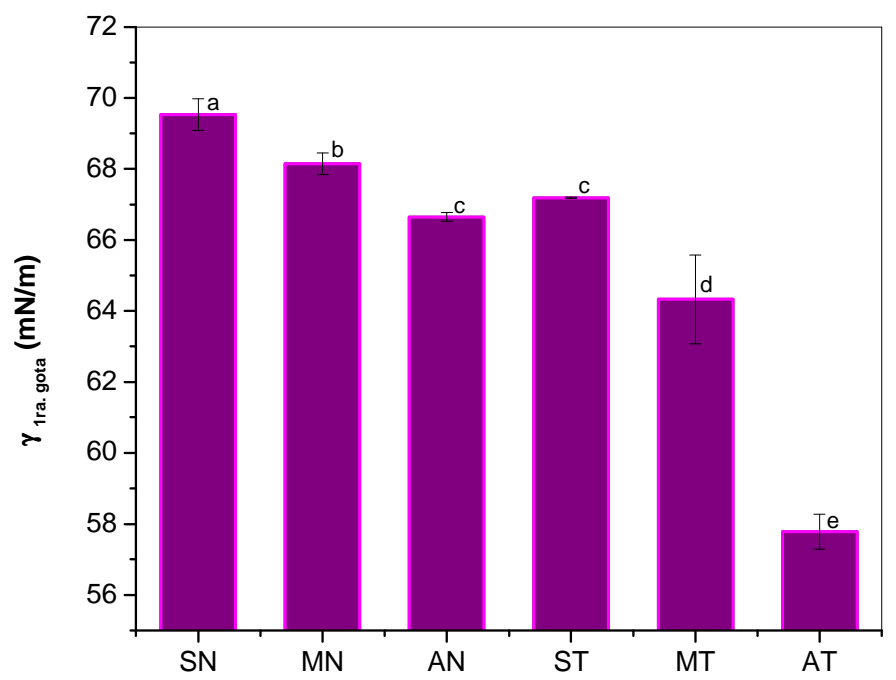

Figura 1.22.: Valor de la tensión superficial en el momento de caída de la primera gota para las distintas muestras. Las barras con letras iguales no son significativamente diferentes $(\alpha=0,05$, Fisher test $)$. 
Es probable que la disminución detectada se deba al menor tamaño de las proteínas pos-tratamiento sea por disociación de subunidades o por la hidrólisis que sufrieron las proteínas de AT y de MT. Todos estos eventos que producen una reducción de los tamaños moleculares tienen como consecuencia un cambio en la movilidad de los polipéptidos lo que les permite difundir más rápidamente en el medio acuoso para alcanzar la interfase (Ward y Tordai 1946; RuízHenestrosa, Sánchez y col. 2009). El tratamiento ácido, al producir un desplegamiento de la estructura proteica pudo haber producido además aumento de la flexibilidad molecular, lo que implicaría un aumento de la velocidad de reordenamiento y reacomodamiento en la interfase que como consecuencia produciría también un aumento en la velocidad de descenso de la tensión interfacial. Xu y Damodaran (1994) estudiando el comportamiento en la interfase de la lisozima nativa y desnaturalizada con urea a $\mathrm{pH}$ 7.0, obtuvieron con la proteína desnaturalizada un aumento crítico en la velocidad y capacidad de descenso de la tensión interfacial debido al desplegamiento de la estructura globular rígida producido por la urea.

Tabla 1.2.: Tensiones superficiales al tiempo infinito de las distintas muestras calculadas a partir de las ordenadas al origen de las rectas de tensión superficial vs. raíz cuadrada del tiempo para las distintas muestras.

\begin{tabular}{rc}
\hline Muestra & $\gamma(\mathbf{m N} / \mathbf{m})$ \\
\hline $\mathrm{SN}^{\mathrm{a}}$ & $52,8 \pm 0,4$ \\
$\mathrm{MN}^{\mathrm{b}}$ & $48,6 \pm 0,1$ \\
$\mathrm{AN}^{\mathrm{b}}$ & $48,9 \pm 0,0$ \\
$\mathrm{ST}^{\mathrm{a}}$ & $52,8 \pm 0,9$ \\
$\mathrm{MT}^{\mathrm{c}}$ & $46,6 \pm 0,2$ \\
$\mathrm{AT}^{\mathrm{c}}$ & $46,2 \pm 0,2$ \\
\hline
\end{tabular}

Los superíndices con letras iguales no son significativamente diferentes $(\alpha=0,05$, Tukey test).

Si de los datos de las curvas de la Figura 1.21. ( $\gamma$ en función de $t$ ) se grafica $\gamma$ en función de $\mathrm{t}^{1 / 2}$, las curvas se linealizan. Haciendo una regresión lineal de los datos linealizados el valor de la ordenada al origen representaría la magnitud de la tensión superficial a tiempo infinito. Los valores de las ordenadas de origen calculadas se muestran en la Tabla 1.2. En el caso de las proteínas de soja, el 
tratamiento ácido no modificó este valor, sin embargo en el caso de la mezcla de aislados como en el caso de las proteínas de amaranto se produjo una disminución luego de ser sometidos al tratamiento ácido. Además, la capacidad tensioactiva de las especies proteicas de amaranto, es mayor que las de las proteínas de soja tanto antes como después del tratamiento. Se destaca que para mezcla de aislados proteicos, los valores de tensión al infinito no son el promedio de los valores obtenidos con soja y amaranto, sino que disminuyen tanto como los de amaranto, por lo que se puede deducir la existencia de un sinergismo entre las dos especies cuando son sometidas al tratamiento ácido. Esto puede deberse a que son sólo las proteínas de amaranto las que llegan a la interfase en este tipo de experimentos por la mayor velocidad adsorción y de reacomodamiento en la misma o que el contacto íntimo de las distintas especies proteicas produce interacciones que permiten que las proteínas presentes en el aislado proteico de soja sean más efectivas en la disminución de la tensión.

\subsubsection{Propiedades espumantes}

Las espumas son dispersiones de gas en matrices líquidas o sólidas (Langevin 2008). Para que las espumas líquidas puedan formarse deben contener agentes tensioactivos en la interfase para disminuir la tensión superficial entre la superficie del líquido y la fase gaseosa. En los alimentos estos agentes tensioactivos suelen ser lípidos (monoglicéridos, diglicéridos, fosfolípidos) o proteínas.

\subsubsection{Velocidad inicial de formación de espuma}

El punto más crítico en la formación de espumas y emulsiones es la reducción rápida de la tensión interfacial del área creada por parte del tensioactivo. Las medidas de la velocidad inicial de formación de espuma para las muestras en estudio se muestran en la Figura 1.23. Ésta evidencia que el tratamiento ácido mejora, en todos los casos, la velocidad de formación de espuma.

Graham y Phillips (1976) demostraron que el factor más importante en la capacidad de formación de espuma de una solución proteica es la velocidad a la cual la proteína puede reducir la tensión interfacial a medida que se va creando mayor superficie debido al batido o al burbujeo. Los resultados de disminución de la tensión superficial (sección 1.2.5.) mostraron que las proteínas del amaranto son más veloces y eficientes en este aspecto, resultados coincidentes con los de velocidad inicial de formación de espumas. En la Figura 1.23. se puede ver que 
los valores de velocidad inicial de formación de espuma para las muestras sin tratar son algo mayores en el caso AN y para las muestras que fueron sometidas al tratamiento ácido, las cuales no presentan diferencias significativas entre ellas.

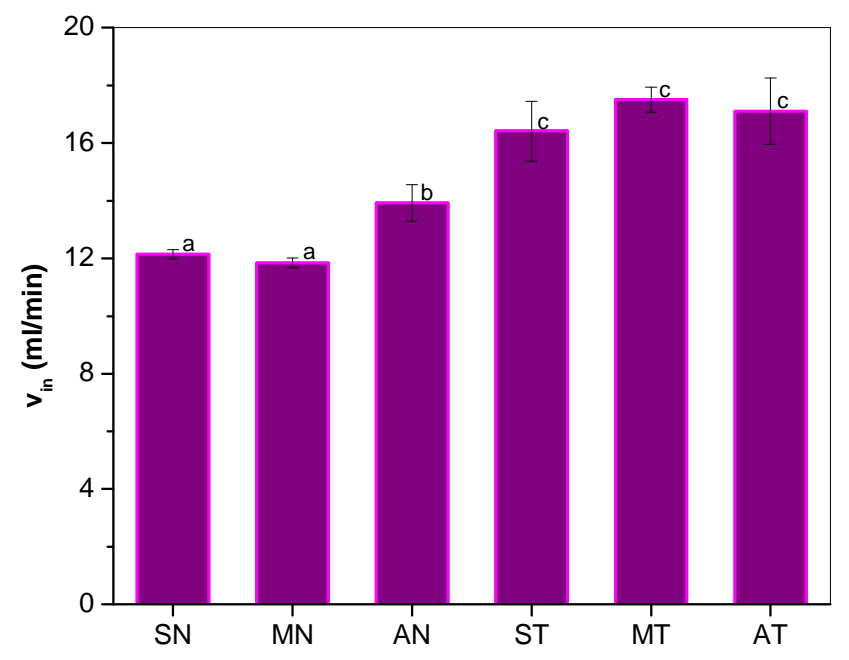

Figura 1.23.: Velocidades iniciales de formación de espumas para las muestras. Las barras con letras iguales no son significativamente diferentes ( $\alpha=0,05$, Fisher test).

Para poder formar espumas la proteína tiene que llegar rápidamente a la interfase para acomodarse y cambiar la conformación (Damodaran 1994), por lo tanto es necesario que se encuentre soluble (Walstra 1989; Yalçin y Çelik 2007). No se pudo observar una correlación entre la velocidad de formación de espuma y la solubilidad de las distintas muestras (Figura 1.24.). Mientras AN y AT presentan menor solubilidad siempre, la velocidad de formación de espumas en los dos casos es igual comparando AT con ST y MT o mayor comparando AN con SN y MN. Esto evidencia que aún en menor cantidad, las proteínas solubles de amaranto tienen una mayor capacidad para formar espumas que las proteínas de soja. 


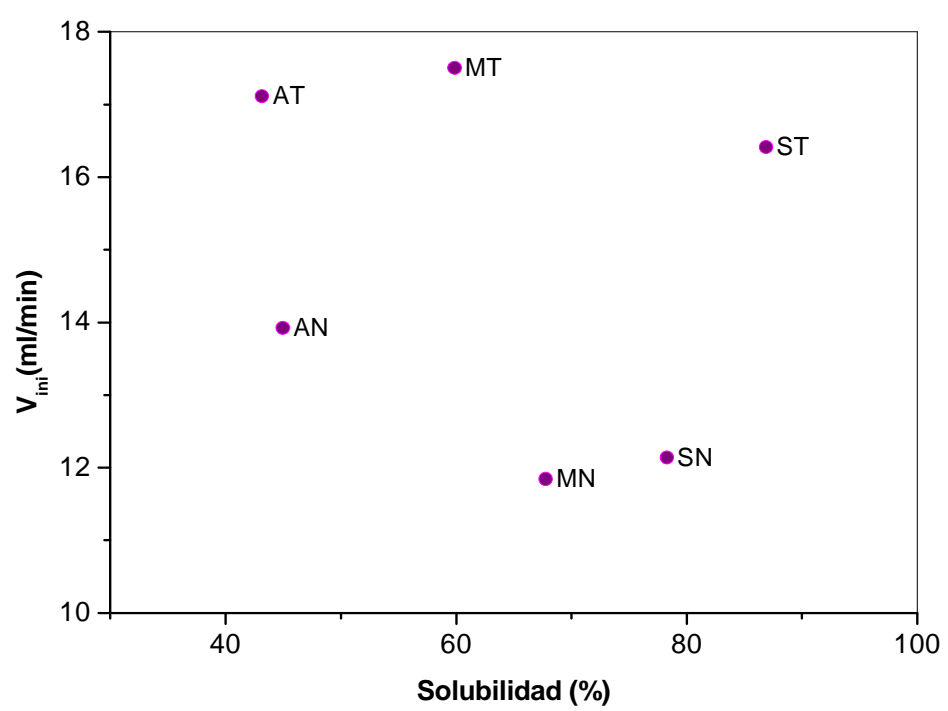

Figura 1.24.: Gráfico de velocidad inicial de formación de espuma en función de la solubilidad.

\subsubsection{Estabilidad de espumas:}

Una proteína va a resultar un buen agente estabilizante de una espuma si sus moléculas son capaces de formar un film viscoelástico en la interface por medio de interacciones intermoleculares (Damodaran 1997).

La Figura 1.25. muestra los resultados obtenidos del tiempo medio de vida de las espumas formadas con las distintas muestras bajo ensayo. En primer término se puede observar que el comportamiento de las muestras después del tratamiento ácido presenta en todos los casos mucha mayor estabilidad. En el caso de las muestras nativas SN tiene la mayor estabilidad y AN la menor de todas. MN mostró un comportamiento intermedio. Sin embargo cuando se compara entre si las muestras tratadas por ácido se destaca el comportamiento que presenta MT. Luego del tratamiento se produjo un efecto sinérgico entre las proteínas de soja y amaranto, que permitió que los tiempos medios no fuesen el resultado de un efecto aditivo entre las especies por separado sino que sean mayores al promedio. Como consecuencia de esto no se observan diferencias significativas entre los valores de estabilidad de las proteínas de ST y de MT que fueron las espumas más estables de todas las evaluadas.

Evidentemente, los cambios que se producen en la estructura nativa de las proteínas por la exposición al pH ácido son favorables para la estabilización de la espuma. Como se demostró en experimentos anteriores (DSC, FPLC, PAGE), las 
proteínas se encuentran con un menor grado de estructuración luego del tratamiento a $\mathrm{pH}$ ácido (sección 1.2.1.2.2.).

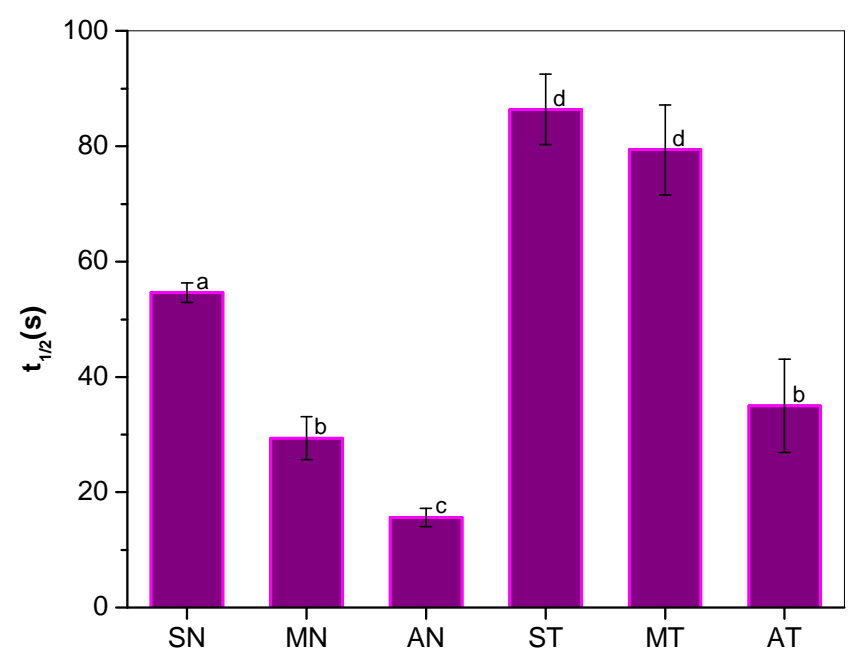

Figura 1.25.: Tiempos de desestabilización del 50\% de la espuma formada para las muestras con y sin tratamiento ácido. Las barras con letras iguales no son significativamente diferentes $(\alpha=0,05$, Fisher test $)$.

Se debe tener en cuenta que la proteína cuando se adsorbe en la interfase tiende a cambiar su conformación para acomodar partes hidrofóbicas e hidrofílicas en las zonas de mayor afinidad. Probablemente en este caso el hecho de que la proteína se encuentre con la estructura más extendida y más flexible permite que los reacomodamientos y que las interacciones entre las moléculas proteicas del film superficial se den con mayor rapidez y facilidad, siendo esta una condición necesaria para la estabilización de una espuma. Hay que recordar que la espuma es un sistema que se desestabiliza a gran velocidad por efectos de la gravedad y de la tensión superficial. Como vimos en la sección 1.2.5. el aumento de complejidad en la estructura proteica, hace más lenta la capacidad que tiene la proteína de actuar como tensioactivo. Xu y Damodaran (1994) mencionan que el cambio de la estructura terciaria de las proteínas es muy importante en el cambio de las propiedades de las espumas, situación que se dio en todas las muestras utilizadas luego de someter a los aislados proteicos al tratamiento ácido.

Los resultados de estabilidad influyen sobre los de velocidad inicial de formación de espuma (sección 1.2.6.1.). Si tenemos en cuenta que a medida que se va formando la espuma simultáneamente se va desestabilizando la que ya está formada, y que además la estabilidad de las espumas de las distintas muestras es menor para espumas realizadas con AT que con ST y MT, se puede concluir que 
la formación de espumas es más rápida cuando se hace a partir de suspensiones de AT. A pesar que AT muestra igual velocidad inicial de formación de espuma, la misma se está desestabilizando más rápido por lo que es necesario formar más espuma para medir, con esta técnica, valores iguales.

\subsubsection{Volumen máximo de líquido incorporado a la espuma}

En la Figura 1.26. se observa que el tratamiento ácido produjo en todos los casos un incremento de los valores obtenidos de incorporación máxima de líquido en la espuma. Teniendo en cuenta que la magnitud de esos volúmenes está influenciada tanto por la velocidad inicial de formación como también por la estabilidad de la espuma a cortos tiempos, los resultados obtenidos concuerdan con los correspondientes a esas otras dos propiedades. El volumen de líquido de la dispersión incorporado a la espuma aumentó luego del tratamiento ácido.

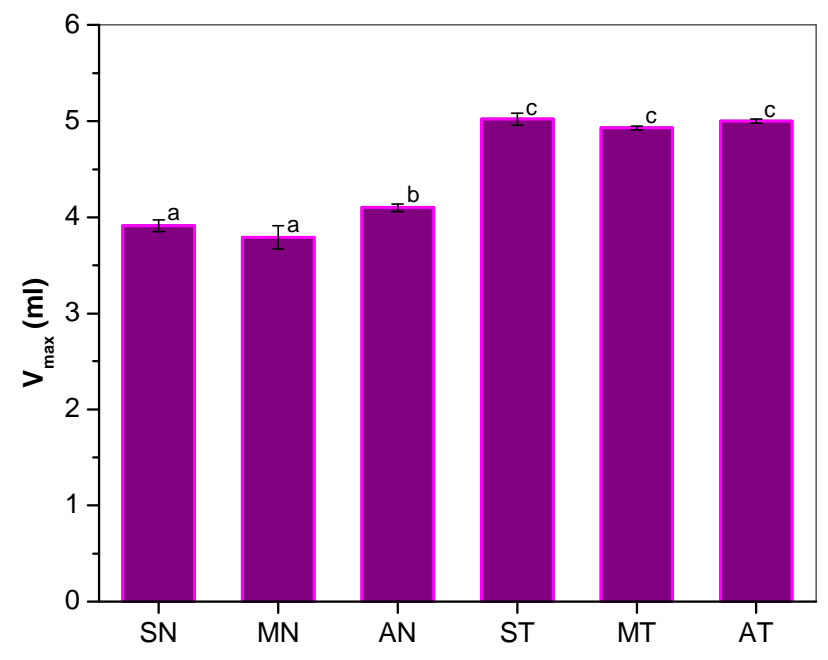

Figura 1.26.: Volúmenes máximos de incorporación de líquido a la espuma para las muestras con y sin tratamiento ácido. Las barras con letras iguales no son significativamente diferentes $(\alpha=0,05$, Fisher test).

La poca estabilidad a largo plazo que tienen las proteínas de amaranto está compensada con la mejor capacidad de formación de espumas que poseen, por esa razón se llegan a volúmenes máximos de líquido incorporado a la espuma significativamente mayores, en el caso de la proteína sin tratar, e iguales con la proteína tratada. Graham y Phillips (1976) relacionaron una buena capacidad espumante con proteínas que posean mayor flexibilidad. Además mencionan que las proteínas globulares altamente ordenadas y de menor flexibilidad tienen mayores dificultades para reordenarse en la interfase lo que resulta en una 
menor capacidad espumante. La exposición al pH ácido desarmó la estructura globular, que no se recuperó luego de llevar el pH nuevamente a un valor cercano a la neutralidad permitiendo mejorar la capacidad para formar espumas.

\subsubsection{Emulsiones}

\subsubsection{Distribución de tamaño de gota y $D_{3,2}$}

Las distribuciones de tamaño de gota expresadas en porcentaje de volumen (Figura 1.27.) muestran que las emulsiones correspondientes a SN y ST presentaron valores pequeños de tamaño de partícula para las condiciones de homogenización establecidas. Los valores más altos de tamaño de gota correspondieron a emulsiones en las que se utilizó AN como agente emulsionante. Cuando las emulsiones se formularon con AT la distribución se corre a la izquierda, hacia menores valores de diámetro de partícula. El mismo corrimiento a la izquierda se produjo con las emulsiones correspondientes a la mezcla de aislados proteicos. Las emulsiones con MT presentan una distribución de tamaño de partícula similar a las distribuciones correspondientes a las emulsiones de soja. El efecto del tratamiento fue favorable para la disminución de los diámetros de las poblaciones de gotas de las emulsiones en los casos de AT y de MT. Todas las distribuciones poseen dos poblaciones diferentes de partículas identificadas por la existencia de dos picos o, en algunos casos, hombros en las curvas de distribución, situación que se puede deber a - una la concentración insuficiente de agente emulsionante durante la homogenización lo que impide que se produzca un descenso mayor en los valores de los diámetros de una gran parte de la población de gotas (McClements 2005), o - al método empleado en la homogenización (Palazolo 2006). Igualmente en todos los casos, la población con mayor importancia en el volumen de aceite emulsionado correspondió a los valores de gota menores. Los valores para el aislado proteico de soja sin tratamiento son similares a los obtenidos por Palazolo, Mitidieri y col. (2003) en condiciones de emulsificación similares. 


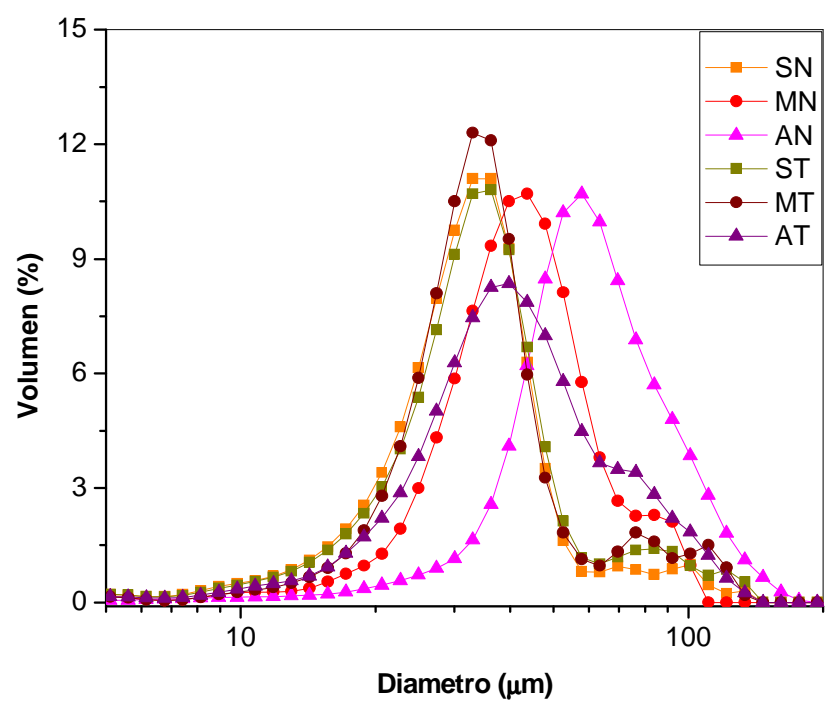

Figura 1.27:: Distribuciones de tamaño de gota en porcentaje de volumen para las emulsiones de las muestras con y sin tratamiento ácido.

Los valores de los $D_{3,2}$ medio de las emulsiones están representados en la Figura 1.28. Los menores valores de $\mathrm{D}_{3,2}$ medio los presentaron las emulsiones correspondientes a SN y ST. Se puede ver también que los valores de $\mathrm{D}_{3,2}$ de las emulsiones de amaranto y la mezcla de aislados disminuyen significativamente luego del tratamiento ácido. En el caso de las emulsiones de MT el $\mathrm{D}_{3,2}$ medio no presentó diferencias significativas a los correspondientes a ST o SN (Fisher $\alpha=0,05)$. Las emulsiones preparadas con AT mostraron valores de $\mathrm{D}_{3,2}$ medio significativamente menores a los de AN.

Los resultados del tamaño de gota muestran que las proteínas de soja son más eficientes que las de amaranto para crear área en la interfase aceite/agua a diferencia de lo que ocurría en la interfase aire/agua. El tratamiento ácido produce incrementos en la eficiencia de creación de área interfacial en el caso de las proteínas de amaranto, y de la mezcla de aislados proteicos. El tratamiento ácido al desestabilizar la estructura empaquetada de las proteínas y producir cierta hidrólisis, pudo haber permitido que las moléculas proteicas cubran mayores porciones de área interfacial para dar lugar a la formación y estabilización de gotas. También se puede observar que la presencia de proteínas de soja mejora notablemente la capacidad emulsionante de las proteínas de amaranto especialmente luego del tratamiento. Resultados similares pueden verse en las microscopías correspondientes al tiempo inicial incluídas en la sección 1.2.7.3. 


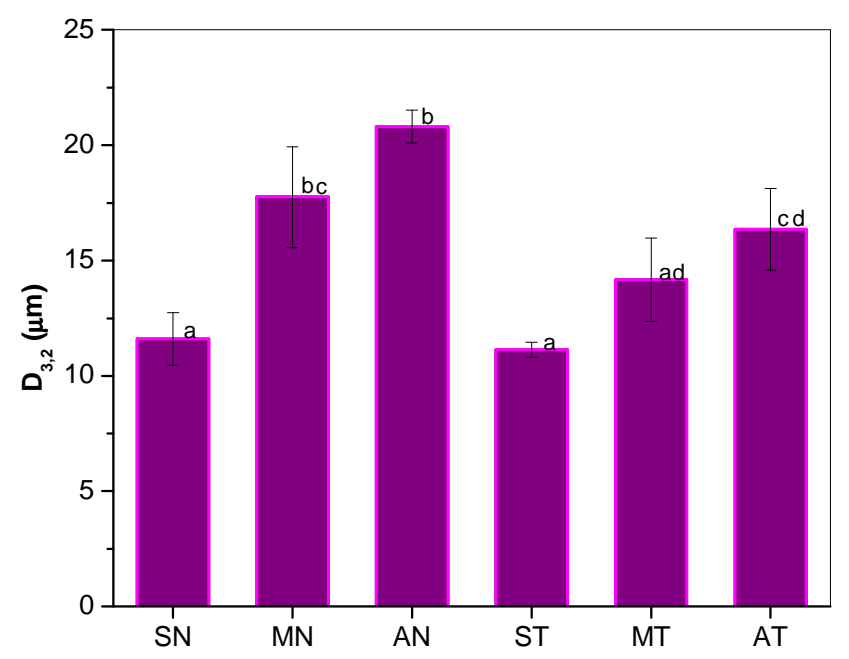

Figura 1.28.: Valores de $\mathrm{D}_{3,2}$ promedio de las gotas de aceite en las emulsiones de las distintas muestras con y sin tratamiento ácido. Las barras con letras iguales no son significativamente diferentes $(\alpha=0,05$, Fisher test).

\subsubsection{Estabilidad de emulsiones}

La estabilidad de las emulsiones fue analizada utilizando el equipo QuickScan descripto en la sección 1.1.13.1.

En la Figura 1.29. se muestra como ejemplo una de las réplicas de las corridas del QuickScan para las muestras nativas.

La Figura 1.30. muestra las cinéticas de \% BS medio de las emulsiones de las distintas muestras en la parte inferior del tubo de emulsión (10-15 mm). En ella se puede ver que las emulsiones de muestras que fueron sometidas al tratamiento ácido retardan la disminución del \% BS respecto a las que no fueron tratadas. Las disminuciones de \%BS se producen por una disminución del número de gotas en la parte baja del tubo debido a la migración de gotas hacia la parte superior producida por la diferencia de densidad de las mismas respecto a la fase acuosa. En algunos casos es más acusado y más veloz el proceso de cremado. Esas diferencias se deben al hecho de que las velocidades de migración de las gotas varían según el tamaño de las mismas como lo expresa la ley de Stokes (sección III.IV.I.). 
(a)
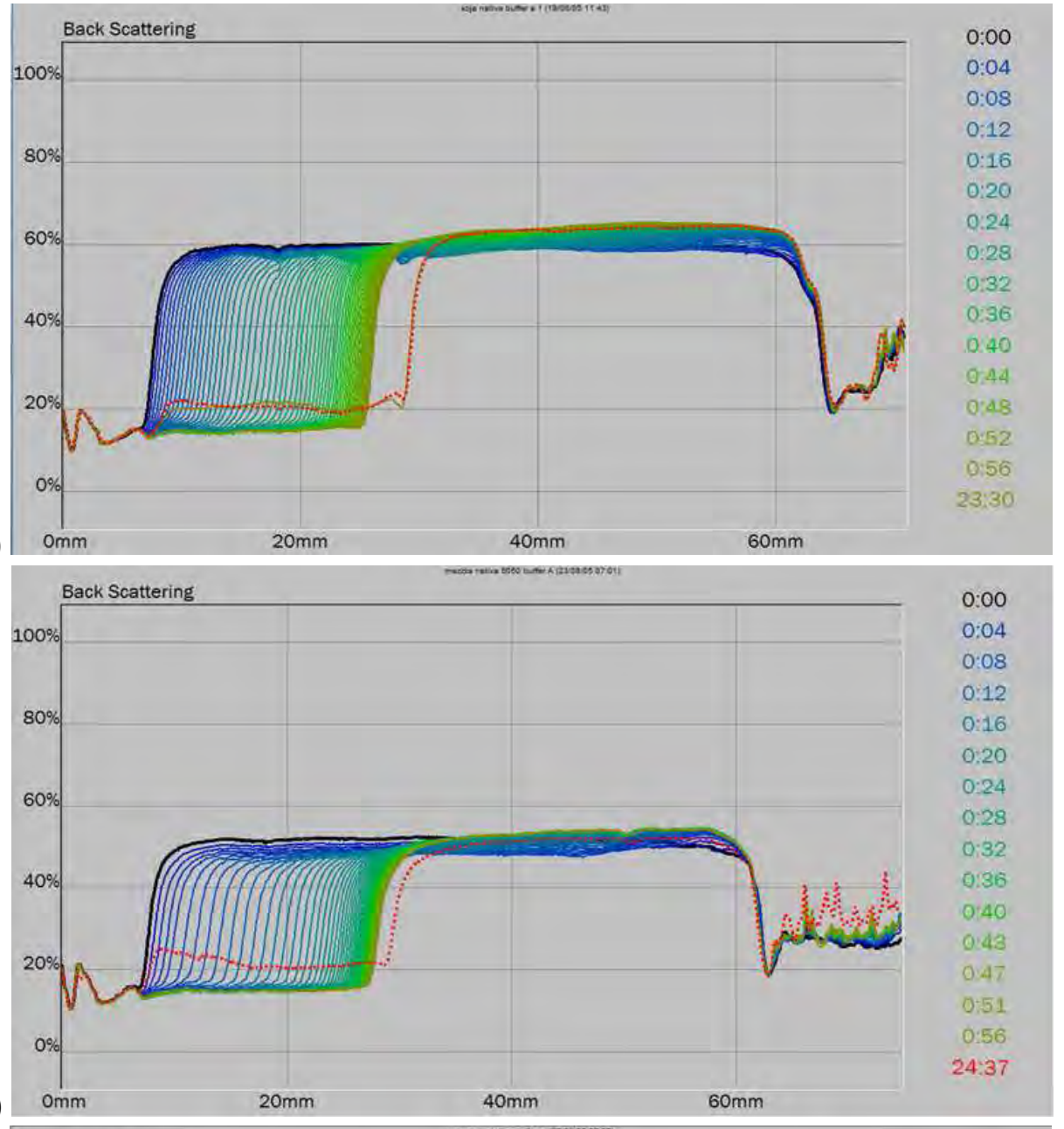

(b)

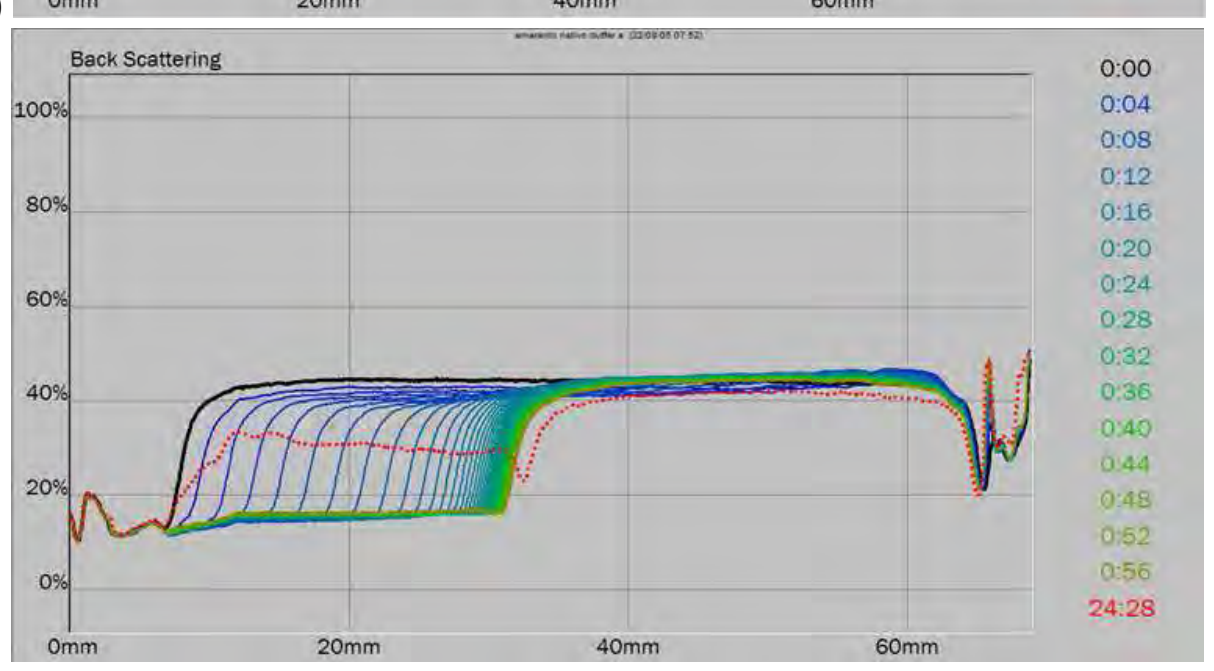

Figura 1.29.: Perfiles de QuickScan de una de las réplicas de las emulsiones de las distintas muestras sin tratamiento ácido. (a) SN, (b) MN, (c) AN. 
Estos resultados coinciden en su comportamiento con las distribuciones de tamaño de gota de la Figura 1.27. ya que las emulsiones que mostraron menores diámetros en las poblaciones de gotas fueron las que tardaron más en cremar. La forma sigmoidea que presentan las curvas se debe al lugar en donde se toma la medida. El período inicial en el que la curva se presenta estable porque no descienden los valores de \%BS medios, se debe a que el frente de cremado todavía no pasó por la zona de medida y una vez que comienza a pasar comienza a descender dicho valor. Este tiempo tiene que ver con la velocidad a la que ascienden la mayoría de las gotas, por lo tanto cuanto mayor es su valor, mayor es su estabilidad frente al cremado.

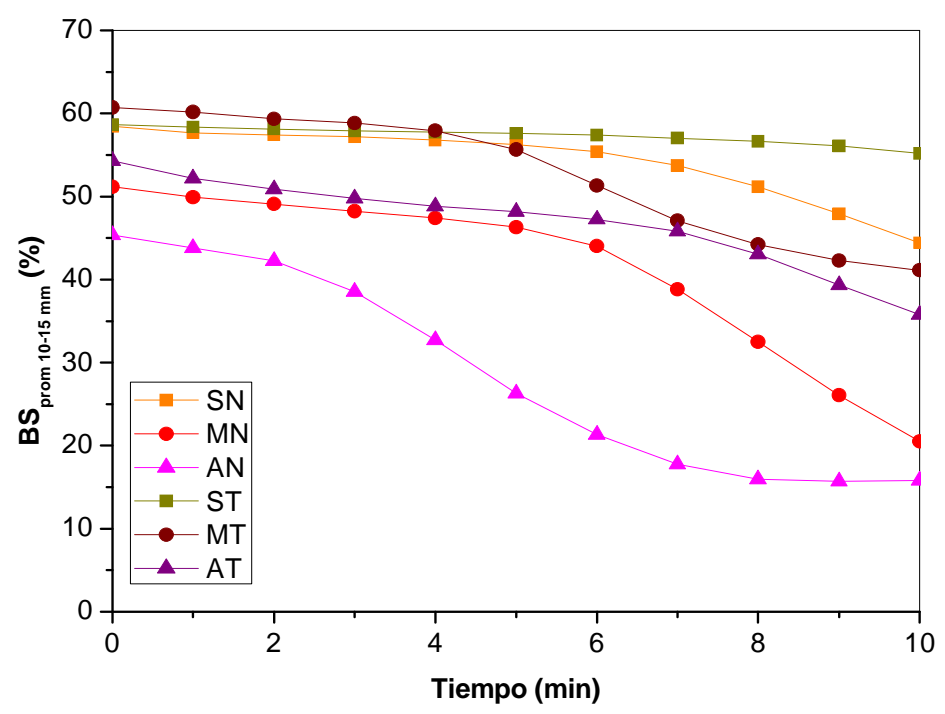

Figura 1.30.: Cinéticas de valores medios de \%BS en la parte baja de la celda de medida (10$15 \mathrm{~mm}$ de altura) obtenidas a partir de las curvas obtenidas con el QuickScan.

A partir de las cinéticas de movimiento de partículas obtenidas con el QuickScan se pueden calcular diferentes constantes que representan el comportamiento de las emulsiones frente a los distintos modos de desestabilización (descriptos en la sección 1.1.13.2.).

De las cinéticas de la parte inferior de la celda de medida $(10-15 \mathrm{~mm})$ se puede obtener la constante $\mathrm{K}_{0,1}$ que da una idea de la velocidad de clarificación de la parte inferior de la emulsión debido al cremado que se produce por la acción de la gravedad sobre las gotas de la emulsión. Los valores de las $\mathrm{K}_{0,1}$ calculados a partir de las emulsiones de las distintas muestras están representados en la Figura 1.31. Las emulsiones que presentaron un valor menor de $\mathrm{K}_{0,1}$ fueron aquellas formuladas con SN, ST, MN y MT seguidas por AT y finalmente AN. El 
tratamiento ácido de los aislados disminuye $\mathrm{K}_{0,1}$ significativamente solo en el caso de las emulsiones de amaranto, mientras que en las emulsiones de las otras muestras no se observaron diferencias significativas antes y después del tratamiento. Los resultados coinciden con la distribución de tamaño de gota (Figura 1.27.) ya que las muestras que presentaban emulsiones con mayor tamaño de gota son las que presentaron una $\mathrm{K}_{0,1}$ mayor, por lo tanto las que creman a mayor velocidad.

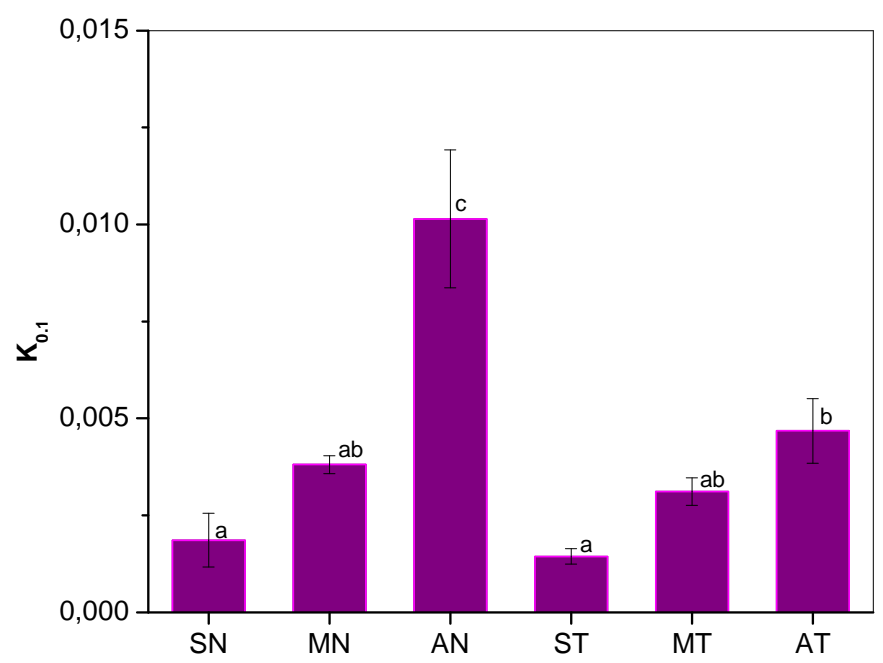

Figura 1.31.: Valores de la constante $\mathrm{K}_{0,1}$ de las emulsiones de las distintas muestras. Las barras con letras iguales no son significativamente diferentes $(\alpha=0,05$, Tukey test).

A partir de las curvas obtenidas con el QuickScan también se calcularon las cinéticas de \%BS medio en la parte superior del tubo (40-50 mm). Esas cinéticas están representadas en la Figura 1.32. En ella se puede observar el comportamiento del \%BS medio de la fase crema con el tiempo, ya que la crema se va acumulando en la parte alta del tubo por la acción de la gravedad. Observando los valores de \%BS medio en esta zona, se puede seguir el proceso de acumulación de gotas que favorece la coalescencia debido a que la distancia entre gotas es menor y que su empaquetamiento es más compacto. La coalescencia de las gotas se detecta como un descenso del \%BS medio por la disminución de la población de gotas y el aumento del tamaño de las mismas, ambos fenómenos contribuyen al descenso del back scattering en emulsiones con tamaños de gota mayores a $0,5 \mu \mathrm{m}$. 
En la Figura 1.32. se observa que las emulsiones preparadas con AT y MT presentan \%BS de la crema mayores a lo largo de toda la curva que sus correspondientes muestras nativas AN y $\mathrm{MN}$ respectivamente. Este comportamiento se relaciona con el hecho de que la cantidad de gotas es mayor para las emulsiones preparadas con las muestras AT y MT comparadas con las emulsiones preparadas con las AN y MN. SN y ST muestran valores similares entre sí. Las emulsiones de MT presentan valores de \%BS mayores que cualquiera de las otras muestras. En las cinéticas se detecta un descenso inicial de \%BS medio y un posterior aumento del mismo. El descenso inicial se debe al hecho que durante los primeros minutos de la vida en la emulsión se producen coalescencia y floculación con una gran intesidad que luego disminuye. Esto ocurre porque al inicio las gotas tienen zonas superficiales sin proteína dado que no transcurrió un tiempo suficiente para que las moléculas proteicas cubran toda la gota. Ese descenso en el número de gotas (coalescencia) o de gotas individuales (floculación) produce una disminución del \%BS medio. Por el contrario, el aumento posterior del \%BS medio, se debe a la acumulación de gotas en la parte superior del tubo como consecuencia del cremado.

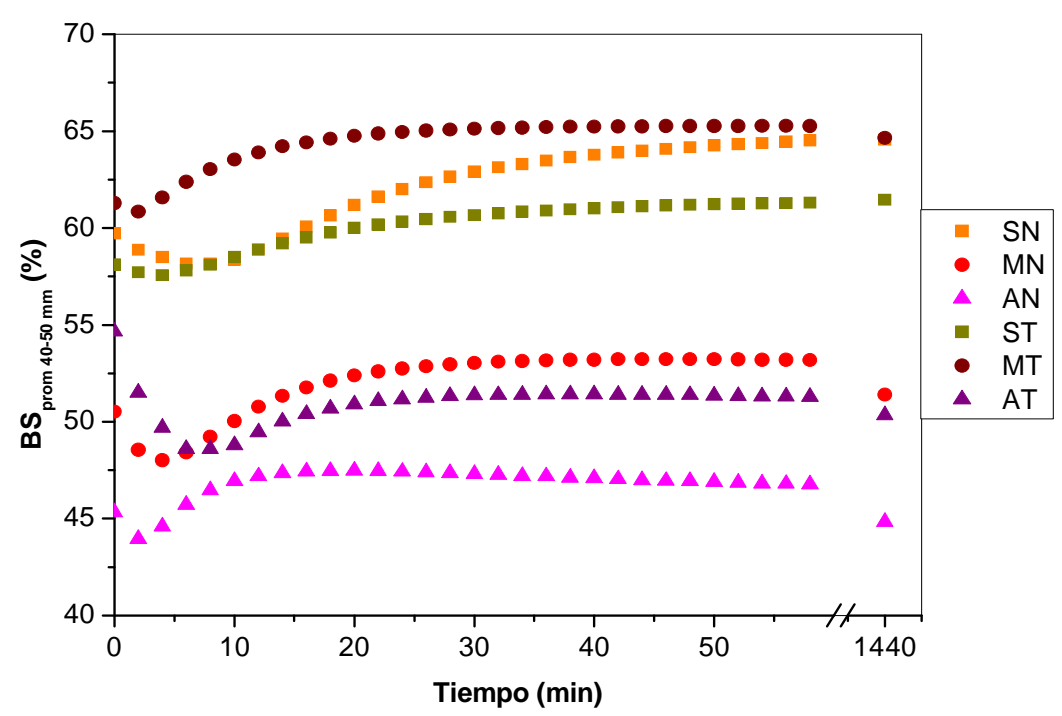

Figura 1.32.: Cinéticas de valores medios de \%BS en la parte superior de la celda de medida (40-50 mm de altura) obtenidas a partir de las curvas del QuickScan de las emulsiones de las distintas muestras.

En la Figura 1.33. se muestra una relación del \%BS inicial con los $\mathrm{D}_{3,2}$ iniciales de las distintas emulsiones. Se puede ver claramente que cuando los valores \%BS iniciales son mayores el tamaño de gota promedio es menor. Esto es observable 
en emulsiones con tamaños de gota del orden de las de estos ensayos, de alrededor de $10 \mu \mathrm{m}$, el \%BS máximo se produce en partículas de alrededor de 0,5 um (Mengual, Meunier y col. 1999), cuando son muy pequeñas (50 nm) las emulsiones se vuelven transparentes por no poder difractar la luz (Schramm 2005). El coeficiente de correlación $\mathrm{r}$ es de $-0,83$. Una tendencia similar fue obtenida por Palazolo, Sorgentini y col. (2005).

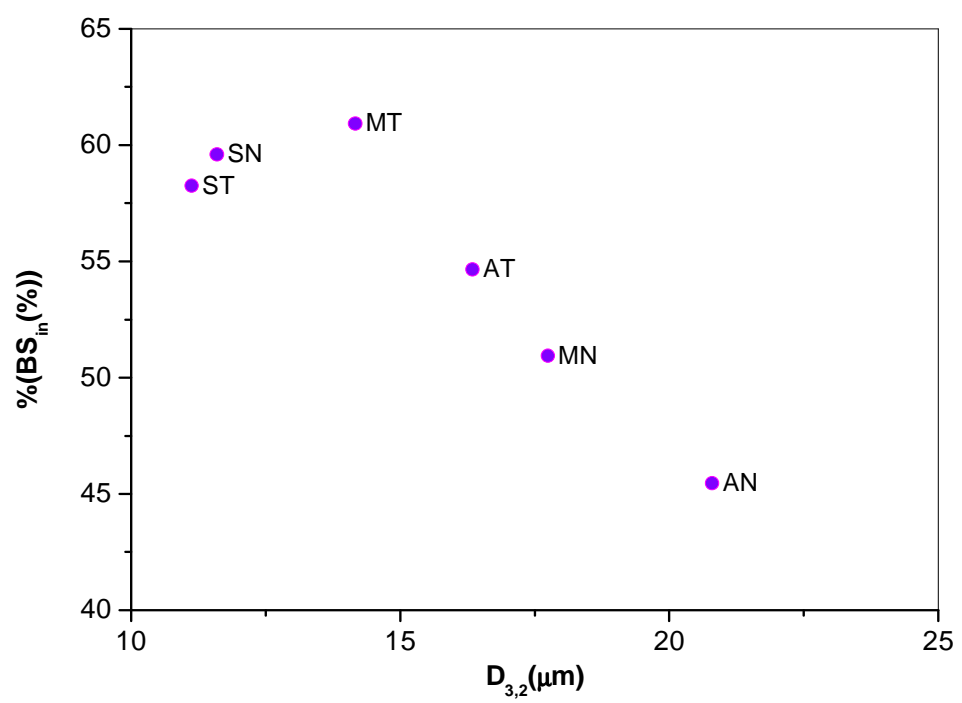

Figura 1.33.: Correlación existente entre los valores de D3,2 con el \%BS inicial.

A partir de las cinéticas de la Figura 1.32. se calculó el porcentaje de desestabilización de la crema como se explicó en la sección 1.1.13.2. En la Figura 1.34. se muestran los valores de la desestabilización de la crema de las diferentes muestras. En el gráfico pueden observarse los efectos variables que produjo el tratamiento en las muestras. En las emulsiones de SN y ST no hay diferencias significativas ( $\alpha=0,05$, Tukey). En el caso de la mezcla de aislados el tratamiento ácido disminuye significativamente la desestabilización de la crema hasta minimizarla como ocurre en las muestras más estables (SN y ST). En cambio las emulsiones preparadas con AN y AT no presentaron diferencias significativas habiendo sido estas emulsiones las que presentaron mayor desestabilización de la crema. Sin embargo hay que tener en cuenta que las emulsiones de AT parten de tamaños de gota menores y \%BS mayores y que a las $24 \mathrm{~h}$ muestran \%BS mayores que los que muestran las emulsiones de AN. La desestabilización relativa se mantuvo igual, pero en presencia de AT se generó una mayor área interfacial que en el caso de AN. Quizás utilizando mayores concentraciones de 
proteína en ambos casos, tanto el \%BS como la desestabilización relativa de la crema sean menores para el caso de AT.

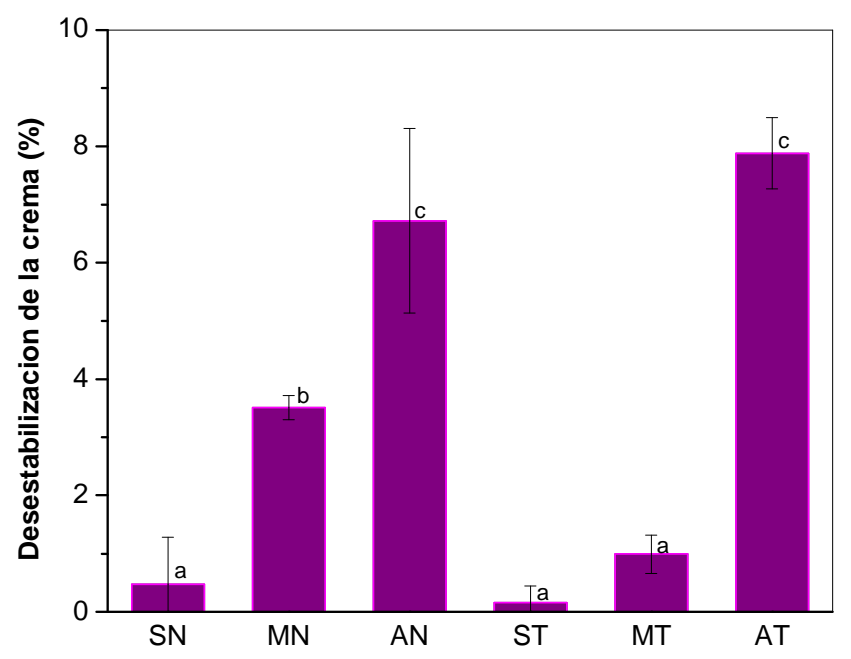

Figura 1.34.: Valores de desestabilización de la fase crema de las emulsiones de las distintas muestras. Las barras con letras iguales no son significativamente diferentes $(\alpha=0,05$, Tukey test).

En la Figura 1.35. se puede observar el porcentaje que ocupa la fase crema o emulsión concentrada a las 3 y $24 \mathrm{~h}$ de almacenamiento estacionario de la emulsión respecto del total de la celda de medida. El resto de la celda está ocupado por la fase clara que puede ser la fase continua de la emulsión, en este caso buffer $\mathrm{A}$, o a una emulsión muy diluida que prácticamente no contuviera gotas de aceite dispersas. Se puede observar que luego del tratamiento ácido aumenta el porcentaje de la fase crema lo que demuestra una mayor estabilidad con respecto a la desestabilización por cremado. Además se puede ver que los valores a las $3 \mathrm{~h}$ y $24 \mathrm{~h}$ son similares, por lo tanto la mayor aparición de fase límpida ocurre en las primeras horas de almacenamiento de la emulsión. Probablemente el tratamiento ácido al desplegar y hacer más flexibles las proteínas permite, luego de la adsorción en la interfase, la aparición de regiones que producen impedimento estérico por la formación o presencia de bucles o colas que penetran más en la fase acuosa y permiten que las gotas se mantengan más separadas y por lo tanto que el empaquetamiento sea menos compacto, en definitiva que la fase crema ocupe más volumen. Hay que tener en cuenta que las moléculas más flexibles tienen regiones de penetración relativamente grandes, en cambio las proteínas con una estructura globular más compacta tendrán regiones más pequeñas (McClements 2005). Esta misma situación, cuando hay suficiente 
agente emulsificante, puede resultar en lo que se llama repulsión estérica, que ayudaría a evitar la coalescencia al impedir que los films interfaciales entren en contacto. Cuando la concentración de emulsificante es escasa, el mismo fenómeno puede producir floculación por puenteo, aumentando la probabilidad de que dos interfases interaccionen y puedan coalescer (Nguyen y Schulze 2004).

(a)

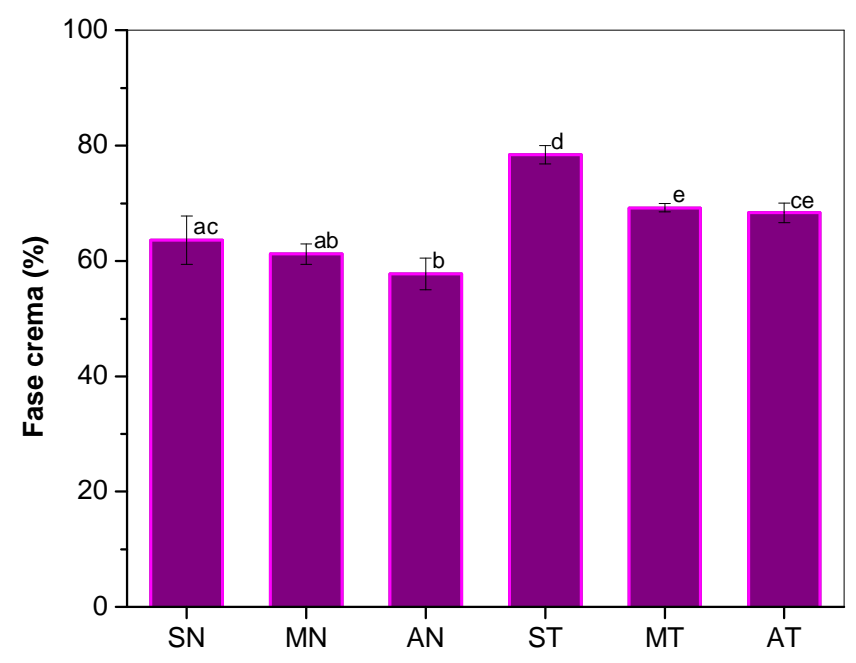

(b)

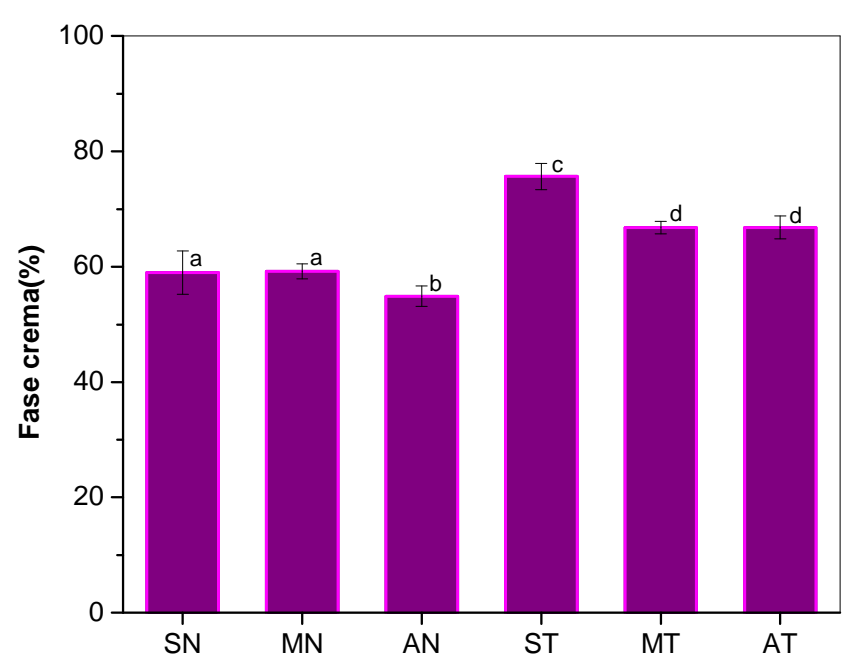

Figura 1.35.: Porcentajes de fase crema ((a) $3 \mathrm{~h}$, (b) $24 \mathrm{~h}$ de almacenamiento estacionario .de las emulsiones de las distintas muestras. Las barras con letras iguales no son significativamente diferentes $(\alpha=0,05$, Fisher test). 


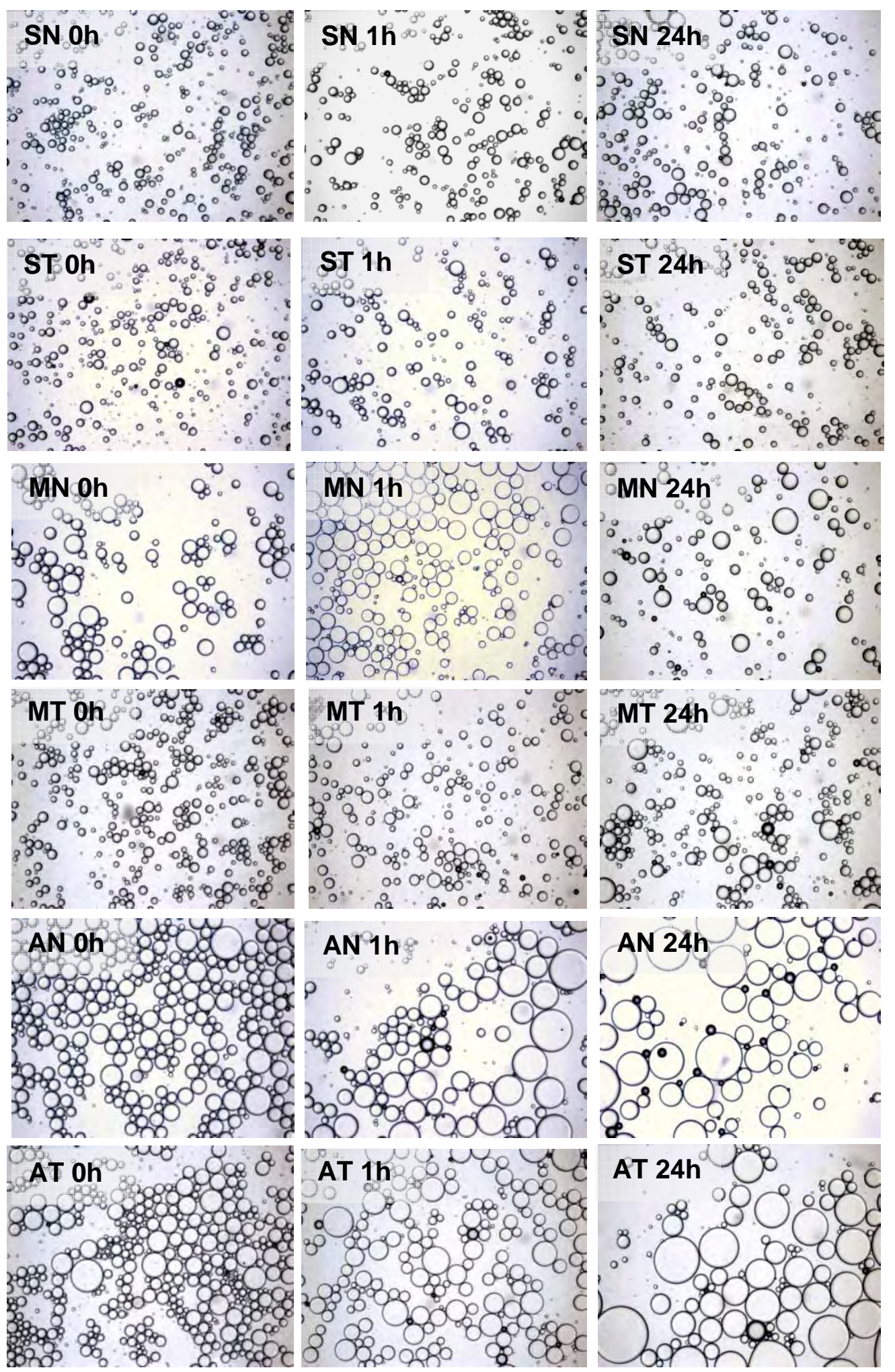

Figura 1.36.: Microscopías ópticas 100X de las distintas emulsiones a distintos tiempos de maduración de la emulsión ( $0 \mathrm{~h}, 1 \mathrm{~h}$ y $24 \mathrm{~h}$ de almacenamiento estacionario). $1 \mathrm{~cm}$ en la foto equivale a $285 \mu \mathrm{m}$. 


\subsubsection{Microscopía de las emulsiones}

Las siguientes fotos obtenidas por microscopía óptica (Figura 1.36.) muestran las gotas de las distintas emulsiones en distintos tiempos de su vida. En ellas se puede observar que el tratamiento ácido influyó más en el caso de de la mezcla de aislados proteicos tanto en la formación de gotas como en la estabilidad de las mismas cambiando notablemente los tamaños de las gotas y su estabilidad en el tiempo. Se puede destacar la mayor capacidad de las proteínas de soja para formar emulsiones estables antes y después del tratamiento ácido. Las emulsiones preparadas con aislado proteico de amaranto fueron las que presentaron tamaños de gota mayores al inicio y resultaron las más inestables en el tiempo.

\subsection{Conclusiones}

El tratamiento ácido provocó la disociación y una desnaturalización parcial de las especies proteicas presentes en el aislado proteico de soja, siendo más susceptible la fracción $11 S$ que la $7 \mathrm{~S}$ a la desnaturalización por ácido. El tratamiento ácido produjo disociación y la desnaturalización parcial o total de las proteínas presentes en los aislados de soja y amaranto. Durante el tratamiento ácido se activaron además proteasas aspárticas presentes en el aislado de amaranto que provocaron la hidrólisis de algunos polipéptidos para dar especies de menor tamaño molecular. En la mezcla de aislados proteicos cuando se realizó el tratamiento ácido, las proteasas aspárticas actuaron también sobre algunas de las proteínas de soja.

La solubilidad en el buffer utilizado de las especies proteicas presentes en las diferentes muestras no varió significativamente luego del tratamiento ácido.

El tratamiento ácido mejoró las capacidades tensioactivas de las proteínas, especialmente en el caso de MT y de AT logrando mayores descensos de la $\gamma$ en menor tiempo. Esto se vio reflejado en mayores velocidades iniciales de formación de espuma para el caso de las especies tratadas respecto a las que no fueron sometidas al tratamiento ácido.

La mejora de la actividad superficial debida al tratamiento ácido también resultó en una mayor incorporación de volumen de líquido a la espuma. 
La estabilidad de las espumas formuladas con las especies tratadas fue mejor en todos los casos que las correspondientes a las proteínas sin tratar. SN mostró espumas más estables que MN y AN. ST mostró espumas mucho más estables que AT, sin embargo MT mostró un comportamiento interesante ya que no disminuyó significativamente la estabilidad de la espuma en comparación con la espuma preparada con ST, pero si aumentó de manera contundente la estabilidad de la espuma si es comparada con la espuma de AT. MT produjo espumas con una estabilidad mayor que el promedio de las correspondientes a ST y AT. Esto puede deberse a la hidrólisis parcial que ocurre sobre las proteínas de ambas especies cuando son sometidas al tratamiento ácido, que aumentaría sustancialmente la estabilidad de las espumas o la interacción entre ellas de manera que la favorezca.

En cuanto a las emulsiones, las muestras sin tratar produjeron emulsiones con mayores valores de tamaño de gota que sus correspondientes sometidas a tratamiento ácido, excepto para las proteínas de soja con las que se obtuvieron resultados estadísticamente iguales. En todas las condiciones ensayadas las emulsiones formuladas con proteínas de soja presentaron distribuciones de tamaño de gota con diámetros menores que las formuladas con proteínas de amaranto. Como se puede deducir de la ley de Stokes esto se reflejó en el comportamiento de las emulsiones respecto al cremado ya que las emulsiones de especies tratadas en medio ácido tardaron más en cremar que las no tratadas. En cuanto a la estabilidad de las emulsiones el tratamiento ácido produjo mejoras importantes de la misma en el caso de MT. En las emulsiones, al igual que en las espumas, se observó un efecto beneficioso para la estabilidad de la emulsión cuando las proteínas de soja y amaranto fueron sometidas al tratamiento ácido en forma conjunta. La estabilidad de las emulsiones de MT fue mayor que el promedio de la estabilidad entre las emulsiones de ST y AT. En emulsiones de preparadas con proteínas de soja el tratamiento no produjo efectos significativos mientras que las preparadas con AN son menos estables, al menos en las concentraciones de proteína y de aceite que se utilizaron para los ensayos.

Los cambios que se produjeron en las espumas y las emulsiones luego del tratamiento ácido se pueden atribuir a las mismas causas indicadas previamente, mayor flexibilidad molecular por la disociación y desplegamiento de los polipéptidos que componen las muestras, además de la hidrólisis que se produjo en los casos de AT y MT.

El tratamiento ácido produjo cambios favorables en la función espumante y emulsificante de los aislados proteicos de soja y amaranto siendo especialmente 
efectivo en la formación y estabilización de espumas y emulsiones formuladas con mezclas de aislados. El tratamiento ácido de los aislados proteicos de amaranto y soja complementados sería una alternativa válida en la mejora de las propiedades funcionales de superficie de los aislados proteicos de amaranto a efectos de ser utilizados como ingredientes en la formulación de alimentos. 
Capítulo 1: Tratamiento ácido de aislados de soja y amaranto 



\section{Capítulo 2 \\ Hidrólisis enzimática de aislados proteicos de amaranto}

\subsection{Materiales y Métodos}

\subsubsection{Preparación de harina y aislado de amaranto}

La harina y el aislado de amaranto (AI), amaranthus hypochondriacus, se prepararon de la manera descripta en la sección 1.1.1.

\subsubsection{Caracterización química de los aislados}

Se realizó de la misma manera que la detallada en la sección 1.1.2.

Los resultados obtenidos, expresados en porcentaje $\mathrm{p} / \mathrm{p}$ fueron:

- cenizas: $2,44 \% \pm 0,32 \%$

- proteínas: $78,9 \% \pm 0,1 \%$ (base seca)

- humedad: $3,91 \% \pm 0,08 \%$ 


\subsubsection{Hidrólisis del AI y medida del grado de hidrólisis}

Las distintas muestras se prepararon por hidrólisis enzimática del aislado proteico de amaranto con alcalasa (proteasa de B. Licheniformis; cat\# P4860; Sigma Chemicals, EE.UU) en una concentración de $0,8 \mu \mathrm{L}$ de enzima por cada gramo de aislado, o con tripsina (10600 BAEE unidades / mg sólido; Sigma Chemicals, EE.UU) en una concentración de $10 \mathrm{mg}$ de enzima por gramo de aislado. El AI se dispersó en buffer fosfato, $\mathrm{pH} 7,8$; fuerza iónica $0,1 \mathrm{M}$, en una concentración de $10 \mathrm{mg} / \mathrm{ml}$ y se agitó durante $1 \mathrm{~h}$ a $37^{\circ} \mathrm{C}$; luego se agregó la enzima. La hidrólisis se llevo a cabo durante $20 \mathrm{~min}$ con tripsina y durante 20 y $240 \mathrm{~min}$ con alcalasa. La reacción de hidrólisis se detuvo por calentamiento en un baño de agua a $85^{\circ} \mathrm{C}$ durante $10 \mathrm{~min}$. Transcurrido ese tiempo la suspensión se enfrió en un baño de hielo, se la congeló y liofilizó. Luego de liofilizada se la almacenó a $4{ }^{\circ} \mathrm{C}$ hasta su utilización.

El grado de hidrólisis (\%GH) alcanzado se determinó utilizó el método del ácido trinitrobencenosulfónico (TNBS) (Adler-Nissen 1979) que reacciona con los grupos amino libres pudiéndose cuantificar colorimétricamente.

El aislado proteico hidrolizado con tripsina mostró un \%GH de 2,2 (TH2.2), mientras que los aislados hidrolizados con alcalasa mostraron un \%GH de 1,7 (AH1.7) y 9,5 (AH9.5) para 20 min y 240 min de hidrólisis respectivamente.

La caracterización química de los hidrolizados (TH2.2, AH1.7 y AH9.5) mostró un valor de cenizas de $28,2 \% \pm 0,1 \%$ en todas las muestras hidrolizadas. Este valor es superior al obtenido con AI debido a las cenizas que aportan el buffer utilizado para suspender el aislado antes de llevar a cabo la hidrólisis.

\subsubsection{Soluciones buffer utilizadas}

En las distintas experiencias se utilizaron las siguientes soluciones buffer. Buffer pH 2,0: $\mathrm{H}_{3} \mathrm{PO}_{4}$ 0,0183 M; Na H $\mathrm{PO}_{4}$ 0,0166 M; NaCl 0,0304 M; $\mu$ 0,05. Buffer pH 4,0: $\mathrm{HCH}_{2} \mathrm{COOH}$ 0,0288 M; $\mathrm{HCH}_{2} \mathrm{COONa} 0,0061 \mathrm{M} ; \mathrm{NaCl} 0,0409 \mathrm{M} ; \mu$ 0,05 .

Buffer pH 6,3: $\mathrm{NaH}_{2} \mathrm{PO}_{4}$ 0,0286 M; $\mathrm{Na}_{2} \mathrm{HPO}_{4}$ 0,0063 M; $\mu$ 0,05. Buffer pH 8,0: Tris $\mathrm{HCl} \mathrm{0,023} \mathrm{M;} \mathrm{Tris} \mathrm{base} \mathrm{0,0119} \mathrm{M;} \mathrm{NaCl}$ 0,024 M; $\mu$ 0,05. A todas las soluciones se les agregó azida de Na en una concentración de 0,015\% para evitar la proliferación microbiana. 


\subsubsection{Solubilidad}

Se realizaron medidas de solubilidad en las soluciones buffer de diferente $\mathrm{pH}$ $(2,0 ; 4,0 ; 6,3$ y 8,0$)$. Se suspendieron las muestras de manera que la concentración de proteína fuese de $1 \mathrm{mg} / \mathrm{ml}$ y se procedió de igual forma que en la sección 1.1.5.

\subsubsection{Cromatografía rápida de proteínas en medio líquido (FPLC)}

Las cromatografías FPLC se realizaron de la manera explicada en la sección 1.1.8.3. pero utilizando buffers de $\mathrm{pH} 2,0 ; 6,3$ y 8,0 para la solubilización y elución de las proteínas en la corrida cromatográfica.

\subsubsection{Electroforesis}

Se realizaron SDS-PAGE de todas las muestras en condiciones reductoras (sección 1.1.6.).

\subsubsection{Curvas de tensión superficial en la balanza de} Langmuir

La balanza de Langmuir es una adaptación de la lámina o placa de Wilhelmy y permite medir la tensión superficial en la interfase aire/agua que va a depender de la presencia de moléculas o partículas tensioactivas en la interfase.

\subsubsection{Placa de Wilhelmy}

Cuando una lámina delgada es sumergida en un líquido, la tensión superficial se manifiesta por un menisco que se forma a lo largo de su perímetro.

El equilibrio de fuerzas verticales muestra que el peso, w, del menisco soportado por la lámina es igual a la fuerza aportada por la superficie. Esta fuerza es igual a la componente vertical de la tensión superficial, $\gamma \times \cos \theta$, donde $\theta$ es el ángulo de contacto con la placa, multiplicado por el perímetro de la placa $\mathrm{p}$, entonces: 
(1) $\mathrm{F}=\mathrm{p} \times \gamma \times \cos \theta$

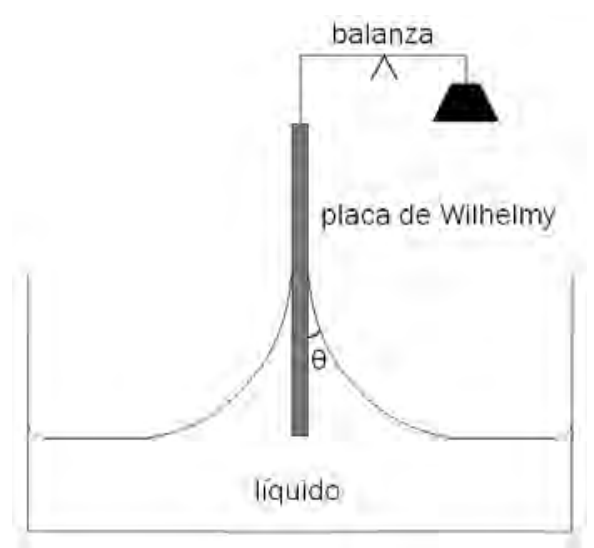

Figura 2.1.: Esquema de la placa de Wilhelmy en la superficie de un líquido.

La medición del peso del menisco permite calcular el valor de la tensión superficial. Esta medida se debe hacer en una balanza de precisión. La utilización es simple en particular en el caso de un ángulo de contacto cercano a 0 como sucede con una placa de platino, vidrio o de papel absorbente (materiales que se suelen usar para su confección). Al ser el ángulo prácticamente 0 , la fuerza medida no depende del ángulo de contacto y la relación se simplifica a:

$$
\text { (2) } \gamma=\mathrm{F} / \mathrm{p}
$$

El peso del líquido adherido a la lámina es directamente proporcional a la tensión superficial. La tensión es dependiente de la temperatura por lo tanto las medidas deben hacerse a temperatura controlada.

\subsubsection{Balanza de Langmuir}

La concentración de tensioactivo presente en la interfase va a modificar la tensión superficial. En el caso de la balanza de Langmuir, se varía la concentración de tensioactivo por la variación del tamaño de la superficie.

La balanza de Langmuir está constituida por una cuba de teflón con dos barreras de teflón que pueden ser movidas de manera muy precisa y programada por un motor. Estas barren la superficie del líquido que se encuentra en la cuba y permite variar la densidad de las moléculas en la superficie. 


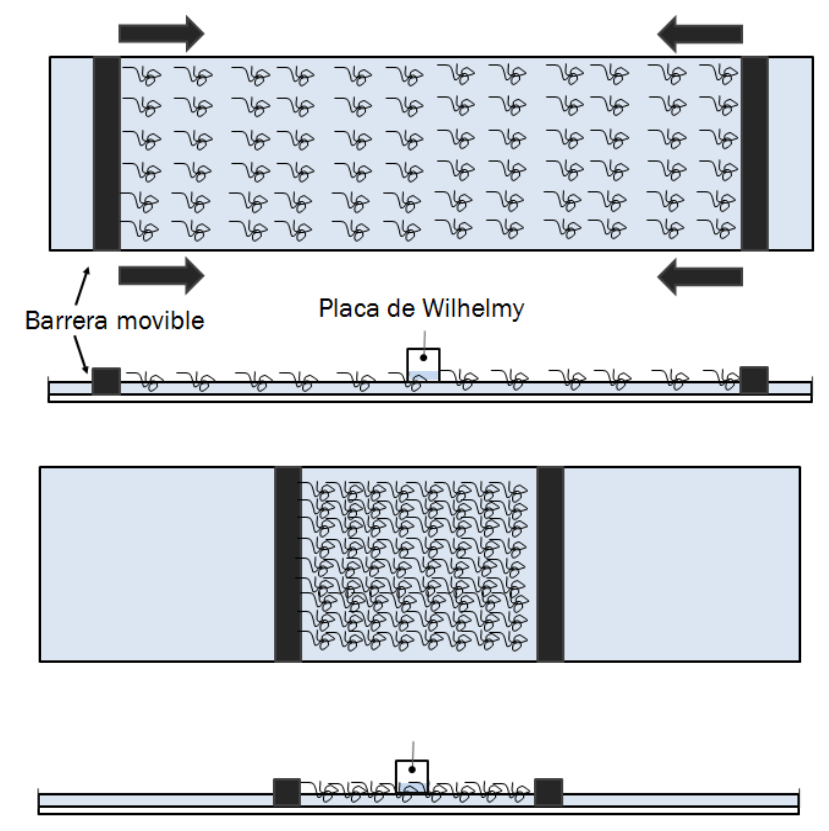

Figura 2.2.: Representación simple con vistas vertical y horizontal de la balanza de Langmuir antes y después del cierre del área entre barras.

La presencia de la capa de moléculas tensioactivas sobre la superficie disminuye la energía de la misma. La presión superficial, $\Pi$, es definida como la diferencia entre la tensión superficial del líquido solo, $\gamma_{0}$, y el líquido cubierto por la capa de moléculas de tensioactivo, $\gamma$.

(3) $\Pi=\gamma_{0}-\gamma$

La capacidad de los tensioactivos de acumularse en la interfase favorece la expansión de la misma y la disminución de la tensión superficial.

\subsubsection{Ensayos}

Para realizar las experiencias se utilizó una balanza de Langmuir modelo Nima 601BAM (Nima Techonology Ltd, Inglaterra). Como placa de Wilhelmy se utilizó un papel de filtro Whatman 43 de $1 \times 1 \mathrm{~cm}$, completamente humedecible con un ángulo $\theta$ despreciable. 
Las muestras utilizadas de aislados e hidrolizados fueron suspendidas en los buffers de $\mathrm{pH} 2,0$ y 8,0 en una concentración de $2 \mathrm{mg} / \mathrm{ml}$ agitadas durante $1 \mathrm{~h}$ a temperatura ambiente y luego centrifugadas por $30 \mathrm{~min}$ a $10000 \mathrm{~g}$ a $20{ }^{\circ} \mathrm{C}$. El sobrenadante fue lo que se utilizó en las experiencias. Cien $\mu l$ de las soluciones de proteína se sembraron con una microjeringa en distintas concentraciones (para obtener distintas cantidades de proteína total sembrada) cubriendo toda la superficie del buffer contenido en la cuba de la balanza. El área inicial, con las barreras abiertas, fue de $350 \mathrm{~cm}^{2}$. Se dejó el sistema por $1 \mathrm{~h}$ para que las proteínas se puedan adsorber y reordenar en la superficie. Transcurrido ese lapso se procedió a disminuir el área de la balanza. Esto se hizo a una velocidad de cierre de las barreras que producía una disminución del área de $40 \mathrm{~cm}^{2} / \mathrm{min}$ hasta llegar a un valor final de $40 \mathrm{~cm}^{2}$ de área final. Las variaciones detectadas por la placa fueron registradas a lo largo de todo el proceso por un adquisidor de datos asociado a una PC. Las cantidades de proteína sembrada fueron 25, 35, 50 y 100 $\mu \mathrm{g}$ para todas las muestras ensayadas. Todas las medidas se realizaron a $20^{\circ} \mathrm{C} \pm$ $0,2{ }^{\circ} \mathrm{C}$.

\subsubsection{Tensiometría de gota dinámica y reología interfacial}

\subsubsection{Tensiometría de gota:}

La tensiometría de gota permite medir la tensión interfacial. Cuando una gota de un fluido está en contacto con otro fluido, la forma de la gota va a estar determinada por dos efectos: el de la tensión interfacial entre los dos fluidos que forzará a la gota a tomar la forma esférica y el efecto de la atracción gravitatoria que tenderá a producir una elongación o aplastamiento de la gota. Para una gota asimétrica la ecuación de Laplace toma la forma:

(4) $(1 / x) \times d(x \operatorname{sen} \theta) / d x=(2 / b)-c \times z$

donde $x$ y $z$ son las coordenadas cartesianas para todos los puntos del perfil de la gota. El origen de coordenadas está considerado en el ápice de la gota, b es el radio de curvatura en el ápice, $\theta$ es el ángulo de la tangente en el perfil, c la constante de capilaridad definida como $\mathrm{c}=\mathrm{g} \Delta \rho / \gamma$, con g igual a la aceleración de la gravedad, $\Delta \rho$ la diferencia de densidad de los dos fluidos y $\gamma$ la tensión interfacial. 


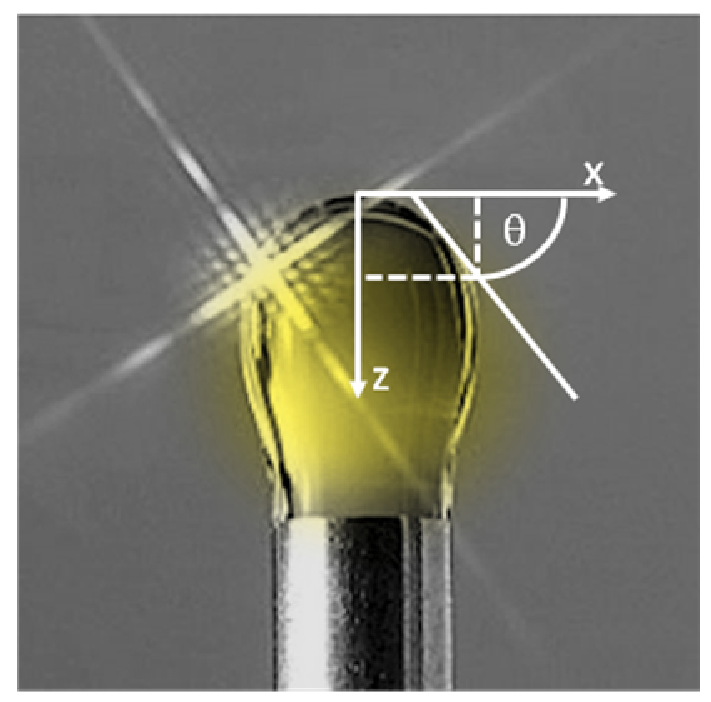

Figura 2.3.: Perfil de una gota de un fluido en un medio de mayor densidad. En la figura están detalladas las coordenadas cartesianas.

La gota puede ser pendiente, por ejemplo una gota de agua en aire, o como en nuestro caso montante, una gota de aceite en un medio acuoso.

\subsubsection{Reología interfacial}

En nuestro caso la reología interfacial se estudió por reología dilatacional. Para hacerlo se producen dilataciones y compresiones precisas de la interfase de manera sinusoidal. El módulo dilatacional de un interfase es la relación entre el valor de la tensión interfacial de la misma y la deformación de su área (dA/A0). Si una superficie se comprime y dilata sucesivamente a una frecuencia $\omega$ y a una amplitud $\Delta \mathrm{A}$ para una interfase viscoelástica, puede aparecer un desfasaje entre la variación de la deformación $\left(\triangle \mathrm{A} / \mathrm{A}_{0}\right)$ y la tensión interfacial expresado como el valor de un ángulo de desfasaje $(\theta)$. El módulo dilatacional de la interface $\mathrm{E}$ se transforma en un número complejo compuesto por una parte real E' (elástica) que representa la energía almacenada y una parte imaginaria E" (viscosa) correspondiente a mecanismos que disipan la energía mecánica:

$$
\text { (5) } \quad \mathrm{E}=\mathrm{E}^{\prime}+i \mathrm{E}^{\prime \prime}=|\mathrm{E}| \cos \theta+i|\mathrm{E}| \operatorname{sen} \theta
$$


E se calcula de la fórmula:

(6) $|\mathrm{E}|=\left[\left(\mathrm{E}^{\prime}\right)^{2}+\left(\mathrm{E}^{\prime \prime}\right)^{2}\right]^{1 / 2}$

Un aumento del valor de E está relacionado con una mayor resistencia de la interfase lo que implica, por ejemplo, que en una emulsión las gotas fuesen más resistentes a la coalescencia. La técnica de la gota oscilante permite medir los módulos viscoelásticos interfaciales de una gota de aceite formada en una fase acuosa. Las oscilaciones pueden hacerse mientras se va formando el film o cuando el film ha llegado al equilibrio.

\subsubsection{Operación}

Las medidas fueron realizadas en un tensiómetro de gota automático (ITconcept, Francia) descripto por Benjamins, Cagna y col. (1996).

Las muestras fueron preparadas en los buffers de $\mathrm{pH} 2,0$ y 8,0 por agitación a temperatura ambiente y posterior centrifugación $\left(10000 \mathrm{~g}, 30 \mathrm{~min}, 20^{\circ} \mathrm{C}\right)$. Para los ensayos se utilizó el sobrenadante.

Se colocaron aproximadamente $6 \mathrm{ml}$ de la solución proteica en una cubeta de cuarzo termostatizada a $20{ }^{\circ} \mathrm{C} \pm 0,2{ }^{\circ} \mathrm{C}$. El equipo (Figura 2.4.) consta de una jeringa con una aguja en forma de $U$ acoplada que se sumerge dentro de la solución proteica. Con la jeringa se forma la gota montante de aceite que es la analizada para obtener los valores de tensión interfacial dinámica. En los ensayos se crearon gotas con un volumen de $8 \mu \mathrm{l}$ que tenían, al inicio de las experiencias, una superficie aproximada de $18 \mathrm{~mm}^{2}$. Se midió la tensión interfacial dinámica a lo largo de $15000 \mathrm{~s}$. Todos los cálculos de la tensión interfacial a partir del perfil laplaciano de la gota fueron realizados mediante el software Windrop.

El mismo tensiómetro de gota fue utilizado para hacer las medidas de reología interfacial dilatacional. Se realizaron expansiones y compresiones periódicas sinusoidales del volumen de gota. Para ello se utilizó una frecuencia de 0,02 Hz y una amplitud de deformación del $\pm 2,5 \%$ del valor inicial del área de la gota. Este valor de amplitud se encontraba dentro del rango de viscoelasticidad lineal. Se hicieron medidas a lo largo de $15000 \mathrm{~s}$ en series de 10 oscilaciones. En estas condiciones se obtuvieron los valores de $\mathrm{E}$ y del ángulo $\theta$. 


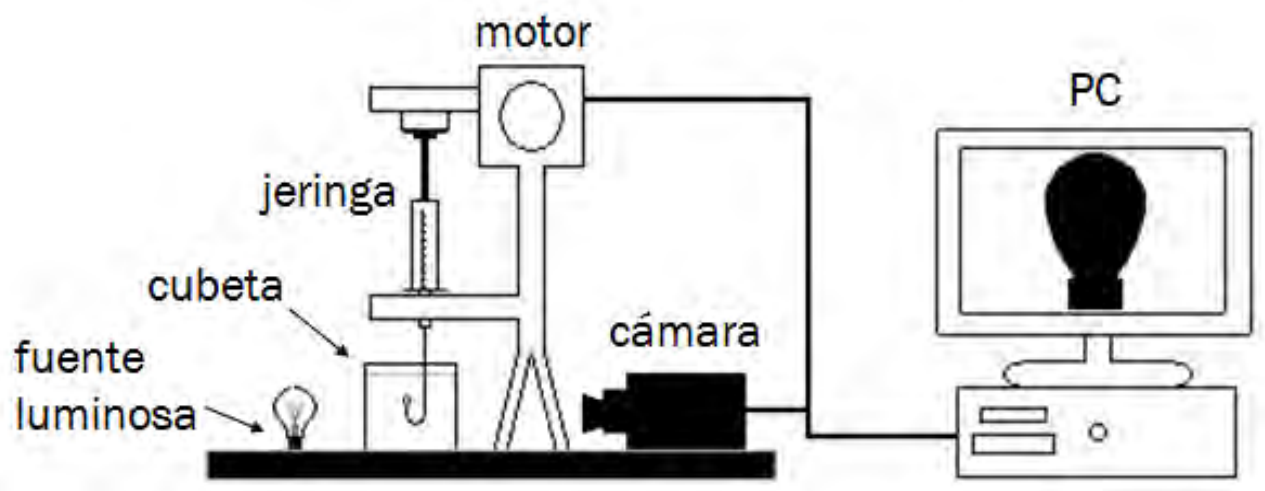

Figura 2.4.: Representación esquemática del tensiómetro de gota automático.

\subsubsection{Preparación de emulsiones}

\subsubsection{Emulsiones con menor relación proteína/aceite}

Las emulsiones fueron preparadas a $\mathrm{pH}$ 2,0, 6,3 y 8,0. Las mismas se prepararon a partir de suspensiones de proteína al 0,1\% (1 $\mathrm{mg} / \mathrm{ml})$ que fueron agitadas durante $1 \mathrm{~h}$ a temperatura ambiente. Se usaron $16 \mathrm{ml}$ de suspensión proteica para emulsionar $4 \mathrm{ml}$ de aceite refinado de girasol (relación de aceite/agua o $\phi=$ $0,2)$. En este caso para la homogenización se utilizó un emulsificador por ultra sonido SONICS Vibra Cell VCX750 (Vibra Cell sonics materials Inc., EE.UU) a una potencia del $50 \%$ que corresponde a $375 \mathrm{~W}$. Se aplicaron 2 pulsos de $5 \mathrm{~s}$ cada uno usando la punta sonicadora estándar de $10 \mathrm{~mm}$, sumergida hasta $1 / 3$ en un vaso de precipitados con un diámetro de $28 \mathrm{~mm}$. Mientras se emulsificaba, se agitó la muestra a velocidad moderada con un agitador magnético para permitir que toda la mezcla pasase por la zona de emulsificación.

\subsubsection{Emulsiones con mayor relación de proteínalaceite}

Estas emulsiones fueron preparadas con las muestras AI, AH9.5 y TH2.2. Se dispersaron $5 \mathrm{mg} / \mathrm{ml}$ de proteína en buffer $\mathrm{pH}$ 2,0 y pH 8,0. La mezcla se agitó durante $1 \mathrm{~h}$ a velocidad moderada a temperatura ambiente. A las mismas muestras se las dispersó en una concentración de $15 \mathrm{mg} / \mathrm{ml}$, se centrifugaron $20 \mathrm{~min}$ a $15000 \mathrm{~g}$ con una temperatura controlada de $20^{\circ} \mathrm{C}$, y al sobrenadante se lo diluyó con el mismo buffer en cantidad suficiente para obtener concentraciones proteicas en solución de $5 \mathrm{mg} / \mathrm{ml}$.

En un tubo plástico de $15 \mathrm{ml}$ se colocaron $5 \mathrm{ml}$ de suspensión proteica con $550 \mu \mathrm{l}$ de aceite refinado de girasol (relación de aceite/agua o $\phi=0,1$ ). Para la 
homogenización se utilizó un emulsificador por ultra sonido (Vibra Cell 250E, $500 \mathrm{~W}$ ) a una potencia de $175 \mathrm{~W}$, utilizando una microsonda cónica de $5 \mathrm{~mm}$ de diámetro (Bioblock). Se homogeneizó en modo pulse seleccionando un valor de sonicación del 50\% del tiempo, durante un tiempo total de 5 min. La microsonda quedó inmersa una profundidad de $15 \mathrm{~mm}$ en la mezcla. El tubo fue sumergido en un baño de hielo durante la emulsificación para evitar el sobrecalentamiento de la muestra por la acción de ultrasonido.

\subsubsection{Estabilidad de emulsiones}

En el caso de las emulsiones con menor relación proteína/aceite las medidas de estabilidad de las emulsiones se realizaron con el QuickScan explicado en la sección 1.1.13.1. en los buffers de $\mathrm{pH}$ 2,0; 6,3 y 8,0. Los valores de BS se midieron a intervalos de $3 \mathrm{~min}$ durante $3 \mathrm{~h}$ y luego se hizo una medida puntual a las $24 \mathrm{~h}$.

\subsubsection{Distribución de tamaño de gota de las emulsiones aceitelagua}

Para las distribuciones de tamaño de gota de las emulsiones se utilizó el mismo método descripto en la sección 1.1.14. utilizándose como analizador de tamaño de gota un equipo Saturn DigiSizer 5200 (Micromeritics, EE.UU).

Para las emulsiones con menor relación proteína/aceite se hicieron medidas al finalizar la emulsificación en presencia y ausencia de SDS.

En el caso de las emulsiones con mayor relación de proteína/aceite se realizaron medidas al finalizar la emulsificación, a las $24 \mathrm{~h}$ y luego de 7 días de almacenamiento de la emulsión y a partir de esas medidas se calcularon los porcentajes de floculación y de coalescencia en el tiempo de la siguiente manera:

$$
\% \text { floc }=\left(\mathrm{d}_{3,2}(\mathrm{t})-\mathrm{d}_{3,2}+\operatorname{sDs}(\mathrm{t})\right) / \mathrm{d}_{3,2}+\operatorname{SDS}(\mathrm{t}) \times 100
$$

$$
\% \text { coal }=\left(\left(\mathrm{d}_{3,2} \operatorname{sDS}(\mathrm{t})-\mathrm{d}_{3,2} \operatorname{SDS}\left(\mathrm{t}_{0}\right)\right) / \mathrm{d}_{3,2} \operatorname{sDS}\left(\mathrm{t}_{0}\right) \times 100\right.
$$




\subsubsection{Microscopía óptica}

Las emulsiones con menor relación proteína/aceite fueron analizadas mediante microscopía óptica de igual modo y con el mismo equipo indicado en la sección 1.1.15. Para la evaluación de la estabilidad en el tiempo, se tomaron muestras de emulsión para su observación al finalizar la homogenización, a las $3 \mathrm{~h}$ y a las $24 \mathrm{~h}$ de almacenamiento estacionario.

\subsubsection{Determinación de proteína adsorbida}

La técnica Patton y Huston (1986) y adaptada por Le Denmat (Le Denmat, Anton y col. 2000) se basa en la separación de las gotas de aceite por centrifugación en un gradiente de sacarosa para separar glóbulos grasos de leche. Esta técnica permite separar las gotas lipídicas de la fase continua y lavarlas en forma simultánea.

La determinación de proteína adsorbida se realizó sobre las emulsiones con mayor relación de proteína aceite. Se tomaron $2 \mathrm{ml}$ de emulsión y se mezclaron suavemente con $2 \mathrm{ml}$ de una solución de sacarosa al 50\% p/p para aumentar la densidad de la fase continua. Simultáneamente se preparó un tubo plástico de $15 \mathrm{ml}$ con $10 \mathrm{ml}$ de solución de sacarosa de 15\% p/p. Los $4 \mathrm{ml}$ de emulsión con la solución de sacarosa concentrada fueron colocados, con ayuda de una jeringa en el fondo del tubo que contenía los $10 \mathrm{ml}$ de la solución de sacarosa menos concentrada. Los tubos se centrifugaron a $3000 \mathrm{~g}$ por $2 \mathrm{~h}$ a $10^{\circ} \mathrm{C}$. Luego de la centrifugación las gotas de aceite recubiertas de proteínas interfaciales y libres de sustancias no adsorbidas ascendieron a la parte alta del tubo, mientras que las proteínas de la fase continua migraron hacia el fondo del tubo. Luego los tubos se congelaron en posición vertical. 


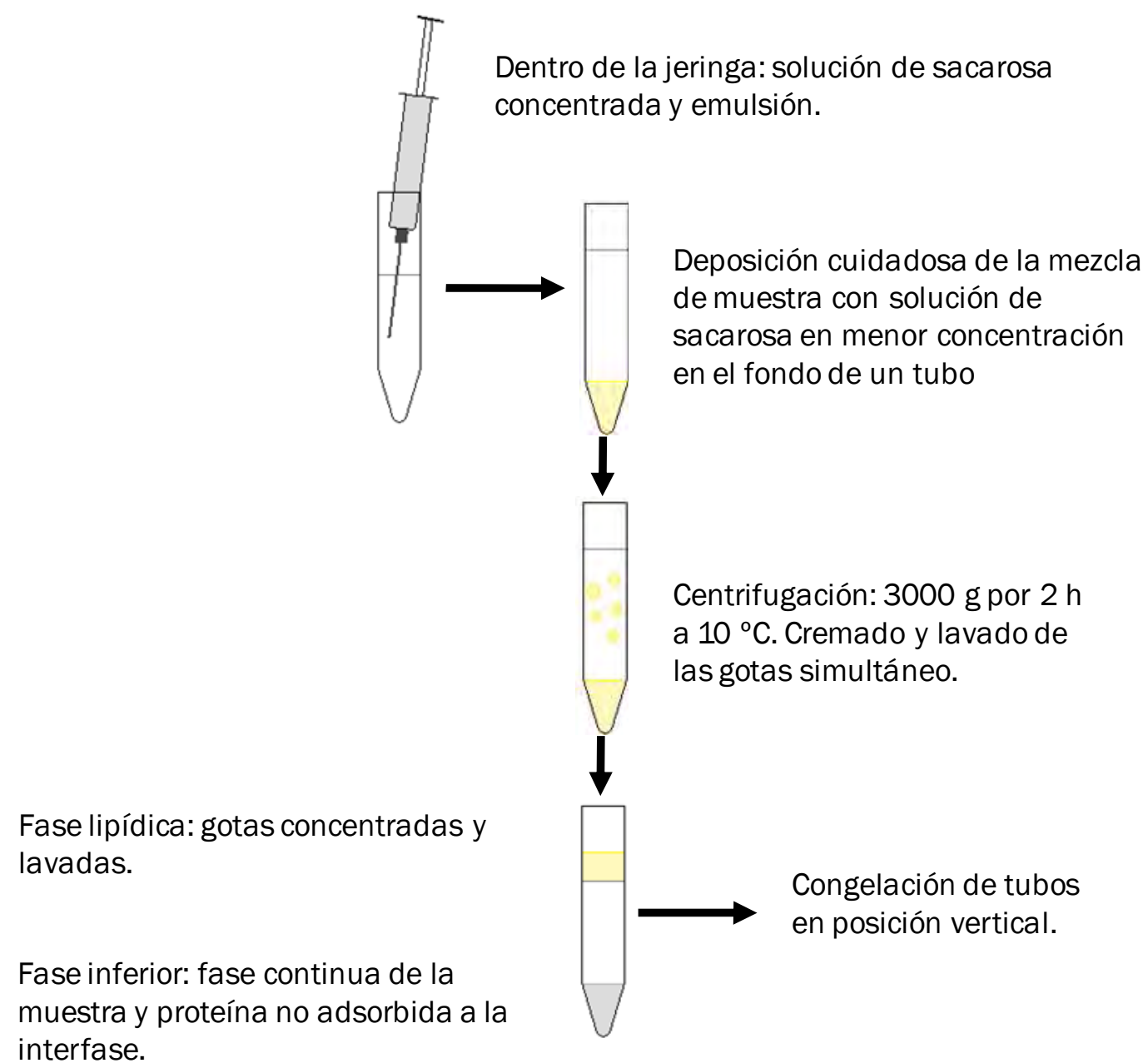

Figura 2.5.: esquema de separación y lavado de gotas de emulsión de la fase continúa.

Posteriormente los tubos congelados se cortaron con la ayuda de una sierra eléctrica en una posición del tubo que permitió separar la fase inferior de la superior. La fase superior se descongeló y se recuperó con la ayuda de una espátula y se colocó en otro tubo plástico de $15 \mathrm{ml}$ que contenía $3 \mathrm{ml}$ de solución de SDS 1\%. El SDS tiene la función de desplazar las proteínas de la interfase a la fase acuosa por ser mejor agente tensioactivo. A los tubos con la fase crema y el SDS se los dejó en reposo $1 \mathrm{~h}$ a temperatura ambiente y luego se centrifugaron a $3000 \mathrm{~g}$ durante $1 \mathrm{~h}$ a $10{ }^{\circ} \mathrm{C}$. Se recuperó la fase inferior de los tubos que contiene las proteínas desorbidas de la interfase por el SDS. Luego se analizaron las proteínas de la interfase por electroforesis SDS-PAGE (sección 1.1.6.). 


\subsection{Resultados y Discusión}

\subsubsection{Determinación de tamaños moleculares}

\subsubsection{SDS-PAGE}

En las electroforesis de la Figura 2.6. puede verse que AI muestra un patrón de bandas similar al de AH1.7 que se diferencia sólo por la mayor densidad de bandas en la zona de menores pesos moleculares. En la calle correspondiente a la muestra AH9.5 se detecta mejor la disminución de tamaño de los polipéptidos ya que se observa la desaparición casi total del polipéptido $\mathrm{M}$ de $56 \mathrm{kDa}$ y la aparición de un polipéptido de alrededor de $39 \mathrm{kDa}$. También aparecen numerosos polipéptidos de bajo peso molecular. En el caso de TH2.2 el patrón de bandas se encuentra más corrido a valores de menor peso molecular. Esto se atribuye a las diferentes especificidades de corte de la enzimas tripsina y alcalasa relacionadas con la secuencia aminoacídica del sustrato (AI).

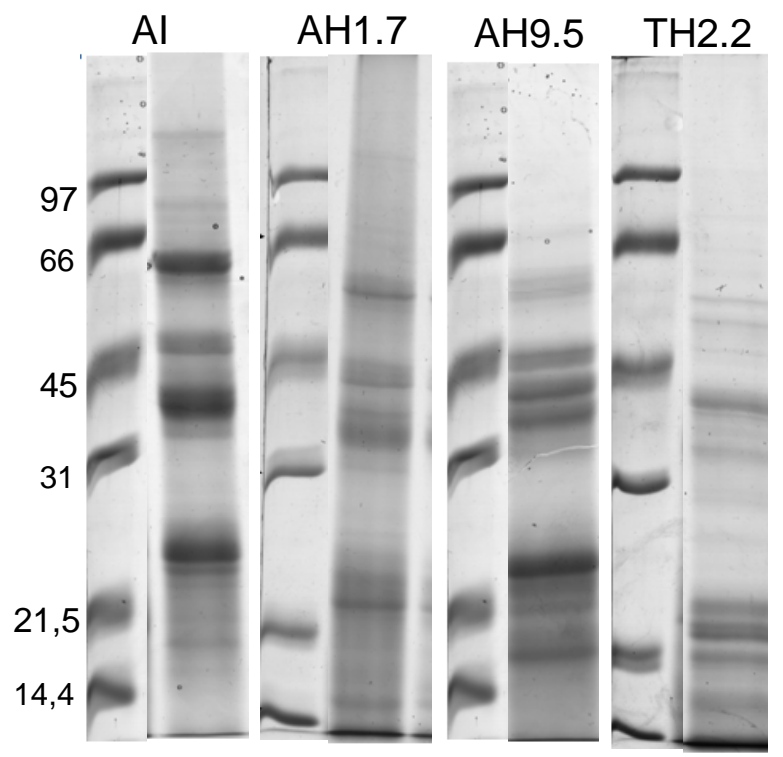

Figura 2.6.: SDS-PAGE en condiciones reductoras de las distintas muestras. 


\subsubsection{Cromatografías FPLC}

Según lo revelado por la cromatografía de exclusión molecular (Figura 2.7.), las fracciones solubles en los diferentes buffers difirieron en la distribución de tamaños moleculares. A pH 8,0 la fracción soluble de AI (figura 2.7. (a)) muestra la presencia de polímeros de globulina-P (componente I en la figura, con masas moleculares que varían entre 500 y $300 \mathrm{KDa}$ ), moléculas de globulina-P y $11 \mathrm{~S}$ de $280 \pm 7 \mathrm{kDa}$ (componente II), que fueron descriptos por Martínez, Castellani y col., (1997) y especies de masas moleculares menores a $100 \mathrm{kDa}$ (componente III) perteneciente a las albúminas. Las fracciones solubles de hidrolizados de alcalasa (AH1.7 y AH9.5) no mostraron agregados de alto peso molecular, pero si una mayor proporción de especies monoméricas y polipéptidos de bajo peso molecular resultantes de la hidrólisis. En AH9.5 a pH 8,0 se puede observar la inversión de los picos que eluyen aproximadamente a $22 \mathrm{ml}$ mostrando un cambio hacia menores valores moleculares debido a la hidrólisis. Los hidrolizados con tripsina mostraron no sólo componentes de bajo peso molecular, sino también agregados solubles, aunque en una proporción mucho menor que la encontrada en el aislado sin hidrolizar, AI, exhibiendo además pesos moleculares intermedios (que corresponden a masas moleculares 68 a $14 \mathrm{kDa}$ ). Las especies que se encuentran en la fracción soluble a $\mathrm{pH}$ 6,3 fueron similares a las detectadas a $\mathrm{pH} 8,0$ con la diferencia que presentaron algo menos de especies de alto peso molecular, especialmente en AI. A pH 2,0 las especies que se observaron fueron polipéptidos de baja masa molecular, incluso en AI. Esto se debería a reacciones de disociación de los polipéptidos, además de la hidrólisis que se produce a $\mathrm{pH} 2,0$ 

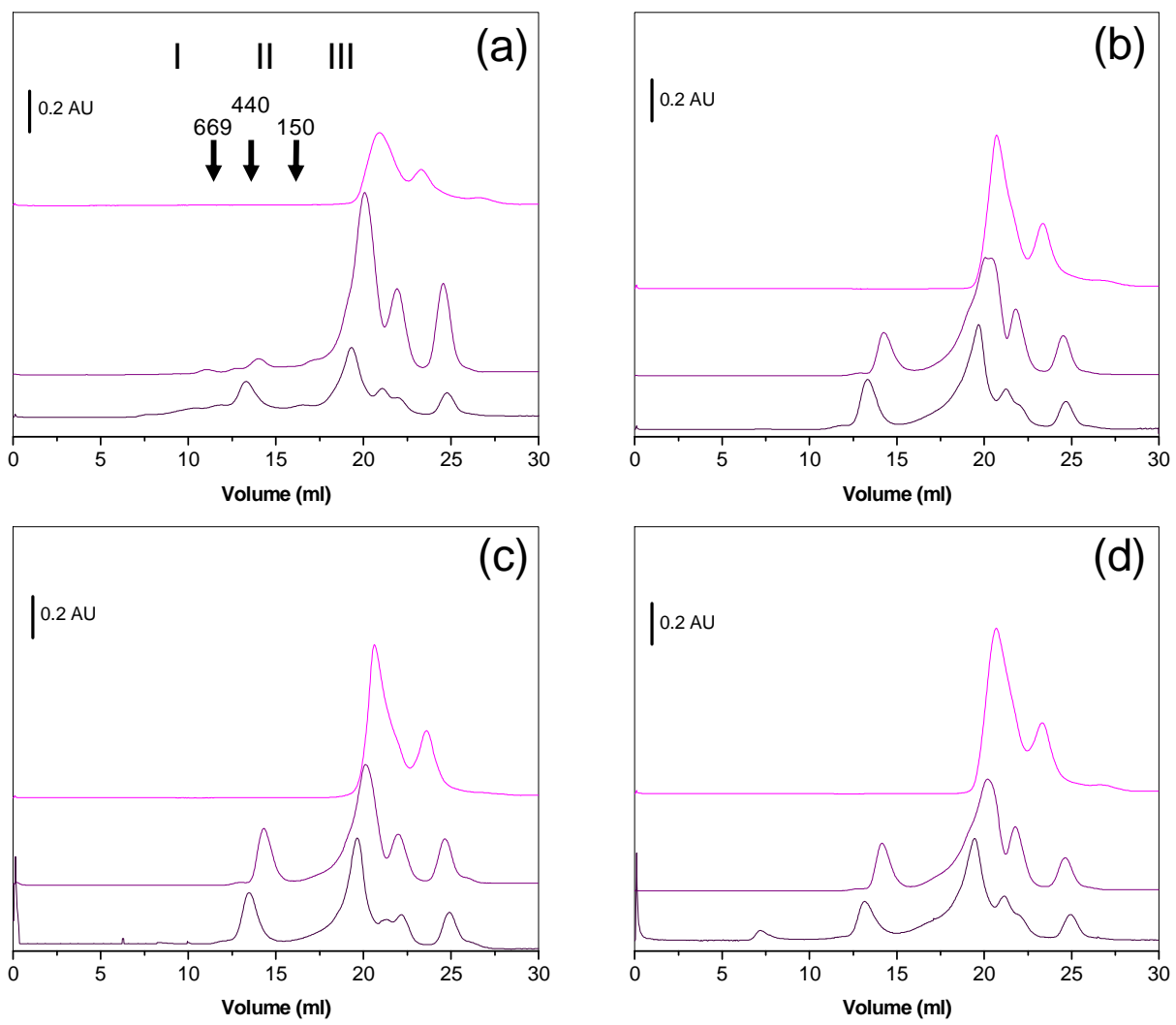

Figura 2.7.: Cromatografías FPLC de proteínas de amaranto solubles hidrolizadas y sin hidrolizar, AI (a) AH1.7 (b), AH9.5 (c), TH2.2 (d) a: pH 2 ( | ), pH 6.3 ( I ) y pH 8 ( I ).

\subsubsection{Solubilidad}

En la Figura 2.8. se pueden observar las curvas de solubilidad de las muestras en estudio en función del $\mathrm{pH}$ a baja fuerza iónica $(0,06 \mathrm{M})$. Para todas las muestras se detecta un descenso en los porcentajes de proteína soluble en las zonas de $\mathrm{pH}$ intermedias $(4,0-6,3)$. Este descenso se debe a que el punto isoeléctrico de las proteínas presentes en el aislado se encuentra entre $\mathrm{pH}$ 4,5 y 6,0 (Marcone y Yada 1992) y por consiguiente las mismas precipitan por la agregación que se produce al disminuir la repulsión electrostática. A pH 2,0 la mayor solubilidad la presentó AI y TH2.2, mientras que los menores valores fueron obtenidos para las muestras AH1.7 y AH9.5. A pH 4,0, cercano al punto isoeléctrico de las proteínas, el grado de hidrólisis parece tener mayor influencia sobre la solubilidad ya que AI es la muestra menos soluble, siendo TH2.2 la más soluble seguida por AH9.5. A pH 6,3 TH2.2 es mucho más soluble que las otras muestras, aproximadamente el doble. A pH 8,0 la muestra más soluble sigue siendo TH2.2 pero se produce un 
incremento mayor de la solubilidad de AI con respecto a las muestras AH1.7 y AH9.5. A pH 9,0 la muestra más soluble vuelve a ser AI seguida por TH2.2 y luego AH9.5 y AH 1.6, un comportamiento similar al que se obtuvo con las muestras a $\mathrm{pH} 2,0$.

AI parece ser más afectada a los $\mathrm{pH}$ cercanos al punto isoeléctrico que las proteínas hidrolizadas, ya que presenta bruscos descensos de la solubilidad a esos $\mathrm{pHs}$, sin embargo a $\mathrm{pHs}$ extremos presenta solubilidades mayores. Si observamos los valores de solubilidad de las muestras hidrolizadas con alcalasa, vemos que el aumento del grado de hidrólisis favoreció la solubilidad proteica, ya que para todos los pHs AH9.5 presentó solubilidades mayores que AH1.7. Si comparamos TH2.2 con AH9.5 podemos ver que en este caso el grado de hidrólisis no fue lo más influyente, sino la naturaleza de los polipéptidos resultantes de la hidrólisis enzimática dado que TH2.2 a pesar de tener menor grado de hidrólisis presentó mayor solubilidad en todos los $\mathrm{pH}$. La hidrólisis con la enzima tripsina, favoreció la solubilidad a valores de $\mathrm{pH}$ cercanos al punto isoeléctrico de la mezcla de proteínas. Vale recordar que TH2.2 fue la muestra que presentó polipéptidos más pequeños según las electroforesis SDS-PAGE.

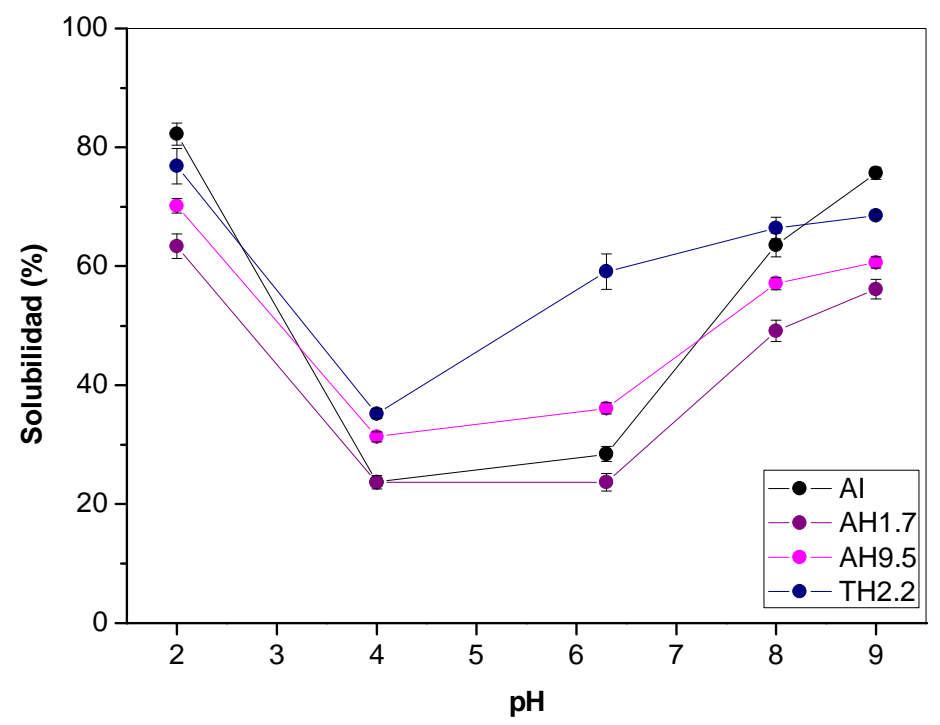

Figura 2.8.: Curvas de solubilidad en función del pH de cada una de las muestras en condiciones de baja fuerza iónica $(0,06 \mathrm{M})$.

La tripsina y la alcalasa son parte de la familia de las serinproteasas. La tripsina hidroliza el enlace peptídico del lado del carboxilo de la arginina y de la lisina mientras que la alcalasa hidroliza enlaces peptídicos en los que participan una 
gran cantidad de aminoácidos hidrofóbicos diferentes como Phe, Tyr, Trp, Leu, Ile, Val, Met en su grupos carboxilo terminal. Condés, Scilingo y col. (2009) mostraron que la globulina $11 \mathrm{~S}$ y la globulina-P son las proteínas más sensibles a la acción de la tripsina. Vecchi (2007) mostró que los polipéptidos B de 11S, de naturaleza hidrofóbica, fueron resistentes a la acción de la alcalasa. De acuerdo con Chabanon, Chevalot y col. (2007) la hidrólisis de las proteínas de canola con alcalasa tuvo lugar en toda la proteína conduciendo a la aparición de una gran proporción de péptidos intermediarios siguiendo un mecanismo zipper. Si consideramos los resultados de solubilidad (Figura 2.8.) y teniendo en cuenta el mecanismo de acción de la alcalasa, es posible que durante las etapas tempranas de la hidrólisis, la enzima libere péptidos hidrofóbicos capaces de interactuar y formar agregados insolubles estabilizados por interacciones hidrofóbicas. Este fenómeno se favorecería a $\mathrm{pHs}$ cercanos al punto isoeléctrico promedio de esas proteínas. También es probable que las muestras que fueron sometidas al proceso de hidrólisis descripto en la sección 2.1.3. se hayan agregado como consecuencia del tratamiento térmico que se les aplicó para detener la acción de la enzima, entonces el hecho de estar más hidrolizadas no contrarrestaría la agregación que se produciría por el tratamiento térmico.

\subsubsection{Curvas de tensión superficial en la balanza de Langmuir}

\subsubsection{En $p H 2,0$}

En la Figura 2.9. se muestran las curvas de tensión superficial en la balanza de Langmuir a $\mathrm{pH}$ 2,0 correspondientes a AI sembrada en diferentes cantidades sobre la superficie de la balanza. Ellas muestran un incremento de los valores de presión superficial $(\pi)$ a valores de área mayores cuando se aumenta la cantidad de proteína sembrada. Cuando el área de la balanza fue la mínima, $40 \mathrm{~cm}^{2}$, las curvas correspondientes a 35, 45 y $90 \mu \mathrm{g}$ de proteína sembrada llegaron a valores similares de $\pi$. Cuando se sembraron $9 \mu \mathrm{g}$ no se pudo observar aumento de la presión interfacial para ningún valor de área. 


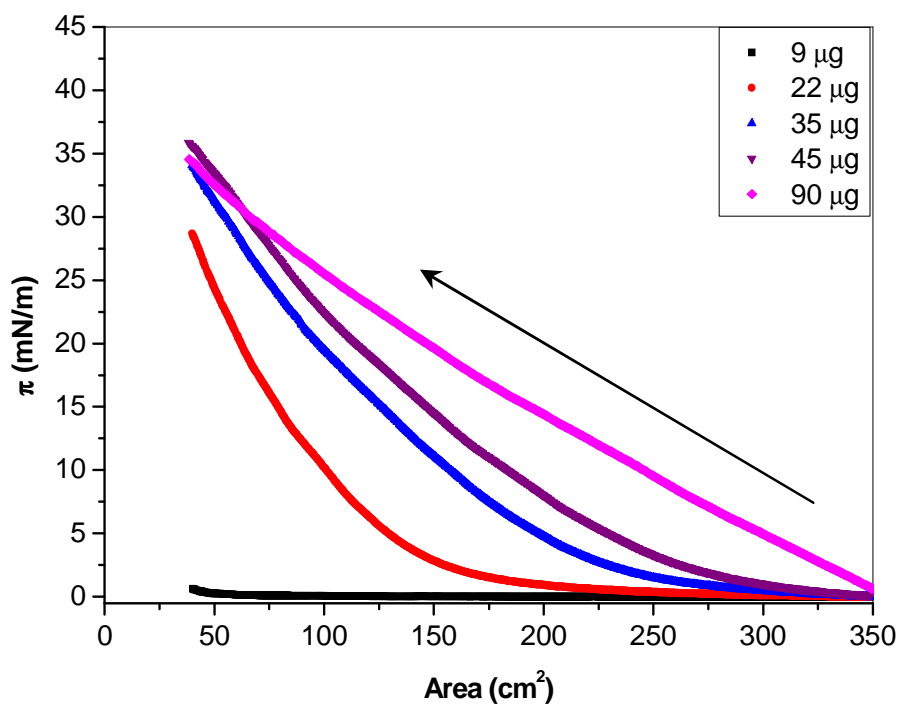

Figura 2.9.: Curvas de tensión superficial en la balanza de Langmuir a pH 2,0, en la interfase $\mathrm{a} / \mathrm{w}$ de la muestra AI sembrada en diferentes cantidades, indicadas en la figura, sobre la superficie de la balanza. La flecha muestra el sentido de la reducción controlada de la superficie de la balanza.

Para realizar las experiencias de las diferentes muestras se sembró una cantidad de proteína de $35 \mu \mathrm{g}$. Las curvas de $\pi$ en función del área están representadas en la Figura 2.10. AI y TH2.2, mostraron más eficiencia para aumentar la presión superficial de todas las muestras ensayadas. Las muestras hidrolizadas con alcalasa precisaron áreas menores para elevar los valores de la presión superficial en la misma magnitud que las otras muestras. La muestra AH29.6 corresponde a un aislado proteico de amaranto hidrolizado con alcalasa con un grado de hidrólisis alto, 29,6 \%. Aparentemente el alto grado de hidrólisis afecta en forma negativa la capacidad tensioactiva de los péptidos resultantes. Estos péptidos, probablemente, no tengan una actividad tensioactiva debido a que no se mantienen mucho tiempo en la interfase y pasan al seno del líquido debido a su pequeño tamaño que les da mucha más movilidad. Otra posibilidad a considerar es que los péptidos generados por su pequeño tamaño y menor flexibilidad no puedan acomodar zonas de preponderante naturaleza hidrofóbica o hidrofílica hacia las respectivas fases. 


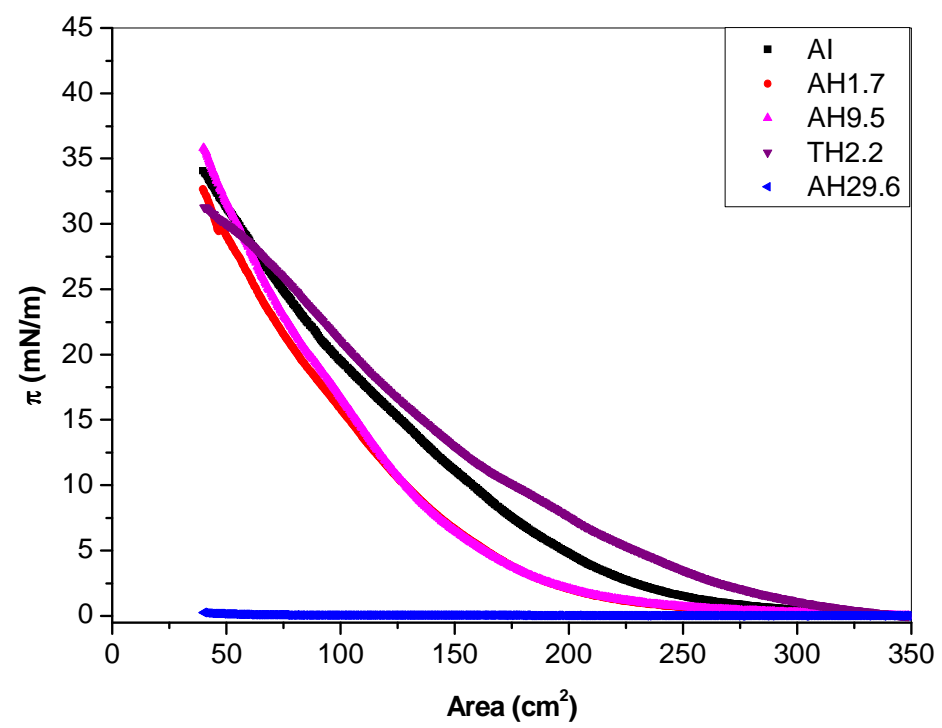

Figura 2.10.: Curvas de tensión superficial en la balanza de Langmuir a pH 2,0, en la interfase a/w de las distintas muestras sembradas ( $35 \mu \mathrm{g}$ de proteína) sobre la superficie de la balanza. AH29.6 corresponde a la isoterma de la muestra de aislado proteico de amaranto hidrolizado con alcalasa con un grado de hidrólisis alto, 29,6\%.

\subsubsection{2. $\operatorname{En} p H 8,0$}

En la Figura 2.11. se muestran las curvas de Langmuir a $\mathrm{pH} 8,0$ correspondientes a la muestra $\mathrm{AI}$ sembrada en distintas concentraciones. Al igual que a $\mathrm{pH} 2,0$ se ve que los valores de presión interfacial aumentan a valores de área mayores a medida que se aumenta la cantidad de proteína sembrada en la superficie. En las curvas pueden observarse puntos de inflexión en la pendiente. Esos puntos de inflexión se deberían a cambios estructurales a nivel de la membrana superficial como la formación de bucles y colas en las moléculas proteicas que protruden en el seno de alguna de las dos fases (aire o agua) (Kim, Cornec y col. 2005). El punto de inflexión más evidente, sucede cuando las curvas llegan a valores de presión superficial de aproximadamente de entre 12 y $15 \mathrm{mN} / \mathrm{m}$ en todas las curvas exceptuando la isoterma en la que se sembraron $9 \mu \mathrm{g}$ de proteína que no llegó a esos valores. 


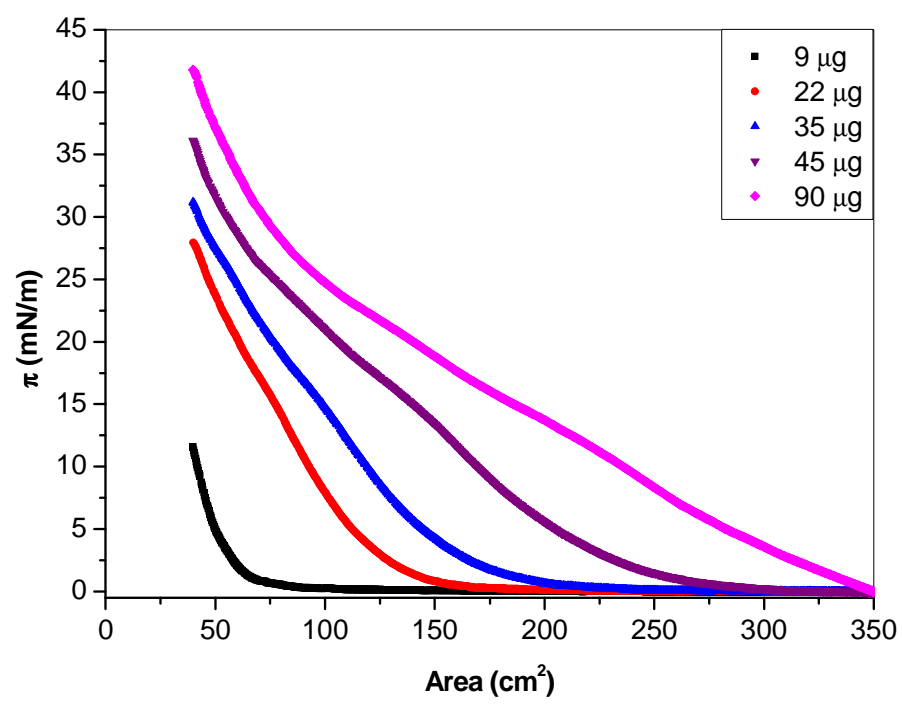

Figura 2.11.: Curvas de tensión superficial en la balanza de Langmuir a pH 8,0, en la interfase a/w de la muestra AI sembrada, en diferentes cantidades indicadas en la figura, sobre la superficie de la balanza.

Las distintas muestras a pH 8,0 se comportaron como muestra la Figura 2.12. La muestra $\mathrm{AI}$ necesitó un área más pequeña para poder producir un aumento en la tensión interfacial. A pH 8,0 las proteínas de AI se encuentran muy estructuradas y compactas ya que presentan mayor entalpía de desnaturalización (sección 1.2.1.1.) (Martínez y Añón 1996). Las dos muestras hidrolizadas con alcalasa tuvieron un comportamiento similar y presentaron curvas casi solapadas la una con la otra. La muestra TH2.2 mostró valores muy por encima del resto de las muestras indicando mayor actividad interfacial. Evidentemente la hidrólisis con tripsina produjo polipéptidos con mayor facilidad de adsorberse y reorientarse en la interfase aire/agua. Este hecho probablemente aumenta la eficiencia de su acción como agente tensioactivo. En esta experiencia se podría haber mantenido la superficie de la balanza en el estado de menor área durante algún período de tiempo para ver si la presión superficial se modificaba por cambios estructurales a nivel molecular lo que podría haber brindado información acerca de la rigidez de las estructuras proteicas en la interfase aire/agua. 


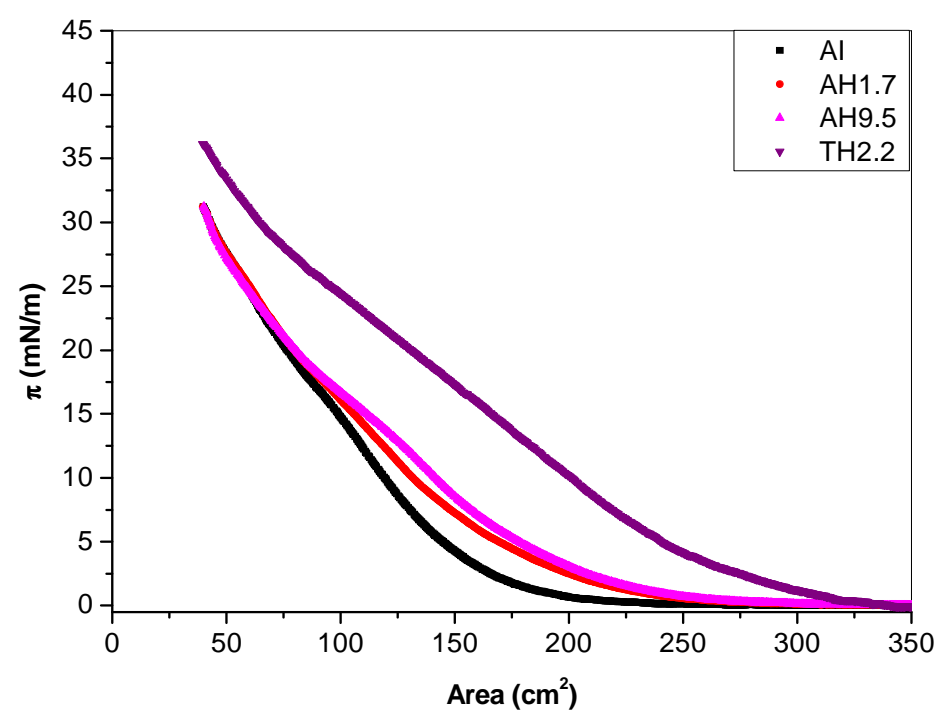

Figura 2.12.: Curvas de tensión interfacial en la balanza de Langmuir a $\mathrm{pH}$ 8,0, en la interfase a/w de las distintas muestras sembradas en una cantidad de $35 \mu \mathrm{g}$ de proteína sobre la superficie de la balanza.

\subsubsection{Comparación entre $\mathrm{pH} 2,0$ y $\mathrm{pH} 8,0$}

La muestra AI a pH 2,0 llega a un valor máximo de la presión interfacial a partir de $35 \mu \mathrm{g}$ de proteína en la superficie de la balanza en tanto que a $\mathrm{pH}$ de 8,0 a mayor cantidad de proteína sembrada, mayor es el valor de la presión interfacial alcanzado. Si se comparan los comportamientos de $\mathrm{AI}$ a $\mathrm{pH} 2,0$ y $\mathrm{pH} 8,0$, se observa que para la misma disminución en el área, las presiónes interfaciales mayores fueron alcanzados por las proteínas en el buffer de $\mathrm{pH}$ 2,0. A pH 8,0, sólo en el caso de $90 \mu \mathrm{g}$ de proteína se alcanzan valores de presión interfacial mayores que a $\mathrm{pH}$ 2,0. Estas diferencias pueden atribuirse al hecho que a $\mathrm{pH} 8,0$ las proteínas se encuentran más compactas, ocupando menos superficie por molécula, lo que les permite empaquetarse sobre la superficie con mayor facilidad, siendo esta una situación que favorecería el aumento de la concentración proteica en la interfase y que permitiría arribar a valores de presión interfacial mayores. Los cambios en la pendiente de las curvas a $\mathrm{pH} 8,0$ no se detectan a $\mathrm{pH} 2,0$, lo que sugiere que a $\mathrm{pH} 8,0$ se producen cambios en la estructura de la monocapa y que estos cambios no son evidentes al pH ácido. Como las proteínas que se encuentran en el aislado proteico de amaranto tienen su punto isoeléctrico entre pHs 4,5 y 6,5 (Konishi, Fumita y col. 1985; Konishi, Horikawa. y col. 1991) el signo de la carga eléctrica y la estructura molecular es 
diferente a los dos pHs ensayados, situación que probablemente es la responsable de las diferentes propiedades de la interfase detectadas en función del $\mathrm{pH}$.

Si comparamos las distintas muestras sembradas a la misma concentración, vemos que a $\mathrm{pH}$ 2,0, a medida que se cierra el área de la balanza, las muestras tardan menos en producir incrementos en la tensión interfacial, excepto para la muestra TH2.2. La mayor eficiencia en las muestras a $\mathrm{pH} 2,0$ para aumentar la presión interfacial se puede atribuir al desplegamiento que sufren las moléculas por el $\mathrm{pH}$ ácido que permite que ocupen una mayor superficie, precisando menor cantidad de moléculas para producir efectos tensioactivos mensurables por esta técnica.

Con respecto a las diferentes muestras a $\mathrm{pH}$ 2,0, las menos eficientes en elevar los valores de $\pi$ fueron AH1.7 y AH9.5, sin embargo a pH 8,0 lo fue AI. A pH 8,0 el aislado no se encuentra desnaturalizado, en cambio los hidrolizados están desplegados, al menos parcialmente, debido al tratamiento térmico que sufrieron para detener la acción de la proteasa. Esos cambios estructurales, principalmente en el caso de TH2.2, aumentaron la eficacia de las proteínas para incrementar o elevar la presión superficial. Esta hipótesis podría también explicar el hecho que la muestra AI sea la que presentó mayores cambios en el comportamiento con la variación de $\mathrm{pH}$, ya que su estructura sería la más afectada.

\subsubsection{Cinéticas de tensión interfacial en la interfase aceitelagua}

\subsubsection{En $p H 2,0$}

Los gráficos a $\mathrm{pH}$ 2,0 de la variación de la tensión interfacial en la interfase o/w a diferentes concentraciones de AI obtenidos con el tensiómetro de gota (Sección 2.1.9.) se muestran en la Figura 2.13. A los $15000 \mathrm{~s}$ se puede observar que las curvas correspondientes a las concentraciones $0,1,0,5$ y $1 \mathrm{mg} / \mathrm{ml}$, alcanzan un valor de tensión interfacial de alrededor de $8 \mathrm{mN} / \mathrm{m}$, en cambio en las curvas correspondientes a 0,01 y $0,05 \mathrm{mg} / \mathrm{ml}$ no se arribaron a esos valores sino que estos se mantuvieron más altos. 


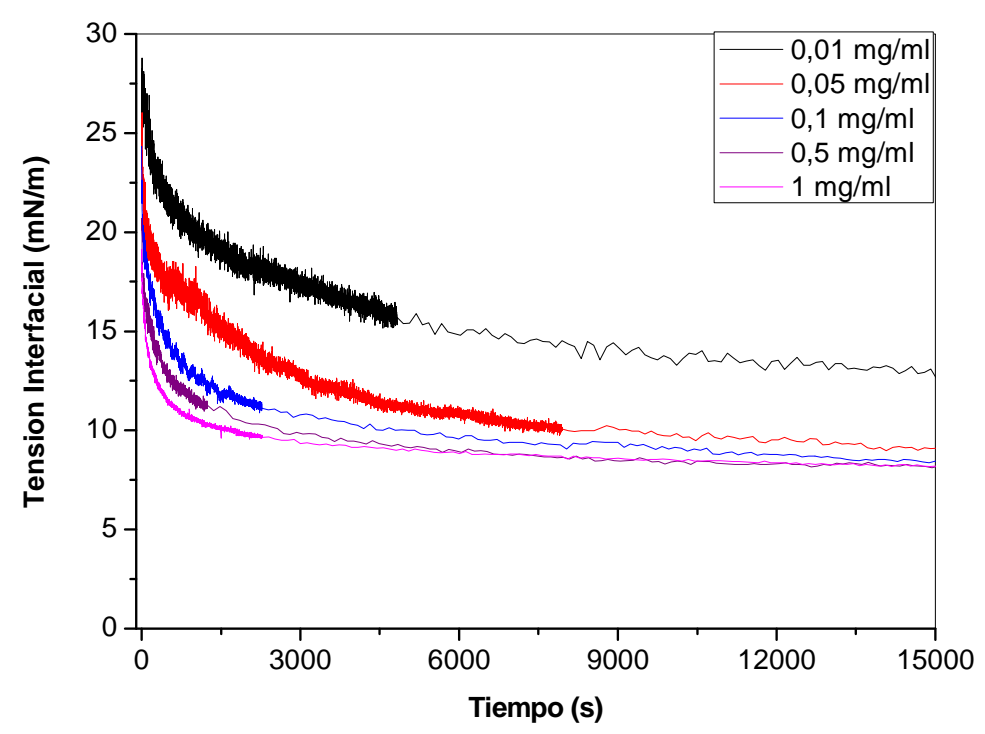

Figura 2.13.: Cinéticas de tensión interfacial a pH 2,0, en la interfase o/w de la muestra AI a distintas concentraciones indicadas en la figura.

Si prestamos atención a las curvas durante los primeros segundos, se observa que en ese lapso se produce el descenso más veloz de la tensión interfacial. En la Figura 2.14. se han graficado las curvas durante los primeros $200 \mathrm{~s}$. En ellas se observa que en la primera medida, el valor de tensión interfacial se hace cada vez menor al aumentar la concentración. Para la menor concentración, $0,01 \mathrm{mg} / \mathrm{ml}$, la primera medida de tensión fue de alrededor de $27,5 \mathrm{mN} / \mathrm{m}$, en tanto que para un $1 \mathrm{mg} / \mathrm{ml}$, el primer valor medido descendió a menos de $20 \mathrm{mN} / \mathrm{m}$. Este comportamiento indica que la adsorción de las proteínas, o al menos de algunas de ellas, a la interfase se produce a gran velocidad y provocan un descenso de la tensión interfacial de manera instantánea. Por consiguiente las proteínas responsables tendrían una alta velocidad de reorientación y reacomodamiento que les permitiría maximizar los efectos tensioactivos con gran rapidez. 


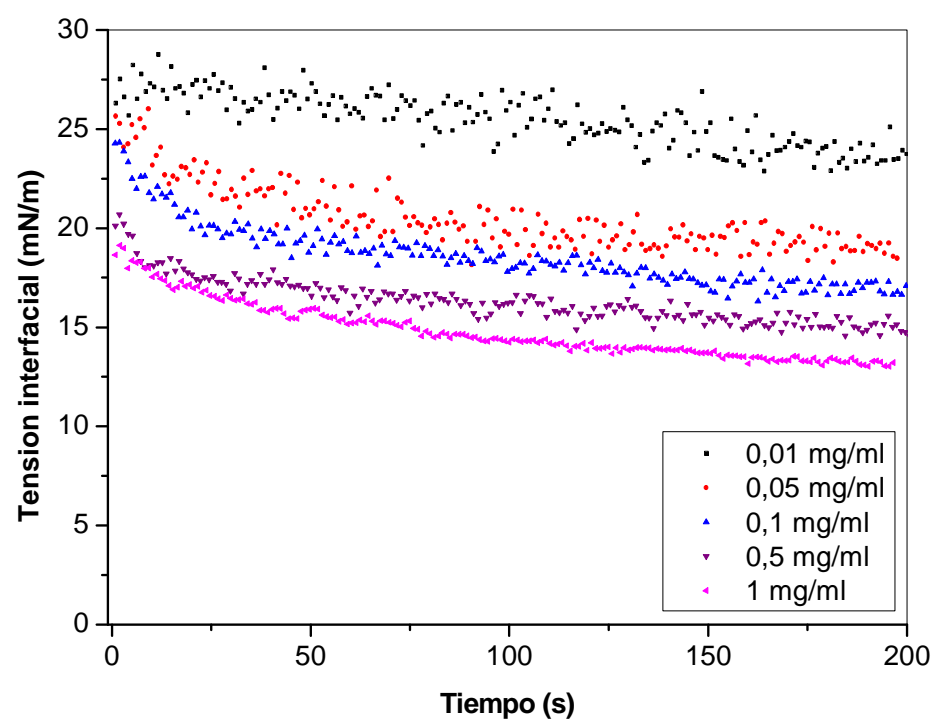

Figura 2.14.: Cinéticas de tensión interfacial durante los primeros $200 \mathrm{~s}$, en la interfase o/w de la muestra $\mathrm{AI}$ en distintas concentraciones indicadas en la figura a $\mathrm{pH} 2,0$.

En base a los resultados obtenidos para diferentes concentraciones de $\mathrm{AI}$ a $\mathrm{pH}$ 2,0, se decidió trabajar con con el resto de las muestras a $0,1 \mathrm{mg} / \mathrm{ml}$ (Figura 2.15.). Con AI y TH2.2 se lograron valores de tensión interfacial inferiores a los correspondientes a las muestras hidrolizadas con alcalasa, AH1.7 y AH9.5. Resulta interesante el comportamiento presentado por la muestra con mayor grado de hidrólisis, AH9.5, ya que con esa muestra se obtuvieron, a lo largo de toda la experiencia, valores de tensión interfacial superiores a los de otras muestras. Se puede pensar que al ser los polipéptidos más pequeños, tienen mayor facilidad para arribar a la interfase pero evidentemente la naturaleza de los mismos no les permite ser tan eficientes para producir un mayor descenso de la tensión interfacial. 


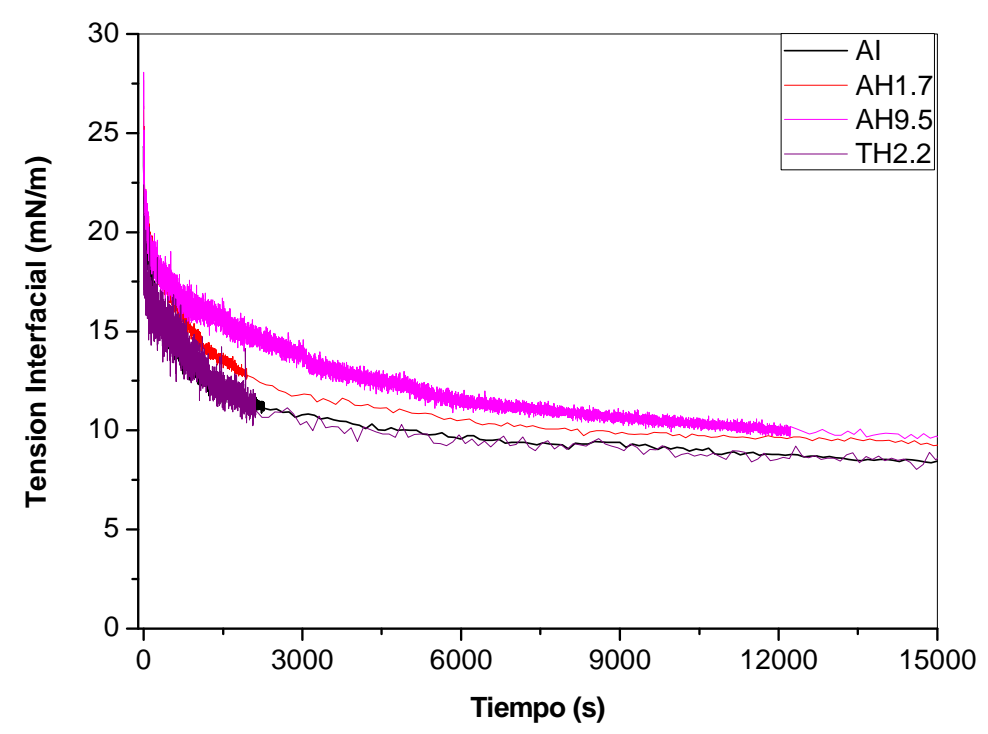

Figura 2.15.: Cinéticas de tensión interfacial en la interfase $\mathrm{o} / \mathrm{w}$ de las diferentes muestras indicadas en la figura en condiciones de $\mathrm{pH}$ 2,0 en una concentración de proteína de 0,1 $\mathrm{mg} / \mathrm{ml}$.

Las cinéticas de tensión interfacial durante los primeros 200 s muestran que en la primera medida se obtienen valores de tensión interfacial diferentes según las muestras (Figura 2.16.). Mientras que para AI y TH2.2 se alcanzan valores entre 22 y $24 \mathrm{mN} / \mathrm{m}$, para AH1.7 y AH9.5 los valores variaron de 26 a $28 \mathrm{mN} / \mathrm{m}$. Esto da una idea de la facilidad de los polipéptidos para disminuir la tensión interfacial según el estado en el que se encuentren. Las proteínas de amaranto nativas o hidrolizadas con tripsina tienen una estructura que favorece el descenso rápido de la tensión interfacial respecto a los polipéptidos obtenidos por acción de alcalasa, la cual hace que disminuya la capacidad tensioactiva de los mismos. 


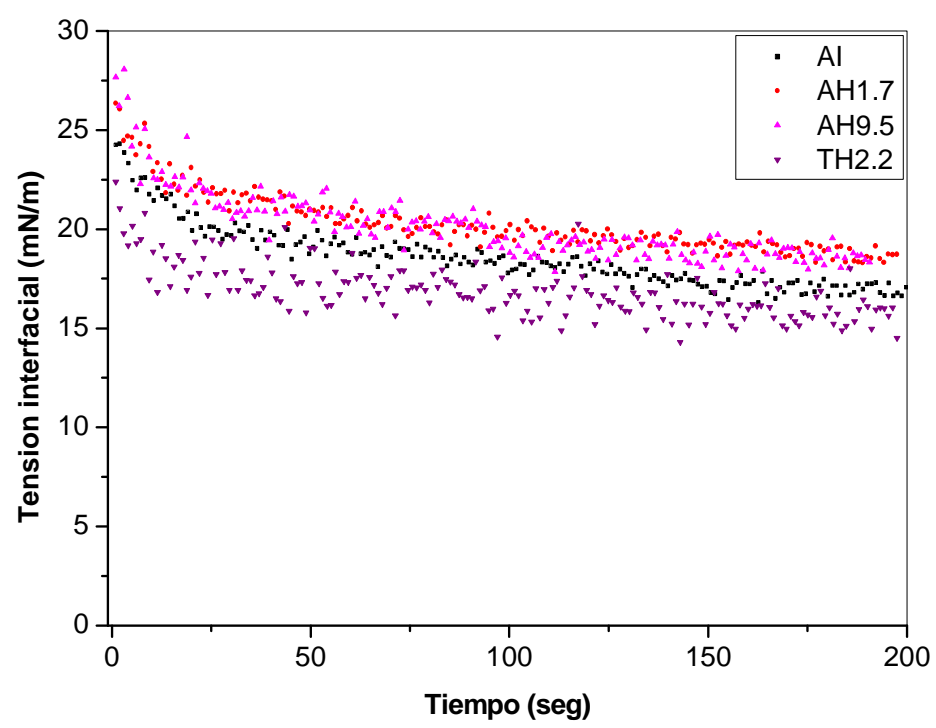

Figura 2.16.: Cinéticas de tensión interfacial durante los primeros $200 \mathrm{~s}$ en la interfase $\mathrm{o} / \mathrm{w}$ de las diferentes muestras indicadas en la figura en condiciones de $\mathrm{pH} 2,0$.

\subsubsection{2. $E n p H ~ 8,0$}

En la Figura 2.17. se muestran las cinéticas a distintas concentraciones de las diferentes muestras a $\mathrm{pH} 8,0$. A los $15000 \mathrm{~s}$ se llega al descenso máximo de la tensión interfacial a partir de concentraciones de $0,5 \mathrm{mg} / \mathrm{ml}$ de proteína. Si lo comparamos con las cinéticas a $\mathrm{pH}$ 2,0 podemos comprobar que en este caso se necesita mayor concentración de proteína para llegar a los valores de equilibriodurante ese tiempo. A pH 8,0 el equilibrio se logra a partir de una concentración proteica de $0,5 \mathrm{mg} / \mathrm{ml}$.

En las cinéticas durante los primeros $200 \mathrm{~s}$ se observa un comportamiento similar a los $15000 \mathrm{~s}$ (Figura 2.18). Al inicio de las mediciones a medida que aumenta la concentración de proteína en la interfase los valores de tensión interfacial son menores, indicando una alta velocidad de adsorción y reacomodamiento para minimizar la energía libre del sistema 


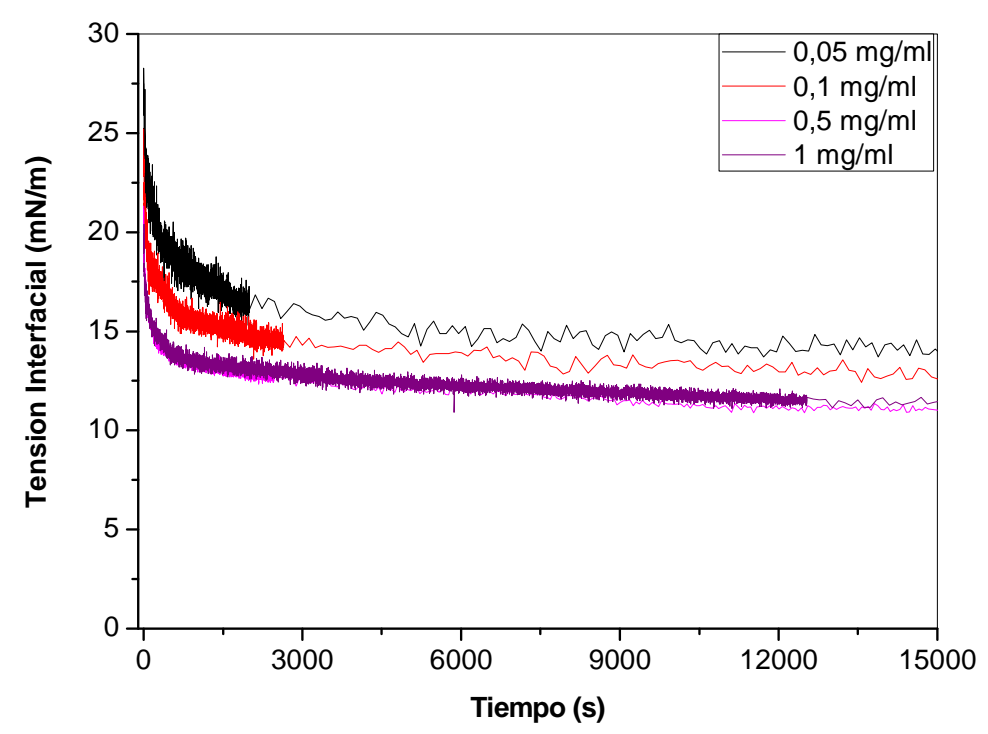

Figura 2.17.: Cinéticas de tensión interfacial a pH 8,0, en la interfase o/w de la muestra AI a distintas concentraciones, indicadas en la figura.

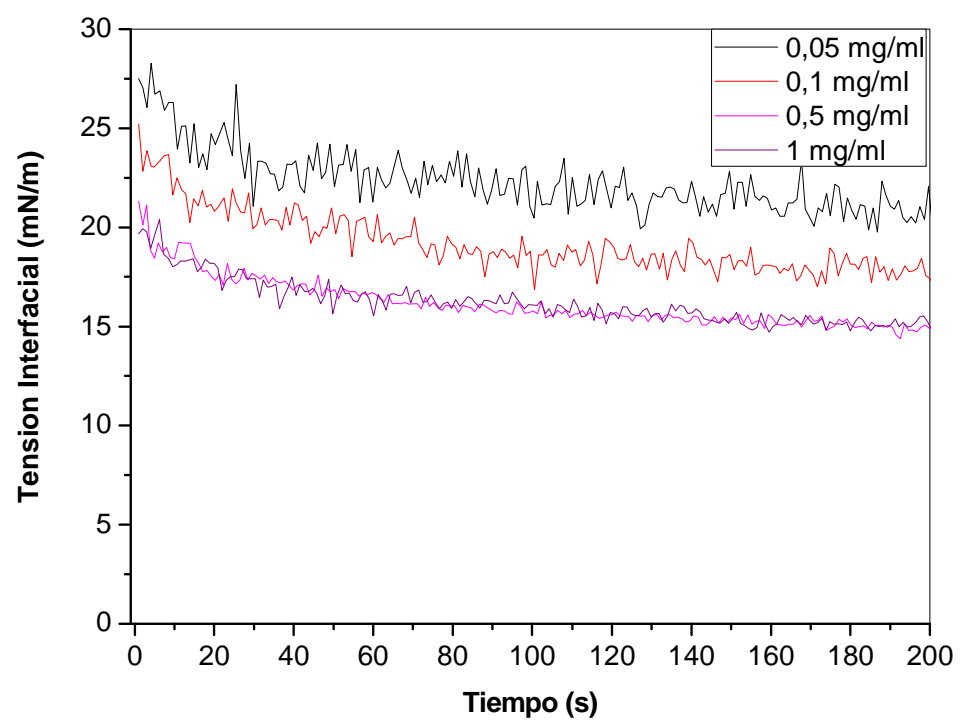

Figura 2.18: Cinéticas de tensión interfacial a pH 8,0 durante los primeros $200 \mathrm{~s}$, en la interfase o/w de la muestra $\mathrm{AI}$ a distintas concentraciones, indicadas en la figura.

En la Figura 2.19. se muestran las cinéticas de tensión interfacial a pH 8,0 correspondientes a las distintas muestras en una concentración proteica de 0,1 $\mathrm{mg} / \mathrm{ml}$. Las muestras que llegaron a valores menores de tensión interfacial 
durante los $15000 \mathrm{~s}$ fueron AI y TH2.2. AH1.7 y AH9.5 produjeron descensos menores de la tensión interfacial comparados con las otras dos muestras. La hidrólisis con alcalasa no pareció ayudar al descenso de la tensión, sin embargo si se mejoró mediante la hidrólisis con tripsina.

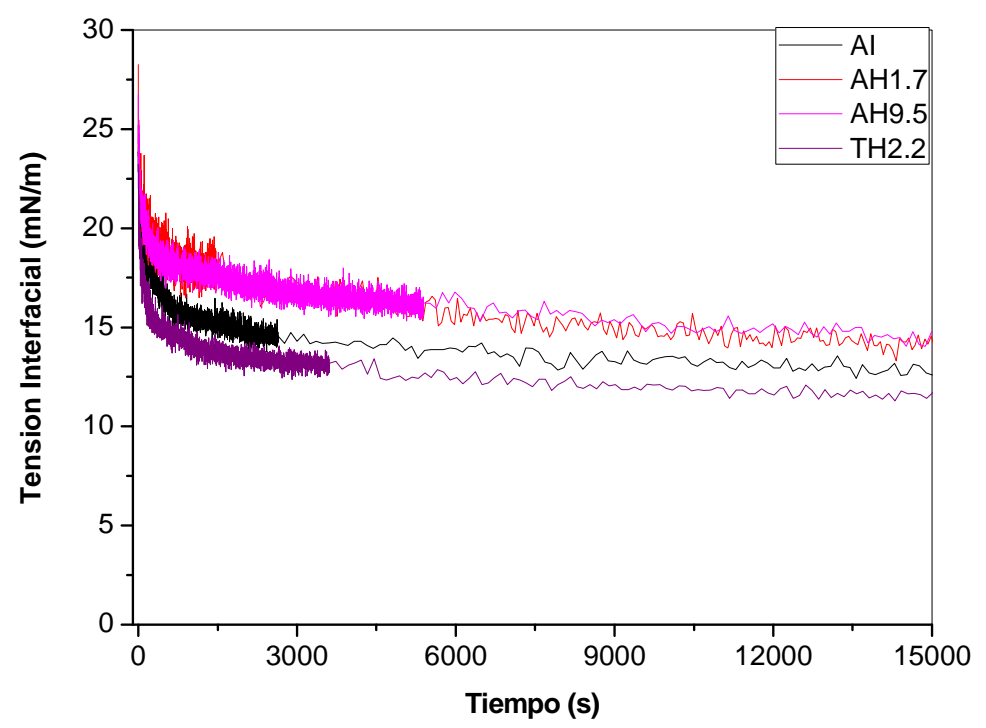

Figura 2.19.: Cinéticas de tensión interfacial en la interfase o/w de las diferentes muestras indicadas en la figura a $\mathrm{pH} 8,0$ y $0,1 \mathrm{mg} / \mathrm{ml}$.

\subsubsection{Comparación entre $\mathrm{pH} 2,0$ y $\mathrm{pH} 8,0$}

A pH 2,0 los valores de tensión interfacial a los que se llegó luego de 15000 s de adsorción fueron algo menores que los que se obtuvieron a $\mathrm{pH} 8,0$. También a $\mathrm{pH}$ 2,0 se necesitó menos concentración proteica para producir los mayores descensos de tensión interfacial. Evidentemente hay una mayor eficiencia de estas proteínas para producir descensos de la tensión interfacial a $\mathrm{pH}$ ácido. Hay que tener en cuenta que a $\mathrm{pH}$ 2,0 la proteína se encuentra con un alto grado de desnaturalización mientras que a $\mathrm{pH} 8,0$ el grado de desplegamiento es sensiblemente menor. El hecho que a $\mathrm{pH}$ 2,0 las moléculas proteicas se encuentren disociadas y más desplegadas permitiría una mayor libertad y flexibilidad para anclarse en la interfase y la posibilidad de aquirir una conformación más adecuada para disminuir la tensión interfacial existente entre la fase acuosa y el aceite. En cambio la mayor asociación y estructuración de las moléculas proteicas a $\mathrm{pH} 8,0$ dificultaría los cambios conformacionales que 
deben ocurrir a nivel molecular para producir un descenso de la tensión interfacial

Hay que recordar que a $\mathrm{pH}$ 2,0, AI sufre una hidrólisis (sección 1.2.1.2.2.) que pudo afectar las propiedades tensioactivas de las moléculas ya sea por modificar la flexibilidad de las mismas como por disminuir el tamaño, lo que aumentaría la velocidad de difusión de las moléculas a la interfase.

La Figura 2.20. (a) y (b) muestra las cinéticas de descenso de la tensión interfacial en coordenadas semilogarítmicas, de la muestra $\mathrm{AI}$ a los dos $\mathrm{pH}$ y a distintas concentraciones. Algunos autores (Beverung, Radke y col. 1999; Casçao Pereira, Thédoly y col. 2003) definen la cinética de la tensión interfacial como 3 régimenes definidos. En la Figura 2.20.(a) sólo pueden observarse los dos primeros ya que el régimen III no pudo determinarse debido a que los experimentos finalizaron antes de que pudiera manifestarse.

El régimen I corresponde al período de inducción durante el cual no se llega a cubrir lo suficiente la interfase con proteína y por ende no se reduce la tensión interfacial. Durante este período la difusión de las proteínas limita la velocidad de disminución de la tensión superficial. Se puede observar en ambos pHs que el régimen I dura menos tiempo con el aumento de la concentración. Esto resulta de las mayores posibilidades de las moléculas para arribar a la interfase. No se pueden observar grandes diferencias entre los dos $\mathrm{pH}$ en los tiempos del régimen I. El régimen II es una etapa de saturación de la monocapa y se encuentran diferencias entre los dos $\mathrm{pHs}$ ensayados. Las pendientes de las curvas a $\mathrm{pH} 2,0$ son más pronunciadas que a $\mathrm{pH} 8,0$. A partir de esto se puede relacionar que la proteína a $\mathrm{pH}$ 2,0 se encontraría en un estado más flexible y menos estructurado que a $\mathrm{pH} 8,0$ (sección 1.2.1.1.) por la disociación y la hidrólisis que se produce a $\mathrm{pH}$ ácido (sección 1.2.2.). Esto le permite acomodarse y establecer interacciones con más facilidad que cuando se encuentra globular lo que aumenta la velocidad de descenso de la tensión interfacial. Por ejemplo la $\beta$ caseína que es una proteína flexible produce pendientes más negativas que la lisozima que es más rígida y estructurada (Beverung, Radke y col. 1999; Freer, Yim y col. 2004). 
(a)

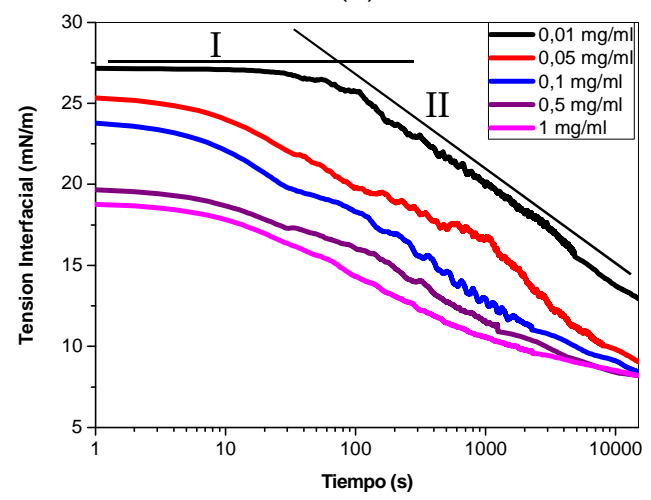

(b)

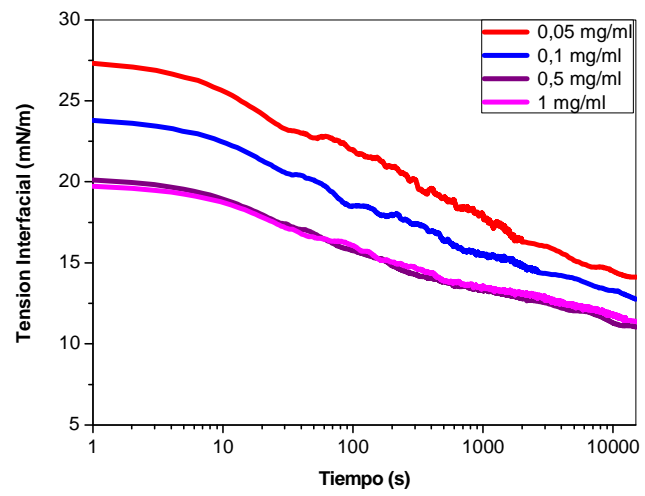

Figura 2.20.: Cinéticas de tensión interfacial en la interfase $\mathrm{o} / \mathrm{w}$ de $\mathrm{AI}$ en distintas concentraciones indicadas en las figuras: (a) pH2,0, (b) pH 8,0.

Si comparamos el régimen II de las distintas muestras a ambos pHs (Figura 2.21.) sucede lo mismo que para AI a distintas concentraciones: la pendiente es de mayor magnitud a $\mathrm{pH}$ 2,0, lo que implica reordenamientos más fáciles y efectivos en la interfase a ese pHque permiten un mejoramiento de las propiedades tensioactivas.

(a)

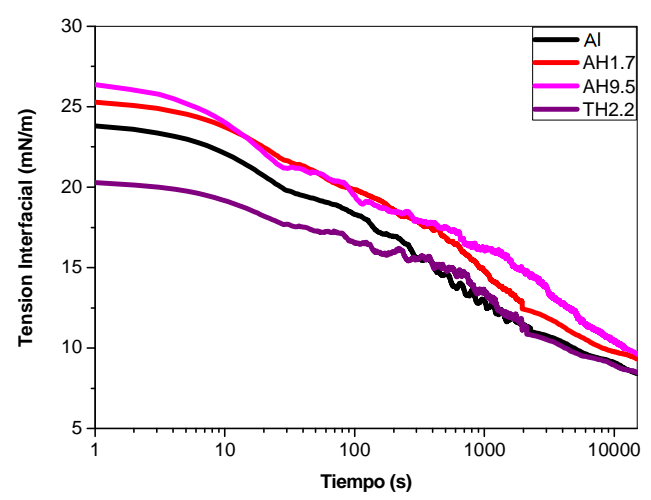

(b)

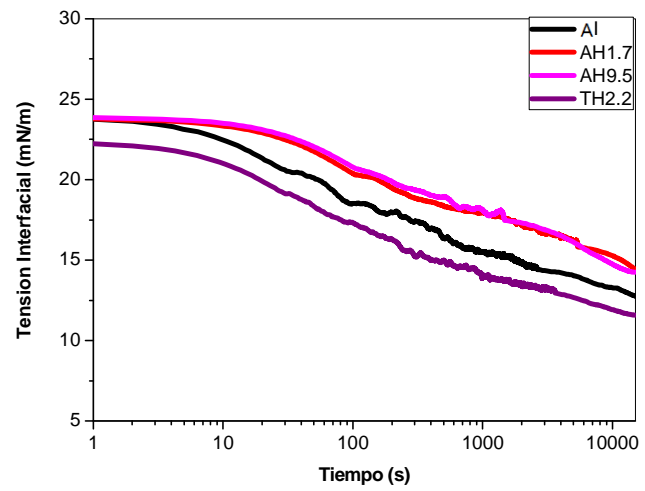

Figura 2.21:: Cinéticas de tensión interfacial en la interfase o/w de las distintas muestras indicadas en las figuras en una concentración 0,1 mg/ml: (a) pH 2,0, (b) pH 8,0.

\subsubsection{Reología interfacial en la interfase aceitelagua}

Las medidas de reología interfacial mostraron valores entre 3 y 4 veces superiores del módulo complejo interfacial en el caso de las interfases a $\mathrm{pH}$ 2,0 que a $\mathrm{pH} 8,0$ (Figura 2.22.). Las diferencias de esta magnitud pudieron ser causadas por la interacción en las proteínas en la interfase de una mayor 
cantidad de zonas hidrofóbicas que se expusieron hacia al exterior de la estructura proteica por el sometimiento de las proteínas a las condiciones ácidas de $\mathrm{pH}$. Otra causa puede deberse a la interacción de grupos sulfhidrilo para pasar a formar puentes disulfuro al entrar en contacto íntimo en la interfase. Es necesario que estos grupos sulfhidrilo no formaran parte de puentes disulfuro para que puedan reaccionar. Castellani, Martínez y col. (1999) informaron en las globulinas de amaranto la existencia de grupos sulfhidrilos libres que se encuentran ocultos hacia el interior de la estructura. Estos pudieron haberse expuesto por la desnaturalización proteica ocurrida a $\mathrm{pH}$ ácido según muestran los valores de entalpías de DSC de la Tabla 1.1 de la sección 1.2.1.1. (AN pH 2,0 y $\mathrm{AN} \mathrm{pH} \mathrm{8,0).} \mathrm{Se} \mathrm{debe} \mathrm{tener} \mathrm{en} \mathrm{cuenta} \mathrm{que} \mathrm{la} \mathrm{formación} \mathrm{de} \mathrm{puentes} \mathrm{disulfuro} \mathrm{a} \mathrm{pH}$ 2,0 es más lenta pero sin embargo puede darse, y la probabilidad de que se formen aumenta por la alta concentración de proteína que se da en la interfase (Darby y Creighton 1995).

A pH 8,0 muchas de las zonas hidrofóbicas se encuentran ocultas hacia el interior de la estructura globular de las proteínas evitando el agua del medio. Aunque las proteínas sufran un cambio conformacional o desnaturalización parcial cuando se adsorben en la interfase, ese cambio normalmente se produce muy lentamente en una proteína globular porque para producirlo tiene que atravesar una barrera energética grande (Dickinson, Rolfe y col. 1990; McClements, Monahan y col. 1993). En cambio con la desnaturalización producida a $\mathrm{pH} 2,0$ se abrió la estructura. Estos aumentos en los módulos de viscoelasticidad del film pueden resultar en un incremento de la resistencia de la película interfacial y a la coalescencia (Izmailova, Yampolskaya y col. 1999; Maldonado-Valderrama, Martín-Rodriguez y col. 2008).

Si comparamos las muestras a cada uno de los $\mathrm{pH}$, se puede advertir que mientras a $\mathrm{pH}$ 2,0 AI presenta un módulo interfacial mayor que las otras muestras, a pH 8,0, su módulo es menor. Evidentemente, el hecho de no haber sufrido hidrólisis hace que a $\mathrm{pH} 8,0$ muestre en los tiempos del ensayo valores de módulo interfacial menores que con las muestras hidrolizadas. Probablemente los cambios conformacionales para aumentar el número de interacciones entre moléculas y así darle más rigidez al film son más lentos que con las muestras que sufrieron hidrólisis debido a la mayor estructuración que presentarían las proteínas en el caso de AI. Es razonable suponer que si los tiempos ensayados hubiesen sido mayores el valor del módulo hubiera sido similar a los de las otras muestras. En cambio cuando AI se encuentra a $\mathrm{pH}$ 2,0, las proteínas sufren 
cambios estructurales a todos los niveles de estructura, y son favorables para que puedan producir films con mayor viscoelasticidad.

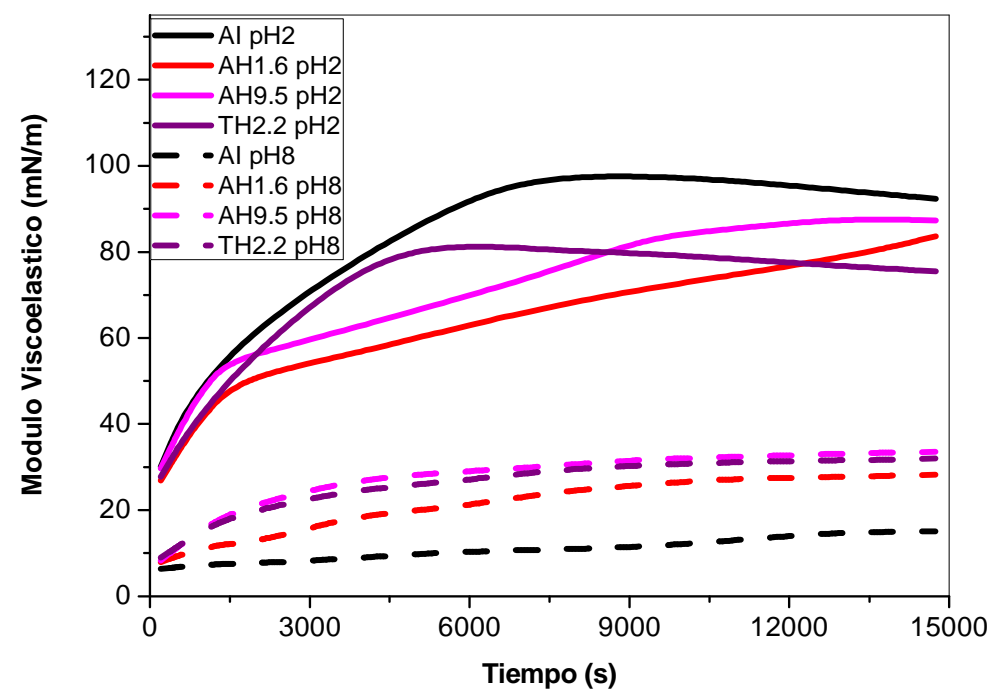

Figura 2.22.: Curvas de reología interfacial vs el tiempo de maduración de la interfase o/w de las distintas muestras a los distintos pHs (indicado en la figura).

\subsubsection{Emulsiones con baja relación proteinalaceite}

\subsubsection{Actividad emulsificante}

La Figura 2.23.(a) muestra la distribución de tamaño de partículas, en ausencia de SDS, expresada en porcentaje del volumen de las emulsiones obtenidos inicialmente con AI, AH1.7, TH2.2 AH9.5 y a diferentes $\mathrm{pH}$ de la fase continua $(2,0,6,3$ y 8,0$)$. En todos los casos las distribuciones de tamaño de partícula fueron bimodales, con dos poblaciones definidas: (I) gotas con un diámetro menor a $2 \mu \mathrm{m}$, y (II) gotas con un diámetro medio superior a $10 \mu \mathrm{m}$. La contribución de la población I al volumen total de la fase dispersa no fue significativa, pero su importancia aumenta si se considera el área interfacial creada durante el proceso de homogeneización (cuadro insertado en la Figura 2.23.(a)). Al cambiar el pH del medio, las distribuciones para las emulsiones obtenidas con AI exhiben sólo un pequeño cambio. Para la población II los valores de diámetro de gota varían de 10 a $100 \mu \mathrm{m}$, mientras que a los pHs 6,3 y 8 no muestran polidispersidad tan marcada (Figura 2.23.(a)). En el caso de las emulsiones preparadas con los hidrolizados AH1.7, AH9.5 y TH2.2, las 
distribuciones cambiaron significativamente con el $\mathrm{pH}$ de la fase continua (Figura 2.23.(b-d)). Los tamaños de gota de la población II en el caso de los hidrolizados aumentaron notablemente a $\mathrm{pH}$ 6,3 y en menor medida, a $\mathrm{pH} 8,0$, pero no se produjeron cambios importantes a $\mathrm{pH} 2,0$ con respecto a las distribuciones obtenidas para AI. A pH 6,3 y 8,0 el aumento de tamaño de gota para la población II fue más evidente en las emulsiones preparadas a partir AH1.7 y AH9.5, Habiendo sido este efecto más acusado para el mayor grado de hidrólisis (Figura 2.23.(b y c)).
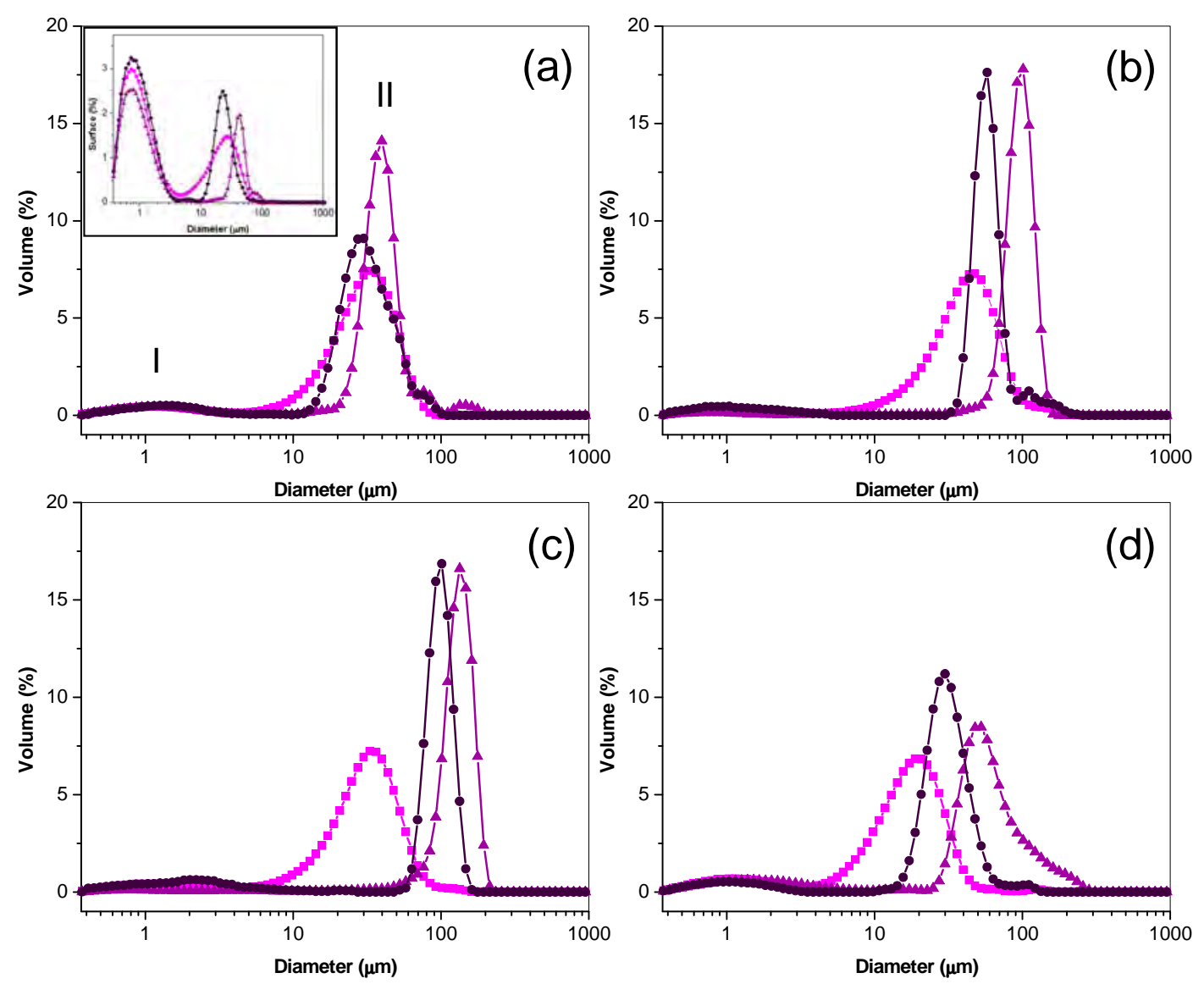

Figura 2.23.: Perfiles de distribuciones de tamaño de gota de emulsiones o/w preparadas con dispersiones de proteínas de amaranto nativas e hidrolizadas: AI (a) AH1.7 (b), AH9.5 (c), TH2.2 (d) a: pH $2(\square)$, pH $6.3(\boldsymbol{\Delta})$ y pH $8(\bullet)$. Las distribuciones están expresadas en volumen de aceite.

Las distribuciones de tamaño de partícula en presencia de SDS (Figura 2.24.) mostraron la misma tendencia que se discutió anteriormente. Sin embargo, las distribuciones de tamaño de partículas a $\mathrm{pH} 2$ presentaron valores de diámetros menores $(<10 \mu \mathrm{m})$ que en ausencia de SDS. 

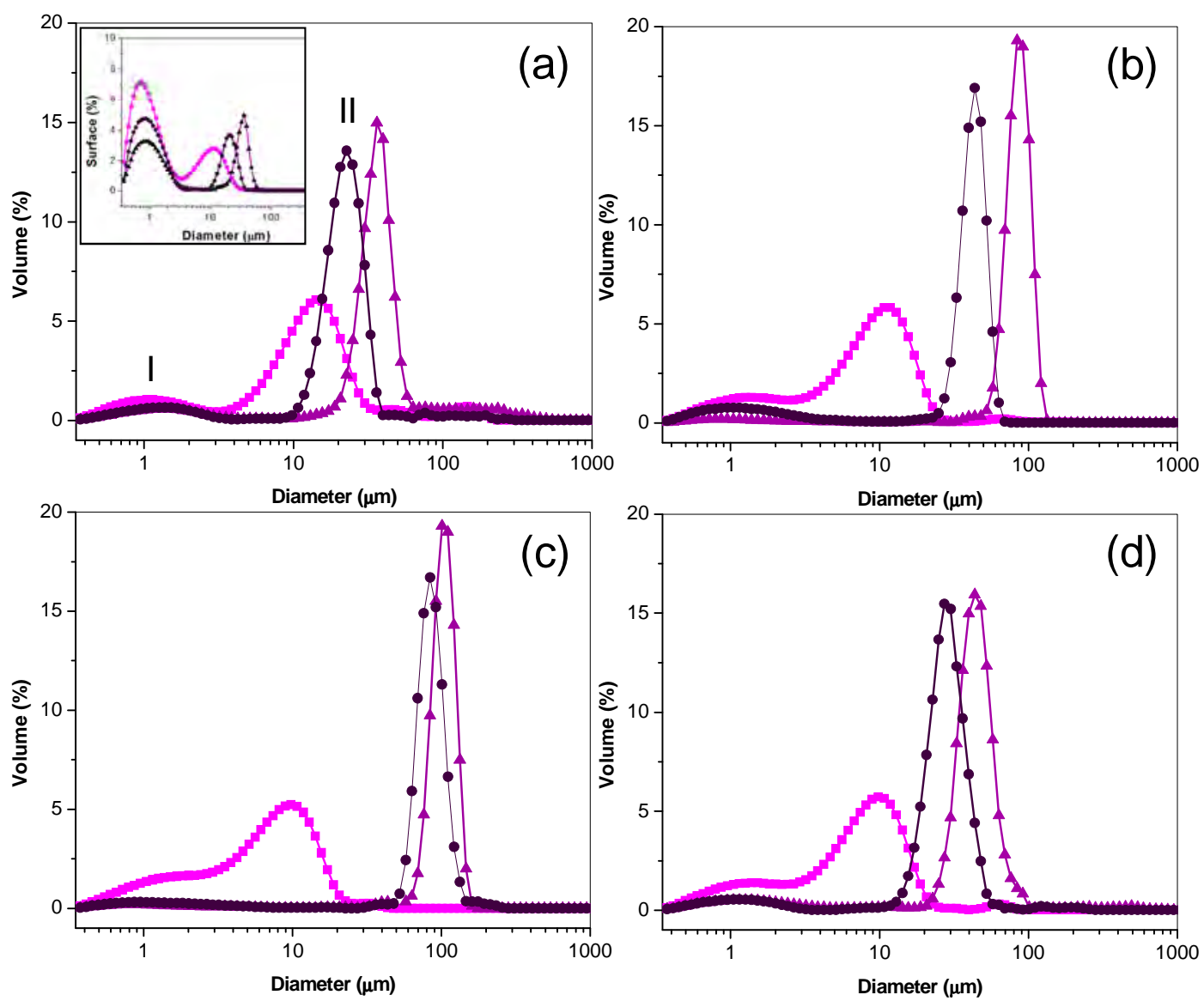

Figura 2.24.: Perfiles de distribuciones de tamaño de gota de emulsiones o/w en presencia de SDS preparadas con dispersiones de proteínas de amaranto nativas e hidrolizadas: AI (a) AH1.7 (b), AH9.5 (c), TH2.2 (d) a: pH 2 (घ), pH $6.3(\mathbf{\Delta})$ y pH $8(\bullet)$. Las distribuciones están expresadas en volumen de aceite.

Las emulsiones con mayor polidispersidad fueron las obtenidas a $\mathrm{pH} 2,0$ independientemente de que se formularan partir del aislado o de cualquiera de los hidrolizados en estudio (Tabla 2.1.). Se detectó una notable reducción de la polidispersidad para las emulsiones preparadas con AH1.7 y AH9.5 a pH 6,3, hecho que también fue observado para AH1.7 a pH 8,0. También se detectó una reducción de polidispersidad para las emulsiones preparadas a partir TH2.2 al aumentar el $\mathrm{pH}$ de la fase continua.

El área interfacial específica creada (SIA) por AI varió significativamente con los cambios de $\mathrm{pH}$ de la fase continua de la emulsión, dando valores más altos a $\mathrm{pH}$ 2,0 (Tabla 2.1.). En el caso de las emulsiones preparadas con hidrolizados, la SIA más alta se obtuvo a $\mathrm{pH} 2,0$. A los $\mathrm{pH} 8,0$ y 6,3 la SIA fue un 50\% y 80\% menor 
que la obtenida a $\mathrm{pH}$ 2,0, respectivamente. La disminución de la SIA, con el pH para AI fue menor que la correspondiente a los hidrolizados.

Los perfiles de back scattering (BS) iniciales obtenidos en función de la longitud del tubo o celda de medida del Quickscan, pueden proporcionar alguna información acerca de la microestructura de la emulsión original. Los valores de BS dependen del tamaño de las gotas, como también de la fracción volumétrica de la fase dispersa. En el caso de las emulsiones recién preparadas las gotas se distribuyen uniformemente a lo largo del tubo de ensayo ya que todavía no se pueden visualizan los procesos de desestabilización y estas se conservan como un sistema más o menos homogéneo. En esta situación, los valores iniciales de BS permiten hacer una determinación cualitativa del tamaño de la gota de la emulsión. Como se muestra en la Figura 2.25., el \%BS inicial tiende a disminuir con el aumento de los valores de $\mathrm{d}_{4,3}$. Las gotas de menor tamaño corresponden a las emulsiones a pH 2,0 que reflejan una mayor proporción de la luz incidente.

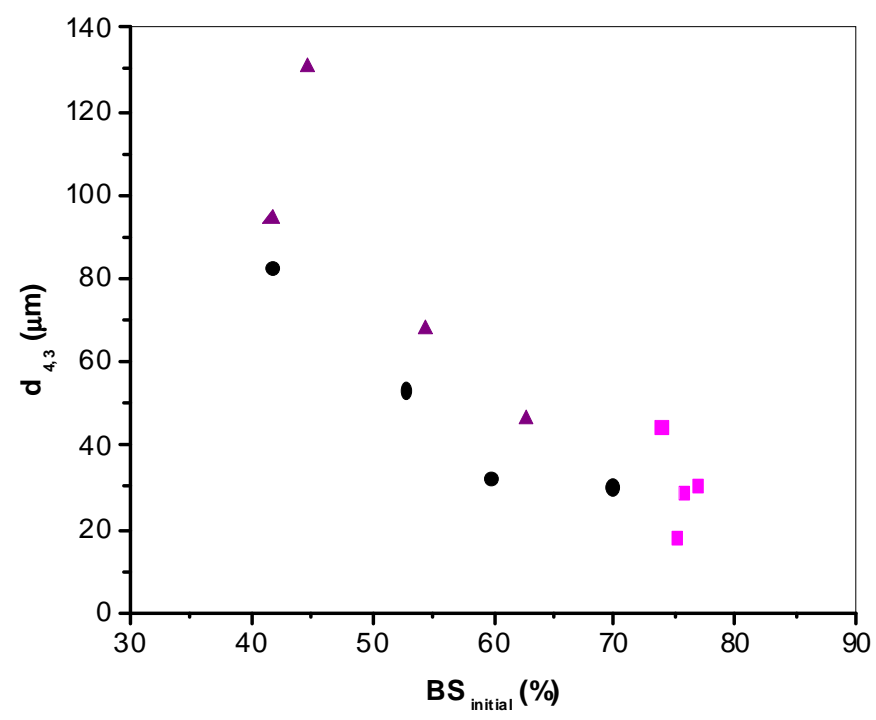

Figura 2.25.: Relación entre $\mathrm{d}_{4,3} \mathrm{y} \% \mathrm{BS}$ in de emulsiones $\mathrm{o} / \mathrm{w}$ preparadas con dispersiones de aislados proteicos de amaranto hidrolizados y sin hidrolizar: pH $2(\square), \mathrm{pH} 6.3(\boldsymbol{\Delta})$ y pH $8(\bullet)$.

Relaciones similares fueron obtenidas por Márquez (Marquez, Palazolo y col. 2005) y Palazolo (Palazolo 2006) para las emulsiones de leche de soja, aceite vegetal y grasa láctea, y emulsiones realizadas con aislados proteicos de soja y con proteínas de soja nativas y desnaturalizadas, respectivamente. La comparación de las distribuciones de tamaño de partícula a pH 6.3 y 8.0 para las emulsiones producidas con los diferentes hidrolizados indica que la acción de la alcalasa produjo péptidos con menor actividad emulsificante (partículas grandes 
con menor SIA) tendencia que se intensificó con el incremento del grado de hidrólisis.

\subsubsection{Estabilidad de emulsiones}

Para evaluar las cinéticas de cremado floculación de las emulsiones, se analizaron los perfiles de \%BS durante las primeras 3 y a las 24 horas de almacenamiento.

La migración de las gotas, en una emulsión de aceite en agua, se produce en dirección a la parte superior de la celda de medida por la acción de la gravedad, llevando a la disminución de la población de gotas en la parte inferior del tubo y la consiguiente reducción del \%BS en esa zona. Por lo tanto, la cinética de cremado-floculación se determina a partir de valores medios BS\% (\%BSav) en función del tiempo en la zona del tubo que va desde los 10 a los $15 \mathrm{~mm}$ desde el fondo. La figura 2.26. muestra las cinéticas de cremado-floculación que corresponden a las emulsiones preparadas de $\mathrm{AI}$ a los tres valores de $\mathrm{pH}$ elegidos. Las emulsiones preparadas a $\mathrm{pH}$ 6,3, exhiben el mayor grado de desestabilización tal como lo indica la veloz caída del \%BS ${ }_{\mathrm{av}}$ con el tiempo, seguida por las emulsiones preparadas a $\mathrm{pH}$ 8,0. Las emulsiones preparadas a pH 2,0 se mantuvieron estables por más de $30 \mathrm{~min}$. Además en el último caso, la clarificación de las fase acuosa inferior a $40 \mathrm{~min}$ de almacenamiento fue significativamente menor que la de las emulsiones realizadas a $\mathrm{pH} 6,3$ y 8,0. Se observaron cambios similares de la fase continua para las emulsiones preparadas con AH1.7, AH9.5 y TH2.2. Las emulsiones obtenidas con AH1.7 y TH2.2, exhibieron mayor estabilidad, particularmente a $\mathrm{pH}$ 2,0. El comportamiento de las emulsiones luego de 24 h (1440 min) de almacenamiento estacionario siguió la misma tendencia que la observada durante las primeras horas. 

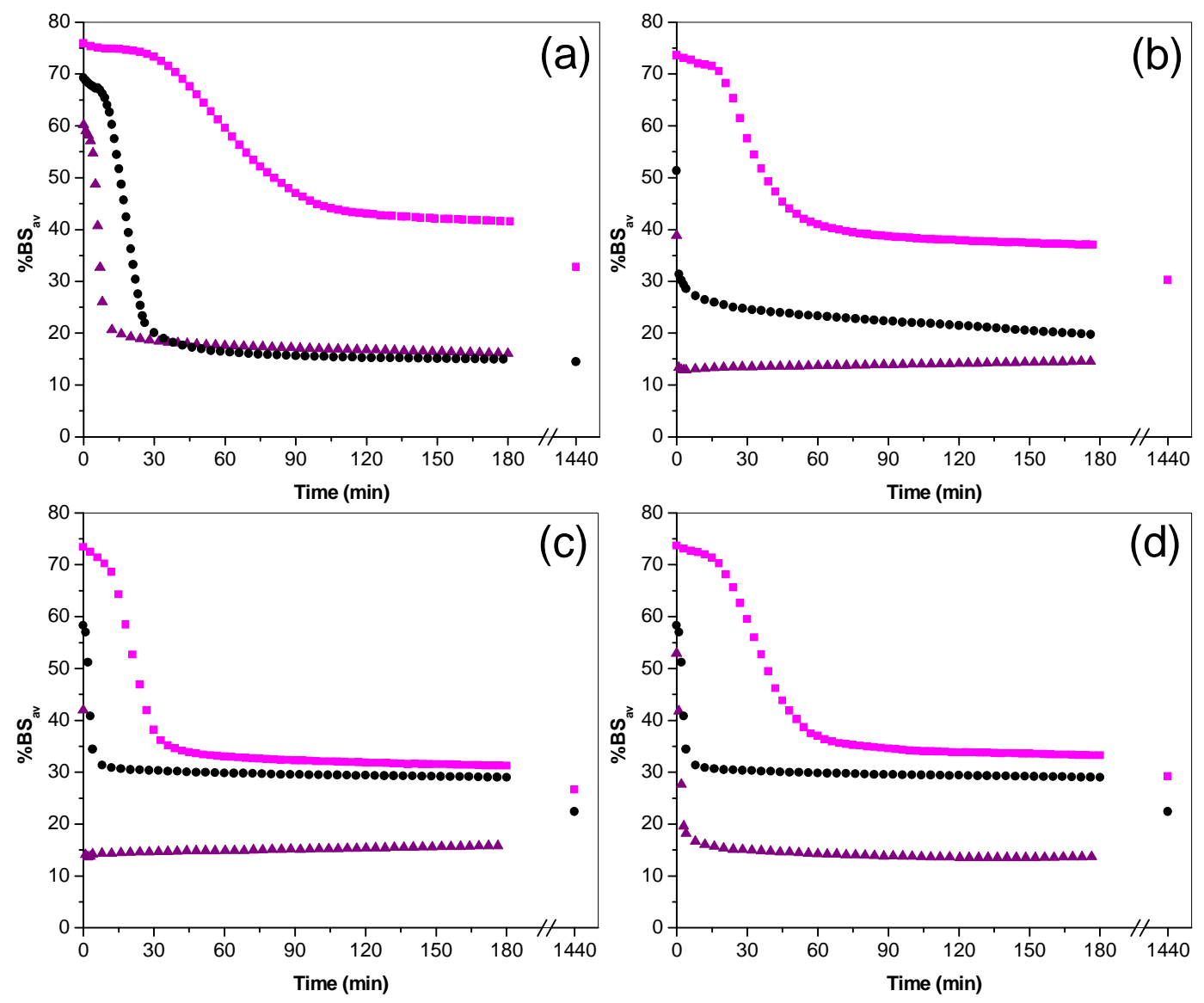

Figura 2.26.: Cinéticas de desestabilización, clarificación en la zona baja del tubo, 10-15 mm, correspondiente a emulsiones $\mathrm{o} / \mathrm{w}$ preparadas con dispersiones de proteínas de amaranto hidrolizadas y sin hidrolizar, AI (a) AH1.7 (b), AH9.5 (c), TH2.2 (d) a: pH 2 (匹), pH 6.3 (스) y $\mathrm{pH} 8,0(\bullet)$. Valores a $1440 \mathrm{~min}(24 \mathrm{~h})$ que no aparecen en la figura tienen valores de \%BSav menores al $5 \%$.

La Figura 2.27. muestra la constante de desestabilización $\mathrm{k}_{0.1}$ que proporciona información acerca de la tasa de clarificación de la parte inferior del tubo de medida $(10-15 \mathrm{~mm})$ hasta que se reduce un $10 \%$ el valor inicial de $\%$ BS. Se puede observar que las emulsiones más inestables son aquellas preparadas con los hidrolizados obtenidos por tratamiento con alcalasa a $\mathrm{pH} 6,3$ y 8,0. 


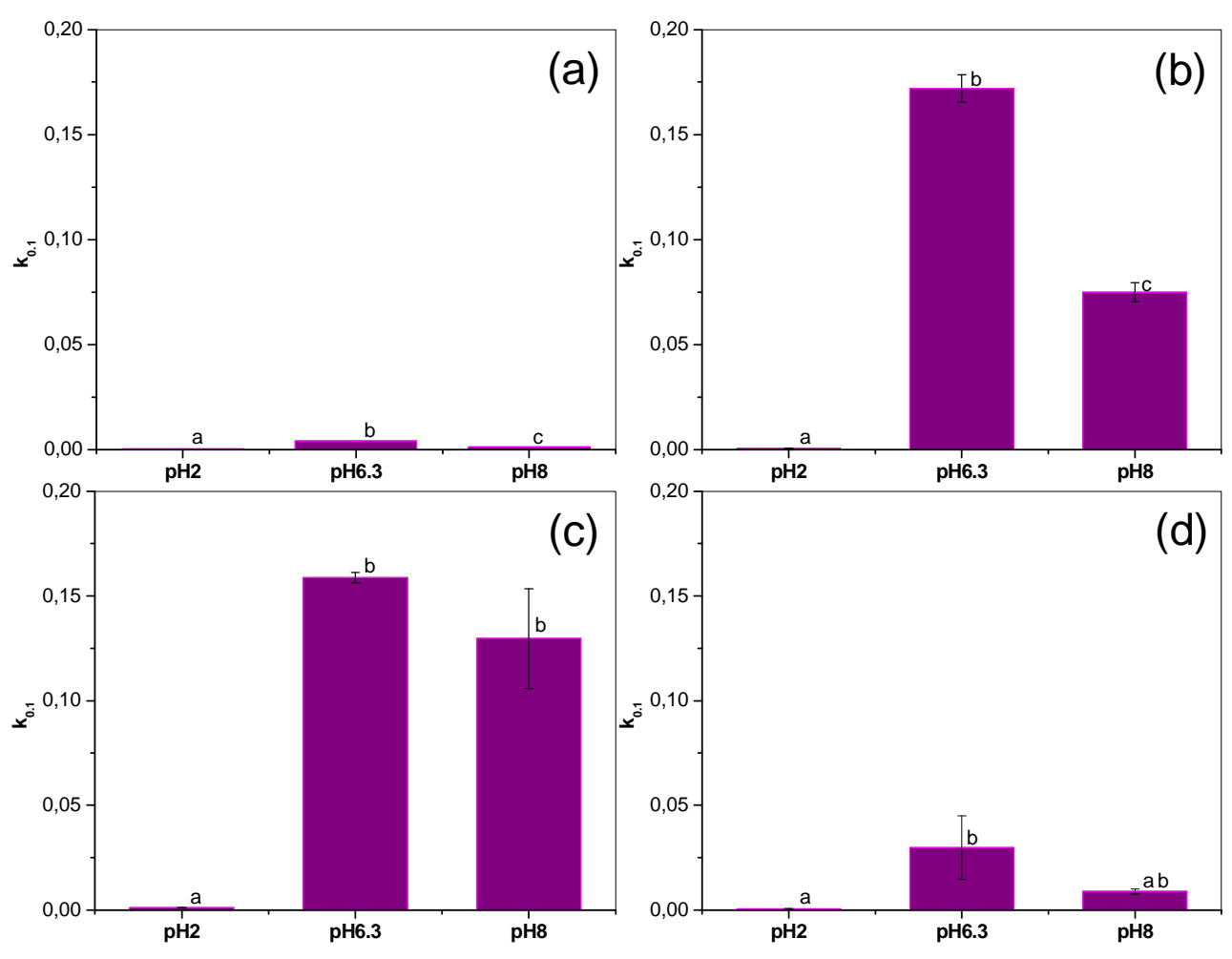

Figura 2.27.: Constante de cremado $\mathrm{k}_{0,1}$, a diferentes $\mathrm{pHs}$ correspondientes a emulsiones o/w preparadas con dispersiones de AI (a), AH1.7 (b), AH9.5 (c) y TH2.2 (d). Las barras con letras iguales no son significativamente diferentes $(\alpha=0,05$, Tukey test).

Las cinéticas de floculación y coalescencia de la fase de crema se determinaron a partir de la variación de la \%BSav en la parte superior $(40-50 \mathrm{~mm})$ de la celda de medida. Los resultados obtenidos para todas las muestras ensayadas se muestran en la Figura 2.28. Para emulsiones preparadas a partir de AI con un $\mathrm{pH}$ de 6,3 y 8,0 , se puede observar una reducción inicial de $\% B S_{a v}$, seguido de un aumento de este parámetro hasta alcanzar un valor prácticamente constante a los $28 \mathrm{~min}(\mathrm{pH}$ 6,3 ) o $40 \mathrm{~min}(\mathrm{pH} \mathrm{8,0).}$

Este comportamiento del \%BSav se debe a la variación en el número y tamaño de las gotas presentes en la fase de crema. El ascenso de las gotas de la fase inferior se acompaña de un aumento en $\% \mathrm{BS}_{\mathrm{av}}$, que se produjo con mayor rapidez en las emulsiones realizadas a $\mathrm{pH}$ de 6,3 (Figuras 2.26. y 2.27). Las emulsiones preparadas a $\mathrm{pH}$ 2,0 mostraron sólo un leve aumento de \%BS con el tiempo, resultado que evidencia su mayor estabilidad en el proceso de cremadofloculación. El comportamiento de las emulsiones preparadas con AH1.7 y AH9.5 fue muy diferente a $\mathrm{pH}$ 6,3 y 8,0, dado que ambas emulsiones mostraron una reducción de \%BSav con el tiempo de almacenamiento, sugiriendo un 
proceso de coalescencia que predomina sobre el aumento de la población de gotas en la fase de crema. Sin embargo para AI y TH2.2 se puede observar una pequeña coalescencia a $\mathrm{pH}$ 6,3 a las $24 \mathrm{~h}$ de almacenamiento. El comportamiento de las emulsiones preparadas a partir de TH2.2 fue similar al de las emulsiones a en las que se utilizó $\mathrm{AI}$, aunque los valores $\% \mathrm{BS}_{\mathrm{av}}$ fueron ligeramente inferiores (especialmente a $\mathrm{pH} 6,3$ y 8,0).
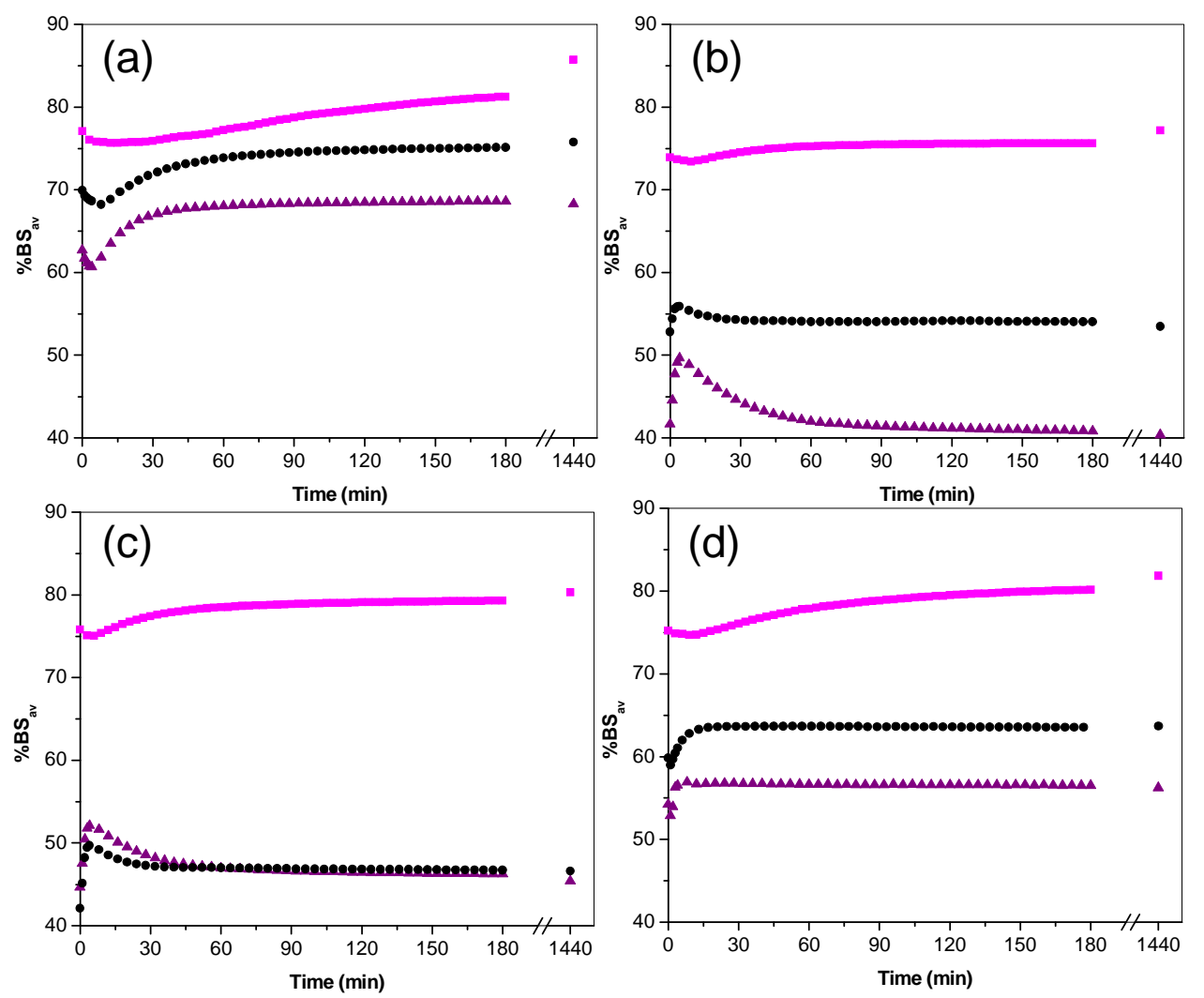

Figura 2.28.: Cinéticas de desestabilización, coalescencia y floculación en la zona alta del tubo, 40-50 mm, correspondiente a emulsiones o/w preparadas con dispersiones de proteínas de amaranto hidrolizadas y sin hidrolizar, AI (a) AH1.7 (b), AH9.5 (c), TH2.2 (d) a: pH 2 (匹), $\mathrm{pH} 6.3(\mathbf{\Delta})$ y $\mathrm{pH} 8(\bullet)$.

La Figura 2.29. muestra el porcentaje de desestabilización de la fase crema considerando el comportamiento de las emulsiones a las $24 \mathrm{~h}$ de almacenamiento estacionario. Los resultados obtenidos confirman la tendencia que se había observado durante las primeras $3 \mathrm{~h}$ de almacenamiento. Los mayores porcentajes de desestabilización de la fase crema correspondieron a las muestras hidrolizadas con alcalasa, AH1.7 y AH9.5, a pHs 6,3 y 8,0. En los mismos casos se observó una clara disminución de la luz dispersada por las partículas que fue 
una consecuencia de la reducción del número de partículas y en un incremento en su diámetro debido a la coalescencia detectada.
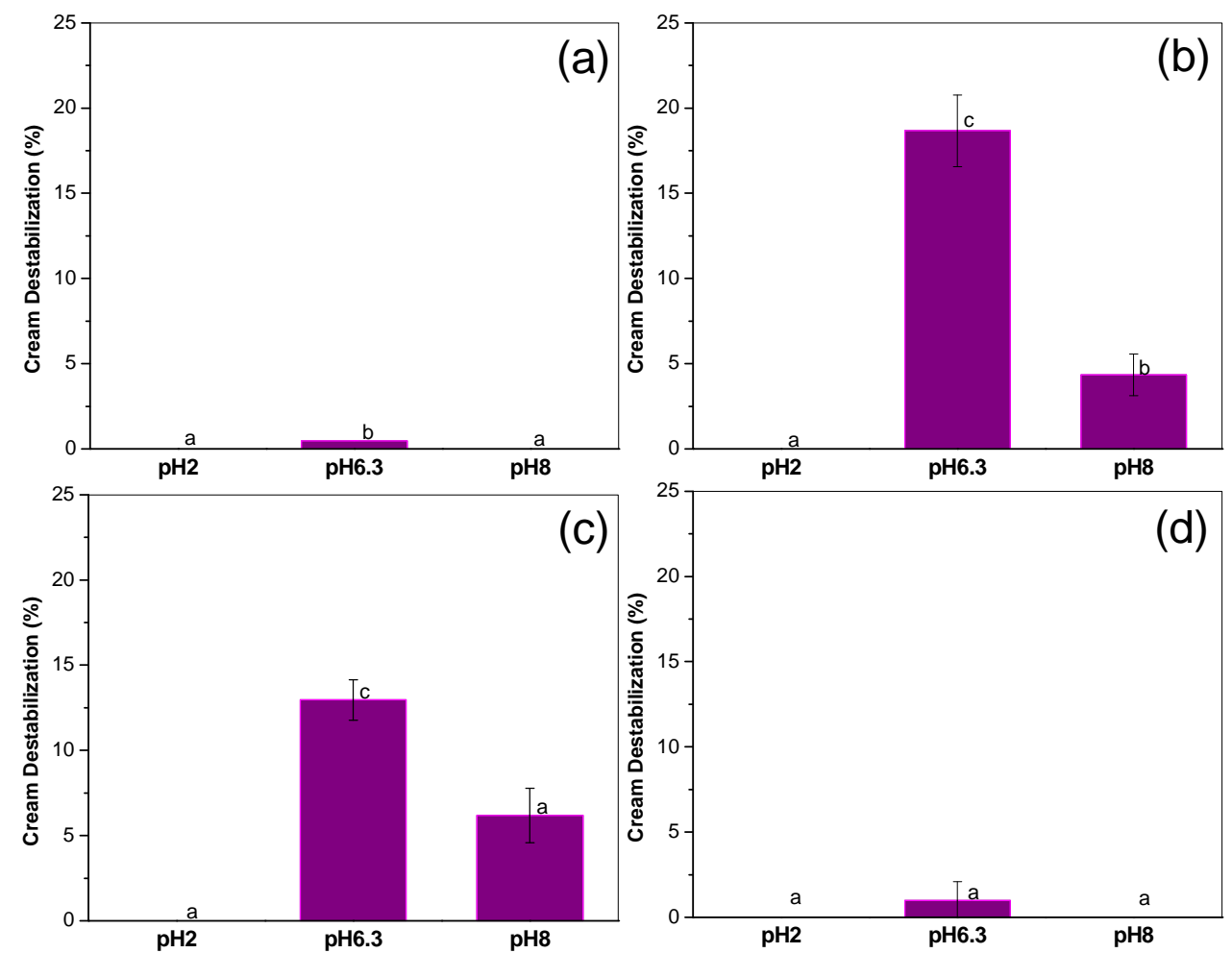

Figura 2.29.: Desestabilización de la crema a diferentes pHs correspondientes a emulsiones o/w preparadas con dispersiones de AI (a), AH1.7 (b), AH9.5 (c) y TH2.2 (d). Las barras con letras iguales no son significativamente diferentes $(\alpha=0,05$, Fisher test).

Las micro fotografías de las emulsiones preparadas a distintos $\mathrm{pH}$ y a diferentes tiempos de almacenamiento estacionario se muestran en las Figuras 2.30., 2.31. y 2.32. En ellas se puede observar la gran diferencia que existe en el diámetro de las gotas a los diferentes $\mathrm{pHs}$ ensayados, como también las diferencias existentes entre las distintas muestras. A pH 2.0 se distinguen en todos los casos gotas más pequeñas, tamaño que casi no varió con el tiempo de almacenamiento de la emulsión lo que indica mayor estabilidad con respecto a la coalescencia. Las emulsiones formuladas a $\mathrm{pH}$ 6,3 fueron las que mostraron mayores diámetros de gota, mientras que las obtenidas a $\mathrm{pH} \mathrm{8,0}$ presentaron diámetros intermedios. Las emulsiones preparadas con AH1.6 y AH9.5 presentaron una menor estabilidad a $\mathrm{pH}$ 6,3 y 8,0 con una coalescencia muy acusada en las primeras $3 \mathrm{~h}$ de almacenamiento, y de las dos mostró ser más inestable la preparada con la muestra con mayor grado de hidrólisis (AH9.5). A pH 6,3 y 8,0 las emulsiones 
más estables fueron las obtenidas con AI y TH2.2, ambas con mayor estabilidad a $\mathrm{pH}$ 8,0 que a $\mathrm{pH}$ 6,3 siendo las preparadas con AI algo más estables que las de TH2.2. Estos resultados son coincidentes con los obtenidos con el QuickScan y por las medidas de distribución de tamaño de gota y $\mathrm{d} 4,3$ medio (secciones 2.2.6.1. y 2.2.6.2.).

AI

AH1.7

$\mathrm{Oh}$

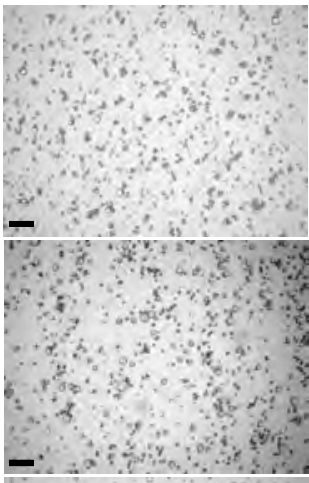

AH9.5

TH2.2
$3 h$

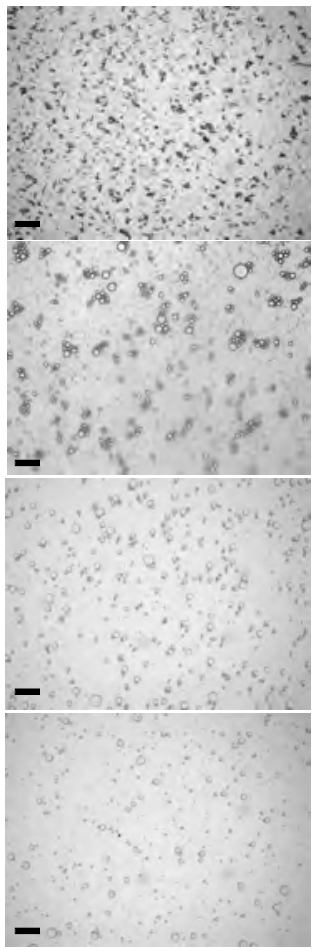

$24 \mathrm{~h}$

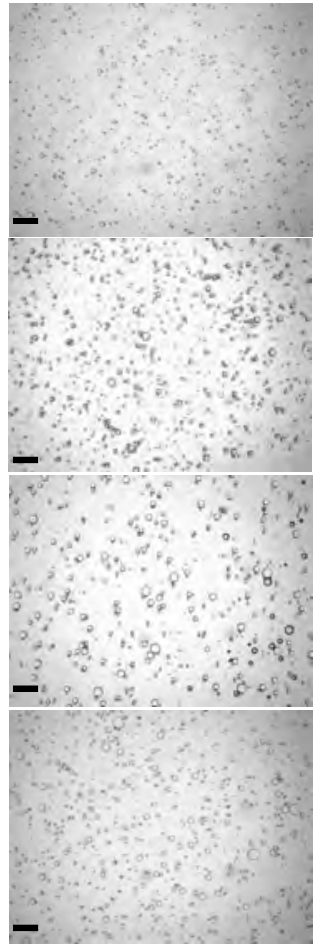

Figura 2.30.: Microscopías ópticas 100X de las distintas emulsiones de las distintas muestras a $\mathrm{pH}$ 2,0 y a los diferentes tiempos que se indican en cada una. La marca en las fotos equivale a $100 \mu \mathrm{m}$. 
Oh

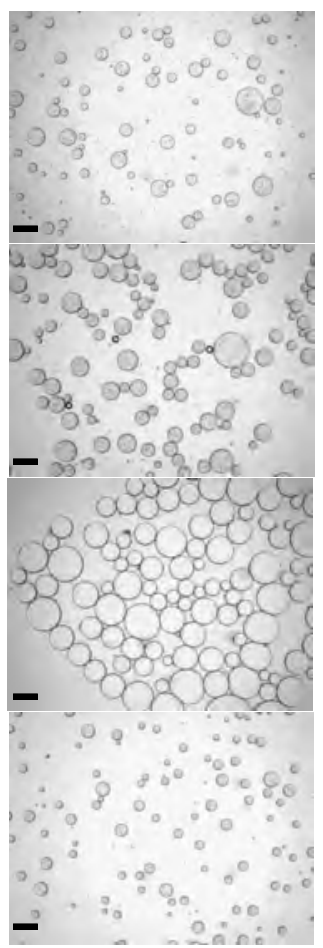

$3 h$

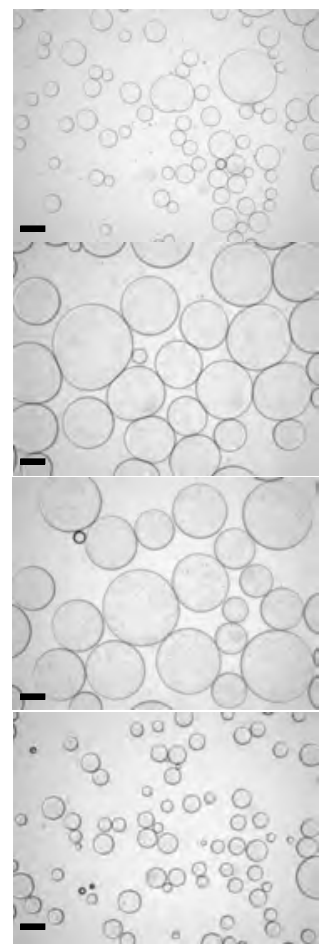

$24 \mathrm{~h}$

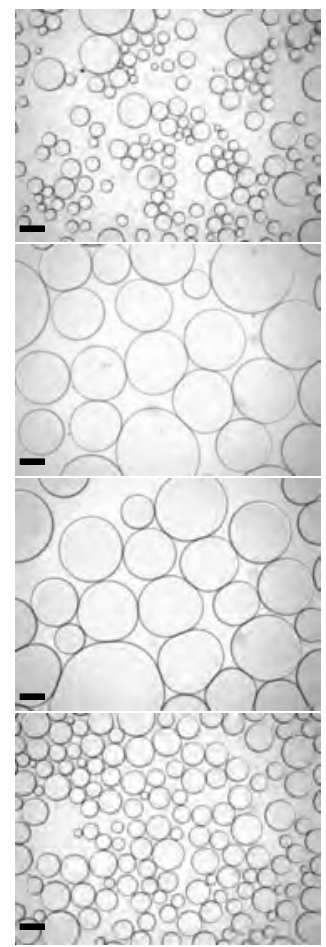

Figura 2.31.: Microscopías ópticas 100X de las distintas emulsiones de las distintas muestras a pH 6,3 y a los diferentes tiempos que se indican en cada una. La marca en las fotos equivale a $100 \mu \mathrm{m}$. 
$\mathrm{Oh}$

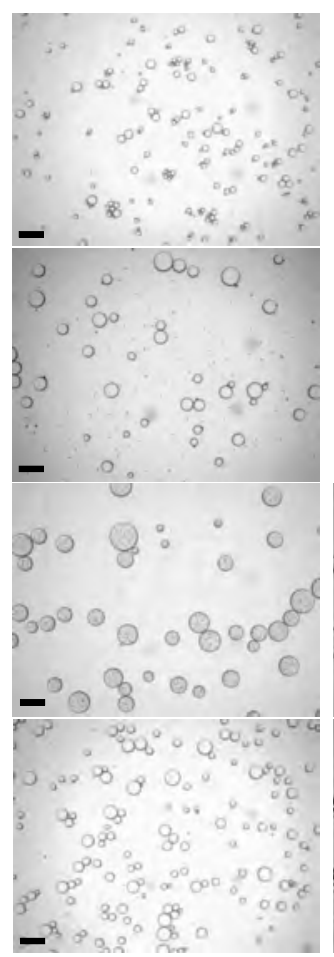

$3 \mathrm{~h}$

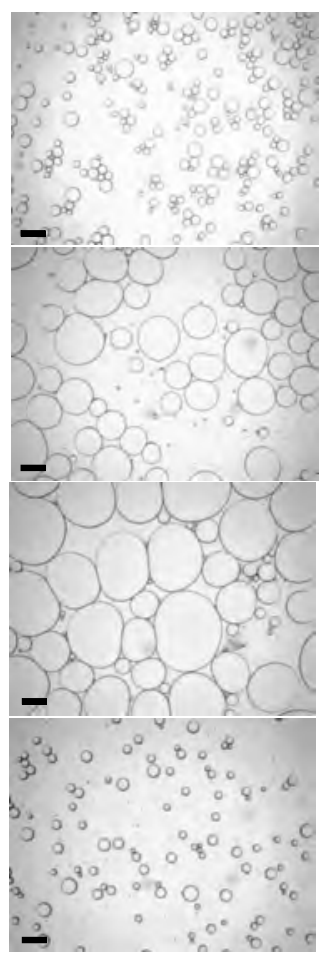

$24 \mathrm{~h}$

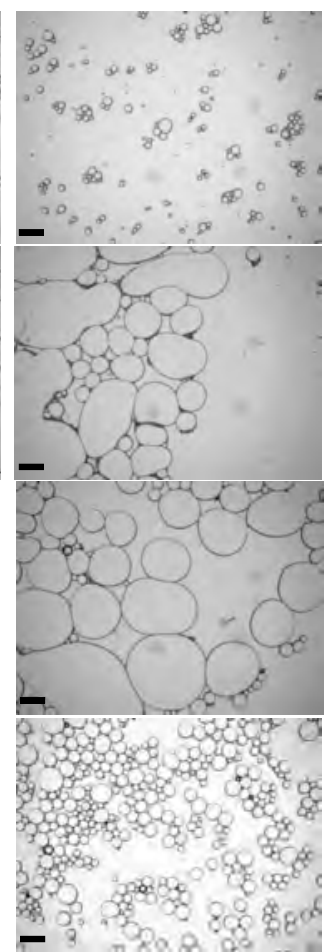

Figura 2.31.: Microscopías ópticas 100X de las distintas emulsiones de las distintas muestras a pH 8,0 y a los diferentes tiempos que se indican en cada una. La marca en las fotos equivale a $100 \mu \mathrm{m}$.

Los valores medios de los diámetros volumétricos $\mathrm{d}_{4,3}$ en presencia o ausencia de SDS se muestran en la Tabla 2.1. En el caso de todas las emulsiones a $\mathrm{pH} 2,0, \mathrm{~d}_{4,3}$ exhibió una reducción de los valores promedio en presencia de SDS, sugiriendo la existencia de flóculos entre las partículas. Sin embargo, el diámetro medio de los flóculos a $\mathrm{pH}$ 2,0 fue menor o igual que el tamaño de las gotas individuales de las emulsiones preparadas a $\mathrm{pH} 6,3$ y 8,0. 
Tabla 2.1.: Distintos parámetros en las emulsiones de las distintas muestras a los diferentes pHs. La desviación estándar máxima fue: $\mathrm{d}_{4,3}: 4 \%, \mathrm{~d}_{3,2}$ y SIA: $6 \%$

\begin{tabular}{lccccc}
\hline Muestra & $\mathbf{d}_{4,3}$ prom $(\mu \mathrm{m})$ & Polidispersidad & $\begin{array}{c}\mathbf{d}_{3,2 \text { prom }}(\mu \mathrm{m}) \\
\text { sDs }\end{array}$ & $\begin{array}{c}\mathbf{d}_{4,3} \text { prom }(\mu \mathrm{m}) \\
\text { sDs }\end{array}$ & $\begin{array}{c}\text { SIA(m } 2 / \mathbf{m l}) \\
\text { sDs }\end{array}$ \\
\hline AI pH2 & 31,1 & 1,4 & 4,2 & 14,7 & 0,28 \\
AI pH6.3 & 46,4 & 0,9 & 9,8 & --- & 0,12 \\
AI pH8 & 30,1 & 1,2 & 7,9 & 26,3 & 0,15 \\
AH1.7 pH2 & 44,7 & 1,6 & 3,6 & 10,0 & 0,33 \\
AH1.7 pH6.3 & 94,6 & 0,5 & 22,5 & 86,6 & 0,05 \\
AH1.7 pH8 & 53,4 & 0,6 & 6,9 & 38,9 & 0,17 \\
AH9.5 pH2 & 28,9 & 1,6 & 3,2 & 7,4 & 0,38 \\
AH9.5 pH6.3 & 131,0 & 0,6 & 24,6 & 116,3 & 0,05 \\
AH9.5 pH8 & 82,8 & 1,2 & 15,3 & 87,2 & 0,08 \\
TH2.2 pH2 & 18,5 & 1,7 & 3,4 & 8,7 & 0,35 \\
TH2.2 pH6.3 & 67,8 & 1,5 & 13,5 & 71,0 & 0,09 \\
TH2.2 pH8 & 32,3 & 1,0 & 9,1 & 37,4 & 0,13 \\
\hline
\end{tabular}

El análisis de los resultados a $\mathrm{pH} 6.3$ y 8.0 de la fase continua muestra claramente que la hidrólisis de las proteínas de amaranto con alcalasa reduce significantemente su acción como estabilizante de las emulsiones de aceite en agua especialmente contra la coalescencia.

\subsubsection{Relación entre solubilidad, características interfaciales y comporatmiento de las emulsiones}

La velocidad de cremado de una partícula esférica está regida principalmente por la ley de Stokes, aunque esta tiene muchas limitaciones para describir el comportamiento de las emulsiones reales. Estas limitaciones incluyen la existencia del movimiento browniano, la polidispersidad, las interacciones coloidales entre partículas, el grado de hidratación de las gotas y el comportamiento reológico de la fase continua (McClements 2005). Las emulsiones obtenidas a $\mathrm{pH}$ 2,0 preparadas con AI mostraron el mayor grado de floculación y la menor velocidad de cremado. En esas condiciones de $\mathrm{pH}$ los 
polipéptidos presentan una carga neta positiva $y$ se encuentran desnaturalizados, además de parcialmente hidrolizados, exponiendo residuos hidrofóbicos, los que pueden promover la formación de flóculos por interacciones hidrofóbicas. La mayor estabilidad al cremado de las emulsiones obtenidas a $\mathrm{pH}$ 2,0 puede deberse a la mayor polidispersidad producida en esas condiciones y también a la formación de una red abierta de flóculos que afectaría el movimiento de las gotas.

A pH 2,0 tiene predominancia la presencia de polipéptidos desplegados y de menor peso molecular resultantes de la disociación y de la hidrólisis de las proteínas de amaranto. Los resultados indican que en el estado en el que se encuentran las proteínas sometidas a esa condición de $\mathrm{pH}$, se obtienen emulsiones con gotas más pequeñas en las que no se detecta coalescencia dentro de las $24 \mathrm{~h}$. Las proteínas aumentan su actividad emulsificante y son capaces de formar un film interfacial más resistente que a $\mathrm{pH} 8,0$. Esto pudo demostrarse por los ensayos de tensión interfacial en la interfase aceite/agua, las curvas de tensión interfacial en la balanza de Langmuir en la interfase aire/agua y las medidas de reología interfacial, todos ensayos en los que se comparan las distintas muestras a $\mathrm{pH} 2,0$ y 8,0 (secciones 2.2.3., 2.2.4. y 2.2.5.). Estos resultados concuerdan con lo obtenidos por Martin, Bos y Van Vliet (Martin, Bos y col. 2002) con proteínas de soja, quienes encontraron que las especies con coeficiente de sedimentación $3 \mathrm{~S}$ (predominantes a pH ácido) y la glicinina 11S, podrían formar entrecruzamientos. Sin embargo las formas 35 presentan mayor facilidad y velocidad de desplegamiento y reordenamiento en la interfase, lo que se debería a la alta flexibilidad resultante de fuerzas de repulsión electrostática dentro de la molécula (Martin, Bos y col. 2002).

La menor solubilidad y la consecuente presencia de una mayor cantidad de agregados, junto a la existencia de especies proteicas de menor tamaño debido a la hidrólisis (sección 2.2.1.1.) además de la naturaleza de los polipéptidos obtenidos, tendría implicancias en el fenómeno de coalescencia detectado en las emulsiones preparadas con AH1.7 y con AH9.5. A pH 6,3 los hidrolizados tratados con alcalasa dieron emulsiones con un alto grado de coalescencia coincidiendo con la baja solubilidad medida a ese $\mathrm{pH}$. Sin embargo la baja solubilidad no constituiría la única causa de la desestabilización por coalescencia, dado que AI coalesce sólo un poco y tiene una solubilidad igual o menor que la de AH1.7 y AH9.5. El tipo y cantidad de interacciones entre moléculas en la interfase son también de mucha importancia en la formación de un film que tenga propiedades intrínsecas que impidan la ruptura de la membrana 
interfacial. A pH 8,0, de acuerdo los resultados de reología interfacial, la muestra AI formó films menos viscoelásticos, situación que desfavorecería la estabilidad del film. Hay que considerar que las moléculas de AI son de mayor tamaño que en las otras muestras y que podrían penetrar una mayor distancia en la fase continua. Esto impediría el contacto íntimo de los films interfaciales por impedimento estérico, reduciendo las posibilidades de coalescencia (McClements 2004).

En resumen, a pH 2,0 se producen cambios en las moléculas que modifican la estructura de las muestras de una manera que les permite una mejor penetración en la interfase y una mejor interacción entre ellas, favoreciendo la formación y estabilidad de las emulsiones obtenidas. A pH 2,0 los hidrolizados presentaron una actividad emulsificante algo mayor, pero una estabilidad ante el cremado algo menor. Además se puede decir que el efecto del grado de hidrólisis fue más importante a pH 6,3 y 8,0, habiendo sido menos estables las emulsiones obtenidas con hidrolizados proveniente de la hidrólisis con la enzima alcalasa.

\subsubsection{Emulsiones con alta relación proteína/aceite}

La Figura 2.31. muestra las distribuciones de tamaño de gota volumétricas de las distintas emulsiones. Para todas las muestras en ausencia de SDS se puede observar que se produce más floculación a pH 2,0 que a pH 8,0 en función del tiempo. Además resulta evidente que en las emulsiones formuladas con proteína total (soluble e insoluble) la floculación es más extensa que en aquellas formuladas con proteína soluble. A pH 2,0 dentro de los 7 días de almacenamiento prácticamente no se observa coalescencia en ninguna muestra, sin embargo a pH 8,0 se puede observar, en todas las muestras, desestabilización por coalescencia, principalmente en la emulsión preparada con la muestra de mayor grado de hidrólisis (AH9.5). Al inicio, todas las emulsiones a $\mathrm{pH}$ 2,0 en presencia de SDS son monomodales, solo comienza a aparecer una población muy pequeña de gotas de mayor tamaño con el correr de los días, en cambio en ausencia de SDS se pueden observar numerosas modas debidas a floculación. En el caso de las emulsiones a $\mathrm{pH} 8,0$, para la muestra de mayor grado de hidrólisis, AH9.5, en presencia de SDS, las distribuciones están más corridas a la derecha, hacia valores de diámetro de gotas mayores y con el tiempo aparecen muy acusadas nuevas poblaciones debidas a la coalescencia.

Las mismas tendencias, que las observadas con las distribuciones de tamaño de gota, se pueden observar en la Figura 2.32. la cual muestra los $d_{3,2}$ medios así 
como en los porcentajes de floculación (Figura 2.33.) y de coalescencia (Figura 2.34.). Los valores de $\mathrm{d}_{3,2}$ correspondientes a emulsiones preparadas a $\mathrm{pH} 8,0$, en general son mayores que los correspondientes a emulsiones a $\mathrm{pH}$ 2,0, por otra parte es posible apreciar que los valores mayores corresponden a las emulsiones obtenidas a partir de AH9.5. En las Figuras 2.32. y 2.33 puede verse que en ciertos casos, principalmente en las muestras de proteína dispersadas en un medio de $\mathrm{pH} 8,0$, , se produce un alto grado de floculación durante el primer día de almacenamiento de la emulsión y que a los 7 días algunos de los flóculos formados se rompen dismuyendo en consecuencia el diámetro $\mathrm{d}_{3,2}$. Este último hecho podría atribuirse al hecho que luego de la emulsificación permanecienron zonas en la interfase de gotas no cubiertas por tensioactivo; estas zonas pudieron acercarse y colisionar o entrar en contacto con zonas de otras gotas con la interfase cubierta y producir así floculación por puenteo. Con el correr de los días, la adsorción de mayor cantidad de proteína en las interfases y el pequeño grado de coalescencia producido, pudo haber cambiado la geometría de las interfases de las gotas que integraban los flóculos, facilitándose la separación de gotas y la disminución de los valores de los d3,2 medidos en ausencia de SDS. La Figura 2.34. muestra que la coalescencia de las emulsiones a $\mathrm{pH} 8,0$ fue mayor que la correspondiente a las emulsiones a $\mathrm{pH}$ 2,0. Evidentemente las diferencias reológicas del film interfacial influyen en este aspecto, haciendo que las gotas obtenidas a $\mathrm{pH}$ 2,0 resulten más resistentes a la ruptura de sus films que las de pH 8,0 las cuales mostraban un módulo interfacial de menor magnitud. También se puede ver que a $\mathrm{pH}$ 2,0 las emulsiones que mostraron más coalescencia fueron las preparadas con AH9.5, especialmente a partir de la fracción de proteína soluble. 

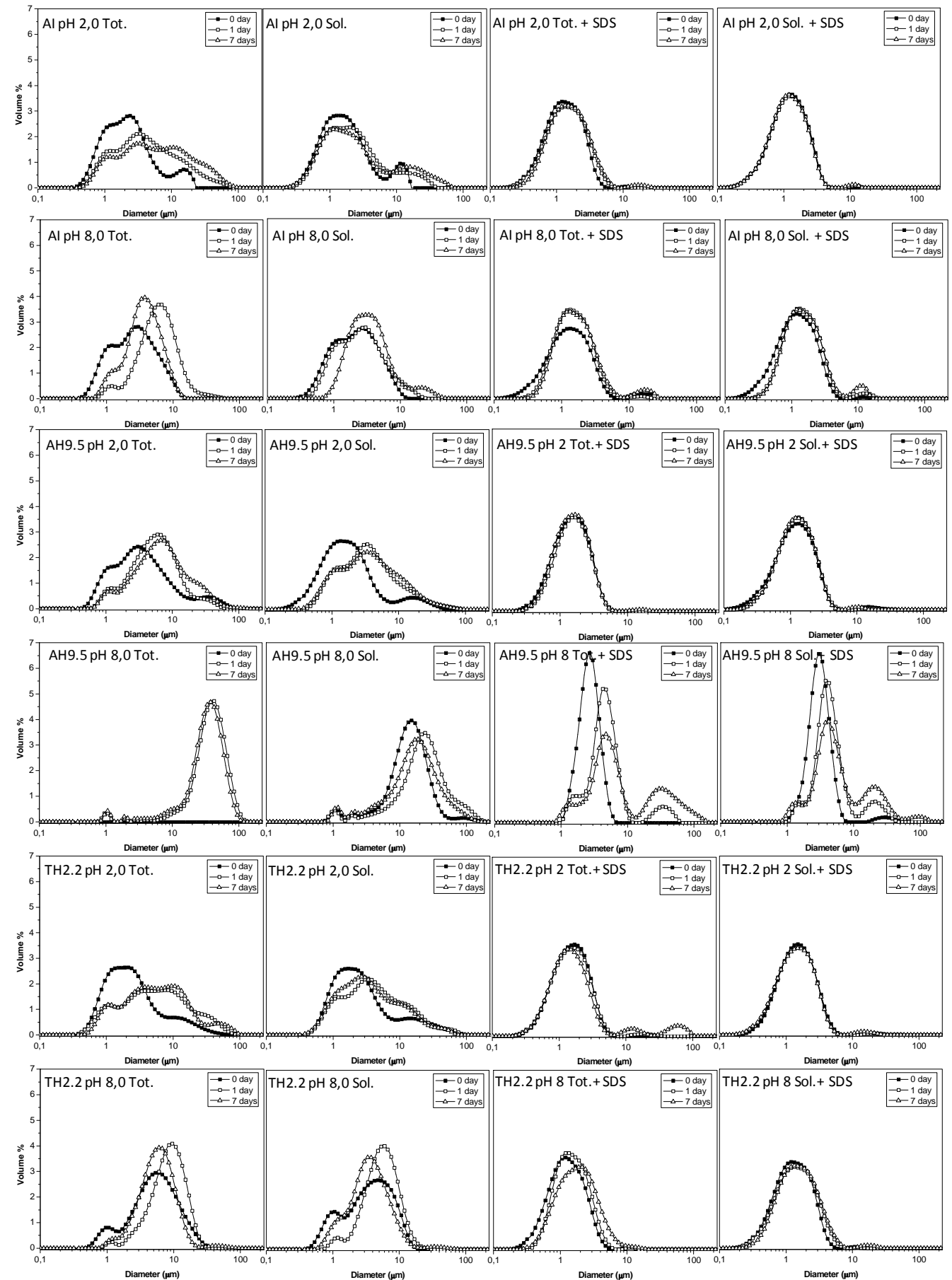

Figura 2.31.: Distribuciones de tamaño de gota (\% de volumen) de las emulsiones de las distintas muestras a $\mathrm{pH} 2,0$ y 8,0 realizadas con proteína soluble (Sol.) y soluble e insoluble (Tot.), con y sin el agregado de SDS para romper flóculos y a los diferentes tiempos (indicado en la figura).

Las diferencias entre formular emulsiones con proteína soluble o proteína soluble e insoluble, no introdujo grandes diferencias en los comportamientos de 
las emulsiones, sólo se detectaron algunas diferencias en el grado de floculación de las emulsiones preparadas con proteína soluble el cual fue más reducido.

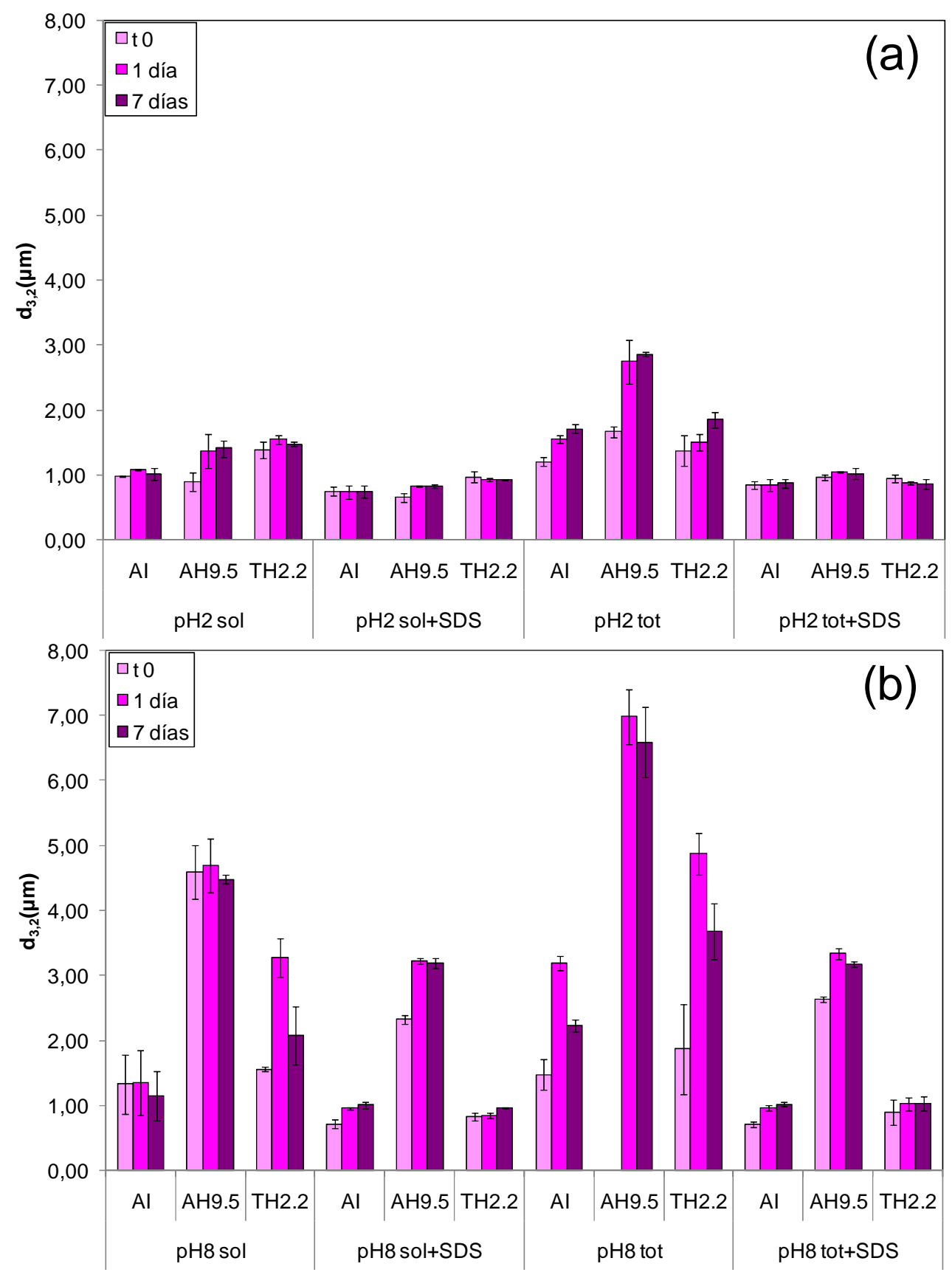

Figura 2.32.: Valores de d3,2 medio de las emulsiones obtenidas a : (a) $\mathrm{pH}$ 2,0 y (b) $\mathrm{pH} 8,0$; formuladas con proteína soluble (Sol.) y soluble e insoluble (Tot.), con y sin agregado de SDS a diferentes tiempos de almacenamiento (indicado en la figura). 


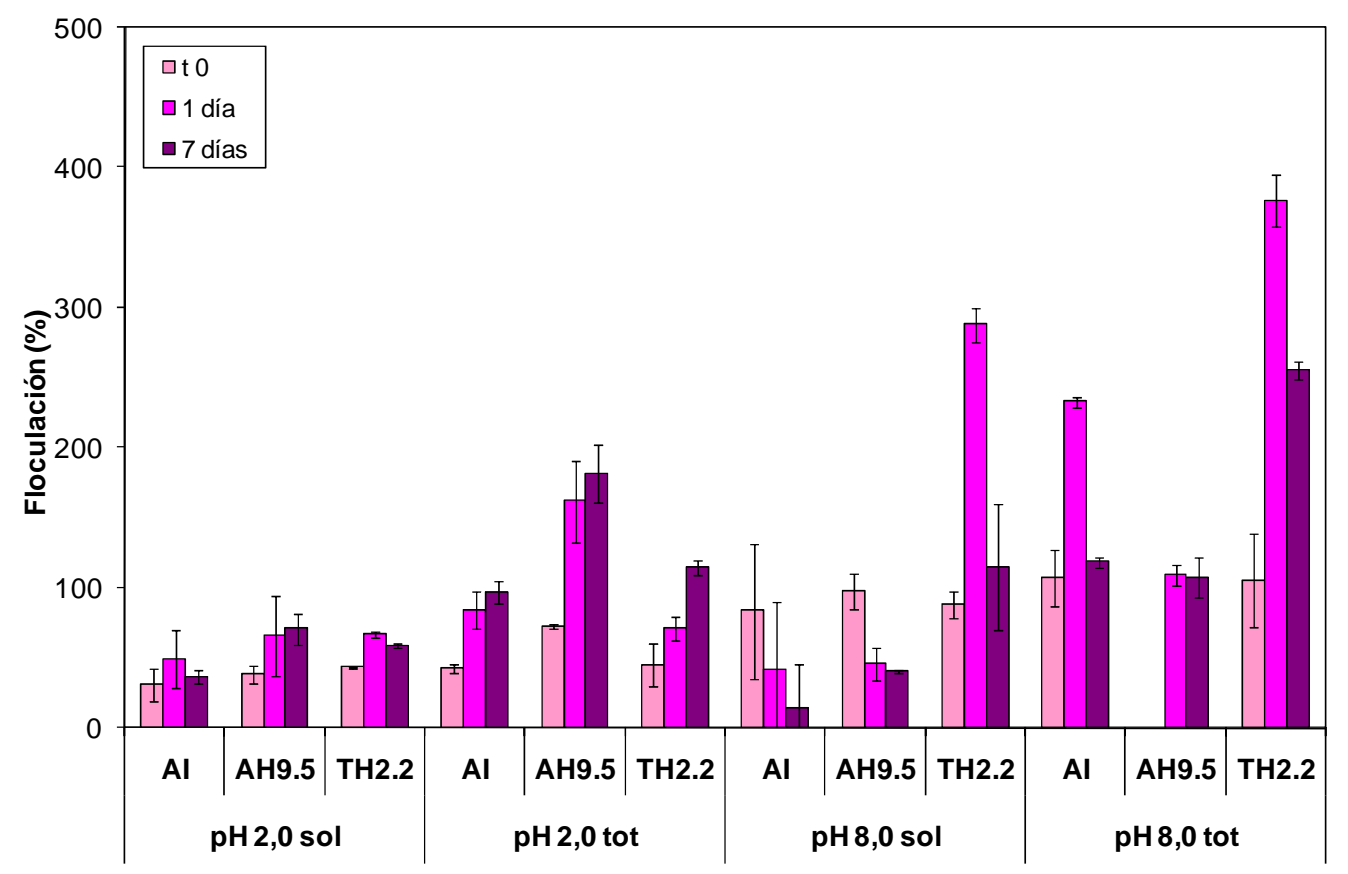

Figura 2.33.: Porcentaje de floculación de las muestras a los distintos pHs $(2,0$ y 8,0); formuladas con proteína soluble (Sol.) y soluble e insoluble (Tot.), a diferentes tiempos de almacenamiento (indicado en la figura).

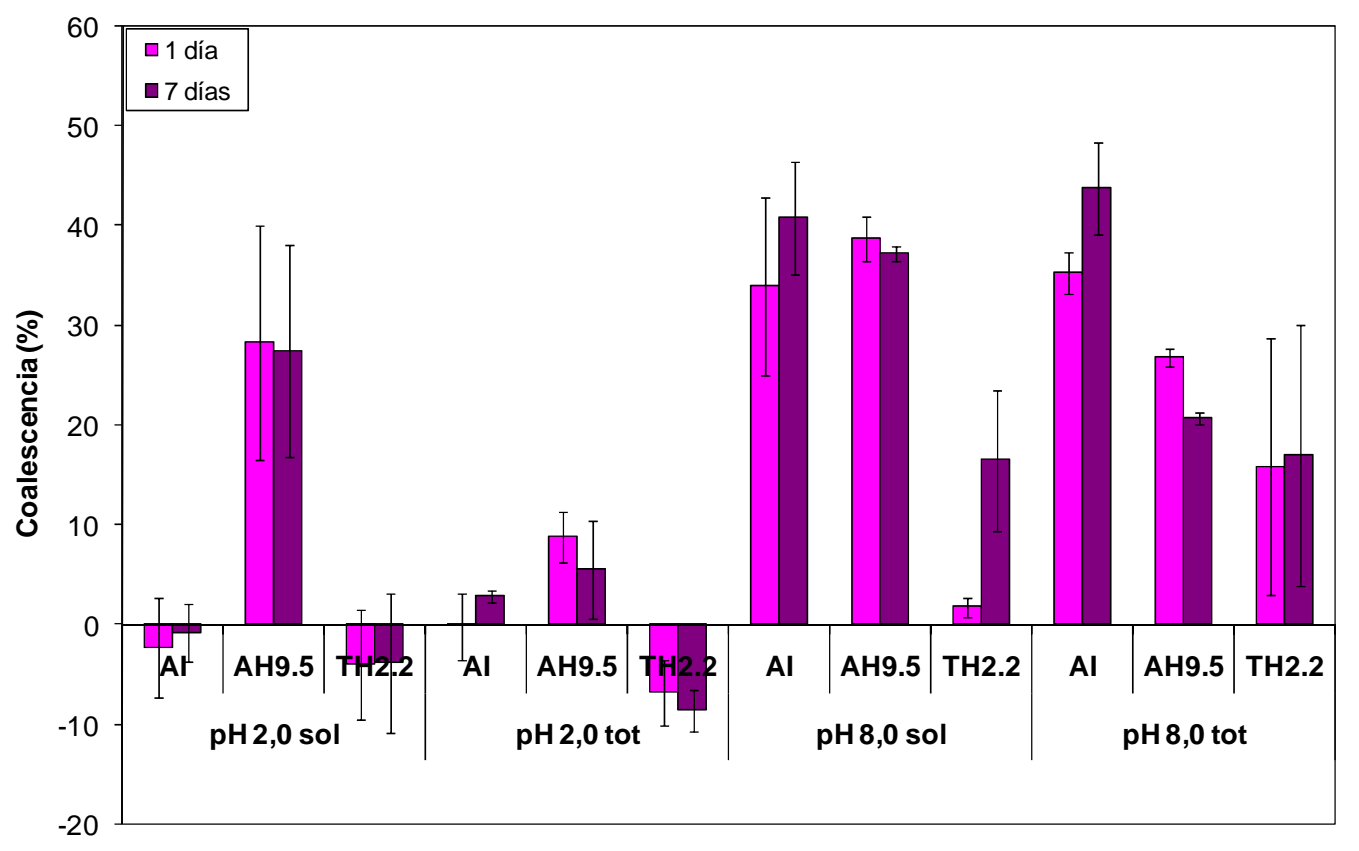

Figura 2.34.: Porcentaje de coalescencia de las a los distintos pHs $(2,0$ y 8,0$)$; formuladas con proteína soluble (Sol.) y soluble e insoluble (Tot.), a diferentes tiempos de almacenamiento (indicado en la figura). 
El análisis de proteína en la interfase se realizó mediante el método de Patton modificado (sección 2.1.14.). Los perfiles electroforéticos de las diferentes muestras correspondientes a las proteínas de las dispersiones originales y aquellas presentes en la interfase, tanto a $\mathrm{pH} 2,0$ como 8,0, no mostraron diferencias significativas. (Figura 2.35). Este resultado indicaría que no existiría, en ninguno de los casos analizados, una migración selectiva de algún/algunos polipéptidos a la interfase aceite/agua.

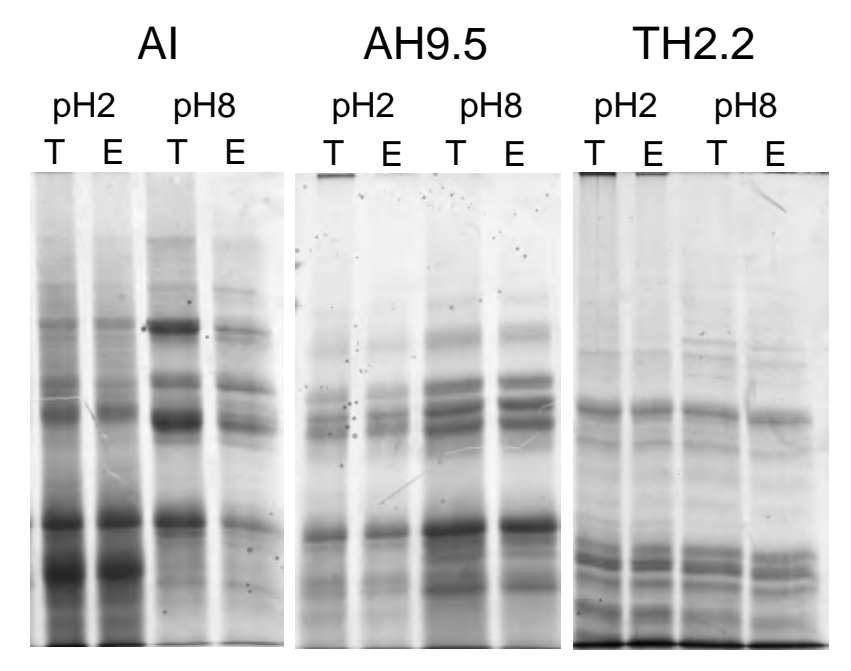

Figura 2.35. Perfiles electroforéticos de proteínas de las distintas muestras en la suspensión inicial (T), y la proteína adsorbida en la interfase o/w (E) a pH 2,0 y 8,0.

Comparando las emulsiones preparadas con alta y baja proporción de aceite en presencia de SDS, Figuras 2.24 y 2.31 respectivamente, se puede ver que a menor proporción de aceite las distribuciones de tamaño de gota están mucho más corridas a la izquierda, o sea hacia valores de diámetro más pequeños. Lo mismo se evidencia al comparar los valores de $\mathrm{d}_{3,2}$ que disminuyen de 2 a 5 veces con la disminución de la proporción de aceite de la emulsión. Evidentemente estas diferencias se podrían atribuir a diferencias en la relación proteína/aceite. El resultado de que el área interfacial creada sea menor se debe a la limitada cantidad de proteína que pueda ejercer un efecto tensioactivo en el sistema. Las emulsiones formuladas con AH9.5 con alta y baja proporción de aceite y $\mathrm{pH}$ 8,0, fueron las que presentaron mayores tamaños de gota. 


\subsection{Conclusiones}

Las distintas muestras proteicas utilizadas variaron en su grado de hidrólisis y en la enzima que se utilizó para hidrolizarlas; además los experimentos se realizaron a distintos $\mathrm{pH}$. Si bien se detectó influencia del grado de hidrólisis y de la enzima usada en las distintas propiedades de la emulsión, fueron más importantes los cambios que se produjeron por la variación del $\mathrm{pH}$ del medio. A pH 2,0 las proteínas se encontraron disociadas y desplegadas. En el caso de AI, que no se lo sometió a una hidrólisis con enzimas exógenas, se demostró que sufre una hidrólisis cuando se incuba a pH 2,0 debido a la acción de enzimas endógenas aspárticas que se activan a $\mathrm{pH}$ ácido.

La solubilidad de todas las muestras fue superior a $\mathrm{pH}$ ácido $(2,0)$ y mínima a $\mathrm{pH}$ cercano al pI promedio de las distintas especies proteicas presentes.

Las diferentes muestras a $\mathrm{pH}$ 2,0 fueron más eficientes para disminuir la tensión interfacial, hecho comprobado al detectarse un descenso de la misma con menor concentración de proteína adsorbida en la interfase aire/agua $(\mathrm{a} / \mathrm{w})$ y aceite/agua $(\mathrm{o} / \mathrm{w})$. En la interfase $\mathrm{o} / \mathrm{w}$ las proteínas a $\mathrm{pH} 2,0$ permiten llegar a valores de tensión interfacial menores que las proteínas a $\mathrm{pH}$ 8,0. Sin embargo en la interfase a/w las proteínas a $\mathrm{pH} 8,0$ necesitan una mayor concentración proteica pero pueden reducir en mayor grado la tensión superficial que las proteínas en un medio a $\mathrm{pH}$ 2,0. La diferencia en la concentración superficial necesaria para producir descensos de la tensión interfacial se debería al hecho que las proteínas a $\mathrm{pH}$ 2,0 al estar extendidas y presentar una mayor flexibilidad pueden cubrir una mayor superficie de la interfase y acomodar mejor las zonas afines a cada una de las fases que cuando se encuentran más estructuradas como ocurre a $\mathrm{pH}$ 8,0 . Las proteínas más estructuradas tienen que superar una barrera energética mayor para orientar sus grupos hidrofóbicos e hidrofílicos en función de la disminución de la energía libre interfacial. Las proteínas a pH 2,0 al estar más extendidas interaccionaron más en la interfase, lo que condujo a un módulo complejo mayor en el film interfacial o/w que el detectado a $\mathrm{pH} 8,0$. El mayor módulo complejo se debió principalmente al comportamiento elástico de la interfase. La diferencias observadas en las interfases a ambos $\mathrm{pHs}$ se reflejaron en variaciones del comportamiento de las emulsiones $\mathrm{o} / \mathrm{w}$ con el $\mathrm{pH}$ estabilizadas por las diferentes muestras.

Cuando la relación de proteína/aceite de todas las emulsiones preparadas a $\mathrm{pH}$ 2,0 fue baja los tamaños de gota fueron menores que los correspondientes a las 
emulsiones a pH 6,3 y 8,0. Esto tuvo como consecuencia velocidades de cremado más lentas y la no existencia de coalescencia durante el almacenamiento. A pH 6,3 y 8,0 las emulsiones se comportaron de diferente manera dependiendo de la existencia o no de hidrólisis, de la enzima utilizada y del grado de hidrólisis alcanzado. Las emulsiones que mostraron menores tamaños de gota, velocidades de cremado más lentas y un bajo grado de coalescencia, correspondieron a proteínas sin hidrolizar o hidrolizadas con tripsina (AI y TH2.2). En cambio, las emulsiones formuladas a partir de hidrolizados proteicos obtenidos por la acción de alcalasa mostraron mayores tamaños de gota que redundaron en mayores velocidades de cremado y una desestabilización por coalescencia muy acusada con el tiempo de almacenamiento. A pH 8,0 se observó al aumentar el grado de hidrólisis (1,7 a 9,5\%) una disminución de la eficiencia de los polipéptidos como agentes emulsificantes y estabilizantes, hecho que no ocurrió a pH 6,3.

Las emulsiones formuladas a partir de las diferentes muestras, con alta relación proteína/aceite y $\mathrm{pH}$ 2,0 mostraron tamaños de gota similares entre si y una alta estabilidad frente a la coalescencia en el almacenamiento. Las emulsiones preparadas con AI y TH2.2 a pH 8,0 mostraron tamaños de gota iniciales similares al correspondiente a las emulsiones a $\mathrm{pH} 2,0$ pero presentaron coalescencia en el almacenamiento. La muestra AH9.5 produjo emulsiones con valores más grandes de tamaño de gota y un grado de coalescencia más acusado. Evidentemente las condiciones de $\mathrm{pH}$ influyeron en gran manera en el comportamiento superficial de las proteínas de amaranto, siendo éstas mucho más eficientes como tensioactivo a $\mathrm{pH}$ 2,0. Este comportamiento es atribuido al desplegamiento y flexibilidad que adquieren los polipéptidos de amaranto en estas condiciones. Dependiendo de la concentraciónde proteína utilizada, se lograron obtener emulsiones con buenas características también a pH 8,0.

El tratamiento de las proteínas de amaranto con enzimas exógenas no determinó una mejora sustancial en las propiedades superficiales de las proteínas, provocando en algunos casos un empeoramiento. 



\section{Conclusiones Generales}

En este trabajo nos propusimos estudiar el comportamiento espumante y emulsificante de las proteínas de amaranto solas o en presencia de proteínas de soja. El estudio se realizó en diferentes condiciones con y sin la aplicación de tratamientos químicos o enzimáticos simples que modificaran el comportamiento de las proteínas, el cual se trató de relacionar con la estructura de las mismas en las distintas circunstancias. Esto tuvo como objetivo aportar información que pueda resultar en una nueva fuente proteica de alto valor nutricional con posible utilización como un ingrediente funcional en la formulación de alimentos.

Las proteínas de amaranto cuando fueron combinadas con las proteínas de soja y además se les aplicó un tratamiento ácido, mejoraron notablemente la formación y estabilización de las espumas y emulsiones respecto a las formuladas con proteínas de amaranto también tratadas a $\mathrm{pH}$ ácido.

La mezcla de proteínas tratada en medio ácido no mostró diferencias significativas en la formación y estabilización de espumas y emulsiones comparada con las proteínas de soja tratadas en iguales condiciones.

El tratamiento ácido mejoró las propiedades de las proteínas en forma aislada, especialmente en el caso de las proteínas de amaranto. Igual tendencia ha sido descrita por distintos autores con referencia a las propiedades funcionales de superficie de proteínas de soja tratadas a $\mathrm{pH}$ ácido (Wagner, Sorgentini y col. 1996; Wagner y Gueguen 1999 a y b). El mejoramiento detectado ha sido atribuido al desplegamiento y pérdida de estructura de las proteínas luego del tratamiento ácido.

El pH del medio en el que se suspendieron las muestras afectó más las propiedades de las emulsiones obtenidas que el el tratamiento hidrolítico de las proteínas empleadas como tensioactivos. A pH 2,0 las proteínas mostraron una 
capacidad superior para formar y estabilizar emulsiones, la que se atribuyó al desplegamiento y aumento de la flexibilidad de los polipéptidos, y a la mayor posibilidad de interacción entre moléculas en la interfase.

El proceso de hidrólisis no mejoró las propiedades emulsificantes de las proteínas de amaranto en términos de formación y estabilidad, a pesar de haber producido un aumento en la solubilidad de las proteínas. Estas propiedades no fueron modificadas o empeoraron dependiendo de la enzima y grado de hidrólisis alcanzado.

Basándose en los efectos que produce el tratamiento ácido o las distintas condiciones de $\mathrm{pH}$, resulta evidente que la desestructuración de las moléculas proteicas presentes en los aislados de amaranto y soja es favorable para mejorar las propiedades funcionales de superficie. Las moléculas más abundantes en los aislados proteicos de semillas vegetales tienen un alto grado de estructuración que juega en contra de su capacidad espumante y emulsificante. El hecho de poder disociar y desplegar esa gran estructura que poseen las proteínas originalmente, y de darle más libertad y flexibilidad a los polipéptidos, hace que aumente la capacidad de los mismos para la formación y estabilización de espumas y emulsiones.

El conocimiento de las variaciones estructurales y de las propiedades funcionales que se producen en las proteínas de soja y amaranto permitirá plantear otros tratamientos tecnológicos variando las condiciones de aplicación de los mismos que tengan por finalidad lograr cambios estructurales favorables para el mejoramiento de las propiedades funcionales de este tipo de proteínas. También resulta interesante el estudio de la combinación de diferentes fracciones de proteínas de distintos orígenes que puedan contribuir al mejoramiento de distintas etapas de los procesos fisicoquímicos involucrados en la formación de espumas y emulsiones.

Estas opciones se plantean a efectos de obtener nuevos ingredientes de fuentes proteicas alternativas con una funcionalidad específica y un buen valor nutricional para su utilización en la formulación de alimentos. 


\section{Bibliografía}

Abugoch, L. (2006). Relación estructura-funcionalidad de glutelinas y aislados proteicos de amaranto (Amaranthus hypochondriacus) Universidad Nacional de La Plata, La Plata.

Adachi, M; Kanamori, J; Masuda, T; Yagasaki, K; Kitamura, K; Mikami, B y Utsumi, S. (2003). Crystal structure of soybean $11 \mathrm{~S}$ globulin: glycinin A3B4 homohexamer. PNAS, 100, 7395-7400.

Adachi, M.; Takenaka, Y.; Gidamis, A. B.; Mikami, B. y Utsumi, S. (2001). Crystal structure of soybean proglycinin A1a B1b homotrimer. J. Mol. Biol., 305, 291-305.

Adamson, A. (1976). Physical cemistry of surfaces. New York: Wiley.

Adler-Nissen, J. (1979). Determination of the degree of hydrolysis of food protein hydrolysates by trinitrobenzenesulfonic acid. Journal of Agricultural and Food Chemistry, 27, 1256-1262.

Aluko, R. E., \& Yada, R. Y. (1993). Relationship of hydrophobicity and solubility with some functional properties of cowpea (vigna unguiculata) protein isolate. Journal of the Science of Food and Agriculture, 62, 331-335.

Becker, R., Wheeler, E. L., Lorenz, K., Stafford, A. E., Grosjean, O. K., Betschart, A. A., \& Saunders, R. M. (1981). A compositional study of amaranth grain. J. Food Sci., 46, 1175-1180. 
Benjamins, J., Cagna, A., \& Lucassen-Reynders, E. H. (1996). Viscoelastic properties of triacylglycerol/water interfaces covered by proteins. Colloids and Surfaces A: Physicochemical and Engineering Aspects, 114, 245-254.

Beverung, C. J., Radke, C. J., \& Blanch, H. W. (1999). Protein adsorption at the oil/water interface: Characterization of adsorption kinetics by dynamic interfacial tension measurements. Biophysical Chemistry, 81, 59-80.

Bijsterbosch, B. H., Bos, M. T. A., Dickinson, E., Van Opheusden, J. H. J., \& Walstra, P. (1995). Brownian dynamics simulation of particle gel formation: From argon to yoghurt. Faraday Discussions, 101, 51-64.

Blum, H., Beier, H., \& Gross, H. (1987). Improved silver staining of plant proteins, rna and DNA in polyacrilamide gels. Electrophoresis, 8, 93-99.

Bos, M. A., \& Van Vliet, T. (2001). Interfacial rheological properties of adsorbed protein layers and surfactants: A review. Advances in Colloid and Interface Science, 91, 437-471.

Bressani, R. (1994). Composition and nutritional properties of amaranth. Amaranth. Biology, chemistry and technology. Boca Raton, CRC Press,10, 185205.

Burgess, D. J., \& Sahin, N. O. (1997). Interfacial rheological and tension properties of protein films. Journal of Colloid and Interface Science, 189, 74-82.

Cardamone, M. and N. K. Puri (1992). Spectrofluorimetric assessment of the surface hydrophobicity of proteins. Biochem. J. 282: 589-593.

Carrier, V., \& Colin, A. (2003). Coalescence in draining foams. Langmuir, 19, $4535-4538$.

Casçao Pereira, L. G., Thédoly, O., Blanch, H. W., \& Radke, C. J. (2003). Dilatational rheology of bsa conformers at the air/water interface. Langmuir, 19, 2349-2356. 
Castellani, O. F., Martínez, E. N., \& Añón, M. C. (1999). Role of disulfide bonds upon the structural stability of an amaranth globulin. Journal of Agricultural and Food Chemistry, 47, 3001-3008.

Castellani, O. (2000). Caracterización estructural y fisicoquímica de la globulinaP de amaranto. Tesis doctoral. Universidad Nacional de La Plata, La Plata.

Chabanon, G., Chevalot, I., Framboisier, X., Chenu, S., \& Marc, I. (2007). Hydrolysis of rapeseed protein isolates: Kinetics, characterization and functional properties of hydrolysates. Process Biochemistry, 42, 1419-1428.

Claughton, S. M., \& Pearce, R. J. (1989). Preparation and properties of acidmodified sunflower protein isolate. Journal of Food Science, 54, 357-361.

Condés, M. C., Scilingo, A. A., \& Añón, M. C. (2009). Characterization of amaranth proteins modified by trypsin proteolysis. Structural and functional changes. LWT - Food Science and Technology, 42, 963-970.

Damodaran, S. (1994). Structure-function relationship of food proteins. In N. S. Hettiarachchy, \& Z. G.R. (Eds.), Protein functionality in food systems, New York: Marcel Dekker.

Damodaran, S. (1997). Protein-stabilized foams and emulsions. En S. Damodaran, \& A. Paraf (Eds.), Food proteins and their applications (pp. 57-107). New York: Marcel Dekker.

Darby, N., \& Creighton, T. E. (1995). Disulfide bonds in protein folding and stability. En S. B.A. (Ed.), Protein stability and folding (pp. 219-252). Totowa, NJ.

De La Fuente Feria, J., \& Rodríguez Patino, J. M. (1995). Destabilization of monoglyceride monolayers at the air-aqueous subphase interface. 2. The role of film elasticity. Langmuir, 11, 2090-2097.

Demetriades, K., Coupland, J. N., \& McClements, D. J. (1997). Physical properties of whey protein stabilized emulsions as related to ph and nacl. Journal of Food Science, 62, 342-347. 
Dickinson, E. (1992). Structure and composition of adsorbed protein layers and the relationship to emulsion stability. J. Chem. Soc., Faraday Trans., 88.

Dickinson, E. (1999). Adsorbed protein layers at fluid interfaces: Interactions, structure and surface rheology. Colloids and Surfaces B: Biointerfaces, 15, 161176.

Dickinson, E. (2003). Hydrocolloids at interfaces and the influence on the properties of dispersed systems. Food Hydrocolloids, 17, 25-39.

Dickinson, E., \& Euston, S. R. (1991). Computer simulation of bridging flocculation. Journal of the Chemical Society, Faraday Transactions, 87, 21932199.

Dickinson, E., \& Matsumura, Y. (1991). Time-dependent polymerization of betalactoglobulin through disulphide bonds at the oil-water interface in emulsions. Int J Biol Macromol., 13.

Dickinson, E., Owusu, R. K., \& Williams, A. (1993). Orthokinetic destabilization of a protein-stabilized emulsion by a water-soluble surfactant. Journal of the Chemical Society, Faraday Transactions, 89, 865-866.

Dickinson, E., Rolfe, S. E., \& Dalgleish, D. G. (1990). Surface shear viscometry as a probe of protein-protein interactions in mixed milk protein films adsorbed at the oil-water interface. Int J Biol Macromol., 12.

Erickson, D. (1995). Practical handbook of soybean processing and utilization St. Louis: AOCS - United Soybean Board.

Erickson, D., Ed. (1995). Practical Handbook of soybean processing and utilization. St. Louis, AOCS - United Soybean Board.

Euston, S. R., Finnigan, S. R., \& Hirst, R. L. (2001). Heat-induced destabilization of oil-in-water emulsions formed from hydrolyzed whey protein. Journal of Agricultural and Food Chemistry, 49, 5576-5583. 
Faergemand, M., Murray, B. S., \& Dickinson, E. (1997). Cross-linking of milk proteins with transglutaminase at the oil-water interface. Journal of Agricultural and Food Chemistry, 45, 2514-2519.

Franco, D. (2004). Aceite de soja, análisis de la cadena alimentaria Buenos Aires, República Argentina.

Freer, E. M., Yim, K. S., Fuller, G. G., \& Radke, C. J. (2004). Interfacial rheology of globular and flexible proteins at the hexadecane/water interface: Comparison of shear and dilatation deformation. Journal of Physical Chemistry B, 108, 38353844 .

Gallagher, S. R., Ed. (2000). 10 - Electrophoresis. Current Protocols in Protein Science, John Wiley \& Sons.

Gau, C. S., Yu, H., \& Zografi, G. (1994). Surface viscoelasticity of b-casein monolayers at the air/water interface by electrocapillary wave diffraction. Journal of Colloid and Interface Science, 162, 214-221.

Gorinstein, S., Moshe, R., Greene, L. J., \& Arruda, P. (1991). Evaluation of four amaranthus species through protein electrophoretic patterns and their amino acid composition. Journal of Agricultural and Food Chemistry, 39, 851-854.

Gorinstein, S., Delgado-Licon, E., Pawelzik, E., Permad, H. H., Weisz, M., \& Trakhtenberg, S. (2001). Characterization of soluble amaranth and soybean proteins based on fluorescence, hydrophobicity, electrophoresis, amino acid analysis, circular dichroism, and differential scanning calorimetry measurements. Journal of Agricultural and Food Chemistry, 49, 5595-5601.

Gharsallaoui, A., Cases, E., Chambin, O., \& Saurel, R. (2009). Interfacial and emulsifying characteristics of acid-treated pea protein. Food Biophysics, 4, 273280.

Graham, D. E., \& Phillips, M. C. (1976). The conformation of proteins at the air water interface and their role in stabilizing foams. In R. J. Akers (Ed.), Foams (pp. 237-255). New York: Academic Press. 
Graham, D. E., \& Phillips, M. C. (1979). Proteins at liquid interfaces. III. Molecular structures of adsorbed films. Journal of Colloid and Interface Science, $70,427-439$.

Halling, P. J. (1981). Protein-stabilized foams and emulsions. Critical reviews in food science and nutrition, 15, 155-203.

Hayakawa, S., \& Nakai, S. (1985). Relationships of hydrophobicity and net charge to the solubility of milk and soy proteins. Journal of Food Science, 50, 486491.

He, H. P., \& Corke, H. (2003). Oil and squalene in amaranthus grain and leaf. Journal of Agricultural and Food Chemistry, 51, 7913-7920.

Hjemel, L., M, \& Chrambach, A. (1981). Electrophoresis and electrofocusing in detergent containing media: A discussion of basic concepts. Electrophoresis, 2, 111.

Ivanov, I. B., Danov, K. D., \& Kralchevsky, P. A. (1999). Flocculation and coalescence of micron-size emulsion droplets. Colloids and Surfaces A: Physicochemical and Engineering Aspects, 152, 161-182.

Izmailova, V. N., Yampolskaya, G. P., \& Tulovskaya, Z. D. (1999). Development of the rehbinder's concept on structure-mechanical barrier in stability of dispersions stabilized with proteins. Colloids and Surfaces A: Physicochemical and Engineering Aspects, 160, 89-106.

Kanu, P. J., Kanu, J. B., Sandy, E. H., Kandeh, J. B. A., Mornya, P. M. P., \& Zhou, H. (2009). Optimization of enzimatic hydrolysis of defatted sesame flour by different proteases and their effect on the functional properties of the resulting protein isolate. American Journal of Food Technology, 4, 226-240.

Karayannidou, A., Makri, E., Papalamprou, E., Doxastakis, G., Vaintraub, I., Lapteva, N., \& Articov, G. (2007). Limited proteolysis as a tool for the improvement of the functionality of sunflower (helianthus annus 1.) protein isolates produced by seeds or industrial by-products (solvent cake). Food Chemistry 104, 1728-1733. 
Kashaninejad, M., Ahmadi, M., Daraei, A., \& Chabra, D. (2008). Handling and frictional characteristics of soybean as a function of moisture content and variety. Powder Technology, 188, 1-8.

Kato, A., \& Nakai, S. (1980). Hydrophobicity determined by a fluorescence probe method and its correlation with surface properties of proteins. Biochim Biophys Acta, 624, 13-20.

Kauzmann, W., Ed. (1959). Some factors in the interpretation of protein denaturation en, C. B. Anfinsen Jr. (Ed.), Advances in Protein Chemistry (pp 158). London: Academic Press Inc.

Keshavarz, E., \& Nakai, S. (1979). The relationship between hydrophobicity and interfacial tension of proteins. Biochim Biophys Acta, 576, 269-79.

Kim, D. A., Cornec, M., \& Narsimhan, G. (2005). Effect of thermal treatment on interfacial properties of $\beta$-lactoglobulin. Journal of Colloid and Interface Science, 285, 100-109.

Kjeldahl, J. (1883). Neue methode zur bestimmung des stickstoffs in organischen körpern. Zeitschrift für Analytische Chemie, 22, 366-382.

Klitzing, R., \& Müller, H.-J. (2002). Film stability control. Current Opinion in Colloid and Interface Science, 7, 42-49.

Kloek, W., van Vliet, T., \& Meinders, M. (2001). Effect of bulk and interfacial rheological properties on bubble dissolution. Journal of Colloid and Interface Science, 237, 158-166.

Konishi, Y., Fumita, Y., Okuno, K., \& Fuwa, H. (1985). Isolation and characterization of globulin from seeds of amaranthus hypochondriacus. Agricultural and Biological Chemistry 49, 6.

Konishi, Y., Horikawa, K., Oku, J., Azumaya, J., \& Nakatani, N. (1991). Extraction of two albumin fractions from amaranth grains: Comparison of some 
physicochemical properties and the putative localization in the grains. Agricultural and Biological Chemistry, 55, 2745-2750.

Laemmli, U. K. (1970). Cleavage of structural proteins during the assembly of the head of bacteriophage T4. Nature, 227, 680-684.

Lakemond, C. M. M., De Jongh, H. H. J., Hessing, M., Gruppen, H., \& Voragen, A. G. J. (2000). Soy glycinin: Influence of ph and ionic strength on solubility and molecular structure at ambient temperatures. Journal of Agricultural and Food Chemistry, 48, 1985-1990.

Langevin, D. (2008). Aqueous foams: A field of investigation at the frontier between chemistry and physics. ChemPhysChem, 9, 510-522.

Lawal, O. S., Adebowale, K. O., \& Adebowale, Y. A. (2007). Functional properties of native and chemically modified protein concentrates from bambarra groundnut. Food Research International, 40, 1003-1011.

Le Denmat, M., Anton, M., \& Beaumal, V. (2000). Characterisation of emulsion properties and of interface composition in o/w emulsions prepared with hen egg yolk, plasma and granules. Food Hydrocolloids, 14, 539-549.

Li, J. B., Zhang, Y., \& Yan, L. L. (2001). Multilayer formation on a curved drop surface13. Angewandte Chemie International Edition, 40, 891-894.

Loglio, G., Pandolfini, P., Miller, R., Makievski, A. V., Ravera, F., Ferrari, M., \& Liggieri, L. (2001). Novel methods to study interfacial layers Amsterdam: Elsevier.

Loisel, W. G., J.; Popineau, Y (1993). A new apparatus for analyzing foaming properties of proteins. Weinheim, Germany: VCH.

Lowry, O. H., Rosebrough, N. J., Farr, A. L., \& Randall, R. J. (1951). Protein measurement with the folin phenol reagent. J. Biol. Chem., 193, 265-275. 
Lu, J. R., Lee, E. M., Thomas, R. K., Penfold, J., \& Flitsch, S. L. (1993). Direct determination by neutron reflection of the structure of triethylene glycol monododecyl ether layers at the air/water interface. Langmuir, 9, 1352-1360.

Luyten, H., Jonkman, M., Kloek, W., \& van Vliet, T. (1993). Creaming behaviour of dispersed particles in dilute xanthan solutions. In E. Dickinson, \& P. Walstra Eds.), Food colloids and polymers: Stability and mechanical properties, Cambridge: Royal Society of Chemistry.

Ma, C. Y., Khanzada, G., \& Harwalkar, V. R. (1988). Thermal gelation of oat globulin. Journal of Agricultural and Food Chemistry, 36, 275-280.

Mackie, A. R., Gunning, A. P., Ridout, M. J., Wilde, P. J., \& Patino, J. R. (2001). In situ measurement of the displacement of protein films from the air/water interface by surfactant. Biomacromolecules, 2, 1001-1006.

Maldonado-Valderrama, J., Martín-Rodriguez, A., Gálvez-Ruiz, M. J., Miller, R., Langevin, D., \& Cabrerizo-Vílchez, M. A. (2008). Foams and emulsions of [beta]casein examined by interfacial rheology. Colloids and Surfaces A: Physicochemical and Engineering Aspects, 323, 116-122.

Marcone, M. F., Niekamp, F. K., Le Maguer, M., \& Yada, R. Y. (1994). Purification and characterization of the physicochemical properties of the albumin fraction from the seeds of amaranthus hypochondriacus. Food Chemistry, 51, 287-294.

Marcone, M. F., Kakuda, Y., \& Yada, R. Y. (1998). Salt soluble seed globulins of dicotyledonous and monocotyledonous plants II. Structural characterization. Food Chemistry, 63, 265-274.

Marcone, M. F., \& Kakuda, Y. (1999). A comparative study of the functional properties of amaranth and soybean globulin isolates. Nahrung - Food, 43, 368373.

Marcone, M. F., \& Yada, R. Y. (1992). Study of the charge profile and covalent subunit association of the oligomeric seed globulin from amaranthus hypochondriacus. Journal of Agricultural and Food Chemistry, 40, 385-389. 
Markwell, M. A. K., Haas, S. M., Bieber, L. L., \& Tolbert, N. E. (1978). A modification of the lowry procedure to simplify protein determination in membrane and lipoprotein samples. Analytical Biochemistry, 87, 206-210.

Marquez, A. L., Palazolo, G. G., \& Wagner, J. R. (2005). Emulsiones tipo crema preparadas a base de leche de soja: Estudios de estabilidad y determinación de las formulaciones. . Grasas y Aceites (International Journal of Fats and Oils), 56, 59-66.

Martin, A. H., Bos, M. A., \& Van Vliet, T. (2002). Interfacial rheological properties and conformational aspects of soy glycinin at the air/water interface. Food Hydrocolloids, 16, 63-71.

Martin, A. H., Grolle, K., Bos, M. A., Stuart, M. A. C., \& van Vliet, T. (2002). Network forming properties of various proteins adsorbed at the air/water interface in relation to foam stability. Journal of Colloid and Interface Science, 254, 175-183.

Martínez, E. N., \& Añón, M. C. (1996). Composition and structural characterization of amaranth protein isolates. An electrophoretic and calorimetric study. Journal of Agricultural and Food Chemistry, 44, 2523-2530.

Maruyama, N.; Adachi, M.; Takahashi, K.; Yagasaki, K.; Kohno, M.; Takenaka, Y.; Okuda, E.; Nakagawa, S.; Mikami, B. y Utsumi, S. (2001). Cristal Structures of recombinant and native soybean $\beta$-conglycinin $\beta$-homotrimers. European Journal of Biochemistry, 268, 3595-3604.

Matsudomi, N., Sasaki, T., Tanaka, A., Kobayashi, K., \& Kato, A. (1985). Polymerization of deamidated peptide fragments obtained with the mild acid hydrolysis of ovalbumin. Journal of Agricultural and Food Chemistry, 33, 738742.

McClements, D. J. (2000). Comments on viscosity enhancement and depletion flocculation by polysaccharides. Food Hydrocolloids, 14, 173-177.

McClements, D. J. (2004). Protein-stabilized emulsions. Current Opinion in Colloid and Interface Science, 9, 305-313. 
McClements, D. J. (2005). Food emulsions principles, practices, and techniques Boca Raton: CRC Press.

McClements, D. J., Monahan, F. J., \& Kinsella, J. E. (1993). Effect of emulsion droplets on the rheology of whey protein isolate gels. Journal of Texture Studies, $24,411-422$.

Mellema, M., Clark, D. C., Husband, F. A., \& Mackie, A. R. (1998). Properties of $\beta$-casein at the air/water interface as supported by surface rheological measurements. Langmuir, 14, 1753-1758.

Mengual, O., Meunier, G., Cayrao, I., Puech, K., \& Snabre, P. (1999). Turbiscan ma 2000: Multiple light scattering measurement for concentrated emulsion and suspension instability analysis. Talanta, 50, 445-456.

Miller, R., Wüstneck, R., Krägel, J., \& Kretzschmar, G. (1996). Dilational and shear rheology of adsorption layers at liquid interfaces. Colloids and Surfaces A: Physicochemical and Engineering Aspects, 111, 75-118.

Murphy, K., Privalov, P., \& Gill, S. (1990). Common features of protein unfolding and dissolution of hydrophobic compounds. Science, 247, 559-561.

Murray, B. S., \& Ettelaie, R. (2004). Foam stability: Proteins and nanoparticles. Current Opinion in Colloid and Interface Science, 9, 314-320.

Nakai, S. (1983). Structure-function relationships of food proteins: With an emphasis on the importance of protein hydrophobicity. Journal of Agricultural and Food Chemistry, 31, 676-683.

Nakai, S., Li-Chan, E., \& Arteaga, G. E. (1996). Measurement of surface hydrophobicity. En H. G.M. (Ed.), Methods of testing protein functionality (pp. 226-259). London: Chapman.

Nguyen, A. V., \& Schulze, H. J. (2004). Colloidal science of flotation. New York: Marcel Dekker. 
Osborne, T. (1924). The Vegetable Protein. New York. Longmans \& Green.

Palazolo, G. G. (2006). Formación y estabilidad de emulsiones o/w preparadas con proteínas nativas y desnaturalizadas de soja. Universidad Nacional del La Plata, La Plata.

Palazolo, G. G., Mitidieri, F. E., \& Wagner, J. R. (2003). Relationship between interfacial behaviour of native and denatured soybean isolates and microstructure and coalescence of oil in water emulsions - effect of salt and protein concentration. Food Science and Technology International, 9, 409-419.

Palazolo, G. G., Sorgentini, D. A., \& Wagner, J. R. (2005). Coalescence and flocculation in $\mathrm{o} / \mathrm{w}$ emulsions of native and denatured whey soy proteins in comparison with soy protein isolates. Food Hydrocolloids, 19, 595-604.

Paredes-López, O. (1994). Amaranth. Biology, chemistry and technology Boca Raton, EEUU: CRC Press.

Patton, S., \& Huston, G. E. (1986). A method for isolation of milk fat globules. Lipids, 21, 170-174.

Petruccelli, S., \& Añón, M. C. (1994). Relationship between the method of obtention and the structural and functional properties of soy protein isolates. 1 . Structural and hydration properties. Journal of Agricultural and Food Chemistry, 42, 2161-2169.

Petruccelli, S., \& Añón, M. C. (1995). Thermal aggregation of soy protein isolates. Journal of Agricultural and Food Chemistry, 43, 3035-3041.

Pilosof, A. M. R. (2000). Solubilidad. In A. M. R. Pilosof, \& G. B. Bartholomai Eds.), Caracterización funcional y estructural de proteínas (pp. 31-40). Buenos Aires: Eudeba.

Pryde, E. H. (1980). Handbook of soy oil processing and utilization Champaign, USA: American Oil Chemists' Society. 
Pugnaloni, L. A., Dickinson, E., Ettelaie, R., A.R., M., \& Wilde, P. (2004). Competitive adsorption of proteins and low-molecular-weight surfactants: Computer simulation and microscopic imaging. Advances in Colloid and Interface Science, 107, 27-49.

Puppo, M. C., \& Añón, M. C. (1999). Soybean protein dispersions at acid ph. Thermal and rheological properties. Journal of Food Science, 64, 50-56.

Quiroga, A. V. (2008). Globulina-P de amaranto: Análisis de estructura y homología con otras proteínas de reserva. Universidad Nacional de La Plata, La Plata.

Qureshi, A. A., Lehmann, J. W., \& Peterson, D. M. (1996). Amaranth and its oil inhibit cholesterol biosynthesis in 6-week-old female chickens. Journal of Nutrition, 126, 1972-1978.

Rao, M. B., Tanksale, A. M., Ghatge, M. S., \& Deshpande, V. V. (1998). Molecular and biotechnological aspects of microbial proteases. Microbiology and Molecular Biology Reviews, 62, 597-635.

Robins, M. M., Watson, A. D., \& Wilde, P. J. (2002). Emulsions - creaming and rheology. Current Opinion in Colloid and Interface Science, 7, 419-425.

Rodríguez Niño, M. R., Wilde, P. J., Clark, D. C., \& Rodríguez Patino, J. M. (1996). Surface rheological properties of monostearin and monoolein films spread on the air-aqueous phase interface. Industrial and Engineering Chemistry Research, 35, 4449-4456.

Ruíz-Henestrosa, V. P., Sánchez, C. C., Pedroche, J. J., Millán, F., \& Rodríguez Patino, J. M. (2009). Improving the functional properties of soy glycinin by enzymatic treatment. Adsorption and foaming characteristics. Food Hydrocolloids, 23, 377-386.

Rullier, B., Novales, B., \& Axelos, M. A. V. (2008). Effect of protein aggregates on foaming properties of [beta]-lactoglobulin. Colloids and Surfaces A: Physicochemical and Engineering Aspects, 330, 96-102. 
Saint-Jalmes, A., Peugeot, M. L., Ferraz, H., \& Langevin, D. (2005). Differences between protein and surfactant foams: Microscopic properties, stability and coarsening. Colloids and Surfaces A: Physicochemical and Engineering Aspects, $263,219-225$.

Saint-Jalmes, A., Zhang, Y., \& Langevin, D. (2004). Quantitative description of foam drainage: Transitions with surface mobility. The European Physical Journal E: Soft Matter and Biological Physics, 15, 53-60.

Saunders, R., \& Becker, R. (1984). Amaranthus: a potential food and feed resource. En, Advances in Cereal Science and Technology. Pomeraz, Y. Ed. (357397), AACC, St. Paul.

Schramm, L. L. (2005). Emulsions, foams, and suspensions fundamentals and applications. Verlag: Wiley.VCH.

Scilingo, A. A., Molina Ortiz, S. E., Martínez, E. N., \& Añón, M. C. (2002). Amaranth protein isolates modified by hydrolytic and thermal treatments. Relationship between structure and solubility. Food Research International, 35, 855-862.

Segura-Nieto, M., Vázquez-Sánchez, N., Rubio-Velazquez, H., Olguín-Martínez, L. E., Rodríguez-Nester, C. E., \& Herrera-Estrella, L. (1992). Characterization of amaranth (amaranthus hypochondriacus 1.) seed proteins. Journal of Agricultural and Food Chemistry, 40, 1553-1558.

Segura-Nieto, M., Barba De La Rosa, A. P., \& Paredes-Lopez, O. (1994). Biochemistry of amaranth proteins. In O. Paredes-Lopez (Ed.), Amaranth. Biology, chemistry and technology, Boca Raton: CRC Press.

Smith, A. K., \& Cirek, S. J. (1972). Soybeans: Chemistry and technology Westport: AVI Publishing Co.

Smith, T. J. (2000). Squalene: Potential chemopreventive agent. Expert Opinion on Investigational Drugs, 9, 1841-1848. 
Tan, C. T. (2004). Beverage emulsions. In S. Friberg, K. Larsson, \& J. Sjoblom Eds.), Food emulsions, New York: Marcel Dekker.

Townsend,A.A., \& Nakai, S. (1983). Relationships between hydrophobicity and foaming characteristics of food proteins. Journal of Food Science, 48, 588-594.

USDA SR-21. (2008). United States Department of Agriculture, National Nutrient Database for Standard Reference, Release 21.

Utsumi, S., Damodaran, S., \& Kinsella, J. E. (1984). Heat-induced interactions between soybean proteins: Preferential association of $11 \mathrm{~s}$ basic subunits and .Beta. Subunits of 7S. Journal of Agricultural and Food Chemistry, 32, 1406-1412.

Van Aken, G. A. (2004). Coalescence mechanisms in protein-stabilized emulsions. In S. Friberg, K. Larsson, \& J. Sjoblom Eds.), Food emulsions, New York: Marcel Dekker.

Van Aken, G. A., Blijdenstein, T. B. J., \& Hotrum, N. E. (2003). Colloidal destabilisation mechanisms in protein-stabilized emulsions. Current Opinion in Colloid and Interface Science, 8, 371-379.

Van Der Net, A., Drenckhan, W., Weaire, D., \& Hutzler, S. (2006). The crystal structure of bubbles in the wet foam limit. Soft Matter, 2, 129-134.

Van Hunsel, J., \& Joos, P. (1989). Study of the dynamic interfacial tension at the oil/water interface. Colloid \& Polymer Science, 267, 1026-1035.

Van Kalsbeek, H. K. A. I., \& Prins, A. (1999). Foam formation by food proteins in relation to their dynamic surface behavior. En E. Dickinson, \& J. M. RodríguezPatino Eds.), Food emulsions and foams: Interfaces, interactions and stability, Cambrideg, U.K.: Royal Society of Chemistry.

Vecchi, B. (2007). Actividad anti-hipertensiva de péptidos derivados de proteínas de amaranto. Universidad Nacional de La Plata, La Plata.

Vojdani, F. (1996). Solubility. En G. M. Hall (Ed.), Methods of testing protein functionallity (pp. 11-60). London: Chapman. 
Wagner, J. R. (2000). Propiedades superficiales. In A. M. R. Pilosof, \& S. B. Bartholomai Eds.), Caracterización funcional y estructural de proteínas, Buenos Aires: Eudeba.

Wagner, J. R., \& Gueguen, J. (1999 a). Surface functional properties of native, acid-treated, and reduced soy glycinin. 1. Foaming properties. Journal of Agricultural and Food Chemistry, 47, 2173-2180.

Wagner, J.R., \& Gueguen, J. (1999 b). Surface functional properties of native, acid-treated, and reduced soy glycinin. 2. Emulsifying properties. Journal of Agricultural and Food Chemistry, 47, 2181-2187.

Wagner, J. R., Sorgentini, D. A., \& Añón, M. C. (1996). Thermal and electrophoretic behavior, hydrophobicity, and some functional properties of acid-treated soy isolates. Journal of Agricultural and Food Chemistry, 44, 18811889.

Walstra, P. (1989). Principles of foam formation and stability. In A. J. Wilson (Ed.), Foam: Physics, chemistry and structure, London: Springer-Verlag.

Walstra, P. (2000). Sistemas dispersos: Consideraciones básicas. In O. Fennema (Ed.), Química de los alimentos, Zaragoza: Editorial Acribia.

Walstra, P. (2003). Surface phenomena. In P. Walstra (Ed.), Physical chemistry of foods, New York: Marcel Dekker.

Walstra, P., \& De Roos, A. L. (1993). Proteins at air-water and oil-water interfaces: Static and dynamic aspects. Food Reviews International, 9, 503 - 525.

Ward, A. F. H., \& Tordai, L. (1946). Time-dependence of boundary tensions of solutions i. The role of diffusion in time-effects. The Journal of Chemical Physics, $14,453-461$.

Weaire, D., \& Pageron, V. (1990). Frustrated froth: Evolution of foam inhibited by an insoluble gaseous component. Philosophical Magazine Letters, 62, 417 - 421. 
Weiss, J., \& McClements, D. J. (2000). Influence of ostwald ripening on rheology of oil-in-water emulsions containing electrostatically stabilized droplets. Langmuir, 16, 2145-2150.

Wilde, P., Mackie, A., Husband, F., Gunning, P., \& Morris, V. (2004). Proteins and emulsifiers at liquid interfaces. Advances in Colloid and Interface Science, 108-109, 63-71.

Xu, S., \& Damodaran, S. (1994). Kinetics of adsorption of proteins at the air-water interface from a binary mixture. Langmuir, 10, 472-480.

Yalçin, E., \& Çelik, S. (2007). Solubility properties of barley flour, protein isolates and hydrolysates. Food Chemistry, 104, 1641-1647.

Ybert, C., \& di Meglio, J. M. (1998). Ascending air bubbles in protein solutions. The European Physical Journal B - Condensed Matter and Complex Systems, 4, 313-319.

Yin, Tang, Cao, Hub, Wen, \& Yang (2008). Effects of limited enzymatic hydrolysis with trypsin on the functional properties of hemp (cannabis sativa 1.) protein isolate. Food Chemistry, 106, 1004-1013.

Young, S. L., Sarda, X., \& Rosenberg, M. (1993). Microencapsulating properties of whey proteins. 1. Microencapsulation of anhydrous milk fat. J. Dairy Sci., 76, 2868-2877. 